\title{
A New Methodology For Citation Dependent Patent Evaluations
}

\author{
By \\ Derek Kent William Smith
}

A thesis submitted to the Faculty of Graduate and Postdoctoral Affairs in partial fulfillment of the requirements for the degree of

Masters of Applied Science

in

Technology Innovation Management

Carleton University

Ottawa, Ontario

(C) 2014, Derek Kent William Smith 


\begin{abstract}
Patent evaluation methodologies reveal hidden information that enables business decisions. Many of these methodologies may be grouped into a prior art citation dependent category.
\end{abstract}

The problem with this category is citation noise. Citation noise obscures an evaluation leading to very limited and erroneous results. Citation noise is also a gap not well understood by scholars.

The empirical multi-case explanatory approach of this research examined 719 citations and found $87 \%$ of the citations were noise and $13 \%$ had interdependence with a patent. This research further found that interdependency between a citation and patent eliminates citation noise and identifies pertinent and dominant citations.

The theoretical implications are a new understanding of citation noise and dependence, a novel interdependency framework and noise pertinence and dominant citation constructs.

The practice implications are a novel unencumbered patent evaluation methodology where pertinent and dominant citations provide useful, meaningful evaluations and enable better stakeholder decision-making capabilities. 


\section{Acknowledgements}

This journey started in August 2012 with a chance meeting and fascinating discussion with Professor Tony Bailetti over a cup of coffee. That short discussion profoundly changed the next two years of my life. I became a graduate student at Carleton University and started a weekly commute between Richmond Hill Ontario and Ottawa Ontario to attend class.

This particular thesis would never have occurred without Professor Bailetti. He provided very strong, profound and early advice to me. His advice, "Derek, do something your good at". That advice resonated and influenced a deviation deep into the realm of citation dependent patent evaluation methodologies where I could apply my news skills as a researcher and leverage my registered patent agent career skills. Thank you Tony.

This thesis was also made possible as a result of the mentoring, coaching and excellent advice I received from my thesis advisor, Professor Mika Westerlund. I enjoyed being your student and learned a great deal from you on this journey. Thank you Mika.

Dr. Dirk Schlimm and Mr. Michael P. J. McKendry also enabled this journey for me. They helped me open the door to graduate studies. Dirk has also been a wonderful mentor and coach to me on this journey. Thank you Dirk and thank you Mike.

Thank you to Professor Michael Weiss and Professor Steven Muegee. I had the privilege of being your student and learned a great deal about technology innovation management 
from your respective courses and our discussions. I also thank my fellow students, Ms. Asrar Alshaikh, Mr. Mohammad Mehdi Gharaei Manesh, Mr. Anish Kak and Ms. Rawan Bojan. I enjoyed working with you on our group projects and celebrating our publication successes in the TIM Review journal. I would also like to thank two other students, Mr. Peter Uguccioni and Ms. Farzaneh Hosseini Nedjad. I enjoyed our short time together, interesting conversations and ideas about technology innovation management. I would also like to thank Mr. Chris McPhee and Mr. Robert Poole for their advice. Chris, you taught me a great deal about writing quality articles. Thank you Chris.

Commuting to Ottawa over an 80 -week period required a warm or cool place to stay depending upon the season, a few meals, and comfy couches for sleeping. Most importantly interesting conversations. This would not have been possible without the direct support of a few Ottawa based fiends and my daughters who were also attending Carleton at the same time as students. I thank Ms. Krista Smith and Ms. Courtney Smith (Autumn/Winter 2013), Ms. Cathy Lunau (Spring/Summer 2013), Mr. Robert Batch and Ms. Anna Varriano (Autumn 2013) and Mr. Robert Batch (Winter 2014). To my good friend of 43 years, Robert a very special thanks for putting up with me the longest.

Most of all I thank my wife Ms. Joanne Crone for her immeasurable support throughout this difficult and challenging journey. You made this journey in life a reality and this thesis is a reflection of your kindness. Thank you for your constant support throughout the 80 weeks of disruption in our lives. 


\section{Table of Contents}

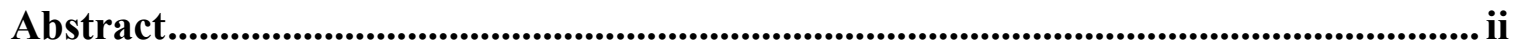

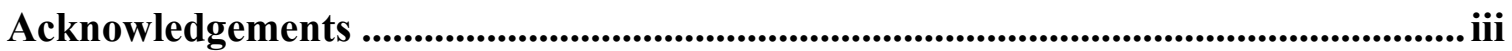

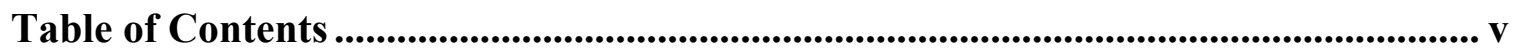

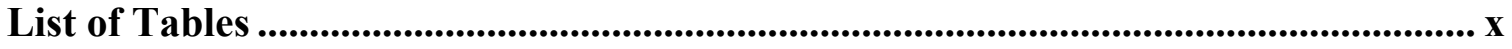

List of Figures.......................................................................................................................... xiv

List of Appendices ..................................................................................................................... xvi

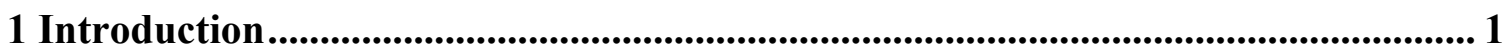

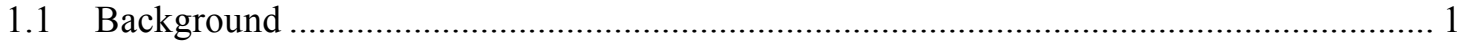

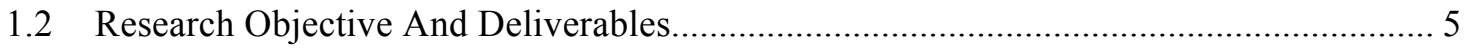

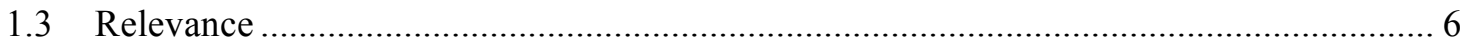

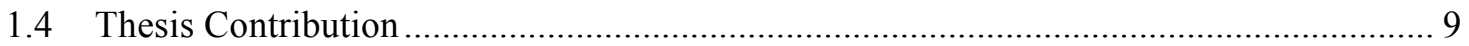

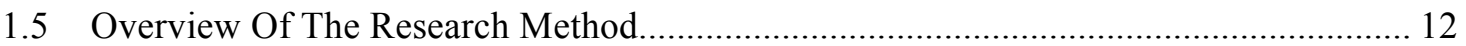

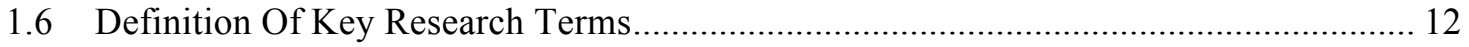

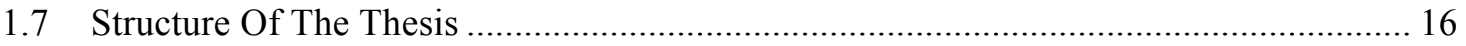

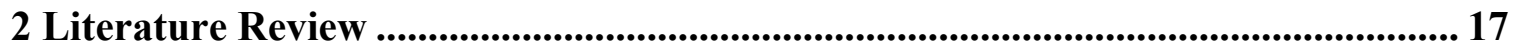

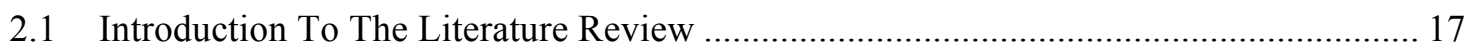

2.2 Stream 1: Citation Dependent Patent Evaluation Methodologies .................................. 19

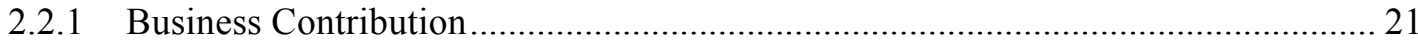

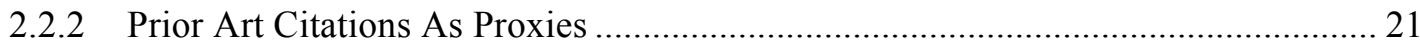

2.2.3 Additional Patent And Business Proxies ............................................................. 22

2.2.4 Summary of Citation Based Patent Evaluation Methodologies............................... 23

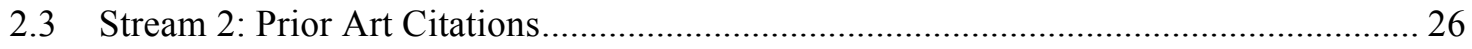

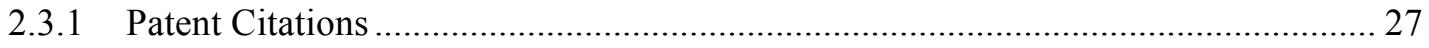

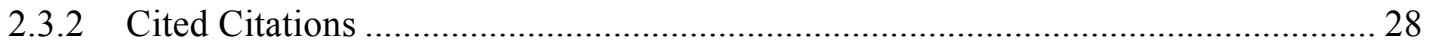




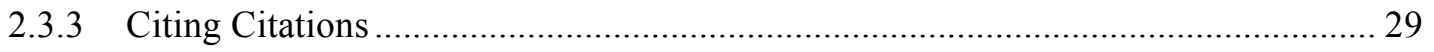

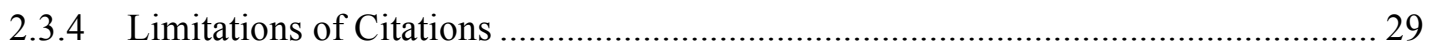

2.4 Stream 3: Interdependencies Between Prior Art Citations and Patents .......................... 30

2.4.1 Legal Role and Function of Prior Art citations....................................................... 31

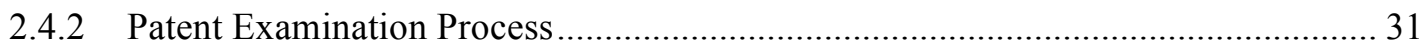

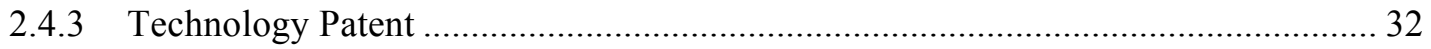

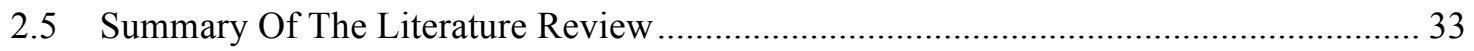

2.5.1 Summary of Citation Based Evaluation Methodologies......................................... 33

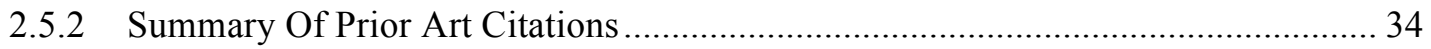

2.5.3 Summary Of Technology Patent Interdependencies ............................................. 35

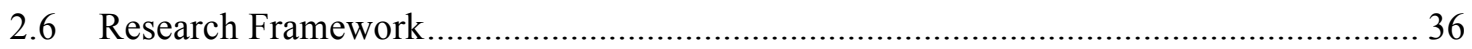

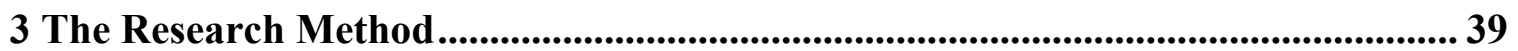

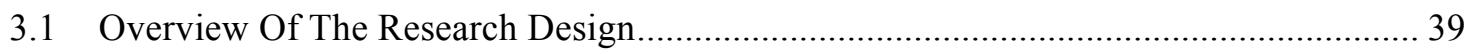

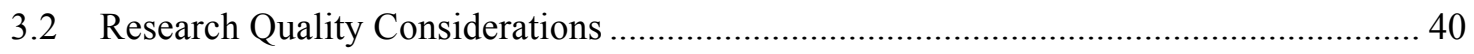

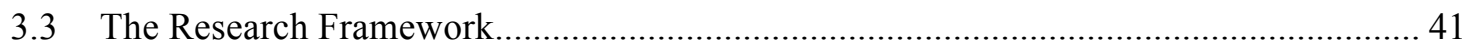

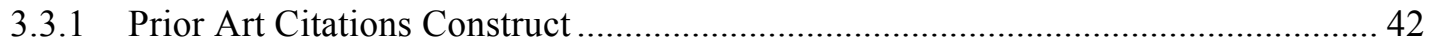

3.3.2 Technology Patent Interdependencies Construct ................................................... 43

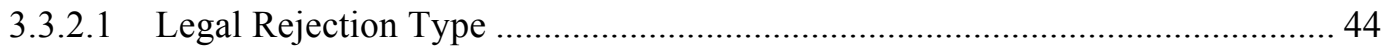

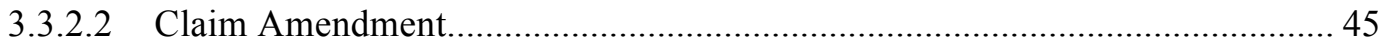

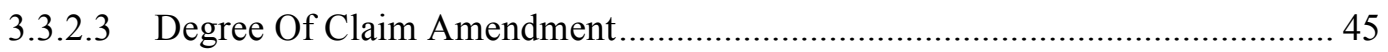

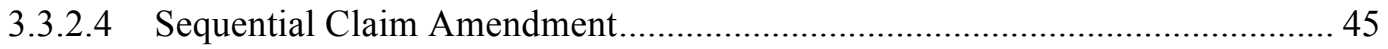

3.3.3 Technology Patent Evaluation Methodologies Construct …................................... 46

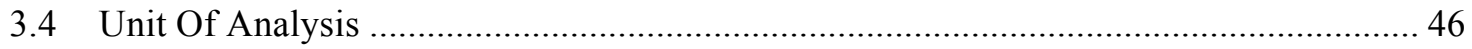

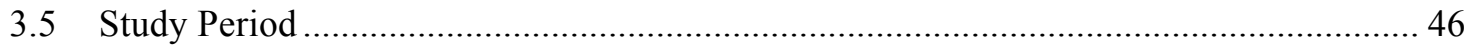

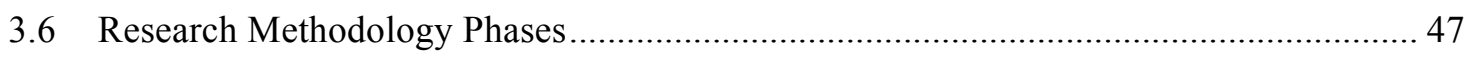

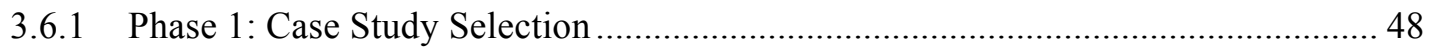




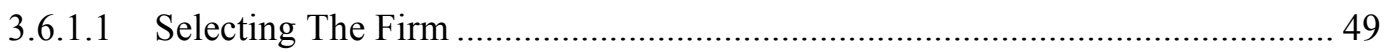

3.6.1.2 Identifying The Leads To Six Potential Cases ................................................ 49

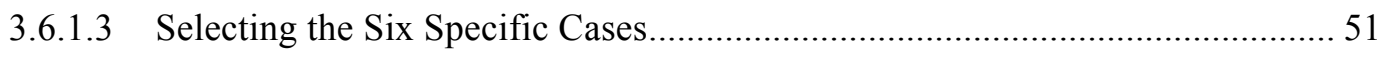

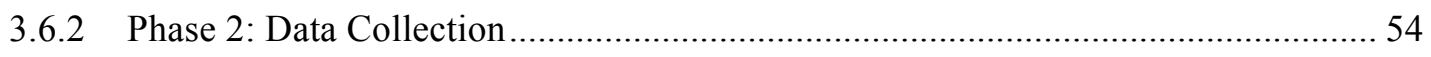

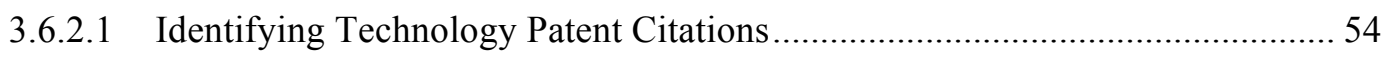

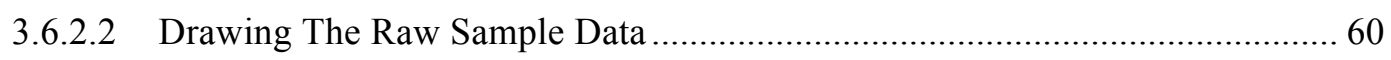

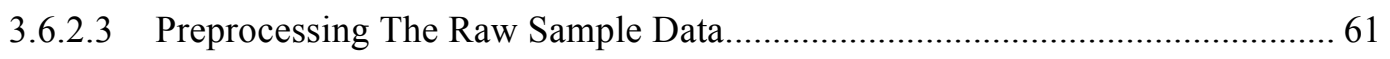

3.6.2.3.1 Preprocessing Criteria For The Initial European Case Data ..................... 62

3.6.2.3.2 Preprocessing Criteria For the Initial United States Case Data ................. 63

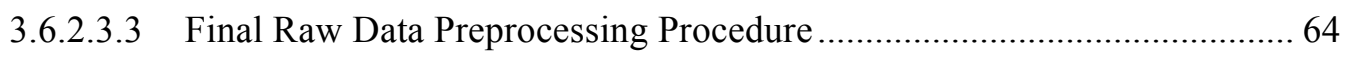

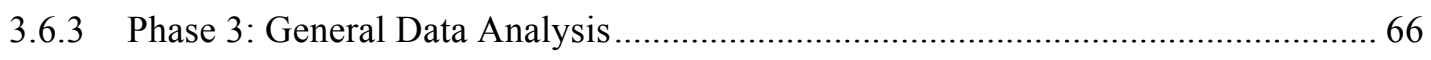

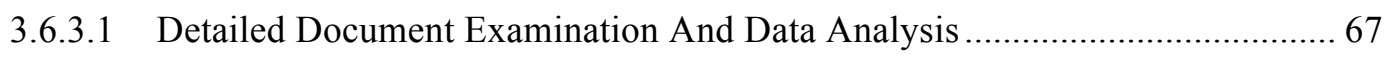

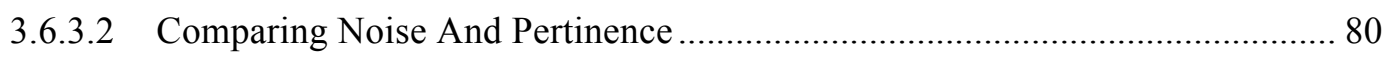

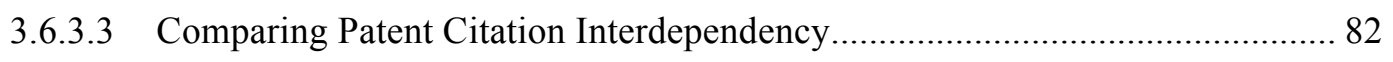

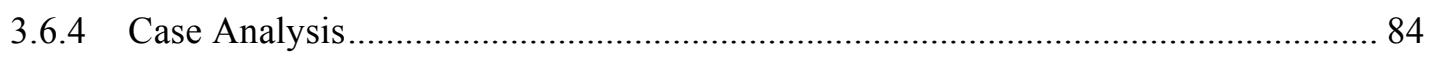

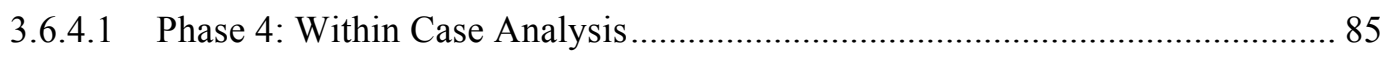

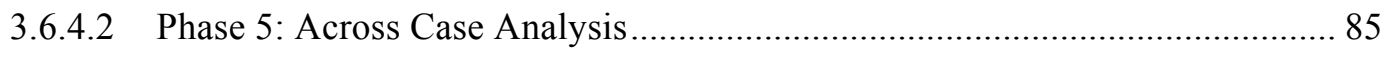

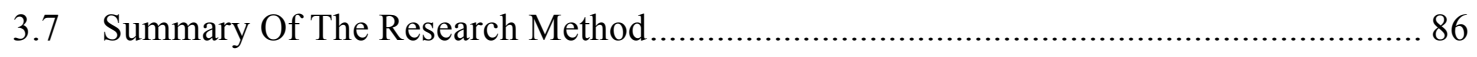

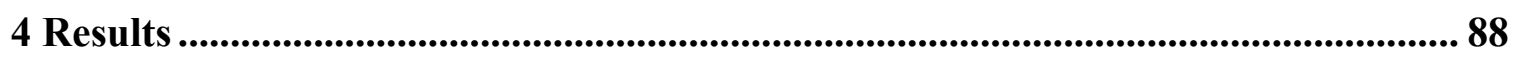

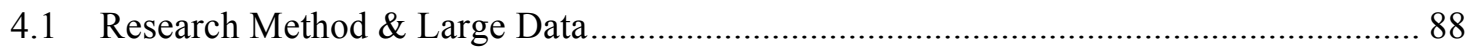

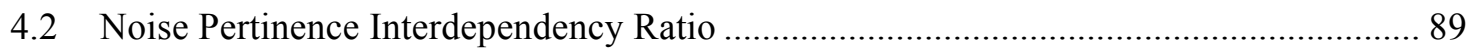

4.2.1 Summary Of Noise Pertinence Interdependency Ratio ......................................... 96

4.2.1.1 Noise Pertinence Ratio Interdependency Construct ....................................... 96

4.3 Dominant Technology Patent Citation Interdependency Ratio..................................... 97

4.3.1 Sole Dominant Technology Patent Citation Interdependency................................ 98

4.3.2 Pooled Dominant Technology Patent Citation Interdependency ........................... 103 
4.3.3 Summary Of Dominant Technology Patent Citation Interdependency Ratio ........ 105

4.3.4 Dominant Technology Patent Citation Interdependency Ratio Construct............... 106

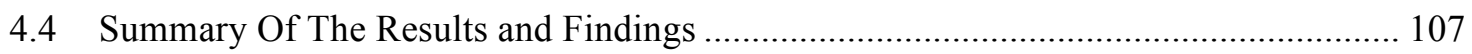

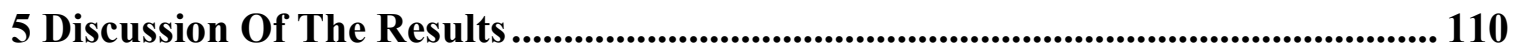

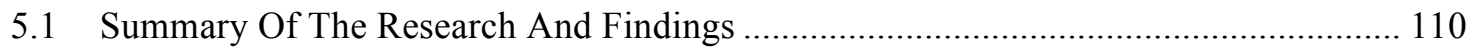

5.2 Extant Literature \& The Research Findings........................................................ 116

5.2.1 Technology Patent Citation Interdependency Framework .................................. 118

5.2.1.1 Noise Pertinence Interdependency Ratio Construct ...................................... 119

5.2.1.2 Technology Patent Citation Interdependency Ratio Construct ....................... 120

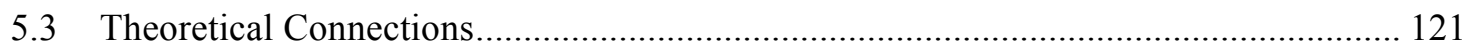

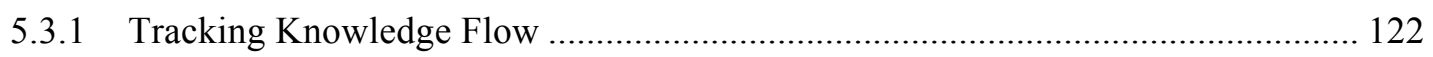

5.3.2 Patents And Technological Or Inventive Value …............................................ 127

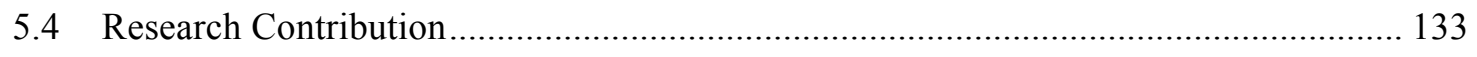

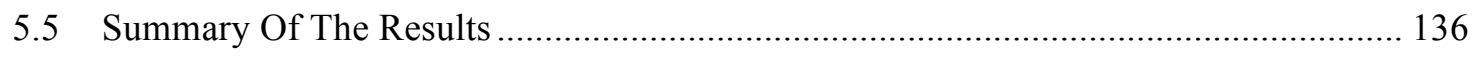

6 Conclusions .......................................................................................................... 138

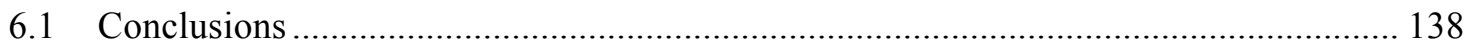

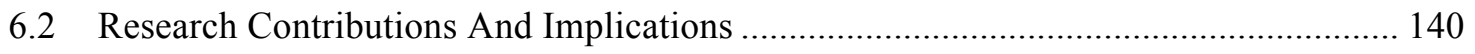

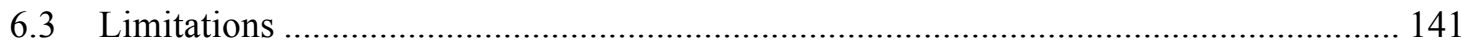

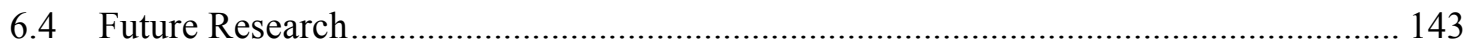

Appendices ............................................................................................................................ 144

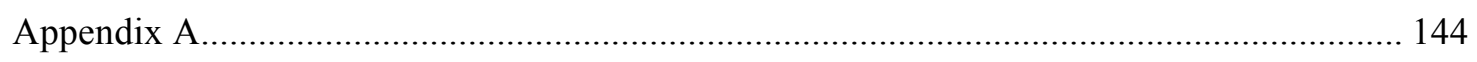

A.1 Stream 1 Prior Art Citation Based Patent Evaluation Methodologies ......................... 144

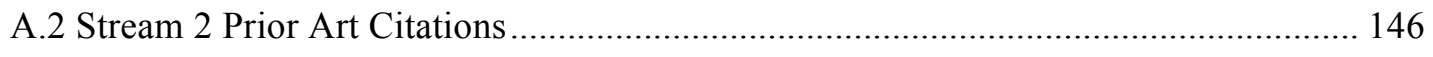

A.3 Stream 3 Interdependency Between Prior Art Citations and Patent .......................... 148

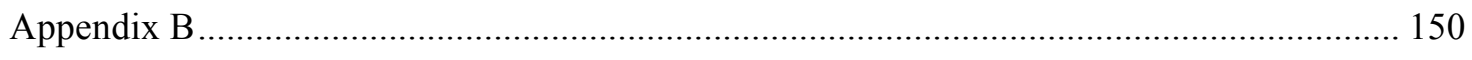


B.1 Case 1 Document Examination And Attribute Coding. ............................................. 150

B.2 Case 2 Document Examination And Attribute Coding. ........................................... 151

B.3 Case 3 Document Examination And Attribute Coding. ........................................... 152

B.4 Case 4 Document Examination And Attribute Coding. .............................................. 153

B.5 Case 5 Document Examination And Attribute Coding. ............................................ 155

B.6 Case 6 Document Examination And Attribute Coding. ............................................. 157

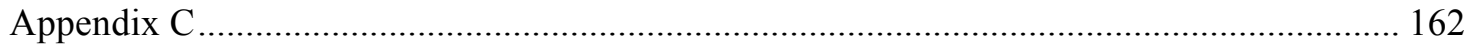

C.1 Case 1 Cited Results Of Independent Claim Examination And Data Analysis. .......... 163

C.2 Case 2 Cited Results Of Independent Claim Examination And Data Analysis. .......... 165

C.3 Case 3 Cited Results Of Independent Claim Examination And Data Analysis. .......... 167

C. 4 Case 4 Cited Results Of Independent Claim Examination And Data Analysis. .......... 168

C.5 Case 5 Cited Results Of Independent Claim Examination And Data Analysis. .......... 171

C.6 Case 6 Cited Results Of Independent Claim Examination And Data Analysis. .......... 174

C.7 Case 2 Citing Results Of Independent Claim Examination And Data Analysis.......... 177

C.8 Case 4 Citing Results Of Independent Claim Examination And Data Analysis.......... 178

C.9 Case 5 Citing Results Of Independent Claim Examination And Data Analysis.......... 180

C.10 Case 6 Citing Results Of Independent Claim Examination And Data Analysis........ 183

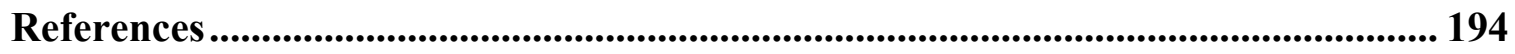




\section{List of Tables}

Table 1: Definition Of Key Research Terms............................................................ 3

Table 2: Citation Dependent Patent Evaluation Methodologies........................................ 20

Table 3: Summary Citation Dependent Patent Evaluation Methodology Applications. .. 25

Table 4: Application And Limitations Of Prior Art Citations............................................ 27

Table 5: Interdependency Between Prior Art Citations And Patents. ................................ 31

Table 6: Research Design Quality Adapted From Yin (2009). ......................................... 41

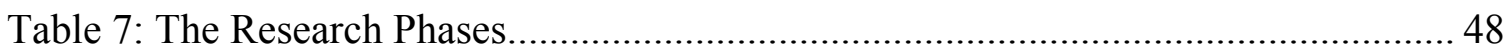

Table 8: The Identified Leads To Six Potential Cases........................................................ 51

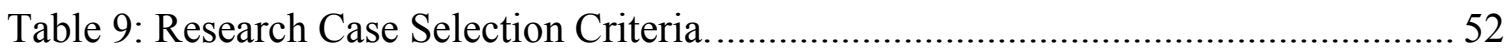

Table 10: Research Case Patent Identification. ………………........................................ 54

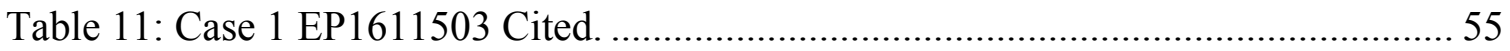

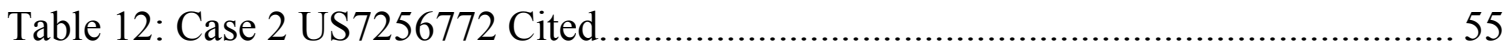

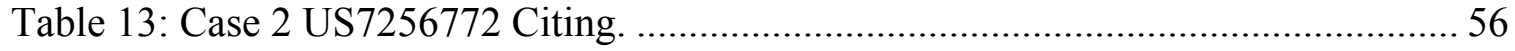

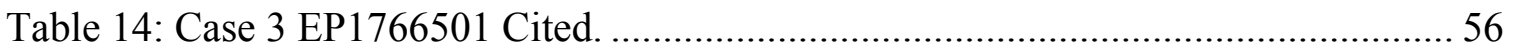

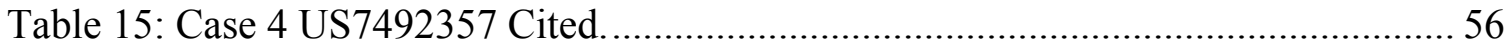

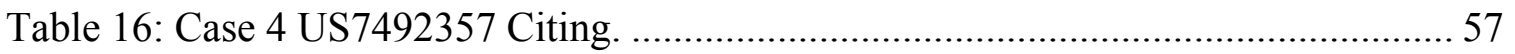

Table 17: Case 5 EP1297488, EP1739528, and EP1739529 Cited................................. 57

Table 18: Case 5 EP1297488, EP1739528, EP1739529 Citing........................................ 57

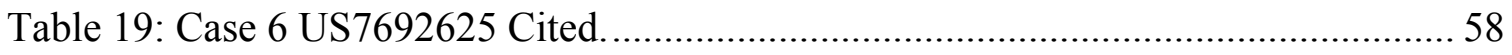

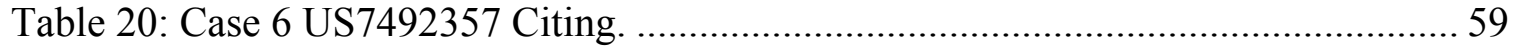

Table 21: Identification Of The Relevant Documents For The European Cases. ............ 62

Table 22: Identification Of The Relevant Documents For The United States Cases. ...... 64 
Table 23: Evidence Case Instrument - Case 4 US7492357 Cited Citations Example..... 68

Table 24: Summary Of The Document Examination And Data Analysis...................... 70

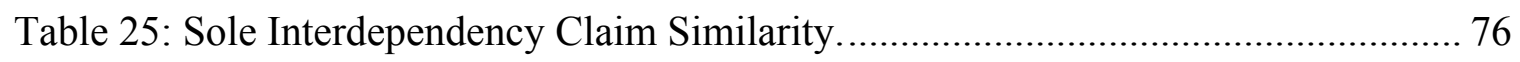

Table 26: Pooled Interdependency Citation And Claim Similarity.............................. 77

Table 27: Summary of Case 1 and Case 2 Citation Interdependency............................ 78

Table 28: Summary of Case 3 and Case 4 Citation Interdependency............................. 78

Table 29: Summary of Case 5 and Case 6 Citation Interdependency............................ 79

Table 30: Data Analysis To Compare Noise And Pertinence....................................... 81

Table 31: Data Analysis To Compare Citation Interdependency. ................................ 83

Table 32: Raw And Preprocessed Research Data Volume.......................................... 89

Table 33: Number Of Identified Technology Patent Citations..................................... 89

Table 34: Summary of Noise Pertinence Ratio Case Results. ..................................... 90

Table 35: Summary of Noise Pertinence Types. ...................................................... 91

Table 36: Sole Dominant Technology Patent Cited Citation....................................... 99

Table 37: Sole Dominant Technology Patent Citing Citation. ...................................... 99

Table 38: Pooled Dominant Technology Patent Citing Citation. ................................. 104

Table 39: Summary Of Key Findings For Noise And Pertinence. .............................. 107

Table 40: Summary Of Key Findings For Dominant Technology Patent Citations....... 108

Table 41: Literature Review Summary Of Stream 1.............................................. 145

Table 42: Literature Review Summary Of Stream 2 ............................................. 147

Table 43: Literature Review Summary Of Stream 3............................................ 149

Table 44: Evidence Case 1: EP1611503 Cited Citations............................................ 150

Table 45: Evidence Case 2: US7256772 Cited Citations. ....................................... 151 
Table 46: Evidence Case 2: US7256772 Citing US8462137 Citations......................... 151

Table 47: Evidence Case 2 US7256772 Citing US8504944 Citations......................... 151

Table 48: Evidence Case 2 US7256772 Citing US20120032922 Citations.................. 152

Table 49: Evidence Case 3 EP1766501 Cited Citations........................................... 152

Table 50: Evidence Case 4 US7492357 Cited Citations. ............................................ 153

Table 51: Evidence Case 4 US7492357 Citing US763002 Citations............................ 153

Table 52: Evidence Case 4 US7492357 Citing US 7751671 Citations......................... 154

Table 53: Evidence Case 4 US7492357 Citing US8462137 Citations.......................... 154

Table 54: Evidence Case 4 US7492357 Citing US8504944 Citations......................... 154

Table 55: Evidence Case 5 EP1297488 cited Citations............................................. 155

Table 56: Evidence Case 5 EP1739528 Cited Citations............................................ 156

Table 57: Evidence Case 5 EP1739529 Cited Citations............................................ 156

Table 58: Evidence Case 5 EP1297488 Citing EP2089791 Citations........................... 156

Table 59: Evidence Case 6: US7692625 Cited Citations. ......................................... 157

Table 60: Evidence Case 6 US7692625 Citing US7932899 Citations.......................... 157

Table 61: Evidence Case 6 US7692625 Citing US8131502 Citations......................... 158

Table 62: Evidence Case 6 US7692625 Citing US8135561 Citations......................... 158

Table 63: Evidence Case 6 US7692625 Citing US8228304 Citations......................... 158

Table 64: Evidence Case 6 US7692625 Citing US8232511 Citations.......................... 159

Table 65: Evidence Case 6 US7692625 Citing US8305363 Citations......................... 159

Table 66: Evidence Case 6 US7692625 Citing US8330726 Citations......................... 159

Table 67: Evidence Case 6 US7692625 Citing US8400415 Citations......................... 160

Table 68: Evidence Case 6 US7692625 Citing US8513546 Citations......................... 160 
Table 69: Evidence Case 6 US7692625 Citing US8515128 Citations.......................... 161

Table 70: Evidence Case 6 US7692625 Citing US8547327 Citations......................... 161 


\section{List of Figures}

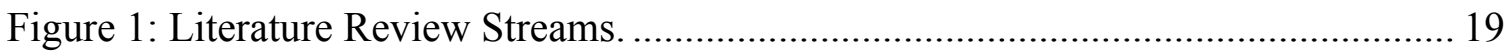

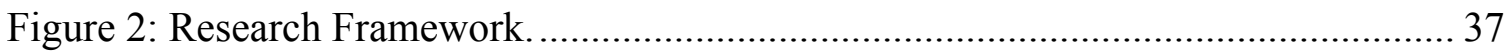

Figure 3: Categories Of Patent Citation Data. .............................................................. 43

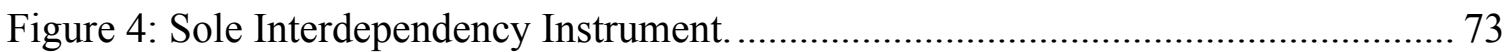

Figure 5: Pooled Interdependency Instrument............................................................. 75

Figure 6: Cited Technology Patent Citation Noise \& Pertinence..................................... 92

Figure 7: Citing Technology Patent Citation Noise \& Pertinence..................................... 93

Figure 8: European Case Noise And Pertinence............................................................ 94

Figure 9: United States Cases Noise And Pertinence. ………........................................ 95

Figure 10: European And United States Noise And Pertinence. ....................................... 95

Figure 11: Emergence Of Noise Pertinence Ratio Construct. ........................................... 97

Figure 12: Sole Interdependency Cited Technology Patent Citations........................... 100

Figure 13: Sole Interdependency Citing Technology Patent Citations............................ 101

Figure 14: Comparison For Sole Interdependency In Europe. ........................................ 101

Figure 15: Comparison For Sole Interdependency In The United States...................... 102

Figure 16: Comparison Of Sole Interdependency In Europe And The United States... 103

Figure 17: Pooled Dominant Technology Patent Citation Interdependencies................ 104

Figure 18: Pooled Comparison Between Europe and United States Cases. ................... 105

Figure 19: Dominant Technology Patent Citation Ratio Construct................................. 106

Figure 20: Summary Of Significant Findings........................................................ 112

Figure 21: Technology Patent Citation Ratio Interdependency Framework. .................. 113

Figure 22: Previous Approach To Evaluate Technology Patents. ................................... 123 
Figure 23: Refined Citation Data Example Patent Evaluation Methodology................ 126

Figure 24: Patent Portfolio Evaluation Example. ................................................... 128

Figure 25: Noise And Interdependency Revealed. ............................................... 131

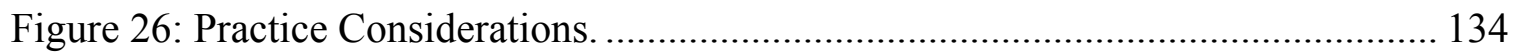




\section{List of Appendices}

Appendix A................................................................. 144

A.1 Stream 1 Prior Art Citation Based Patent Evaluation Methodologies. ........ 144

A.2 Stream 2 Prior Art Citations.......................................... 146

A.3 Stream 3 Interdependency Between Prior Art Citations and Patents........... 148

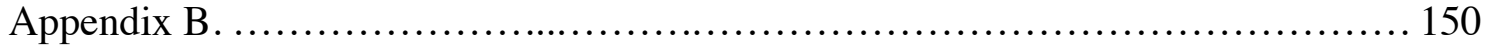

B.1 Case 1 Document Examination And Attribute Coding.................... 150

B.2 Case 2 Document Examination and Attribute Coding.................... 151

B.3 Case 3 Document Examination And Attribute Coding.....................152

B.4 Case 4 Document Examination And Attribute Coding.................... 153

B.5 Case 5 Document Examination And Attribute Coding.................... 155

B.6 Case 6 Document Examination And Attribute Coding..................... 157

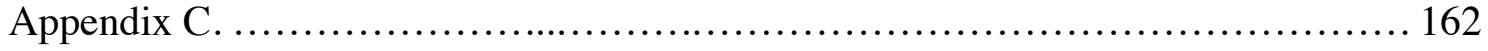

C.1 Case 1 Cited Results Of Independent Claim Examination And Data Analysis 163

C.2 Case 2 Cited Results Of Independent Claim Examination And Data Analysis 165

C.3 Case 3 Cited Results Of Independent Claim Examination And Data Analysis 167

C.4 Case 4 Cited Results Of Independent Claim Examination And Data Analysis 168

C.5 Case 5 Cited Results Of Independent Claim Examination And Data Analysis 171

C.6 Case 6 Cited Results Of Independent Claim Examination And Data Analysis 174

C.7 Case 2 Citing Results Of Independent Claim Examination And Data Analysis177

C.8 Case 4 Citing Results Of Independent Claim Examination And Data Analysis178

C.9 Case 5 Citing Results Of Independent Claim Examination And Data Analysis180

C.10 Case 6 Citing Results Of Independent Claim Examination And Data Analysis183 


\section{Introduction}

Chapter 1 is organized into seven sections and begins with the background and an overview of the research topic. Next, the research objective and deliverables are explained. Then the stakeholders and relevance to the stakeholders are described. Next, the contribution made by this thesis is described. Then an overview of the research method is provided. Key research terms are defined and Chapter 1 concludes with a general outline of the thesis document.

\subsection{Background}

Business based intellectual property assessments are an important ongoing technology innovation management activity. A particular category of business based intellectual property assessment relates to evaluating patent assets. Stakeholders can apply patent evaluation methodologies as part of an effective technology innovation management program (Tseng, 2009). This reveals hidden attributes encapsulated in or surrounding a patent. These hidden attributes are beneficial to enabling a stakeholder's business decision-making capabilities concerning these assets.

One widely utilized and valuable criterion in patent evaluation methodologies is prior art citation data (Reitzig, 2003). Prior art citation data is a list of prior art references cited against the patent during the patent prosecution process. Prior art references are applied as a check and balance during the prosecution process to ensure only new and inventive technology may grant as a technology patent. This eliminates the old and uninventive technology. 
Previous research incorrectly draws an analogy between the prior art citations of a patent and that of citations in academic literature. The purpose of citations in academic literature is to identify and acknowledge the relevance of ideas and research of other authors. Citations in academic literature also avoid the potential issue of plagiarism. These citations provide support, and validity to an author's argument. Citations that have a higher number are considered to be more important than other sources of information in academic literature.

Prior art citations have a different purpose and function with respect to patents. Prior art citations identify old technology relating to an invention claimed in a patent. Prior art citations are applied by a patent Examiner to consider the novelty and inventiveness of an invention claimed in a patent. A higher number of prior art citations does not relate to the importance or source of the old technology. The importance of prior art citations depends upon the amendment, or lack of amendment with respect to the claims of the patent.

Prior art citation data may be applied to patent evaluation methodologies either alone or in combination with other types of business information and data. This depends upon the business requirements of the technology innovation management process and particular needs of the stakeholder.

Prior art citation data may be further described by four key different terminologies. Prior art citation data may be noisy, may include relevant citations, and may include pertinent 
citations and a dominant citation. These key terms have specific definitions in this research as they relate to prior art citation data and are described in Table 1.

\begin{tabular}{l|cl}
\hline Research Term & Definition As It Relates To Prior Art Citations \\
\hline Noise & $\begin{array}{l}\text { A list of prior art citations in the form of prior art citation data contains both meaningful prior art } \\
\text { citation information and meaningless prior art citation information. } \\
\text { Noise is the amount of meaningless prior art citation information. Noisy citations do not force any } \\
\text { change or amendment to the broad claim of the patent. This noise obscures the meaningful prior art } \\
\text { citation information. The amount of noise is indeterminate and limits the results of patent evaluation } \\
\text { methodologies. }\end{array}$ \\
\hline Relevant & $\begin{array}{l}\text { Meaningful prior art citation information are relevant citations. Relevant citations are closely } \\
\text { connected to the patent and may be an indication to the state of the technology, relate to the novelty } \\
\text { of an invention or relate to the inventiveness of an invention. }\end{array}$ \\
\hline Pertinent & $\begin{array}{l}\text { Pertinent citations are citations that are closely connected to a patent and are influential. Pertinent } \\
\text { citations force a change or amendment to the broad patent claim or prevent grant of the patent. }\end{array}$ \\
\hline Dominant & $\begin{array}{l}\text { A dominant prior art citation is the citation that is the most influential or most important citation } \\
\text { associated with and forced a change or amendment to the broad claim of the patent. The dominant } \\
\text { citation may also be the citation that prevented grant of the patent. } \\
\text { A dominant prior art citation has the strongest link to the patent with the highest amount of similarity } \\
\text { and interdependency with the claim of the patent. }\end{array}$ \\
\hline
\end{tabular}

Table 1: Definition Of Key Research Terms.

Although widely utilized, prior art citation data brings a known problem identified in the extant literature as citation noise (Deng, 2008; Hall et al., 2005; Jaffe et al., 1993; Bacchiocchi \& Montobbio, 2010; Criscuolo \& Verspagen, 2008; Gay \& Le Bas, 2005; Gay et al., 2005; Hu \& Jaffe, 2003; Hu et al., 2012; Jaffee \& Trajtenberg, 2002; van Zeebroeck, 2011). This problem was first identified by Jaffe et al. (1993) and has remained unresolved throughout the years.

Citation noise occurs because some citations are not relevant to the patent and other citations are relevant to the patent (Hu \& Jaffe, 2003). Citations may be added during the patent prosecution procedure to avoid the risk of legal consequences (Criscuolo \& Verspagen, 2008). Many different actors may add citations during the procedure. The final decision that determines relevance of a citation rests with a patent Examiner during 
the procedure (Criscuolo \& Verspagen, 2008). Therefore, the research perspective of citation noise is the relevance or lack of relevance of each citation with a patent.

Prior art citation noise impedes the capabilities of patent evaluation methodologies from revealing these valuable hidden attributes encapsulated by the patent. This limits the evaluation and the stakeholders' business decision-making capabilities. This noise is generated during the patent examination process at patent offices further suggesting inefficiencies at patent offices. This is clearly a significant problem of intrinsic importance to many different stakeholders and organizations that take advantage of citation dependent patent evaluation methodologies.

The lack of scholarly knowledge and understanding concerning citation noise is another problem. This problem remains because the understanding is deeply locked within the black box of historical patent data (Reitzig, 2004). Unlocking this black box of patent data requires a specific and unique combination of skills to take the historical patent data and turn it into useful new technology patent citation criteria for patent evaluation methodologies.

A new understanding could eliminate noise by identifying and separating out pertinent and dominant citations from noise. This could also unlock unachieved value in the present citation dependent patent evaluation methodologies and provide stakeholders with better business information concerning their intellectual property assets. Better business information leads to improved decision making capabilities for the stakeholders 
around this important activity in technology innovation management. Additionally, if we could identify a source, or sources of noise or inefficiencies generating this noise, we could further improve patent office policy and procedures and limit generating the noise at the source achieving a global benefit to all stakeholders.

This research seizes a rare opportunity to open up the black box of historical patent data. As both a researcher and professional registered patent agent practitioner with international experience I bring a unique combination of skills that comprehends unlocking the black box. Unlike the research prior to this thesis, the focus of my research goes deeply into the black box and complexities of historical patent data to examine that data and the interdependencies between prior art citations and the corresponding technology patents. Examining the patent data at this level reveals insight, a new framework and a new methodology to refine prior art citation data based upon these interdependencies. This also opens up many new opportunities for stakeholders, policy makers, researchers and provides new capabilities to improve a much larger set of patent evaluation methodologies.

\subsection{Research Objective And Deliverables}

The objective of this thesis is to explain and answer the research question, "How can the interdependencies between a technology patent citation and a technology patent be applied to improve citation dependent patent evaluation methodologies?" 
The research deliverables include the following:

1. A technology patent citation ratio interdependency framework and method that explains how to apply the interdependencies between technology patent citations and technology patents to improve citation dependent patent evaluation methodologies.

2. A noise pertinence interdependency ratio construct based upon the technology patent citation ratio interdependency framework. Application of this construct identifies noise from technology patent citations to reveal interdependency and remove noise in the form of pertinent citations.

3. A dominant technology patent citation interdependency ratio construct based upon the technology patent citation ratio interdependency framework. Application of this construct removes noise from technology patent citations and reveals interdependency in the form of a sole dominant citation.

\subsection{Relevance}

This research is of professional significance to three groups of stakeholders. The first group is (i) executives, (ii) senior managers and (iii) venture capitalists and investors. This group is involved in or responsible for, or conduct, a form of practical business based intellectual property assessment that includes a citation dependent patent evaluation methodology. The second group is intellectual property practitioners. This group is involved in the patent prosecution process. The third group is researchers interested in citation dependent patent evaluation research. 
The relevance to the first group of stakeholders is the ability to identify pertinent and dominant citations from the noise. This improves the results from patent evaluation methodologies. This in turn improves many different types of practical business based intellectual property assessments enabling better stakeholder decisions. This includes: economic value determinations (Harhoff, Scherer, \& Vopel, 2003), effective innovation management (Tseng, 2009), determining the value of innovations (Trajtenberg, 1990), determining future profit earning potential of innovations (Hirschey \& Richardson, 2003), patent portfolio assessments (Trajtenberg, Henderson, \& Jaffe, 1997), determining knowledge flows and spillovers (Caballero \& Jaffe, 1993; Jaffe, Trajtenberg, \& Henderson, 1993; Jaffe \& Trajtenberg, 1996; Jaffe \& Trajtenberg, 1999), identifying sources of commercial technology (Henderson, Jaffe, \& Trajtenberg, 1998) and the organizational impact of commercial innovation (Jaffe, Fogarty, \& Banks, 1998) to identify but a few from the extant literature.

This research is also of professional significance to a second group of stakeholders from the intellectual property profession. This includes (i) patent examiners, (ii) patent agents and attorneys, and (iii) policy makers. These stakeholders are either responsible for the examination of patent applications at a world, regional or national intellectual property office or oversee and set national or international intellectual property policy, rules and procedures. Patent citation data is generated and applied during prosecution of a patent application and patent citation noise generates inefficiencies in the examination process. 
The relevance to the second group of stakeholders is increasing efficiency in the patent examination process. Removing or limiting the generation of patent citation noise at the source could improve efficiencies. Removing the noise at the source is also relevant to the first group of stakeholders from a global perspective by naturally improving one of the key criteria for citation dependent patent evaluation methodologies.

This research is also of professional significance to researchers interested in citation dependent patent evaluation methodologies. This research partially opens up the black box of historical patent data to reveal new insights and new knowledge that can refine patent citation data. This involves removing noise, providing identification of key dominant citations. Overall, this improves the impact of technology patent citation data for use with citation based patent evaluation methodologies.

This research discovers new relationships between the phenomena of prior art citations and the interdependencies with patents. This leads to new research opportunities to test and further extend the theory of refining technology patent citation data through the interdependencies between patent citations and patents. There are also compelling reasons and opportunities for researchers to revisit previous research concerning citation dependent patent evaluation methodologies based upon the new insights formulated by this research. 


\subsection{Thesis Contribution}

There are five theoretical contributions and three practical contributions made by the results of this research.

The first theoretical contribution is in the form of a new research method. The new research method is based upon a combination of theories from Yin (2009), Eisenhardt (1989), Eisenhardt \& Graebner (2007) and Bernard \& Ryan (2010). The combination for this research is unique and likely to yield to methodological findings and advance knowledge in the field of patent citations and the interdependences with patents.

This research makes a second theoretical contribution by providing a new research framework. The new research framework for the interdependencies between technology patent citations and technology patents has not been identified previously. The framework is a synthesis from the three academic literature review streams. The framework includes a prior art citation construct, a technology patent interdependencies construct and a technology patent evaluation methodologies construct (see Figure 2). The technology patent interdependencies construct further identifies attributes located in technology patent data that relate to interdependency between a technology patent citation and a technology patent.

A third theoretical contribution is the new technology patent citation ratio interdependency framework not previously identified by scholars. This framework emerged from the case analysis of this research. It provides the basis for two ratios that 
remove noise from technology patent citation data. The framework includes the noise pertinence interdependency ratio construct and the dominant citation interdependency ratio construct. The noise pertinence interdependency ratio construct includes two attributes that define the noise pertinence ratio. The dominant citation interdependency ratio construct includes two attributes that define the dominant citation ratio. This framework provides the basis for refining technology patent citation data into useful information. Application of this framework removes noise and identifies the pertinent and dominant technology patent citations from the noise inherent in the citation data.

A fourth theoretical contribution is the new noise pertinence ratio construct that provides a first perspective to refine technology patent citation data. Scholars have not previously identified the noise pertinence ratio. This removes technology patent citation noise by permitting the identification of the ratio of pertinent patent citations to noise. Applying the noise pertinence ratio removes noise in the technology patent citation data. The noise pertinence ratio is applicable to patent evaluation methodologies that require a patent citation count or frequency as criteria to the methodologies.

A fifth theoretical contribution is the new dominant citation ratio construct that provides a second perspective to refine technology patent citation data. The dominant citation ratio has not been identified previously. This identifies dominant citations and a degree of interdependency between the technology patent citation and the technology patent. This is a second approach to removing technology patent citation noise by permitting the identification and ranking of key dominant citations. The dominant citation ratio is 
applicable to patent evaluation methodologies that require a connection or path between the citations and technology patents.

This research also makes a first practical contribution by providing a framework, method and explanation for the first group of stakeholders. It provides guidance to stakeholders for refining technology patent citation data into a noise pertinence ratio. The framework is applicable with citation based patent evaluation methodologies that include a citation count as criteria to improve the output from these methodologies.

A second practical contribution is the method and explanation to stakeholders for refining technology patent citation data into a dominant citation ratio. The dominant citation ratio is applicable to citation based patent evaluation methodologies that include citation links or connections as a measure to improve the results from these methodologies.

A third practical contribution is providing a method and explanation to the second group of stakeholders for applying the noise pertinence ratio with an indication to the sequence number of amendments. This contrasts efficiencies and inefficiencies in intellectual property office examination procedures. This is valuable at benchmarking examination procedures and leads to improving intellectual property policies.

Finally and a unique contribution, this research fills an interesting gap in the literature and partially opens up the black box of historical patent data. This reveals new knowledge with respect to technology patent citation data and the interdependencies 
between technology patent citations and technology patents. Researchers may apply this new knowledge with future research into business based intellectual property assessments that include citation dependent patent evaluation methodologies.

\subsection{Overview Of The Research Method}

The method selected for this research to investigate the citation noise problem and interdependency phenomenon is an empirical multi-case research approach. The method follows guidance suggested by Yin (2009), Eisenhardt (1989), Eisenhardt \& Graebner (2007) and Bernard \& Ryan (2010). The research perspective is qualitative to explore, describe and explain the phenomenon.

The sample examined by this research is delimited to set boundaries and controls for the research. Prior art citations are restricted to technology patents and exclude other forms of citations such as academic literature and research. Patents are restricted to technology patents also known as utility patents. Design patents, also known as industrial designs are excluded from the research. Patent claims are restricted to the broad independent claims and exclude the narrower dependent claims.

The research method and the unique design are detailed and fully described in Chapter 3.

\subsection{Definition Of Key Research Terms}

This sub-section presents a list of key terms and associated definitions for aiding a reader's comprehension of key terms used in this research. The key terms defined here 
are either new in the profession, have no general currency or are used in this research with a special definition.

Backward Citations - This term relates to cited technology patent citations. The term is used in the academic literature. It includes all forms of prior art citations and is a broader term than cited technology patent citations. This term is a synonym for cited citations.

Citation Based Patent Evaluation Methodology - This term relates to patent evaluation methodologies that require citation data as an input criterion. The criterion is either based solely upon citation data or in combination with other business and technology criteria to perform a business based evaluation of a patent or group of patents forming a portfolio.

Citation - This term relates to prior art citations. They are applied during prosecution of a patent application as a check and balance for granting patents to only new and inventive inventions. Citations include publically available information such as technology patents, published technology patent applications, brochures, and academic literature.

Cited Technology Patent Citation - This term has special meaning to this research. The term is defined to be a technology patent cited against a key technology patent. The cited technology patent predates the key technology patents priority date or application date. 
Citing Technology Patent Citation - This term has special meaning to this research. The term is defined to be a key technology patent sited against another future technology patent. The citing technology patent postdates the future technology patent.

Dominant Citation Ratio - This is a new term used in this research. The dominant citation ratio is the amount or degree of similarity between the technology patent citation and the technology patent. The ratio is based upon the interdependency formed between the technology patent citation and the technology patent.

Dominant Technology Patent Citation - This is a new term used in this research. The dominant technology patent citation is a technology patent citation that has formed interdependency with the technology patent. The dominant technology patent citation may be a sole dominant technology patent citation in a one-to-one relationship with the technology patent. The dominant technology patent citation may also be a pooled dominant technology patent citation in a many-to-one relationship with the technology patent. The other technology patent citations in the many-to-one relationship have a less degree of interdependency with the technology patent.

Forward Citations - This term relates to citing technology patent citations. The term is used in the academic literature. It includes all forms of prior art citations and is a broader term than citing technology patent citations. The term is a synonym for citing citations. 
Interdependencies - This term has special meaning to this research. The term is defined to be interdependencies between a technology patent citation and a technology patent formed during the course of patent prosecution at a patent office. These interdependencies are based upon a legal rejection to a claim and subsequent amendment to a claim.

Noise Pertinence Ratio - This is a new term used in this research. The noise pertinence ratio is a ratio of the technology patent citation noise to the pertinent technology patent citations.

Patent Evaluation Methodology - This term relates to both the evaluation of a patent and the valuation of a patent. Evaluation relates to non-financial methodologies and valuation relates to financial methodologies.

Pertinent Technology Patent Citation - This is a new term used in this research. The term is defined to be a technology patent citation having interdependency with a technology patent.

Technology Patent - A patent may be a utility patent or a design patent. A technology patent has special meaning to this research and is defined to be a utility patent. The design patent is excluded from this term. 
Technology Patent Citation - This term has special meaning to this research and is defined to be a form of citation based solely on technology patents or technology patent applications. All other forms of citations are excluded from this term.

Technology Patent Citation Noise - This is a new term used in this research. The term is defined to be a technology patent citation devoid of interdependencies with a patent.

Technology Patent Citation Pertinence - This is a new term used in this research. The term is defined to be a technology patent citation with interdependency to a technology patent. The interdependency is formed with the independent claims during prosecution of the patent application.

\subsection{Structure Of The Thesis}

This document is structured into six chapters. Chapter 1 is an introduction to the thesis. Chapter 2 presents a review and lessons learned from the relevant extant literature. Chapter 3 details the case study research methodology. Chapter 4 presents a description of the research results and findings. Chapter 5 is a discussion of the results of the research and Chapter 6 is a description of the conclusions, limitations, implications and opportunities for future research. 


\section{Literature Review}

Chapter 2 is a review of the relevant extant literature for this research. This chapter begins with a brief introduction to the literature review and identifies the three literature streams. A review and summary of the citation dependent patent evaluation methodologies stream is next. Then, a review and summary of the prior art citation stream is provided. Then, a review and summary of the interdependencies between prior art citations and patents stream is provided. Next, a summary and lessons learned from the three streams is provided. Finally, Chapter 2 concludes with a discussion and formulation of the research framework that is inductively abstracted from the review of the extant literature.

\subsection{Introduction To The Literature Review}

Intellectual property, and in particular patents, bring two different forms of business value to a firm. The direct forms of business value are the options for a 20-year monopoly on a technology, technology licensing opportunities, potential royalties and the possible sale of a patent asset. The indirect forms of business value relate to using associated patent and business information to reveal hidden information surrounding the patent. This information includes actors, firms and technology identified through associated links between relevant patents.

Patent evaluation methodologies enable the assessment of patents and business information and reveal hidden information. A particular type of patent evaluation methodology is based in part upon prior art citations. The prior art citations are used as a 
proxy for different types of measures dependent upon the patent evaluation methodology. Prior art citations are also used in the patent prosecution procedure by an Examiner to ensure an invention is new and inventive. The Examiner seeks to identify and apply the relevant prior art citations against the patent application to ensure old uninventive technology does not issue as a patent. The patent examination process is one of rejection, amendment and arguments that lead to interdependency between prior art citations and patents. Prior art citations may include both patent documents and academic research articles and literature.

This literature review has three objectives. A first objective is to reveal and understand the current state of knowledge in citation dependent patent evaluation methodologies. A second objective of this literature review is to reveal and understand the current state of knowledge with respect to prior art citations as a proxy for different measures. A final objective of this literature review is to reveal and understand interdependency between prior art citations and a patent and how interdependency forms during the examination process of a patent application.

This literature review is therefore organized into three streams as shown in Figure 1. The first stream relates to citation dependent patent evaluation methodologies. The second stream relates to prior art citations and the third stream relates to the interdependencies between prior art citations and patents. 


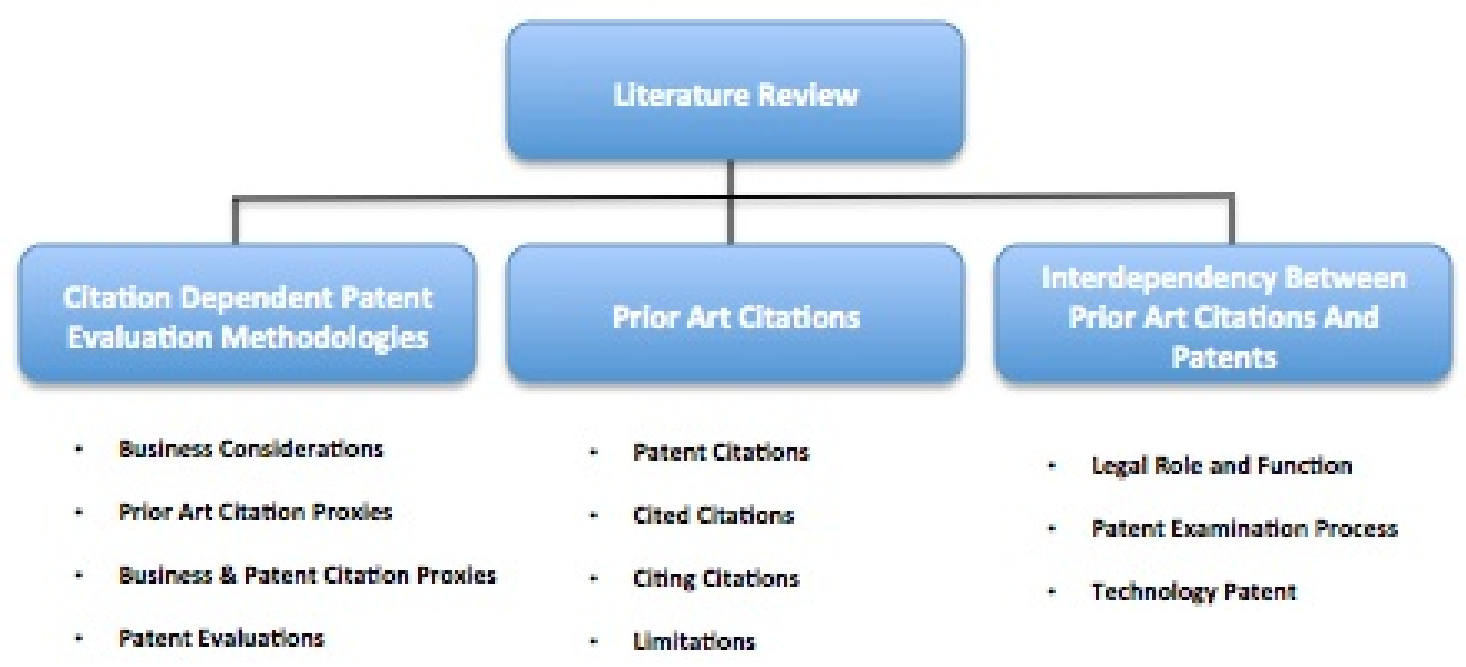

Figure 1: Literature Review Streams.

\subsection{Stream 1: Citation Dependent Patent Evaluation Methodologies}

The strategy to locate and identify literature for this stream started with a broad keyword search in the Business Source Complete database. The keywords were a combination of patent, business, citation, evaluation and valuation. This search resulted in an overall collection of 77 potential articles when restricted to scholarly journals.

A review of the abstracts and introductions with a narrow focus on patent citations removes articles pertaining to other forms of prior art citations. The review also focused upon patent evaluation methodologies that required either alone or in part prior art patent citation data. This resulted in a list of 12 relevant articles that specifically related to the topic of citation based patent evaluation methodologies where the citation is a patent citation. The expanse of the literature spans the years from 1993 to the present, 2014 suggesting a topic of academic interest over many years. Each of the 11 relevant articles is summarized in Table 41 of Appendix A.1. The literature in this stream was further 
inductively synthesized to identify trends across the body of this stream from three specific perspectives as outlined in Table 2 .

The three perspectives provide a specific view of the literature in this stream. A first perspective is an overall business contribution of the citation based patent evaluation methodologies. A second perspective is an indication to the use of prior art citations in the patent evaluation methodologies. The third perspective is an identification and indication to the use of other business or patent based criteria in patent evaluation methodologies and the role of prior art citations.

\begin{tabular}{|c|c|}
\hline Perspective & Citation Dependent Patent Evaluation Methodologies \\
\hline $\begin{array}{c}\text { Business } \\
\text { Contribution }\end{array}$ & $\begin{array}{l}\text { - Product portfolio management, joint ventures and strategic alliances (Bapuji et al., 2011). } \\
\text { - Targeting and due diligence in a mergers and acquisition process to identify key inventors, technology, higher } \\
\text { impact patents and technological compatibility (Brietzman \& Thomas, 2001). } \\
\text { - Measuring firm performance (Chen \& Chang, 2010). } \\
\text { - Measuring economic value of knowledge spillovers (Deng, 2008). } \\
\text { - Determining the value or importance of a patent (Fischer \& Leidinger, 2014; Hall et al., 2005). } \\
\text { - Gaging a firm's inventive and innovative value (Hirschey \& Richardson, 2003). } \\
\text { - Identifying the geographic location of knowledge spillovers (Jaffe et al., 1993). } \\
\text { - Determining the present value and inventiveness of a patent (Reitzig, 2003). } \\
\text { - Comparing innovation on a country basis to identify fundamental, applied, incremental and radical innovation } \\
\text { (Tseng, 2009). }\end{array}$ \\
\hline $\begin{array}{c}\text { Prior Art } \\
\text { Citations } \\
\text { Proxies }\end{array}$ & $\begin{array}{l}\text { Patent Citation Proxies } \\
\text { - Knowledge flow, proxies for internal (self cited) and external (other cited) knowledge (Bapuji et al., 2011). } \\
\text { - } \text { Patent quality (Brietzman \& Thomas, 2001; Hall et al., 2005; Tseng, 2009), forward citations higher future value } \\
\text { (Fischer \& Leidinger, 2014; Hirschey \& Richardson, 2003). } \\
\text { - } \text { Patent value, forward and backward citations as a proxy (Harhoff et al., 2003) and higher counts to other firms } \\
\text { reveal more valuable patents (Chen \& Change, 2010). } \\
\text { - } \text { Knowledge spillovers, cited citations from past to current technology (Deng, 2008; Jaffe et al., 1993). } \\
\text { - Patent Portfolio importance, citing citations are a proxy for importance (Deng, 2008; Jaffe et al., 1993). } \\
\text { - } \text { Scientific advances, forward citations as a proxy (Hirschey \& Richardson, 2003). } \\
\text { - } \text { Research, non-patent citations as a proxy for research (Hirschey \& Richardson, 2003) } \\
\text { - } \text { Novelty and inventiveness, backward citations as a proxy (Reitzig, 2003). } \\
\text { - } \text { Inventor and firm identification (Hall et al., 2005). }\end{array}$ \\
\hline $\begin{array}{c}\text { Patent and } \\
\text { Business } \\
\text { Proxies }\end{array}$ & $\begin{array}{l}\text { Patent \& Technology Proxies: } \\
\text { - Patent counts, patent growth, current impact, linkage to science, technology cycle time, R\&D intensity and } \\
\text { market to book values (stock market value) (Brietzman \& Thomas, 2001). } \\
\text { - } \text { Patent share, relative patent position (Chen \& Chang, 2010). } \\
\text { - } \text { Patent family size as a proxy for economic relevance and IPC classes as a proxy for patent scope (Fischer \& } \\
\text { Leidinger, 2014). } \\
\text { - } \text { Patent family size, opposition outcomes in Europe and IPC classification as a proxy for scope of the patent } \\
\text { (Harhoff et al., 2003). } \\
\text { - } \text { Breadth of claims, degree of difficulty to design around, disclosure and position of a patent in a portfolio of } \\
\text { patents as a proxy for patent value (Reitzig, 2003). } \\
\text { Business Proxies: } \\
\text { - } \quad \text { Market value, optimal value of citations can positively increase market value (Chen \& Chang, 2010). } \\
\text { - } \text { Firm performance, sales is a proxy (Bapuji et al., 2011). } \\
\text { - Market valuation (stock market value and book value) and an R\&D ratio (Deng, 2008). } \\
\text { - Stock market valuation of intangible assets (Hall et al., 2005). } \\
\text { - Stock market prices, number of patents and value of R\&D expenditures (Hirschey \& Richardson, 2003). } \\
\text { - } \text { Inventor and firm information as a proxy for geographic location (Jaffe et al., 1993). }\end{array}$ \\
\hline
\end{tabular}

Table 2: Citation Dependent Patent Evaluation Methodologies. 


\subsubsection{Business Contribution}

Citation based patent evaluation methodologies provide value to stakeholders in a range of business, patent and technology evaluations. This includes three business considerations.

A first business consideration is to evaluate the patent or patents from the business perspective. This includes patent portfolio management, potential joint ventures and strategic alliances (Bapuji et al., 2011), firm performance (Chen \& Chang, 2010) or assessing the innovative value of a firm (Hirschey \& Richardson, 2004).

A second business consideration is to evaluate the patent or patents from an intellectual property perspective. This is to reveal the value or importance of a patent (Fischer \& Leidinger, 2014; Hall et al., 2005) or the present value of a patent (Reitzig, 2003).

A third business consideration is to evaluate the patent or patents from a technology perspective. This reveals the value of knowledge spillovers (Deng, 2008), determining the geographic location of knowledge spillovers (Jaffe et al., 1993) or country based innovation comparisons (Tseng, 2009).

\subsubsection{Prior Art Citations As Proxies}

Prior art citations are used as proxies in three general ways. The proxy may include both cited and citing citations as the proxy. The proxy may only use citing citations or the proxy may only use citing citations. The citations may be further identified as a firm 
citation or a citation external to the firm. Knowledge flow (Bapuki et al., 2011) and knowledge spillovers (Deng, 2008; Jaffe et al., 1993) are one form of proxy from the prior art citations. This illustrates or maps codified knowledge between the prior art citations and the corresponding patents.

Prior art citations may also provide a proxy concerning attributes of the patent. These attributes include: quality (Brietzman \& Thomas, 2001; Hall et al., 2005), value (Harhoff et al., 2002), basicness or inventiveness (Reitzig, 2003), importance of a patent portfolio (Deng, 2008; Jaffe et al., 1993) and the identification of key inventors and firms associated with the patent (Hall et al., 2005).

When the prior art citation is a proxy for the attributes of a patent, a higher number of citations reflect a higher value of the patent attribute and a lower number of citations reflect a lower value of the patent attribute.

\subsubsection{Additional Patent And Business Proxies}

The prior art citation proxies may also be supplemented with either or both additional patent and technology proxies as well as business proxies. This is dependent upon the type of business contribution from the patent evaluation methodology.

The prior art citation proxies are supplemented with business proxies when considering a business contribution from the patent evaluation methodology. This relates to firm performance or economic value, joint ventures, strategic alliances or a mergers and 
acquisition process. The business proxies include sales information (Bapuki et al., 2011), market valuation information (Deng, 2008) and stock market information (Hall et al., 2005; Hirschey \& Richardson, 2004).

The prior art citation proxies may also be supplemented with other patent and technology proxies when the business contribution from the patent evaluation methodology relates to the patent or aspects surrounding the patent. These additional proxies include a count of the patents, patent portfolio growth, current patent impact, linkages to science, the technology cycle time, R\&D intensity (Brietzman \& Thomas, 2002), the share of patents, relative patent position (Chen \& Chang, 2010), the patent family size and international patent classification codes (Fischer \& Leidinger, 2014), opposition outcomes in Europe (Harhoff et al., 2003), the breadth of the patent claims, the degree and difficulty to design around a patent, the patent disclosure and position of the patent in the portfolio (Reitzig, 2003).

\subsubsection{Summary of Citation Based Patent Evaluation Methodologies}

A few scholars have suggested relationships between the prior art citations and a corresponding patent. However these broad assumptions are to general and somewhat misplaced with respect to the relationships between each prior art citation and the corresponding patent. A further gap exists in this stream and in particular, how the relationship between the prior art citation and corresponding patent is formed, what if any real interdependencies exist between each prior art citation and the corresponding patent and how you would identify any of these real relationships. 
A few scholars have also identified a significant problem with prior art citations in the form of noise (Jaffe et al., 1993; Hall et al., 2005; Deng, 2008). However, they do not provide any details nor knowledge to overcome the noise problem leaving an interesting question about the potential value and use of prior art citations in patent evaluation methodologies. The accuracy or merit of patent evaluation methodologies that employ prior art citations as a proxy is also questionable.

Citation dependent patent evaluation methodologies are further summarized in Table 3 to include the focus of the evaluation, business considerations and associated proxies.

An evaluation focus of value brings a particular perspective to the citation proxies. Extant literature suggests that a higher number of cited citations relates to a higher quality and lower inventiveness and more basic invention. A lower number of cited citations relates to a higher level of inventiveness and more advanced invention.

Extant literature suggests that for an evaluation focus on knowledge, a higher number of cited citations relate to a higher amount of knowledge spillover and a lower number of cited citations relates to a lower amount of knowledge spillover.

When the evaluation focus is on innovation, the extant literature suggests that a higher number of cited citations relates to higher value patents with more impact. 


\begin{tabular}{|c|c|c|c|c|}
\hline $\begin{array}{c}\text { Evaluation } \\
\text { Focus } \\
\end{array}$ & Business Consideration & Citation Proxies & Other Proxies & Author (Year) \\
\hline \multirow{4}{*}{ Value } & $\begin{array}{l}\text { Evaluate the value of a } \\
\text { patent. }\end{array}$ & $\begin{array}{l}\text { Citing citations for } \\
\text { quality. }\end{array}$ & $\begin{array}{l}\text { Patent auction price for economic } \\
\text { value. } \\
\text { Patent family size for economic } \\
\text { relevance. } \\
\text { International patent classification } \\
\text { codes for patent scope. }\end{array}$ & $\begin{array}{l}\text { Fischer \& } \\
\text { Leidinger } \\
(2014)\end{array}$ \\
\hline & $\begin{array}{l}\text { Evaluate the value of a } \\
\text { patent. }\end{array}$ & $\begin{array}{l}\text { Citations for patent } \\
\text { value. }\end{array}$ & $\begin{array}{l}\text { Opposition proceedings, family } \\
\text { size and international patent } \\
\text { classification codes for scope of } \\
\text { the patent. }\end{array}$ & $\begin{array}{l}\text { Harhoff et al. } \\
(2003)\end{array}$ \\
\hline & $\begin{array}{l}\text { To evaluate the present value } \\
\text { of a patent }\end{array}$ & $\begin{array}{l}\text { Cited citations for } \\
\text { novelty and } \\
\text { inventiveness. }\end{array}$ & $\begin{array}{l}\text { Life of the patent, breadth of the } \\
\text { claims, degree of difficulty to } \\
\text { design around, disclosure and } \\
\text { position of the patent in a portfolio } \\
\text { for value. }\end{array}$ & Reitzig (2003) \\
\hline & $\begin{array}{l}\text { To evaluate the value of a } \\
\text { patent. }\end{array}$ & $\begin{array}{l}\text { Citations for patent } \\
\text { value. }\end{array}$ & $\begin{array}{l}\text { Patent age, generality, originality, } \\
\text { foreign filings and technology field } \\
\text { for value. }\end{array}$ & $\begin{array}{l}\text { Nair et al. } \\
(2011)\end{array}$ \\
\hline \multirow{3}{*}{ Knowledge } & $\begin{array}{l}\text { Evaluate the economic value } \\
\text { of knowledge spillovers. }\end{array}$ & $\begin{array}{l}\text { Cited citations for } \\
\text { knowledge spillover } \\
\text { Citing citations for } \\
\text { patent importance. }\end{array}$ & $\begin{array}{l}\text { Market valuation (stock market } \\
\text { value and book value) for firm } \\
\text { performance. }\end{array}$ & Deng (2008) \\
\hline & $\begin{array}{l}\text { Evaluate the performance of } \\
\text { a patent based upon the } \\
\text { contribution of external } \\
\text { knowledge flow and internal } \\
\text { knowledge flow. }\end{array}$ & $\begin{array}{l}\text { Firm citations for } \\
\text { internal knowledge flow } \\
\text { Non-firm citations for } \\
\text { external knowledge } \\
\text { flow. }\end{array}$ & Sales for firm performance. & $\begin{array}{l}\text { Bapuji et al. } \\
(2011)\end{array}$ \\
\hline & $\begin{array}{l}\text { Evaluate the value of an } \\
\text { intangible knowledge } \\
\text { codified in a patent. }\end{array}$ & $\begin{array}{l}\text { Citations for importance } \\
\text { of the patent. }\end{array}$ & $\begin{array}{l}\text { Stock market value for firm } \\
\text { performance. }\end{array}$ & $\begin{array}{l}\text { Hall et al. } \\
(2005)\end{array}$ \\
\hline \multirow{3}{*}{ Innovation } & $\begin{array}{l}\text { Identification of key } \\
\text { inventors, key technology } \\
\text { and higher impact patents for } \\
\text { M\&A targeting and due } \\
\text { diligence activities. }\end{array}$ & $\begin{array}{l}\text { Citation quintiles for } \\
\text { high impact patents. }\end{array}$ & $\begin{array}{l}\text { Patent count, recent patents, } \\
\text { linkages to science and emerging } \\
\text { technology and market to book } \\
\text { values for firm performance. }\end{array}$ & $\begin{array}{l}\text { Brietzman \& } \\
\text { Thomas }(2001)\end{array}$ \\
\hline & $\begin{array}{l}\text { To evaluate the quality of a } \\
\text { patent and gage a firms } \\
\text { inventive and innovation } \\
\text { activity. }\end{array}$ & $\begin{array}{l}\text { Citing citations for } \\
\text { important scientific } \\
\text { advances } \\
\text { Non-patent citations for } \\
\text { research. }\end{array}$ & $\begin{array}{l}\text { Stock market price for firm } \\
\text { performance. }\end{array}$ & $\begin{array}{l}\text { Hirschey \& } \\
\text { Richardson } \\
(2003)\end{array}$ \\
\hline & $\begin{array}{l}\text { To compare technological } \\
\text { innovation. }\end{array}$ & $\begin{array}{l}\text { Citations for quality } \\
\text { (high number significant } \\
\text { technology). } \\
\text { Scientific citations for } \\
\text { fundamental or applied } \\
\text { innovation. } \\
\text { Self-citing citations for } \\
\text { incremental or radical } \\
\text { innovation. }\end{array}$ & $\begin{array}{l}\text { International patent classification } \\
\text { codes for technology area. }\end{array}$ & Tseng (2009) \\
\hline
\end{tabular}

Table 3: Summary Citation Dependent Patent Evaluation Methodology Applications. 


\subsection{Stream 2: Prior Art Citations}

The strategy to locate and identify extant literature for this second stream includes two different keyword searches in the Business Source Complete database. This is due to synonyms found in the literature relating to citations (backward or cited and forward or citing). The first keyword search included patent, citation, forward and backward. The second keyword search included patent, citation, citing and cited. The search resulted in a total collection of 94 potential articles. As previously indicated, patent citations are the focus of this research and a review of the abstracts and introductions removed articles to other forms of citations such as academic research citations. This resulted in identifying 12 relevant articles for this stream. In addition, one book on patent citations and innovations (Jaffe \& Trajtenberg, 2002) was also identified for review in this stream. The book is a collection or academic research articles on the subject of patent citations and innovations.

The expanse of this literature stream span is 1990 - 2013; also suggesting this is a topic of academic interest over many years. Each article is summarized in Table 42 of Appendix A.2. The literature in this stream was further inductively synthesized to identify trends in this stream from the four perspectives shown in Table 4.

The four perspectives of this second stream provide a view of the literature from an overall patent citation perspective, the cited citations perspective, the citing citations perspective and the limitations of citation data identified in the extant literature. 


\begin{tabular}{|c|c|}
\hline Perspective & Application And Limitations of Prior Art Citations in Patent Evaluation Methodologies \\
\hline $\begin{array}{l}\text { Patent Citations } \\
\text { (Cited \& Citing) }\end{array}$ & $\begin{array}{l}\text { Knowledge flow: } \\
\text { - Reveal technology knowledge information flows through tracking of the citation and frequency of the citation } \\
\text { (Bacchiocchi \& Montobbio, 2010; Hu \& Jaffe, 2003; Gay \& Le Bas, 2005; Jaffee \& Trajtenberg, 2002), } \\
\text { provide links to identify regions, countries, technologies (Bacchiocchi \& Montabbio, 2010) actors (Gay \& Le } \\
\text { Bas, 2005) and knowledge flow and exchange between actors (Hu \& Jaffe, 2003). } \\
\text { Technological Value: } \\
\text { - Citation rates and frequency in different technology fields or classifications (Hu, et al., 2012; Jaffee \& } \\
\text { Trajtenberg (2002) and original knowledge flow (Gay \& Le Bas, 2005). }\end{array}$ \\
\hline $\begin{array}{l}\text { Cited Citations } \\
\text { (backward) }\end{array}$ & $\begin{array}{l}\text { - Codified knowledge (van Zeebroech, 2011; Gay \& Le Bas, 2005). } \\
\text { - Intermediate value (Kelley et al., 2013). } \\
\text { - Present economic value (Nikulainem, et al., 2008). } \\
\text { - Position the patent with respect to basicness and originality. Low frequency of cited citations suggest a low } \\
\text { basicness and a high technical significance (Nikulainen et al., 2008; Jaffee \& Trajtenberg (2002). }\end{array}$ \\
\hline $\begin{array}{l}\text { Citing Citations } \\
\quad \text { (forward) }\end{array}$ & $\begin{array}{l}\text { - Invention value (Van Zeebroech, 2011) and the flow of new ideas (Gay \& Le Bas, 2005). A high frequency is } \\
\text { a proxy for a high potential or breakthrough innovation (Kelley et al., 2013). } \\
\text { - Economic value, a higher frequency of citing citations suggests higher value to appropriate and apply the } \\
\text { invention (Van Zeebroeck, 2011). }\end{array}$ \\
\hline Limitations & $\begin{array}{l}\text { - } \text { Home bias effect and citation lag (Bacchiocchi \& Montobbio, 2010; Gay et al., 2005). } \\
\text { - Patent citation variability (Nikulainem et al., 2008). } \\
\text { - } \text { Simple patent citation counts are noisy (Hu, et al., 2012). } \\
\text { - } \text { Citations and a count of citations do not reveal the interdependency to a patent (Hu et al., 2012). } \\
\text { - } \text { Citations are noisy (Hu \& Jaffe, 2003) and a poor indicator of economic value (Gay \& Le Bas, 2005). } \\
\text { - } \text { More noise in the United States than in Europe (Gay \& Le Bas, 2005; van Zeebroeck, 2011; Criscudo \& } \\
\text { Verspagen, 2008). } \\
\text { - } \text { Decisions rest with the patent Examiner (Criscudo \& Verspagen, 2008). } \\
\text { - Truncation errors (Jaffee \& Trajtenberg (2002) }\end{array}$ \\
\hline
\end{tabular}

Table 4: Application And Limitations Of Prior Art Citations.

\subsubsection{Patent Citations}

Overall patent citations provide proxies for codified knowledge, the flow of knowledge

and technological value. Patent citations reveal the flow of knowledge by providing the

links between the citations and the patent and the significance or value of the knowledge

through the frequency of citation (Bacchiocchi \& Montobbio, 2010; Hu \& Jaffe, 2003;

Gay \& Le Bas, 2005; Jaffee \& Trajtenberg, 2002). The links between the citations and

the patent also provide a way to identify countries, technologies (Bacchiocchi \&

Montabbio, 2010), the actors (Gay \& Le Bas, 2005) as well as the exchange of

knowledge between actors ( $\mathrm{Hu} \&$ Jaffe, 2003). The citation rates, or frequency of

citations provide the proxy for technological value, a higher frequency suggesting a

higher technological value. 
There is another gap in the extant literature. Patent citations may be applied as proxies for knowledge, the flow of knowledge and technological value. However, extant literature assumes that the patent citations are relevant or pertinent to the patent in order to be used as a count or frequency proxy in patent evaluation methodologies.

\subsubsection{Cited Citations}

Cited citations are a measure and specific proxy for knowledge and technology value. Cited citations represent past codified knowledge (van Zeebroech, 2011; Gay \& Le Bas, 2005) and are sometimes referred to in the literature as backward citations. Value may be the intermediate value of the patent (Kelley et al., 2013) or the present economic value of the patent (Nikulainem et al., 2008) or the basicness and originality of the invention (Nikulainen et al., 2008; Jaffe \& Trajtenberg, 2002). The proxy here depends upon the frequency of the cited citation, low suggesting a higher technological significance due to less transfer of old knowledge and high suggesting a very basic invention due to a higher transfer of old knowledge into the patent.

Another gap appears in the extant literature. This gap is in the application of cited citations as proxies for knowledge and technology value. Again, extant literature assumes that the cited citations are relevant or pertinent to the patent in order to be used as a count or frequency proxy in patent evaluation methodologies. 


\subsubsection{Citing Citations}

Citing citations are also applied as a specific proxy for value. Citing citations relate to invention value (van Zeebroeck, 2011) where a high frequency suggests a high potential or breakthrough innovation (Kelley et al., 2013) leading to many other innovations identified by the citing citations. A higher frequency of citing citations also suggests a higher ability to appropriate and higher economic value (van Zeebroeck, 2011). The same gap applies here to citing citations and the assumption that the citing citations are relevant or pertinent to the patent in patent evaluation methodologies.

\subsubsection{Limitations of Citations}

There are a number of known limitations identified from the literature in this stream. There is a home bias effect (self citing of firms and inventors), citation lag (Bacchiocchi \& Montobbio, 2010; Gay et al., 2005) and truncation errors (Jaffe \& Trajtenberg, 2002). The home bias effect relates to citations being skewed to one geographic location more than other locations. Citation lag relates to the long time required to build citing citations with future patents. Citations are noisy (Hu \& Jaffe, 2003) and much more noisy in the United States when compared with Europe (Gay \& Le Bas, 2005; van Zeebroeck, 2011; Criscudo \& Verspagen, 2008).

A particular concern is raised in the literature. Citations and a count of citations or frequency do not reveal the relationship to a patent (Hu, Rousseau \& Chen, 2012) and the relationship rests with decisions of a patent Examiner (Criscudo \& Verspagen, 2008). 
Therefore, noise is framed for this research as the relevance of lack of relevance of each citation with a corresponding patent (see Table 1).

\subsection{Stream 3: Interdependencies Between Prior Art Citations and Patents}

The strategy to locate and identify literature for this third stream also started with a broad keyword search in the Business Source Complete database. The keywords were a combination of patent, examination and examiner. This resulted in a collection of 31 potential articles. The abstracts and introductions were reviewed through a lens of novelty and inventiveness as these terms relate to the emergence or disappearance of interdependency between prior art citations and patents. This resulted in identifying 8 relevant articles for the literature review in this stream. In addition, two books were identified for this stream. One book relates to examination guidelines at the European Patent Office (European Patent Office, 2007) and a second book relates to patent prosecution at the Untied States Patent \& Trademark Office (Donner, 2007).

The expanse of this literature is 2003 - 2013 suggesting less academic interest in this topic. Each article is summarized in Table 44 of Appendix A.3. The literature in this stream was also further inductively synthesized to identify interdependency trends across the body of this stream into three perspectives shown in Table 5.

The three perspectives of this stream provide an understanding of the role and function of prior art citations, the function of the patent examination process and interdependency between citations a claim of a technology patent. 


\begin{tabular}{|c|c|}
\hline Perspective & Interdependencies Between Prior Art Citations and Technology Patents \\
\hline $\begin{array}{l}\text { Legal Role and } \\
\text { Function of Prior } \\
\text { Art Citations }\end{array}$ & $\begin{array}{l}\text { - Simple lists of prior art citations and their presence do not provide any indication towards the pertinence of } \\
\text { the citation or the lack of pertinence (noise) of the citation (Abbott Laboratories v. Baxter Pharmaceutical } \\
\text { Products Inc., 2003). } \\
\text { - An Examiner uses citations for evaluating and limiting the claims during prosecution. Most citations } \\
\text { provided by applicants are noise and lack pertinence towards the claims (Cotropia et al., 2013). }\end{array}$ \\
\hline $\begin{array}{c}\text { Patent } \\
\text { Examination } \\
\text { Process }\end{array}$ & $\begin{array}{l}\text { - The examination process in Europe and the United States requires an examination of the patent application } \\
\text { and claims for novelty and invention (inventive step / nonobvious) (Kica \& Groenendijk, 2011; Laub, 2006). } \\
\text { The concepts are the same, but the legal requirements and rules are different. } \\
\text { - The process in Europe (European Patent Office, 2007) and the process in the United States (Donner, 2007) } \\
\text { are similar. The patent application is examined in part for novelty and invention. An Examiner rejection } \\
\text { may occur based upon the prior art citations and the claims of the pending patent application. The Applicant } \\
\text { provides a response with arguments to overcome the rejection and the response may include claim } \\
\text { amendments. The Examiner considers the response and the process repeats in a sequence until the patent } \\
\text { application is either granted or refused. } \\
\text { - The patent prosecution highway provides a process between countries to examine patent applications without } \\
\text { the need to change national patent laws (Kukrus \& Kartus, 2007) and this shifts the focus away from national } \\
\text { legal requirements and rules to a focus based upon the requirements of the patent prosecution highway. }\end{array}$ \\
\hline Technology Patent & $\begin{array}{l}\text { - The claims in a patent have a specific form and function detailing elements and the relationship between the } \\
\text { elements (European Patent Office, 2007; Donner, 2007) to define the invention. } \\
\text { - The claims in a patent application may be amended during prosecution to overcome prior art citations } \\
\text { (European Patent Office, 2007; Donner, 2007; Berger et al., 2011). The amount of change in an amendment } \\
\text { to distinguish over the prior art citations when compared to the original wording of the claims reveals the } \\
\text { degree or amount of claim amendment. This reveals the amount of similarity and difference between the } \\
\text { prior art citations and the claims of the patent application. }\end{array}$ \\
\hline
\end{tabular}

Table 5: Interdependency Between Prior Art Citations And Patents.

\subsubsection{Legal Role and Function of Prior Art citations}

Simple lists or counts or frequencies of citations do not provide an indication towards the relevance of the citation or a lack of relevance (noise) with the citations (Abbott laboratories v. Baxter Pharmaceutical Products Inc., 2003). An Examiner at a patent office uses the citations to evaluate and limit the scope of the patent claims during prosecution when there is relevance between the citation and the claims of the pending patent application. Most citations provided by applicants are noise and lack relevance towards the claims of the pending patent application (Cotropia et al., 2013).

\subsubsection{Patent Examination Process}

The process requires an examination of the claims in the patent application for novelty and invention (Kica \& Groenendikj, 2011; Laub, 2006). The concept is the same in 
different jurisdictions but the local or national legal requirements and rules are different between Europe and the United States (European Patent Office, 2007; Donner, 2007). The patent application is examined in part for novelty and inventiveness. An examiner rejection may occur based upon the teaching of the prior art citation. The Applicant provides a response with augments to overcome the Examiner rejection. The response may include claim amendments. The Examiner considers the response (Criscudo \& Verspagen, 2008) and the process repeats in a sequence until the patent application or claims are either granted or refused by the Examiner.

\subsubsection{Technology Patent}

The claims in a technology patent have a very specific form and function that includes each element of the claim and the relationship between each of the elements (European Patent Office, 2007; Donner, 2007). These claims may be amended during the patent examination process to overcome prior art citations (European Patent Office, 2007; Donner, 2007; Berger et al., 2011). The amount of change in the claim reveals the degree or amount of pertinence between the citation and the invention as claimed in the pending patent application. There is no pertinence or emergence of interdependency between the prior art citations and the patent application if the claims are not amended and accepted by the Examiner in the form of an allowance to grant the patent. There is complete pertinence and interdependency between the prior art citations and the patent application if the claims are amended and rejected by the Examiner in the form of a final refusal to allow the patent. There is partial pertinence and interdependency between the prior art 
citations and the patent application if the claims are amended and accepted by the Examiner in the form of an allowance to grant the patent.

Novelty requires a one-to-one relationship between the prior art citation and the patent (European Patent Office, 2007; Donner, 2007). Inventiveness requires a many-to-one relationship between the prior art citation and the patent (European Patent Office, 2007; Donner, 2007).

\subsection{Summary Of The Literature Review}

This sub-section summarizes the results of the extant literature review from two perspectives. The first perspective is what we know from the extant literature. The second perspective is what we do not know from the literature, or the remaining questions that need to be addressed by research. This sub-section begins with a summary of the first stream on citation based patent evaluation methodologies. Then, a summary of the second stream on prior art citations is provided. Finally, this sub-section concludes with a summary of the third stream on interdependencies between prior art citations and patents.

\subsubsection{Summary of Citation Based Evaluation Methodologies}

The extant literature from the citation based patent evaluation methodologies stream revealed the following key knowledge relevant to this research:

1. Citation based patent evaluation methodologies are applicable to three types of evaluations. These types include business, patent and technology evaluations. 
2. Citations as a form of proxy are required in each of the three types of evaluations. The format of the citation (citing or cited) data and proxy varies with the type of evaluation.

3. Additional proxies in the form of business or technology proxies may be required by the type of citation based patent evaluation methodology.

4. Citations are noisy raising a question about the reliability and stakeholder value of citation based patent evaluation methodologies.

The questions that remain as a result of the first stream in the extant literature review are:

1. How can we improve citation based patent evaluation methodologies given the issue surrounding the noise in citation data?

2. How can we overcome the problem that was identified by Jaffe et al. (1993) relating to citation noise that obscures citation based patent evaluation methodologies?

\subsubsection{Summary Of Prior Art Citations}

The extant literature from the prior art citations stream revealed the following key knowledge relevant to this research:

1. Citations are used as proxies for either knowledge flow or technological value of a patent.

2. Cited citations are used as a specific proxy for older codified knowledge.

3. Citing citations are used as a specific proxy to reveal invention and economic value of a patent. 
4. Citations do not reveal interdependency with a patent and are therefore noisy without any indication of relevance or pertinence between a citation and the corresponding patent.

The questions remaining from a result of the second stream in this literature review are:

1. How can we improve the use of citation data with respect to noise?

2. Would it be possible to identify the noise in citation data?

3. Would it be possible to identify the pertinent citations from citation data?

\subsubsection{Summary Of Technology Patent Interdependencies}

The extant literature from the interdependencies between prior art citations and patents stream revealed the following key knowledge relevant to this research:

1. Simple counts or frequencies of citations do not provide any information towards the relevance or pertinence of the citation with the patent and therefore are noisy.

2. The requirements of novelty and inventiveness are universal but the test is different dependent upon national or regional requirements,

3. The process of prosecution defines interdependency between the citation and the patent and the amount of interdependency based upon the amendment to the claim accepted by an Examiner. 
The questions remaining from the third stream in this extant literature review are:

1. Can interdependency between a citation and patent be identified from the historical prosecution history files by locating the rejections and corresponding amendments to the patent claims?

2. Can interdependency reveal noise between a citation and patent?

3. Can interdependency reveal pertinence between a citation and patent?

4. Can interdependency be proportioned between a citation and patent?

5. Can the interdependency between a citation and patent be used to solve the problem of noise in patent citation data?

6. Can the interdependency between a citation and patent us used to improve citation based patent evaluation methodologies?

\subsection{Research Framework}

The present research framework is based upon induction and synthesis from the extant literature and is shown in Figure 2. The framework includes three constructs, a prior art citations construct, a technology patent interdependencies construct and a technology patent evaluation methodologies construct.

The prior art citations construct includes the Technology Patent Citations attribute. The technology patent interdependencies construct includes a Legal Rejection Type attribute, a Claim Amendment attribute, a Degree Of Claim Amendment attribute and the sequential Claim Amendment attribute. The technology patent evaluation methodologies construct includes technology patent citations attribute. 


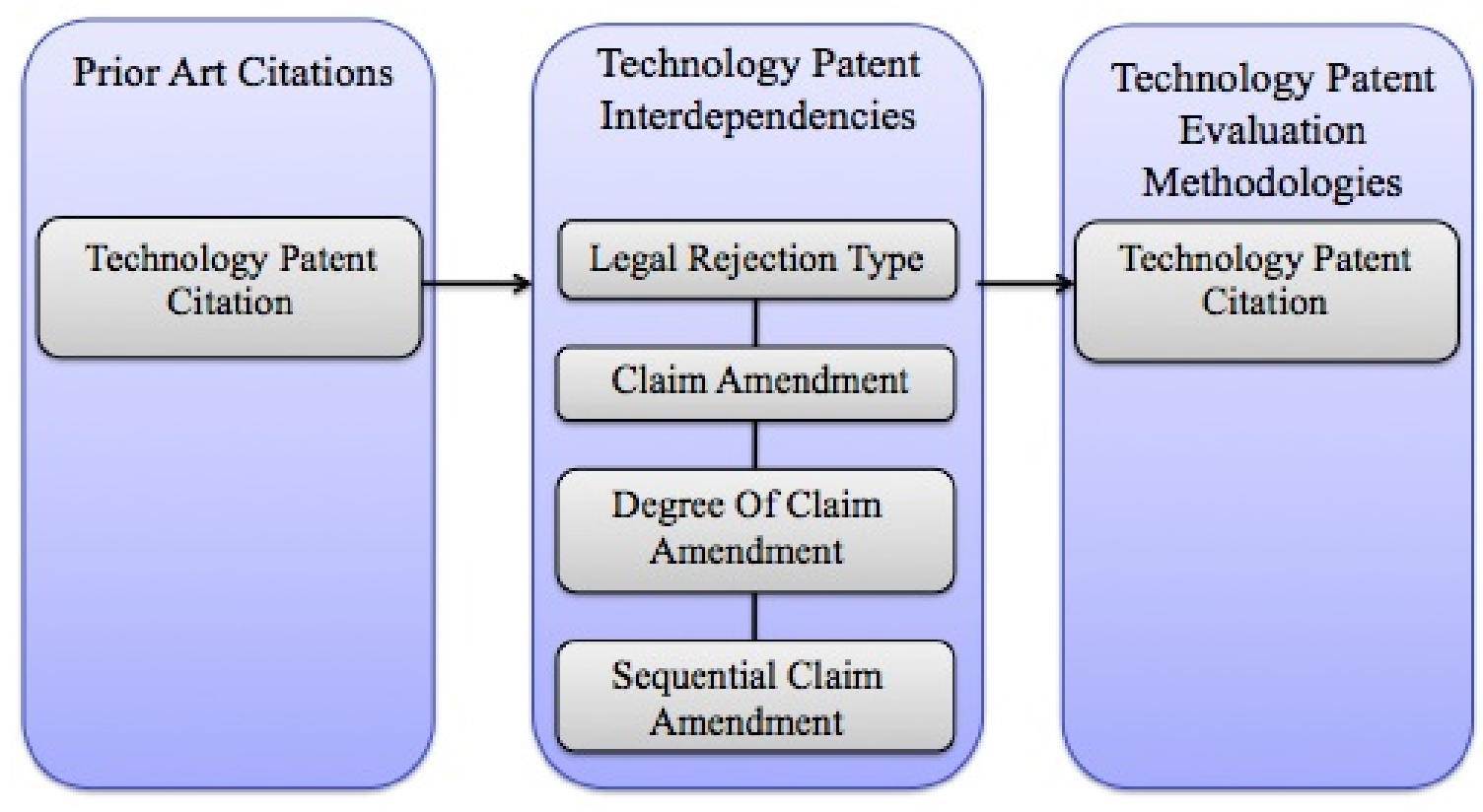

Figure 2: Research Framework.

Previous research provides the technology patent citation and associated noise from the prior art citation construct directly to the technology patent evaluation methodology construct. This research framework introduces the technology patent interdependencies construct between the prior art citations and technology patent evaluation methodologies constructs. The technology patent citation is provided to the technology patent interdependencies construct where the legal rejection type and claim amendment are identified. The degree of claim amendment and sequence of claim amendment are determined. This provides the opportunity to view the interdependency or lack of interdependency between the technology patent citation and the technology patent. The interdependency or lack of interdependency is provided with the technology patent citation to the technology patent evaluation methodology to perform the patent evaluation based upon the interdependency. 
The constructs and attributes of this research framework are fully described in Chapter 3 the research method under Section 3.3 the research framework. 


\section{The Research Method}

Chapter 3 is a detailed description of the research method for this thesis. The method has been precisely followed to create the deliverables. This chapter begins with an overview of the research design. This is followed by a description of research quality considerations. Then, a description of the research framework is provided. The unit of analysis is described. Then, the study period and timeframe are described. Next, a detailed description of the research methodology and the five phases is provided. This chapter concludes with a summary of the research method.

\subsection{Overview Of The Research Design}

This research is an empirical investigation with an explanatory multi-case historical study approach and design. The design is based upon guidance suggested by Yin (2009), Eisenhardt (1989) and Eisenhardt \& Graebner (2007). Yin (2009) suggests a case study approach is appropriate when seeking an answer to "how" types of research questions. The research perspective is qualitative examining historical archive patent documents to explore, describe and explain the phenomenon.

Historical archive patent data and the non-linear relationships in the data are complex (Lee et al., 2013). Eisenhardt \& Graebner (2007) suggest a case study approach is very powerful for developing a rich understanding of complex phenomena. The objective is to develop theory (Eisenhardt \& Graebner, 2007) and select cases likely to replicate. Eisenhardt (1989) suggests that randomization is not necessary in selecting cases and multiple cases add confidence to findings (Yin, 2009) with the intent of replication. 
Eisenhardt (1989) suggests the best range for the number of cases to be between four and ten. This research begins with an initial six cases to be in the best range suggested by Eisenhardt (1989). Further cases were not added as the six cases reached theoretical saturation (Eisenhardt, 1989). The six cases are based upon three international technology patent applications filed under the Patent Cooperation Treaty (PCT) that subsequently entered into the national phase at both the United States Patent \& Trademark Office and the European Patent Office.

Multiple case studies are also appropriate when attempting to externally validate the findings through cross case comparisons. This research approach includes both a within case analysis and a cross case analysis using replication logic as suggested by Yin (2009). Multiple case studies also tend to provide generalizable and testable interpretations of a phenomenon (Eisenhardt \& Graebner, 2007).

\subsection{Research Quality Considerations}

Yin (2009) identified four considerations that relate to the quality of an empirical case study design. Yin (2009) provides a set of tactics to address case study quality in the research design phase. The tactics for this research design are adapted from Yin (2009) and are shown in Table 6. 


\begin{tabular}{l|ll|}
\hline \multicolumn{1}{|c|}{ Quality Aspect } & & \multicolumn{1}{c|}{ Case Study Tactic } \\
\hline $\begin{array}{l}\text { External Validity } \\
\text { (Domain of generalization) }\end{array}$ & $\bullet$ & Use replication logic in a multi-case study. \\
\hline $\begin{array}{l}\text { Construct Validity } \\
\text { (Correct operational measures) }\end{array}$ & $\bullet$ & Use multiple sources of evidence. \\
\hline $\begin{array}{l}\text { Reliability } \\
\text { (Repeatable data collection with same results) }\end{array}$ & $\bullet$ & Establish a chain of evidence. \\
\hline $\begin{array}{l}\text { Internal Validity } \\
\text { (Causal relationships vs. spurious relationships) }\end{array}$ & $\bullet$ & Develop case study database. \\
& $\bullet \quad \begin{array}{l}\text { Explanation building. } \\
\text { Address rival explanations. }\end{array}$ \\
\hline
\end{tabular}

Table 6: Research Design Quality Adapted From Yin (2009).

This research is a multi-case study design and replication logic is selected in the design to address the question of external validity. The European Patent Office and the United States Patent \& Trademark Office are selected as multiple sources of evidence to address the question of construct validity. The design provides for a chain of evidence in the form of detailed procedures and criteria for the data collection phase from the respective patent offices to the research database where the data is maintained.

The Yin (2009) case study protocol is adhered to by this research to address the question of reliability. The research protocol also includes procedures and criteria as detailed in this chapter to ensure this research is repeatable. A later researcher should be able to arrive at the same findings and conclusions. Finally, pattern matching and explanation building is selected in this design for all six cases to address the question of internal validity.

\subsection{The Research Framework}

The research framework is illustrated in Figure 2 of Chapter 2. This section describes the prior art citations construct, the technology patent interdependencies construct and the technology patent evaluation methodologies construct and associated attributes. 


\subsubsection{Prior Art Citations Construct}

Prior art citations include any publically available document. The document must predate the technology patent reference date (either the patent application date or the priority date of the patent application). Publically available documents include technology patents, literature, research articles, brochures and advertisements. This research focuses solely on technology patent citations and expressly excludes all other forms of prior art citations.

A first category of technology patent citation data is cited citations as shown in Figure 3. These are documents that predate the key technology patent reference date and are used to prevent or limit the claims of a patent. They present a view of the historical technology backwards in time and are identified from the technology patent citation list associated with each key technology patent (Criscudo \& Verspagen, 2008).

A second category of patent citation data is citing citations as shown in Figure 3. This occurs when the key technology patent is applied against postdated technology patents to prevent or limit the claims of these post-dated patents. Citing citations present a future view based upon the historical technology forward in time and are identified from secondary resources.

The technology patent citation attribute is used for both the cited citations category and the citing citations category of technology patent citations. This provides an allencompassing view of available technology patent citations surrounding each key 
technology patent for the interdependences of interest between the technology patent citations and the technology patent. This attribute is coded with a unique citation reference number for each technology patent citation to accurately identify the citation.

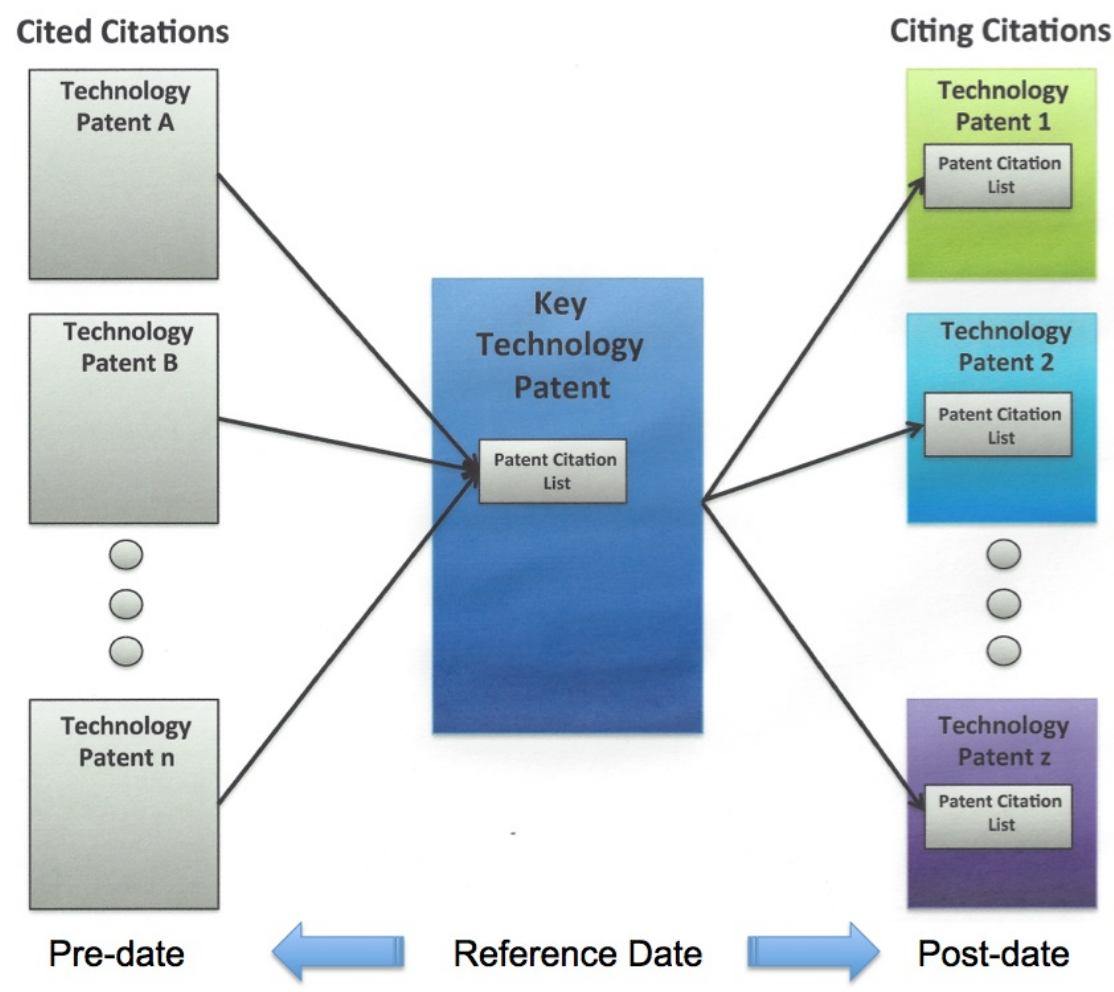

Figure 3: Categories Of Patent Citation Data.

\subsubsection{Technology Patent Interdependencies Construct}

There are two categories of patents. The first category of patent is a technology patent also referred to as a utility patent. The second category of patent is a design patent, also referred to as an industrial design outside the jurisdiction of the United States. The technology patent interdependencies construct is defined for technology patents and expressly excludes design patents. 
There are two types of claims that define the invention of a technology patent. The first type of claim is an independent claim. There may be one or more independent claims in the technology patent such as apparatus claims and method claims. The independent claims are the broadest definition of the invention. The second type of claim is a dependent claim. There may be one or more dependent claims in the patent. Dependent claims are narrow and provide additional details to the independent claims.

This research focuses on independent claims in the technology patent and expressly excludes dependent claims. This research design decision is based upon seeking the interdependencies with the broadest definition and aspects of the invention as defined by the independent claims. This decision also permits managing a large amount of data and the workload required to complete this research.

\subsubsection{Legal Rejection Type}

The Legal Rejection Type attribute provides an indication about the type of interdependency between the technology patent citation and the technology patent. There are two possible relationships for the type of legal rejection and associated interdependency. One type of legal rejection is based upon a one-to-one relationship between the technology patent and technology patent citation. For this type of legal rejection, the Legal Rejection Type attribute is coded "Sole". A second type of legal rejection is based upon a many-to-one relationship between the technology patent citation and the technology patent. For this type of legal rejection, the Legal Rejection Type attribute is coded "Pooled". 


\subsubsection{Claim Amendment}

The Claim Amendment attribute provides an overall indication of a citation forming interdependency or lack of interdependency between the technology patent citation and the technology patent. The attribute may be either coded as a "Yes" to indicate interdependency or "No" to indicate a lack of interdependency between the technology patent citation and the technology patent. When the attribute is coded "Yes", the attribute will also record each independent claim number from the technology patent.

\subsubsection{Degree Of Claim Amendment}

The Degree Of Claim Amendment attribute provides an indication about the amount of interdependency between the technology patent citation and the technology patent. This reflects a relative amount of interdependency with each independent patent claim. This attribute also relates indirectly to the Legal Rejection Type attribute to measure the amount of "Sole" interdependency (one-to-one relationship) or an amount of "Pooled" interdependency (many-to-one relationship). The attribute is coded as a percentage of similarity between 0 and 100 percent for each technology patent citation to measure the amount of change in interdependency.

\subsubsection{Sequential Claim Amendment}

The Sequential Claim Amendment attribute provides an indication into the number of times a technology patent citation was applied against the technology patent application forcing subsequent (more than one amendment) amendments to the independent patent 
claims during prosecution of the patent application. The attribute is coded to a numeric count.

\subsubsection{Technology Patent Evaluation Methodologies Construct}

The technology patent evaluation methodologies construct includes the technology patent citation attribute. The technology citation attribute is a technology patent citation. The citation is devoid of citation noise. It is a citation with pertinence and includes a dominant citation.

\subsection{Unit Of Analysis}

The unit of analysis is a technology patent citation. This includes both cited technology patent citations and the citing technology patent citations. A technology patent citation is selected as the unit of analysis for this research because it relates to a broader body of knowledge in citation based patent evaluation methodologies. This permits generalizing the results of this research to the broader topic (Yin, 2009) of citation based patent evaluation methodologies.

\subsection{Study Period}

The study period for this research relates to the priority date of patent applications filed between the years of 2001 and 2004. This is the oldest possible period of time to select cases from the small patent portfolio of the selected Firm to yield the largest potential sample of technology patent citation data. The sample was drawn on over two days on December 02, 2013 and December 03, 2013. 


\subsection{Research Methodology Phases}

This research seeks to examine technology patent citations and the interdependencies between technology patent citations and the corresponding technology patent. The research offers an explanation, how the interdependencies formed between a technology patent citation and technology patent during prosecution of the patent application can be applied to identify noise inherent in technology patent citation data. The results improve citation dependent patent evaluation methodologies by identifying and eliminating citation noise. The examination includes each technology patent citation associated with the corresponding technology patent and the interdependencies formed, or not formed, as a result of patent prosecution.

The research method and high level phases are based in part on the case study approached suggested by Yin (2009), Eisenhardt \& Graebner (2007) and Eisenhardt (1989). The five high level phases are shown in Table 7.

The specific criteria and detailed procedures for each of the five phases are further described in the following sub-sections. This begins with and introduction to selecting the cases for this research. Then, the data collection phase is described. Next, the data analysis phase is described. Then a discussion of the case analysis phase followed by a discussion of the across case analysis phase. 


\begin{tabular}{|c|c|c|}
\hline $\begin{array}{c}\text { Research } \\
\text { Phase } \\
\end{array}$ & Title & Activities \\
\hline 1 & $\begin{array}{l}\text { Case } \\
\text { Study } \\
\text { Selection }\end{array}$ & $\begin{array}{l}\text { - } \quad \text { Create the criteria, identify and select a Canadian entrepreneurial Firm. } \\
\text { - } \quad \text { Create and use the criteria required to select each case. } \\
\text { - } \quad \text { Identify the leads to six potential cases. } \\
\text { - } \quad \text { Assess the leads with these criteria and select the six cases. }\end{array}$ \\
\hline 2 & $\begin{array}{c}\text { Data } \\
\text { Collection }\end{array}$ & $\begin{array}{l}\text { - Develop a unique research strategy to deal with the issue of large data. } \\
\text { - } \quad \text { Identify all the cited and citing technology patent citations for all six cases. } \\
\text { - } \quad \text { Select the specialized Internet websites containing the historical archival data for all six cases. } \\
\text { Draw the sample from the specialized Internet websites, tag and store the documents in a thesis } \\
\text { database and ensure document integrity. } \\
\text { Develop the criteria for preprocessing the European case data, examine documents and } \\
\text { preprocess the data to identify and code relevant documents from the sample. } \\
\text { Develop the criteria for initial preprocessing the United States data, examine documents and } \\
\text { preprocess the data to identify and code relevant documents from the sample. } \\
\text { Develop the criteria for final preprocessing the data, examine the relevant documents, identify } \\
\text { and code relevant pages from relevant documents in the sample. } \\
\text { Recheck the downloaded sample, all the relevant documents and all relevant pages to ensure } \\
\text { construct validity and reliability. }\end{array}$ \\
\hline 3 & $\begin{array}{c}\text { Data } \\
\text { Analysis }\end{array}$ & 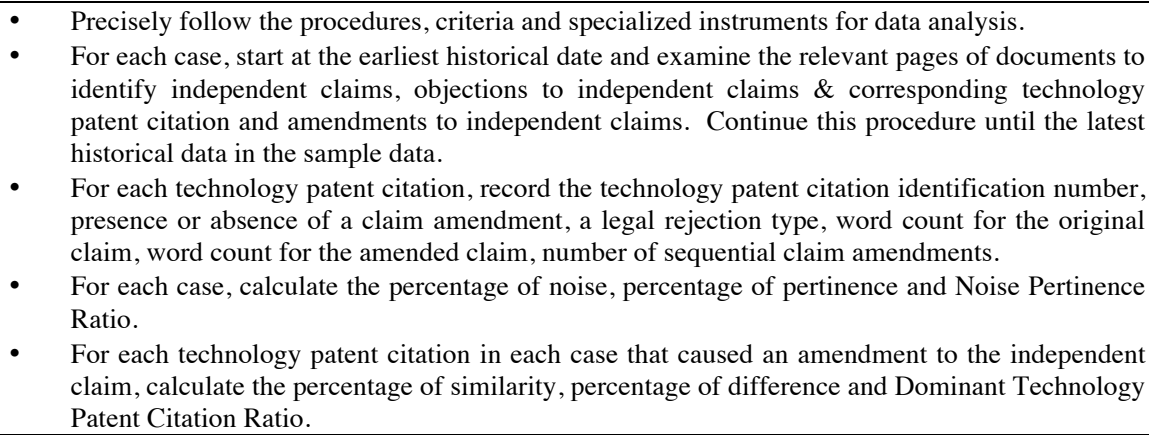 \\
\hline 4 & $\begin{array}{l}\text { Within } \\
\text { Case } \\
\text { Analysis }\end{array}$ & $\begin{array}{l}\text { - Analyze each case with the number of sequential claim amendments, percentage of noise, } \\
\text { percentage of pertinence, Noise Pertinence Ratio, percentage of similarity, percentage of } \\
\text { difference and the Dominant Technology Patent Citation Ratio to identify patterns in each case. }\end{array}$ \\
\hline 5 & $\begin{array}{l}\text { Across } \\
\text { Case } \\
\text { Analysis }\end{array}$ & $\begin{array}{l}\text { - Analyze each case with the number of sequential claim amendments, percentage of noise, } \\
\text { percentage of pertinence, Noise Pertinence Ratio, percentage of similarity, percentage of } \\
\text { difference and the Dominant Technology Patent Citation Ratio to identify patterns in across all } \\
\text { six cases. }\end{array}$ \\
\hline
\end{tabular}

Table 7: The Research Phases.

\title{
3.6.1 Phase 1: Case Study Selection
}

The first phase of this research is identifying and selecting the cases. Phase 1 includes

\author{
three sub-phases. These sub-phases include selecting the firm, identifying the leads to six
}

potential cases and selecting the six specific cases. 


\subsubsection{Selecting The Firm}

The initial criterion for identifying the Firm is to find a mature Canadian company founded by at least one technology entrepreneur. The company must have a successful track record of innovation reflected in a small global patent portfolio. A brief Internet based search reveals a Firm meeting the initial criteria for this thesis. The selected Firm is a Canadian company called SMART Technologies and is located in Calgary Alberta Canada.

The company was co-founded by two technology entrepreneurs, Mr. David Martin and Ms. Nancy Knowlton as a start-up in 1987 (SMART, 2013). In 1991 the Firm created the interactive whiteboard and has continued throughout the years with many additional innovative products. The products have grown beyond the interactive whiteboards to include interactive flat panel displays, tables, interactive displays, wireless technology, audio technology, vision technology and many different types of software products and service innovation. In addition to the commercial breadth of the products, this mature startup has a small global patent portfolio that presents an interesting opportunity for this research. The data is publically available and therefore contact with representatives of the Firm is not necessary for this research.

\subsubsection{Identifying The Leads To Six Potential Cases}

The population for the six cases is the Firm's small global patent portfolio. The first criterion for each of the six cases is to have an old as possible filing or priority date for an international PCT patent application. This provides a better opportunity to obtain citing 
technology patent citation data. The second criterion for each of the six cases is to have a corresponding patent either refused or granted by both the European Patent Office procedure and the United States Patent \& Trademark Office procedure. This provides a very interesting opportunity to examine technology patent citations and the interdependencies from two separate and different jurisdictions and procedures for the same three inventions based upon the same international PCT patent application.

The procedure to identify the leads to the six potential cases is an Internet based search at the World Intellectual Property Organization (WIPO) (www.wipo.org) website. This permits access to the PATENTSCOPE database containing documents for international PCT patent applications (patentscope.wipo.int/search/en/structuredSearch.jsf). The PATENTSCOPE database provides access to international PCT applications using keyword searches.

A keyword search is conducted to identify historical international patent applications to the assignee Firm "Smart Technologies Inc", the legal name of the Firm, using the Applicant Name field in the database search page. In addition, the keyword "WO" is used in the Country field to identify international PCT applications and avoid other national or regional patent applications. The search results in a population of 19 potential international PCT patent applications from which 3 were selected based upon the oldest possible dates that also designated both Europe and the United States. The results are shown in Table 8. 
application at the European Patent Office and an United States patent application at the United States Patent \& Trademark Office.

\begin{tabular}{cllc}
\hline Global Location & \multicolumn{1}{c|}{ Publically Available Internet Documents } & $\begin{array}{c}\text { Research } \\
\text { Cases }\end{array}$ \\
\hline $\begin{array}{c}\text { World Intellectual } \\
\text { Property } \\
\begin{array}{c}\text { Organization (WIPO) } \\
\text { Data }\end{array}\end{array}$ & PCT Application. & $\sqrt{ }$ \\
\cline { 2 - 3 } & PCT International Search Report. & $\sqrt{ }$ \\
\cline { 2 - 3 } $\begin{array}{c}\text { European Patent } \\
\text { Office (EPO) Data }\end{array}$ & EPT Preliminary Examination Report. & $\sqrt{ }$ \\
\cline { 2 - 3 } & EPO Gatent Application. & $\sqrt{ }$ \\
\hline $\begin{array}{c}\text { United States Patent } \\
\text { \& Trademark Office } \\
\text { (USPTO) Data }\end{array}$ & USPTO Patent Application. & $\sqrt{ }$ \\
\cline { 2 - 3 } & USPTO Granted or Refused Patent Application. & $\sqrt{ }$ \\
\hline
\end{tabular}

Table 9: Research Case Selection Criteria.

Each of the three specific European cases must have data that includes the original European patent application, either a granted or refused European patent and an archival historical prosecution history file of data. Each of the three specific United States cases must have data that includes the original United States patent application, either a granted or refused United States patent and an archival historical prosecution history file of data.

The procedure to select the six specific cases is an Internet based search at websites associated with the European Patent Office and the United States Patent \& Trademark Office. Key to this process is the PCT identification serial numbers as shown previously in Table 8.

The European Patent Register website (register.epo.org) provides keyword searching and access to historical patent data. This includes the European patent applications, European 
patents and the archival historical prosecution history files. Each of the three PCT identification numbers is entered into an advanced search page using the Application Number field to identify the corresponding data. Then a high level review is conducted to ensure the corresponding data includes the criteria identified previously in Table 9 for the European cases.

The United States Patent \& Trademark office public pairs website (portal.uspto.gov/pair/PublicPair) provides patent application number searching and access to historical patent data. This includes the United States patent applications, United States patents and the archival historical prosecution history files. Each of the three PCT identification numbers is entered into the search page using the PCT application number field to identify the corresponding data. Then a high level review is conducted to ensure the corresponding data includes the criteria identified previously in Table 9 for the United States cases.

The six specific cases selected for this research based upon the criteria for each case and this selection procedure is summarized in Table 10 by application or patent serial number. The international PCT patent application (WO20040090706) identifies a European case and the corresponding United States case. The international PCT patent application (WO2005106775) identifies another European case and the corresponding United States case. The international PCT patent application (WO2002003316) identifies three European patents (due to a unity of invention issue) as another case and the 
corresponding United States case. This results in identifying six cases (three European and three United States) for this research.

\begin{tabular}{c|ccccc|}
\hline \multirow{2}{*}{$\begin{array}{c}\text { WIPO } \\
\text { Identification }\end{array}$} & $\begin{array}{c}\text { European } \\
\text { Research } \\
\text { Case } \\
\text { Identification }\end{array}$ & $\begin{array}{c}\text { Key } \\
\text { Technology } \\
\text { Patent }\end{array}$ & $\begin{array}{c}\text { United States } \\
\text { Case } \\
\text { Identification }\end{array}$ & $\begin{array}{c}\text { Key } \\
\text { Technology } \\
\text { Patent }\end{array}$ \\
\hline WO2004090706 & Case 1 & EP1611503 & Case 2 & US7256772 \\
\hline WO2005106775 & Case 3 & EP1766501 & Case 4 & US7492357 \\
\hline \multirow{5}{*}{ WO2002003316 } & Case 5 & EP1297488 & & \\
& & EP1739528 & Case 6 & US7692625 \\
& & EP1739529 & & \\
\hline
\end{tabular}

Table 10: Research Case Patent Identification.

\subsubsection{Phase 2: Data Collection}

This sub-section provides a description of the procedures, criteria, documents and specific instruments used for collecting data in this research. The data collection phase comprises three sub-phases and associated criteria and procedures. The first sub-phase requires an identification of both the cited and citing technology patent citations for the six cases. The second sub-phase requires drawing the sample and raw data. The final sub-phase requires preprocessing the raw data to identify relevant documents for this research from the irrelevant documents.

\subsubsection{Identifying Technology Patent Citations}

The cited technology patent citations are identified in the historical data as well as the granted patent for each of the six cases. The citing technology patent citations are not identified directly with the technology patent. Another Internet search using the Google patents website (www.google.com/patents) is required to identify the citing technology 
patent numbers. Each patent number associated with each of the six cases was entered as search criteria in Google patents. The corresponding result provides an identification of the citing technology patent numbers for locating the rest of the sample data. The complete list of cited technology patent citations and citing technology patent citations for all six cases is in Tables 11 through 20 inclusive.

\begin{tabular}{|l|c|c|}
\hline \multicolumn{1}{|c|}{ Cited Technology Patent Citations } & $\begin{array}{c}\text { Technology } \\
\text { Patent }\end{array}$ & \multicolumn{1}{|c|}{$\begin{array}{c}\text { Citing } \\
\text { Technology } \\
\text { Patents }\end{array}$} \\
\hline $\begin{array}{l}\text { US2002036617 US2003025951 } \\
\text { WO0203316 }\end{array}$ & EP1611503 & None \\
\hline
\end{tabular}

Table 11: Case 1 EP1611503 Cited.

\begin{tabular}{|l|c|c|}
\hline \multicolumn{1}{|c|}{ Cited Technology Patent Citations } & $\begin{array}{c}\text { Technology } \\
\text { Patent }\end{array}$ & $\begin{array}{c}\text { Citing } \\
\text { Technology } \\
\text { Patents }\end{array}$ \\
\hline US4144449 US4507557 US4558313 US4742221 US4746770 US4818826 & US7256772 & US8462137 \\
US5097516 US5317140 US5483261 US5502568 US5581276 US5638092 & & US8504944 \\
US5737740 US5825352 US5936615 US5963199 US5982352 US6008798 & US20120032922 \\
US6100538 US6161066 US6208330 US6256033 US6262718 US6310610 & & \\
US6323846 US6335724 US6339748 US6353434 US6359612 US6414671 & & \\
US6421042 US6429856 US6507339 US6531999 US6563491 US6594023 & & \\
US7007619 US6674424 US6710770 US6774889 US6803906 US6933981 & & \\
US20010019325 US20010022579 US20010026268 US20010033274 & \\
US20020036617 US20030001825 US20030025951 US20030085871 & \\
US20040021633 US20040178997 US20040189720 US20050052427 & \\
CA2493236A1 & & \\
DE19810452A1 & & \\
JPH0991094A JPH08240407A JPH09319501A JPS57211637A & & \\
WO1999040562A1 WO2002003316A1 WO2003105074A2 & & \\
\hline
\end{tabular}

Table 12: Case 2 US7256772 Cited. 


\begin{tabular}{|l|l|l|}
\hline $\begin{array}{c}\text { Technology } \\
\text { Patent }\end{array}$ & $\begin{array}{c}\text { Citing } \\
\text { Technology } \\
\text { Patents }\end{array}$ & \multicolumn{1}{|c|}{ Citing Technology Patent Citations } \\
\hline US7256772 & US8462137 & US5764223 US6674424 US7256772 US7492357 \\
& & US20040201575 US20050248539US20090141002 US20100194711 \\
& CN101019096A CN101101509A CN101169831A \\
& TW200925964A TWM358363U \\
\cline { 2 - 3 } & US8504944 & US6100877 US6104387 US6211863 US6323846 US7081886 US7256772 \\
& & US7293246 US7492357 US7646380 US7714849 US7810050 US8164582 \\
& & US20040041842 US20060007170 US20080163131 US20100079412 \\
& & US20100085303 US20110181523 \\
& JP2004054413A JP2009043228A \\
\cline { 2 - 3 } & US20120032922 & US7256772 \\
& US20050017957 US20080097151 US20090279162 US20100283756 \\
\hline
\end{tabular}

Table 13: Case 2 US7256772 Citing.

\begin{tabular}{|l|c|c|}
\hline \multicolumn{1}{|c|}{ Cited Technology Patent Citations } & $\begin{array}{c}\text { Technology } \\
\text { Patent }\end{array}$ & $\begin{array}{c}\text { Citing } \\
\text { Technology } \\
\text { Patents }\end{array}$ \\
\hline US4746770 & EP1766501 & None \\
CA2493236 & & \\
WO0203316 & & \\
\hline
\end{tabular}

Table 14: Case 3 EP1766501 Cited.

\begin{tabular}{|c|c|c|}
\hline Cited Technology Patent Citations & $\begin{array}{c}\text { Technology } \\
\text { Patent }\end{array}$ & $\begin{array}{c}\text { Citing } \\
\text { Technology } \\
\text { Patents }\end{array}$ \\
\hline $\begin{array}{l}\text { US4144449 US4247767 US4507557 US4558313 US4737631 US4742221 US4746770 } \\
\text { US4782328 US4818826 US4822145 US5097516 US5109435 US5130794 US5317140 } \\
\text { US5359155 US5483261 US5483603 US5484966 US5502568 US5554828 US5581276 } \\
\text { US5638092 US5729704 US5736686 US5737740 US5771039 US5818421 US5819201 } \\
\text { US5825352 US5831602 US5911004 US5914709 US5936615 US5963199 US5982352 } \\
\text { US5988645 US6002808 US6008798 US6061177 US6100538 US6118433 US6161066 } \\
\text { US6191773 US6208330 US6252989 US6256033 US6262718 US6310610 US6323846 } \\
\text { US6335724 US6339748 US6353434 US6359612 US6414671 US6421042 US6429856 } \\
\text { US6507339 US6512838 US6518600 US6531999 US6545669 US6559813 US6563491 } \\
\text { US6594023 US6608619 US6626718 US6630922 US6650822 US6674513 US6690363 } \\
\text { US6690397 US6710770 US6774889 US6803906 US6864882 US6933981 US6972401 } \\
\text { US6972753 US7007236 US7015418 US7030861 US7202860 } \\
\text { US20010019325 US20010022579 US20010026268 US20010033274 US20020036617 } \\
\text { US20020050979 US20020163530 US20030001825 US20030025951 US20030043116 } \\
\text { US20030063073 US20030071858 US20030085871 US20030095112 US20030151532 } \\
\text { US20040021633 US20040031779 US20040046749 US20040149892 }\end{array}$ & US7492357 & $\begin{array}{l}\text { US7630002 } \\
\text { US7751671 } \\
\text { US8462137 } \\
\text { US8504944 } \\
\text { US8212857 was } \\
\text { removed from the } \\
\text { sample, contained } \\
\text { a non-technology } \\
\text { patent citation. } \\
\text { US20110246948 } \\
\text { was removed from } \\
\text { the sample, it is } \\
\text { active pending. }\end{array}$ \\
\hline
\end{tabular}

Table 15: Case 4 US7492357 Cited. 


\begin{tabular}{|c|c|c|}
\hline $\begin{array}{c}\text { Technology } \\
\text { Patent }\end{array}$ & $\begin{array}{c}\text { Citing } \\
\text { Technology } \\
\text { Patents }\end{array}$ & Citing Technology Patent Citations \\
\hline \multirow[t]{4}{*}{ US7492357 } & US7630002 & $\begin{array}{l}\text { US4972093 US5515452 US5684530 US6061091 US6088612 US6339748 US6633338 } \\
\text { US6639594 US6788411 US6956963 US6975360 US7006128US7058217 US7342574 } \\
\text { US7398927 US7492357 } \\
\text { US20010012001 US20010055006 US20020113882 US20020186221 } \\
\text { US20050162381 US20050245302 US20060152741US20060202974 } \\
\text { KR20010005203A KR20040072652A KR20050051554A }\end{array}$ \\
\hline & US7751671 & $\begin{array}{l}\text { US5233502 US6031524 US6909425 US7230608 US7432914 US7492357 US7499037 } \\
\text { US7515138 US7515141 } \\
\text { US20010022579 US20030147016 US20040125086 US20050200612 } \\
\text { US20070059520 US20070215451 US20080062149 US20090213094 }\end{array}$ \\
\hline & US8462137 & $\begin{array}{l}\text { US5764223 US6674424 US7256772 US7492357 } \\
\text { US20040201575 US20050248539 US20090141002 US20100194711 } \\
\text { CN101019096A CN101101509A CN101169831A } \\
\text { TW200925964A TWM358363U }\end{array}$ \\
\hline & US8504944 & $\begin{array}{l}\text { US6100877 US6104387 US6211863 US6323846 US7081886 US7256772 US7293246 } \\
\text { US7492357 US7646380 US7714849 US7810050 US8164582 } \\
\text { US20040041842 US20060007170 US20080163131 US20100079412 } \\
\text { US20100085303 US20110181523 } \\
\text { JP2004054413A JP2009043228A }\end{array}$ \\
\hline
\end{tabular}

Table 16: Case 4 US7492357 Citing.

\begin{tabular}{|l|c|c|}
\hline \multicolumn{1}{|c|}{ Cited Technology Patent Citations } & $\begin{array}{c}\text { Technology } \\
\text { Patent }\end{array}$ & $\begin{array}{c}\text { Citing } \\
\text { Technology } \\
\text { Patent } \\
\text { Citations }\end{array}$ \\
\hline WO9940562 & EP1297488 & EP2089791 \\
DE198670452 & & \\
\hline US4746770 US5448263 & EP1739528 & None \\
EP0829798 & & \\
WE19810452 & & \\
\hline US5528263 US5448263 US4746770 & EP1739529 & None \\
WO9940562 WO9921122 WO9940562 & & \\
DE19810452 & & \\
\hline
\end{tabular}

Table 17: Case 5 EP1297488, EP1739528, and EP1739529 Cited.

\begin{tabular}{|c|c|l|}
\hline $\begin{array}{c}\text { Technology } \\
\text { Patent }\end{array}$ & $\begin{array}{c}\text { Citing } \\
\text { Technology } \\
\text { Patents }\end{array}$ & \multicolumn{1}{c|}{ Citing Technology Patent Citations } \\
\hline EP1297488 & EP2089791 & $\begin{array}{l}\text { US7256772 US7057647 US7098392 US7121470 US7532206 US4746770 } \\
\text { US2003046401 } \\
\text { WO9921122 WO2005106775 } \\
\text { EP1297488 }\end{array}$ \\
\hline
\end{tabular}

Table 18: Case 5 EP1297488, EP1739528, EP1739529 Citing. 


\begin{tabular}{|l|c|c|}
\hline \multicolumn{1}{|c|}{ Cited Technology Patent Citations } & $\begin{array}{c}\text { Technology } \\
\text { Patent }\end{array}$ & $\begin{array}{c}\text { Citing } \\
\text { Technology } \\
\text { Patent } \\
\text { Citations }\end{array}$ \\
\hline US4144449 US4247767 US4507557 US4558313 US4737631 US4742221 US4746770 & US7692625 & US7932899 \\
US4782328 US4818826 US4822145 US5097516 US5109435 US5130794 US5317140 & & US8131502 \\
US5359155 US5448263 US5483261 US5483603 US5484966 US5502568 US5528263 & & US8135561 \\
US5554828 US5581276 US5638092 US5729704 US5736686 US5737740 US5745116 & & US8228304 \\
US5771039 US5818421 US5818424 US5819201 US5825352 US5831602 US5911004 & & US8232511 \\
US5914709 US5936615 US5943783 US5963199 US5982352 US5988645 US6002808 & & US8305363 \\
US6008798 US6061177 US6100538 US6118433 US6153836 US6161066 US6191773 & & US8330726 \\
US6208330 US6252989 US6256033 US6262718 US6310610 US6323846 US6335724 & & US8400415 \\
US6339748 US6353434 US6359612 US6414671 US6421042 US6429856 US6507339 & & US8513546 \\
US6512838 US6518600 US6531999 US6545669 US6559813 US6563491 US6594023 & & US8515128 \\
US6608619 US6626718 US6630922 US6650822 US6674424 US6690363 US6690397 & & US8547327 \\
US6710770 US6774889 US6803906 US6864882 US6933981 US6972401 US6972753 & & \\
US7007236 US7015418 US7030861 US7202860 US7274356 & & \\
US20010019325 US20010022579 US20010026268 US20010033274 US20020036617 & & \\
US20020050979 US20020163530 US20030001825 US20030025951 US20030043116 & & \\
US20030063073 US20030071858 US20030085871 US20030095112 & & \\
\hline
\end{tabular}

Table 19: Case 6 US7692625 Cited.

\begin{tabular}{|c|c|c|}
\hline $\begin{array}{c}\text { Technology } \\
\text { Patent }\end{array}$ & $\begin{array}{c}\text { Citing } \\
\text { Technology } \\
\text { Patents }\end{array}$ & Citing Technology Patent Citations \\
\hline \multirow[t]{4}{*}{ US7692625 } & US7932899 & $\begin{array}{l}\text { US4144449 US4468694 US4553842 US4703316 US4893120 US6285359 US6362468 } \\
\text { US6518960 US6608619 US6624833 US6727885 US6760009 US7113174 US7176904 } \\
\text { US7283128 US7432914 US7460110 US7515141 US7522156 US7692625 US7755613 } \\
\text { US20020145596 US20050030287 US20050104860 US20060012579 US20060202974 } \\
\text { US20060232830 US20080143682 US20090135162 US20090213093 US20090219256 } \\
\text { US20090278816 US20090284495 US20090309844 US20090309853 US20100045629 } \\
\text { US20100045634 US20100079412 US20100090987 US20100182279 US20100193259 } \\
\text { DE102007021537A1 } \\
\text { EP1577745A1 } \\
\text { JP2003303046A } \\
\text { WO2008007276A2 WO2009102681A2 WO2009137355A2 WO2010039663A2 } \\
\text { WO2010044575A2 }\end{array}$ \\
\hline & US8131502 & $\begin{array}{l}\text { US4507557 US4782328 US6036189 US6803906 US7109978 US7692625 US7755026 } \\
\text { US7907124 US7924272 } \\
\text { US20050243070 US20090090569 } \\
\text { JP2005025415A JPS59211128A } \\
\text { WO2005034027A1 }\end{array}$ \\
\hline & US8135561 & $\begin{array}{l}\text { US4507557 US4782328 US6036189 US6803906 US7109978 US7692625 US7755026 } \\
\text { US7907124 US7924272 } \\
\text { US20050243070 US20090090569 } \\
\text { JP2005025415A JPS59211128A } \\
\text { WO2005034027A1 }\end{array}$ \\
\hline & US8228304 & 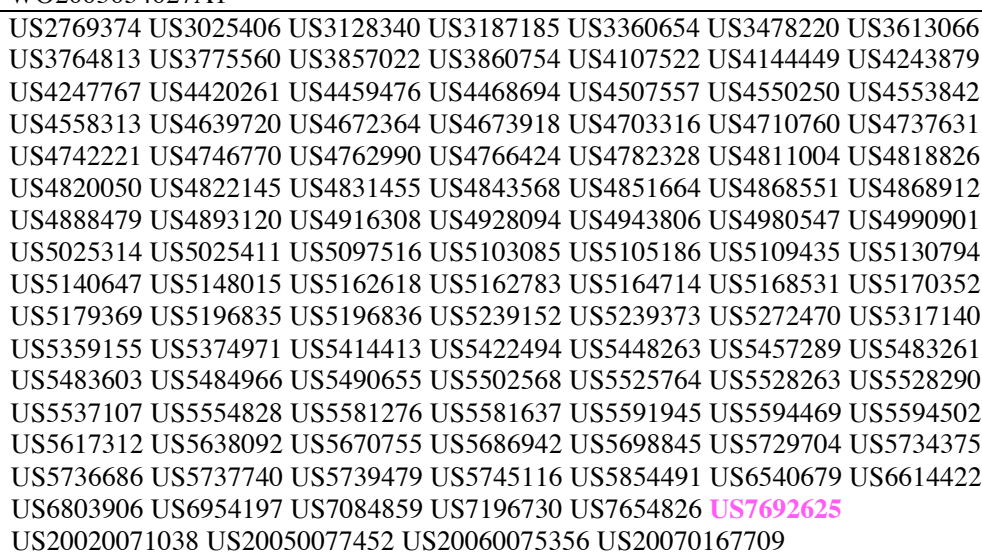 \\
\hline
\end{tabular}




\begin{tabular}{|c|c|}
\hline US8232511 & $\begin{array}{l}\text { US4507557 US4782328 US6036189 US6803906 US7109978 US7692625 US7755026 } \\
\text { US7755613 US7907124 US7924272 } \\
\text { US20050243070 US20090090569 } \\
\text { JP2005025415A JPS59211128A } \\
\text { WO2005034027A1 }\end{array}$ \\
\hline US8305363 & $\begin{array}{l}\text { US4507557 US4782328 US5525764 US6036189 US6335724 US6498602 US6803906 } \\
\text { US6954197 US7109978 US7232986 US7692625 US7755026 US7755613 US7907124 } \\
\text { US7924272 US8167698 } \\
\text { US20050078095 US20050128190 US20050243070 US20050248540 US20070089915 } \\
\text { US20090090569 US20100010773 US20110095977 } \\
\text { JPS59211128A } \\
\text { KR20051025415A } \\
\text { TW201003477A } \\
\text { WO2005034027A1 }\end{array}$ \\
\hline US8330726 & $\begin{array}{l}\text { US3021711 US3722288 US3819857 US4353050 US4529959 US4658373 US4918418 } \\
\text { US4944187 US4951036 US5420379 US5434370 US5543588 US5579037 US5646377 } \\
\text { US5861583 US6338199 US6370965 US6421042 US6471613 US6480187 US6587099 } \\
\text { US6594023 US6608619 US6747631 US6803906 US6914427 US7343813 US7381128 } \\
\text { US7692625 US7703342 US7800362 } \\
\text { US20010019325 US20020075243 US20020105589 US20020145595 } \\
\text { US20030141867 US20040012573 US20040201575 US20050064807 } \\
\text { US20050088424 US20060034486 US20070089915 US20070146958 } \\
\text { US20070214897US20090078059 } \\
\text { DE10252862B3 } \\
\text { EP1698874A1 EP1873507A1 } \\
\text { JP3928976B1 JP2000322201A JP2001265517A JP2002268807A JP2002301264A } \\
\text { JP2003294547A JP2003337071A JP2005096580A JP2005156474A JP2005275760A } \\
\text { JPH0278925A JPH0610269Y2 JPH0646171B2 JPH0755615A JPH01212301A } \\
\text { JPH09113203A JPH10198494A } \\
\text { JPS5146714A JPS5245823A JPS5971141A JPS6231865Y2 JPS57100331A } \\
\text { JPS61135240A JPS62226030A } \\
\text { WO2002003315A1 WO2002003316A1 WO2004104810A1 WO2005052532A1 } \\
\text { WO2006106714A1 WO2007014849A2 WO2008007458A1 WO2008050468A1 }\end{array}$ \\
\hline US8400415 & $\begin{array}{l}\text { US5317140 US6335724 US6411287 US6492633 US6498602 US6803906 US7456824 } \\
\text { US7619617 US7643006 US7692625 US7781722 US7855716 US7907124 } \\
\text { US20010019325 US20010022579 US20050077452 }\end{array}$ \\
\hline US8513546 & $\begin{array}{l}\text { US4331955 US4736330 US4760387 US5691822 US5866895 US6548768 US7692625 } \\
\text { US20020047822 US20030072489 US20080186255 US20080253608 } \\
\text { US20120223140 } \\
\text { TW200525455A TW200532533A TW200706803A TW200734933A TW200741516A }\end{array}$ \\
\hline US8515128 & $\begin{array}{l}\text { US5982352 US6157368 US6393136 US6624833 US6707444 US6961443 US7098956 } \\
\text { US7259747 US7292711 US7526131 US7542072 US7650015 US7692625 US8068641 } \\
\text { US8144123 } \\
\text { US20020036617 US20020097218 US20040032398 US20040070565 US20050122308 } \\
\text { US20060033713 US20070091178 US20080122786 US20090103780 US20090122146 } \\
\text { US20090303176 US20100277412 US20110080490 US20110134237 }\end{array}$ \\
\hline US8547327 & $\begin{array}{l}\text { US5982352 US6157368 US6393136 US6624833 US6707444 US6961443 US7098956 } \\
\text { US7259747 US7292711 US7526131 US7542072 US7650015 US7692625 US8068641 } \\
\text { US8144123 } \\
\text { US20020036617 US20020097218 US20040032398 US20040070565 US20050122308 } \\
\text { US20060033713 US20070091178 US20080122786 US20090103780 US20090122146 } \\
\text { US20090303176 US20100277412 US20110080490 US20110134237 }\end{array}$ \\
\hline
\end{tabular}

Table 20: Case 6 US7492357 Citing.

Following this procedure identified 301 cited technology patent citations, 418 citing technology patent citations for a total number of 719 technology patent citations to examine in this research. 


\subsubsection{Drawing The Raw Sample Data}

The sample is drawn based upon each of the eight technology patent numbers and each of the twenty one citing technology patent numbers as previously identified in Tables 11 through 20 inclusive.

The data for the European technology patent numbers and European citing technology patent numbers is drawn from the European Patent Register website (register.epo.org) by entering the respective patent numbers into the patent search field and downloading a complete set of historical archival PDF documents for each of the six European patent numbers.

The data for the United States technology patent numbers and United States citing technology patent numbers is drawn from the United States Patent \& Trademark office public pairs website (portal.usptogov/pair/PublicPair) by entering the respective united States patent numbers into the patent search field and downloading a complete set of historical archival PDF documents for each of the 23 United States patent numbers.

Upon completion, the sample comprises 27 separate data sets and 2,127 historical archival documents. Eight data sets relate to technology patent cited citations and 19 data sets relate to technology patent citing citations. Each of the 2,127 documents are tagged during the download process with a unique thesis document identification number and stored in a research database. In addition, each of the 2,127 documents is associated with portions of respective governmental database hierarchies. A relevant portion of the 
European patent office database hierarchy is shown in Table 21. A relevant portion of the United States patent office database hierarchy is shown in Table 22.

After drawing the raw sample data, each record was compared with the records at both the European Patent Register website and the United States Patent \& Trademark office public pairs website to ensure accuracy and reliability of data in the sample.

\subsubsection{Preprocessing The Raw Sample Data}

It was anticipated at the beginning of this research that there would be a large amount of historical archival data. This necessitated the design of a very crisp and sophisticated methodology for data document preprocessing. The methodology provided for quick and accurate identification of relevant documents and particular pages from the sample. Preprocessing the raw sample data to identify relevant documents requires a high level visual inspection of each document using two instruments, specific criteria and a research procedure.

The following sub-sections detail how the raw sample data is preprocessed and reduced. This required identification of relevant documents followed by identification of relevant pages within documents. In the following subsections, the instrument and criteria for initial preprocessing the European data is described. Then, the instrument and criteria for initial preprocessing the United States data are described. Finally, the final preprocessing procedure is described. 


\subsection{Preprocessing Criteria For The Initial European Case Data}

The European Patent Office provides a database hierarchy for the historical archival European patent data. That hierarchy is leveraged to some degree as shown in Table 21 to create a first document identification criteria that aids with the preprocessing of the European data. All European data corresponding to the six European patent numbers was downloaded in this format. An associated set of spreadsheets is created to identify and track the data in the sample.

\begin{tabular}{|c|c|c|c|c|c|}
\hline \multirow{2}{*}{$\begin{array}{c}\text { Thesis } \\
\text { Document } \\
\text { ID\# }\end{array}$} & \multicolumn{4}{|c|}{ European Patent Office Data Categories } & \multirow{2}{*}{$\begin{array}{c}\text { Relevant } \\
\text { Document? }\end{array}$} \\
\hline & Date & Document Type & Procedure & $\begin{array}{l}\text { Number } \\
\text { of Pages }\end{array}$ & \\
\hline \multirow{10}{*}{$\begin{array}{c}\text { PDF } \\
\text { document } \\
\text { number as } \\
\text { downloaded } \\
\text { from the } \\
\text { EPO website. }\end{array}$} & \multirow{10}{*}{$\begin{array}{l}\text { Date of } \\
\text { the } \\
\text { document } \\
\text { in the } \\
\text { longitudi } \\
\text { nal } \\
\text { history }\end{array}$} & Claims & $\begin{array}{c}\text { Search / } \\
\text { Examination }\end{array}$ & Value & Potentially \\
\hline & & Amended claims with annotations & $\begin{array}{c}\text { Search / } \\
\text { Examination }\end{array}$ & Value & Potentially \\
\hline & & $\begin{array}{l}\text { Reply to communication from the } \\
\text { Examining Division }\end{array}$ & $\begin{array}{c}\text { Search / } \\
\text { Examination }\end{array}$ & Value & Potentially \\
\hline & & Annex to the communication & $\begin{array}{c}\text { Search / } \\
\text { Examination }\end{array}$ & Value & Potentially \\
\hline & & $\begin{array}{l}\text { Amended claims filed after receipt of } \\
\text { (European) search report }\end{array}$ & $\begin{array}{c}\text { Search / } \\
\text { Examination }\end{array}$ & Value & Potentially \\
\hline & & Grounds for the decision (Annex) & $\begin{array}{c}\text { Search / } \\
\text { Examination }\end{array}$ & Value & Potentially \\
\hline & & $\begin{array}{l}\text { Copy of the international preliminary } \\
\text { examination report }\end{array}$ & $\begin{array}{c}\text { Search / } \\
\text { Examination }\end{array}$ & Value & Potentially \\
\hline & & $\begin{array}{l}\text { Annexes to the international preliminary } \\
\text { examination report }\end{array}$ & $\begin{array}{c}\text { Search / } \\
\text { Examination }\end{array}$ & Value & Potentially \\
\hline & & European search opinion & $\begin{array}{c}\text { Search / } \\
\text { Examination }\end{array}$ & Value & Potentially \\
\hline & & Other document types & $\begin{array}{c}\text { Other } \\
\text { procedures }\end{array}$ & Value & NO \\
\hline
\end{tabular}

Table 21: Identification Of The Relevant Documents For The European Cases.

The historical date of the document in the longitudinal history, the document type and prosecution procedure assist in identifying potentially relevant documents from irrelevant documents. The documents are examined qualitatively to identify documents with the independent patent claims ready for examination and any/all documents with amendments to the independent claims until the final decision to either grant the patent or refuse the patent. The documents are also reviewed to identify documents having 
objections to the independent claims under the European Patent Convention (EPC). This is EPC Article 54 for novelty and EPC Article 56 for inventive step (European Patent Office, 2007), the identified technology patent citation or citations and the relationship of the technology patent citation or citations to the independent claims.

Completing this initial preprocessing procedure results in the identification of relevant documents in the European data. This initial preprocessing procedure was executed twice to ensure reliability of the European data and identified relevant documents.

\subsection{Preprocessing Criteria For the Initial United States Case Data}

The United States Patent \& Trademark Office also provides a database hierarchy for the historical archival United States patent data. That hierarchy is also leveraged to some degree as shown in Table 22 to create an second document identification criteria that aids with the preprocessing of the United States case data to identify relevant documents. All United States data corresponding to the 21 United States patent numbers were downloaded in this format with an associated spreadsheet to identify and track the data.

The historical date of the document in the longitudinal history, the document code, document type and prosecution procedure assist in identifying potentially relevant documents from irrelevant documents. The documents are examined qualitatively to identify documents with the independent patent claims ready for examination, and any/all documents with amendments to the independent claims until the final decision to either grant the patent or refuse the patent. The documents are also reviewed to identify 
documents having objections to the independent claims under 35 United States Code (USC). This is 35 USC 102 for novelty and 35 USC 103 for obviousness (Donner, 2007), the identified technology patent citation or citations and the relationship of the technology patent citation or citations to the independent claims.

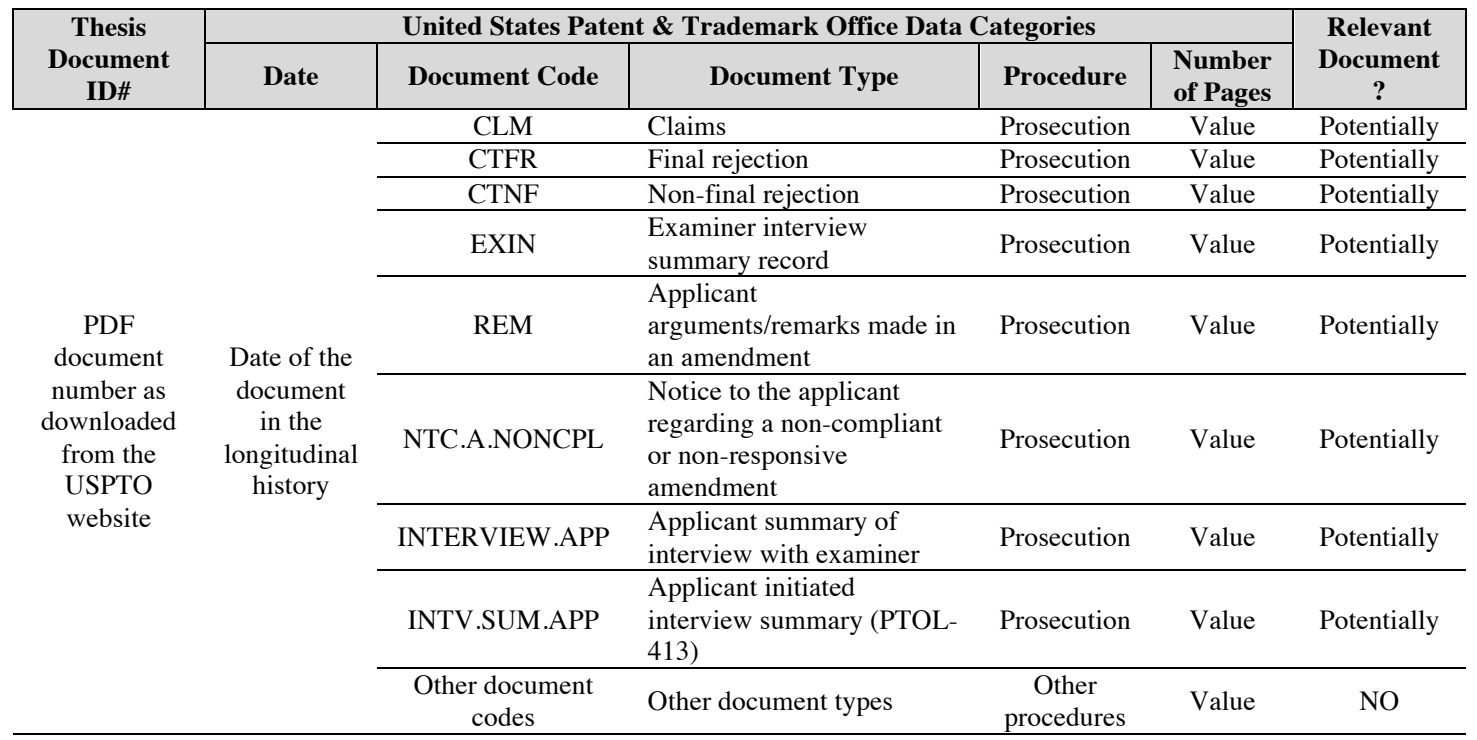

Table 22: Identification Of The Relevant Documents For The United States Cases.

This second initial processing procedure results in the identification of relevant United States documents. This procedure was executed twice to ensure reliability of the United States data.

\subsection{Final Raw Data Preprocessing Procedure}

A final preprocessing procedure is required for all 27 data sets that comprise the sample. The final processing procedure identifies specific pages from within the relevant documents. The first step in the procedure is to locate a relevant document with the 
earliest date in the longitudinal history that includes a set of independent patent claims ready for examination. For both the United States data and the European data this would be a document type of "Claims".

Documents are examined to identify select pages having independent patent claims ready for examination. This includes patent claims as filed (un-amended) or claims amended to comply with formal requirements and pre-examination amendments. The independent claims and text are identified from the document and noted for subsequent data analysis. The document identification number and select pages numbers are noted as a relevant document in each associated spreadsheet.

The second step in the procedure is to locate a relevant document with a later date in the longitudinal history with an objection to the pending independent claims (an objection may not exist if there is a first office action allowance of the claims). For the United States data the document type is either a non-final rejection or a final rejection or a notice to a non-compliant or non-responsive amendment. For the European data the document type is the "grounds for the decision (Annex)" document. An objection is identified from the document by a technology patent citation or citations and at least one type of legal rejection. The document identification number and select page numbers are noted as a relevant document with page numbers in each associated spreadsheet.

The third step in the procedure is to locate a relevant document with a later date in the longitudinal history with a response to the objection with amended independent claims. 
For the United States data the document type may be an interview summary, applicant arguments/remarks made in and amendment. For the European data the document type is a "reply to communication from the Examining Division" and an "Annex to the communication". A listing of claims or an annotation of the claims identifies amendment to the claims in the document. The document identification number and select pages are noted as a relevant in each associated spreadsheet.

The second and third steps in the procedure are repeated throughout the rest of the longitudinal history. Relevant document identification numbers and select page numbers within each document are recorded in the associated spreadsheet as appropriate. The end result is a list of relevant documents and pages for each of the 27 European and United States data sets.

This research procedure was executed twice to ensure errors were not introduced into the preprocessed data sets.

\subsubsection{Phase 3: General Data Analysis}

Completing the final raw preprocessing procedure revealed relevant documents and select relevant pages ready for a detailed examination. Coding of the attributes from the research framework and the initial data analysis follows the document examination. The raw sample included 2,127 documents and 22,495 separate pages. After completion of all the preprocessing procedures, the relevant number of documents is 136 with 294 relevant pages. 
The description of the data analysis phase begins with the overall detailed document examination and analysis of the data. Then, the procedure and data analysis to determine the noise and pertinence of this research is described. Finally, the procedure and data analysis to determine the citation interdependency is described.

\subsubsection{Detailed Document Examination And Data Analysis}

The procedure for the detailed document examination is qualitative. Data analysis is repeated for each dataset and all cases in this research. The starting point in the procedure is to select the relevant documents and relevant pages with the earliest date in the historical timeline with the independent claims of the patent application that are ready for prosecution.

Data analysis begins with a detailed examination of the identified relevant documents and relevant pages with the earliest date in the timeline with the independent claims of the patent application that are read for prosecution. A first instrument shown in Table 23 is developed for this research and applied to assist with document examination, identification of qualitative text evidence and attribute coding based upon the evidence from the documents. 


\begin{tabular}{|c|c|c|c|c|c|c|}
\hline Sequence & $\begin{array}{c}\text { Evidence From Relevant Historical } \\
\text { Document }\end{array}$ & $\begin{array}{c}\text { Legal } \\
\text { Rejection } \\
\text { Type }\end{array}$ & $\begin{array}{l}\text { Total } \\
\text { citations }\end{array}$ & $\begin{array}{l}\text { Relevant } \\
\text { Citations }\end{array}$ & $\begin{array}{c}\text { Claim } \\
\text { Amendment }\end{array}$ & $\begin{array}{l}\text { Examiner } \\
\text { Outcome }\end{array}$ \\
\hline 1 & $\begin{array}{l}\text { Independent Claim "1. An apparatus for } \\
\text { detecting a pointer relative to a touch } \\
\text { surface comprising:" } \\
\text { Independent Claim " } 55 \text {. A camera-based } \\
\text { touch system comprising:" } \\
\text { Independent Claim " } 63 \text {. An apparatus } \\
\text { for detecting a pointer relative to a } \\
\text { generally rectangular touch surface } \\
\text { comprising:" } \\
\text { "Claims } 1-7,9-10,53-59,63-65 \text { are } \\
\text { rejected under } 35 \text { U.S.C. } 102 \text { (b) as being } \\
\text { anticipated by Dunthorn }(5,317,140) . " \\
\text { "Claim } 8 \text { is rejected under } 35 \text { U.S.C. } \\
\text { 102(a) as being unpatentable over } \\
\text { Dunthorn." }\end{array}$ & Sole & 101 & 1 & Yes & Rejection \\
\hline 2 & $\begin{array}{l}\text { "Claims } 1-7,9-10,53-59,63-65 \text { are } \\
\text { rejected under } 35 \text { U.S.C. } 102 \text { (b) as being } \\
\text { anticipated by Dunthorn }(5,316,140) . " \\
\text { "Claim } 8 \text { is rejected under } 35 \text { U.S.C. } \\
\text { 102(a) as being unpatentable over } \\
\text { Dunthorn." }\end{array}$ & Sole & 101 & 1 & Yes & Rejection \\
\hline 3 & $\begin{array}{l}\text { "The allowed claim(s) is/are } 1-39,52- \\
56,59-79, \text { renumbered as } 1-75 " \text {. }\end{array}$ & Sole & 101 & 1 & No & $\begin{array}{l}\text { Notice of } \\
\text { Allowance }\end{array}$ \\
\hline
\end{tabular}

Table 23: Evidence Case Instrument - Case 4 US7492357 Cited Citations Example.

Case 4 US7492357 Cited Citation data is shown in Table 23 as an example. The documents are examined to identify the independent claims in the patent application. Then, the documents are examined for evidence of a legal rejection, evidence of relevant citations used in the legal rejection, evidence of a claim amendment and evidence of the examiner outcome of the claim amendment.

The sequence attribute is coded with a numeric number for each occurrence in the longitudinal history of the data to the point where the evidence reveals a final decision such as a "Notice Of Allowance". The evidence from the relevant historical document is captured in the spreadsheet. For a European Case, evidence of EPC Article 54 relates to "Sole" and EPC Article 56 relates to "Pooled". For a United States Case, evidence of 35 
USC 102 relates to "Sole" and 35 USC 103 relates to "Pooled". The legal rejection type attribute is coded as either a "Sole" or "Pooled" value indicating the type of rejection.

The total number of citations is recorded for each case with the total number of relevant citations based upon the evidence from the historical documents. The claim amendment attribute is coded to a "Yes" if there is evidence of a claim amendment in the relevant historical document. This procedure of document examination continues throughout the longitudinal history of the documents until the evidence reveals the final outcome.

The results of this phase of analysis and data coding are provided in Appendix B in Tables $44-70$ inclusive. A summary for the six cases is shown in Table 24 . 


\begin{tabular}{|c|c|c|c|c|c|c|}
\hline \multirow{2}{*}{ Case } & \multirow{2}{*}{$\begin{array}{c}\text { Claim } \\
\text { Amendment }\end{array}$} & \multirow{2}{*}{ Sequence } & \multirow{2}{*}{$\begin{array}{c}\text { Legal } \\
\text { Rejection } \\
\text { Type }\end{array}$} & \multicolumn{2}{|c|}{ Citations } & \multirow{2}{*}{ Outcome } \\
\hline & & & & Noise & Pertinence & \\
\hline Case 1 EP1611503 Cited & Yes & 3 & Sole & Yes & Yes & Amend \\
\hline Case 2 US7256772 Cited & Yes & 3 & Sole & Yes & Yes & Grant \\
\hline Case 2 US7256772 Citing US8462137 & No & 1 & N.A. & Yes & No & Grant \\
\hline Case 2 US7256772 Citing US8504944 & No & 1 & N.A. & Yes & No & Grant \\
\hline Case 2 US7256772 Citing U20120032922 & Yes & 2 & Pooled & No & Yes & Refuse \\
\hline Case 3 EP1766501 Cited & Yes & 2 & Sole & No & Yes & Refuse \\
\hline Case 4 US7492357 Cited & Yes & 3 & Sole & Yes & No & Grant \\
\hline Case 4 US7492357 Citing US7630002 & Yes & 2 & $\begin{array}{l}\text { Sole \& } \\
\text { Pooled }\end{array}$ & Yes & Yes & Amend \\
\hline Case 4 US7492357 Citing US7751671 & No & 1 & N.A. & Yes & No & Grant \\
\hline Case 4 US7492357 Citing US8462137 & No & 1 & N.A. & Yes & No & Grant \\
\hline Case 4 US7492357 Citing US8504944 & No & 1 & N.A. & Yes & No & Grant \\
\hline Case 5 EP1297488 Cited & Yes & 4 & Sole & Yes & Yes & Amend \\
\hline Case 5 EP1739528 Cited & Yes & 2 & Sole & Yes & Yes & Amend \\
\hline Case 5 EP1739529 Cited & No & 1 & N.A. & Yes & No & Grant \\
\hline Case 5 EP1297488 Citing EP2089791 & Yes & 1 & $\begin{array}{l}\text { Sole \& } \\
\text { Pooled }\end{array}$ & Yes & Yes & Amend \\
\hline Case 6 US7692625 Cited & Yes & 7 & Sole & Yes & Yes & Amend \\
\hline Case 6 US7692625 Citing US7932899 & Yes & 2 & Pooled & Yes & Yes & Amend \\
\hline Case 6 US7692625 Citing US8131502 & No & 1 & N.A. & Yes & No & Grant \\
\hline Case 6 US7692625 Citing US8135561 & No & 1 & N.A. & Yes & No & Grant \\
\hline Case 6 US7692625 Citing US8228304 & Yes & 2 & Pooled & Yes & Yes & Amend \\
\hline Case 6 US7692625 Citing US8232511 & Yes & 2 & Sole & Yes & Yes & Amend \\
\hline Case 6 US7692625 Citing US8305363 & No & 1 & N.A. & Yes & No & Grant \\
\hline Case 6 US7692625 Citing US8330726 & Yes & 1 & Pooled & Yes & Yes & Amend \\
\hline Case 6 US7692625 Citing US8400415 & Yes & 4 & Pooled & Yes & Yes & Amend \\
\hline Case 6 US7692625 Citing US8513546 & Yes & 3 & Pooled & Yes & Yes & Amend \\
\hline Case 6 US7692625 Citing US8515128 & Yes & 2 & Sole & Yes & Yes & Amend \\
\hline Case 6 US7692625 Citing US8547327 & Yes & 3 & Sole & Yes & Yes & Amend \\
\hline
\end{tabular}

Table 24: Summary Of The Document Examination And Data Analysis.

The structure, format and amendments to a patent claim are highly complex. This is especially true when there are multiple amendments and multiple citations over multiple sequences in prosecution. Examining documents, counting the words and applying a descriptive statistic provide a way to view this complex qualitative data and make logical comparisons (Bernard \& Ryan, 2010). The words for the independent claims and all words to claim amendments are examined to provide specific counts of words. 
The word count of the original independent claim is compared with the amended count of words deleted by claim amendments. This comparison provides a percentage of similarity between each original independent claim and the corresponding amended independent claim. This also provides a percentage of difference between the claims. The percentage of similarity reveals the portion of the technology patent citation interdependency with the technology patent based upon and Examiners objection and amendments that delete words from the independent claims to overcome the objection. This reveals the degree of interdependency between the technology patent citation and the independent claims of the technology patent.

The degree of claim amendment attribute provides an indication into the relative amount of amendment to the independent claim. This reflects a move away from the old knowledge codified in the technology patent citation to distinguish the independent claim from this old codified knowledge.

The similarity between the citation and the independent claim language represents a relative amount of the codified old knowledge from the technology patent citation that remains in the claim. The similarity is determined by the following equation.

$$
\text { Similarity }=\left(\frac{\text { Original Word Count }- \text { Deleted Word Count }}{\text { Original Word Count }}\right) * 100
$$

\section{Equation 1: Relative Similarity Between Citation And Patent Claim.}


Then, the degree of claim amendment attribute may be determined by equation 2 .

Degree of Claim Amendment $=100-$ Similarity

\section{Equation 2: Degree of Claim Amendment.}

The allowed claim may contain a relative amount of the technology patent citation and a relative amount of new knowledge not found in the technology patent citation. The relative amount of the technology patent citation is determined by equation 3 and the relative amount of new knowledge is determined by equation 4 .

Relative Citation Amount $=\left(\frac{\text { Original Word Count }- \text { Deleted Word Count }}{\text { Final Amended Word Count }}\right) * 100$

Equation 3: Relative Amount of Citation In Allowed Claim.

Relative New Matter Amount $=\left(\frac{\text { Added Words }}{\text { Final Word Count }}\right) * 100$

Equation 4: Relative Amount of New Matter In Allowed Claim.

The next data analysis procedure is to locate the identified relevant documents and relevant pages with the earliest date in the timeline with the independent claims of the patent application that are ready for prosecution. Each independent claim is examined. Actual words and a count are recorded in a table. Another instrument developed for this 
research is the sole interdependency claim amendment-tracking instrument as shown in

Figure 4 to document the evidence, words, counts and associated descriptive statistics.

\section{Case 1: EP1611503 Cited}

\section{Final US2002036617 Interdependencies With Method Claim 1}

In a touch system having a touch screen with a touch surface on which an image is displayed, a method of automatically mapping a touch screen co-ordinate system to the display co-ordinate system comprising the steps of:

including in said displayed image at least one reference mark, the location of the at least one reference mark in said display coordinate system being known;

\section{acquiring an at lease one image of said touch surface including said displayed image;}

\section{recognizing the at least one reference mark in the acquired images by comparing the at least one acquired images with reference marks stored in a reference mark library;}

determining the location of said at least one reference mark in said at lease one acquired image relative to said touch screen co-ordinate system; and

automatically mapping said touch screen coordinate system to said display coordinate system using said determined location and the location of the at least one reference mark in said display coordinate system.

\begin{tabular}{|c|c|c|c|c|c|c|c|c|}
\hline \multirow{2}{*}{ Citation } & \multicolumn{9}{|c|}{ Amended Claim } & \multicolumn{3}{c|}{ Granted Claim } \\
\cline { 2 - 9 } & $\begin{array}{c}\text { Original } \\
\text { Words }\end{array}$ & $\begin{array}{c}\text { Deleted } \\
\text { Words }\end{array}$ & $\begin{array}{c}\text { Added } \\
\text { Words }\end{array}$ & $\begin{array}{c}\text { Final } \\
\text { Words }\end{array}$ & $\begin{array}{c}\text { Claim } \\
\text { Amendment } \\
\text { Degree }\end{array}$ & Similarity & $\begin{array}{c}\text { Pereentage } \\
\text { Citation }\end{array}$ & $\begin{array}{c}\text { Pereentage } \\
\text { New }\end{array}$ \\
\hline US20050565177 & 127 & 1 & 3 & 160 & $0.79 \%$ & $99.21 \%$ & $78.75 \%$ & $21.25 \%$ \\
\hline
\end{tabular}

Figure 4: Sole Interdependency Instrument.

The sole interdependency instrument presents the evidence from examining the relevant documents and pages. The instrument also records the evidence for the data analysis of the original independent claim and all amendments to the independent claim. The procedure is to use a color, for example yellow to associate original claim language with 
the technology patent citation. A second color, for example blue, is used to identify amended language to the independent claim. The same indications are used as the original relevant documents to indicate deleted text (strike out) and added text (underlined). The instrument keeps a record of the amendments made in the case over multiple documents where a simple count of the words indicates the original number of words, the amended number of words and the degree of similarity between the technology patent citation and the technology patent in the form of a percentage.

The qualitative claim text and all amendments through the longitudinal history are overlaid in the sole interdependency instrument to record the evidence. This procedure of document examination and word counting continues until the evidence reveals the final Examiner outcome that terminates the examination procedure. Then the degree of claim amendment attribute is coded with a percentage. Executing the procedure also records the similarity in the form of a percentage and for the allowed claim, a percentage of interdependency with the citation and a percentage of new claim language in the table.

Another instrument developed for this research is the pooled interdependency claim amendment-tracking instrument as shown in Figure 5. 


\section{Case 4 US7492357 Citing US763002}

\section{Final US20050162381 and US6975360 Interdependencies With Apparatus Claim 14}

An image merging mechanism for use with an interactive display system that includes one or more display layers, a first camera positioned so as to view an illumined surface of the one or more display layers at a first position such that when the an illuminator that is positioned at a particular location is illuminated a specular reflection occurs at an a specular reflection area of an image as captured by the first camera, a second camera positioned so as to view an illuminated surface of the one or more display layers at a second position such that when the illuminator is illuminated from the particular location the second camera is able to view and capture at least a portion of the specular reflection area of the first camera without capturing the specular reflection,

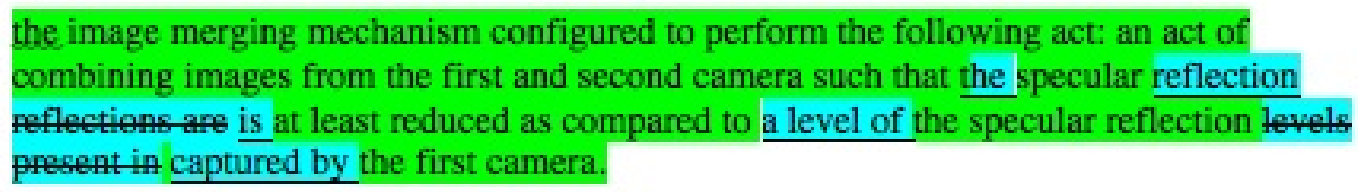

\begin{tabular}{|c|c|c|c|c|c|c|c|c|}
\hline \multirow[b]{2}{*}{ Citation } & \multicolumn{6}{|c|}{ Amended Claim } & \multicolumn{2}{|c|}{ Granted Ciaim } \\
\hline & $\begin{array}{c}\text { Original } \\
\text { Words }\end{array}$ & $\begin{array}{l}\text { Deleted } \\
\text { Words }\end{array}$ & $\begin{array}{l}\text { Added } \\
\text { Words }\end{array}$ & $\begin{array}{l}\text { Final } \\
\text { Words }\end{array}$ & $\begin{array}{c}\text { Claim } \\
\text { Amendment } \\
\text { Degree }\end{array}$ & Similarity & $\begin{array}{c}\text { Percentage } \\
\text { Citation }\end{array}$ & $\begin{array}{c}\text { Percentage } \\
\text { New }\end{array}$ \\
\hline US20050162381 & TID & 2 & 24 & 132 & $1.82 \%$ & 98.183 & $61.36 \%$ & $13.64 \%$ \\
\hline DS6975360 & 41 & 5 & 8 & 44 & $12.19 \%$ & $8781 \%$ & $20.46 \%$ & $4.54 \%$ \\
\hline Totals & TST & 7 & 32 & 176 & & & $81.82 \%$ & T8.18\% \\
\hline
\end{tabular}

Figure 5: Pooled Interdependency Instrument.

The procedure for a pooled interdependency is slightly different from the procedure for a sole interdependency to account for multiple technology patent citations. The procedure with this instrument is to use a first color, for example yellow to associate original independent claim language with the first technology patent citation. Then a second color, for example green, can associate original independent claim language with a second technology patent citation. Other colors may be added as needed if more than two technology patent citations are involved. The independent claim language associated with each technology patent citation comes from the document raising the objection. Another color, for example blue, is used to identify amended language to the independent 
claim. The same indications are used as the original document to indicate deleted text (strike out) and added text (underlined).

The detailed results of this phase of data analysis are provided in Appendix C. Tables 25 and 26 provide a summary of the six cases. The percentages are a measure for the relative amount of interdependency between technology patent citations and the independent claims of the technology patent as shown in Table 25 for the case of sole interdependency.

\begin{tabular}{|c|c|c|c|c|}
\hline Identification & Jurisdiction & $\begin{array}{c}\text { Technology } \\
\text { Patent Citation }\end{array}$ & $\begin{array}{c}\text { Independent } \\
\text { Claim }\end{array}$ & Citation Similarity \\
\hline \multirow{2}{*}{ Case 1 EP1611503 } & \multirow{2}{*}{ Europe } & \multirow{2}{*}{ US2002036617 } & Method 1 & $99.21 \%$ \\
\hline & & & Apparatus 9 & $98.39 \%$ \\
\hline \multirow{2}{*}{ Case 2 US7256772 } & \multirow{2}{*}{ United States } & \multirow{2}{*}{ US6774889 } & Method 1 & $96.92 \%$ \\
\hline & & & Apparatus 12 & $98.57 \%$ \\
\hline Case 3 EP1766501 & Europe & WO200203316 & Apparatus 1 & $87.50 \%$ \\
\hline \multirow{3}{*}{ Case 4 US7492357 } & \multirow{3}{*}{ United States } & \multirow{3}{*}{ US5315140 } & Apparatus 1 & $89.58 \%$ \\
\hline & & & Apparatus 55 & $100.00 \%$ \\
\hline & & & Apparatus 63 & $99.09 \%$ \\
\hline $\begin{array}{l}\text { Case } 4 \\
\text { US7492357 citing } \\
\text { US7630002 }\end{array}$ & United States & US20050162381 & Apparatus 1 & $63.52 \%$ \\
\hline \multirow{2}{*}{ Case 5 EP1297488 } & \multirow{2}{*}{ Europe } & \multirow{2}{*}{ US4746770 } & Apparatus 1 & $93.33 \%$ \\
\hline & & & Method 19 & $97.06 \%$ \\
\hline Case 5 EP1739528 & Europe & WO199940562 & Method 1 & $98.70 \%$ \\
\hline $\begin{array}{l}\text { Case } 5 \text { EP1297488 citing } \\
\text { EP2089791 }\end{array}$ & Europe & US2004201575 & Apparatus 1 & $100.00 \%$ \\
\hline \multirow{3}{*}{ Case 6 US7692625 } & \multirow{3}{*}{ United States } & \multirow{3}{*}{ US4746770 } & Apparatus 1 & $70.59 \%$ \\
\hline & & & Apparatus 25 & $90.68 \%$ \\
\hline & & & Method 46 & $47.89 \%$ \\
\hline $\begin{array}{l}\text { Case } 6 \text { US } 7692625 \text { citing } \\
\text { US8232511 }\end{array}$ & United States & US20050243070 & Apparatus 1 & $100.00 \%$ \\
\hline $\begin{array}{l}\text { Case } 6 \text { US7692625 Citing } \\
\text { US8515128 }\end{array}$ & United States & US7650015 & Apparatus 1 & $100.00 \%$ \\
\hline \multirow{3}{*}{$\begin{array}{l}\text { Case } 6 \text { US7692625 Citing } \\
\text { US8547327 }\end{array}$} & \multirow{3}{*}{ United States } & \multirow{3}{*}{ US6624833 } & Apparatus 1 & $100.00 \%$ \\
\hline & & & Apparatus 25 & $70.56 \%$ \\
\hline & & & Apparatus 26 & $100.00 \%$ \\
\hline
\end{tabular}

Table 25: Sole Interdependency Claim Similarity.

For the case of a "Pooled" type of legal rejection, Table 26 also illustrates the interdependencies between specific parts or portions of each independent claim and the 
portions of the technology patent citations. This is based upon the count of words in the claim that relate to each specific technology patent citation.

\begin{tabular}{|c|c|c|c|c|c|c|}
\hline Identification & Jurisdiction & $\begin{array}{c}\text { Technology } \\
\text { Patent } \\
\text { Citation } \\
\end{array}$ & $\begin{array}{l}\text { Ind. } \\
\text { Claim }\end{array}$ & $\begin{array}{c}\text { Portion } \\
\text { Of } \\
\text { Claim } \\
\end{array}$ & $\begin{array}{c}\text { Citation } \\
\text { Similarity }\end{array}$ & $\begin{array}{c}\text { Portion } \\
\text { Citation } \\
\text { Similarity } \\
\end{array}$ \\
\hline \multirow{2}{*}{$\begin{array}{l}\text { Case } 2 \\
\text { US7256772 } \\
\text { citing } \\
\text { US20120032922 }\end{array}$} & \multirow{2}{*}{ United States } & US7256772 & \multirow{2}{*}{$\begin{array}{c}\text { Apparatus } \\
1\end{array}$} & $49.04 \%$ & $49.04 \%$ & $24.03 \%$ \\
\hline & & $\begin{array}{l}\text { US20050017 } \\
957\end{array}$ & & $50.6 \%$ & $50.96 \%$ & $25.48 \%$ \\
\hline \multirow{2}{*}{$\begin{array}{l}\text { Case } 4 \\
\text { US7492357 } \\
\text { citing } \\
\text { US7630002 }\end{array}$} & \multirow{2}{*}{ United States } & $\begin{array}{l}\text { US20050162 } \\
381\end{array}$ & \multirow{2}{*}{$\begin{array}{c}\text { Apparatus } \\
14\end{array}$} & $75.00 \%$ & $98.18 \%$ & $73.64 \%$ \\
\hline & & US6975360 & & $25.00 \%$ & $87.81 \%$ & $21.95 \%$ \\
\hline \multirow{4}{*}{$\begin{array}{l}\text { Case 5 } \\
\text { EP1297488 } \\
\text { citing } \\
\text { EP2089791 }\end{array}$} & \multirow{4}{*}{ Europe } & $\begin{array}{l}\text { US20042015 } \\
75\end{array}$ & \multirow{2}{*}{$\begin{array}{c}\text { Apparatus } \\
8\end{array}$} & $75.94 \%$ & $100.00 \%$ & $75.94 \%$ \\
\hline & & US7057647 & & $24.06 \%$ & $100.00 \%$ & $24.06 \%$ \\
\hline & & $\begin{array}{l}\text { US20042015 } \\
75\end{array}$ & \multirow{2}{*}{$\begin{array}{c}\text { Apparatus } \\
12\end{array}$} & $70.00 \%$ & $100.00 \%$ & $70.00 \%$ \\
\hline & & US7057647 & & $30.00 \%$ & $100.00 \%$ & $30.00 \%$ \\
\hline \multirow{2}{*}{$\begin{array}{l}\text { Case } 6 \\
\text { US7692625 } \\
\text { citing } \\
\text { US7932899 }\end{array}$} & \multirow{2}{*}{ Unites States } & US7515141 & \multirow{2}{*}{$\begin{array}{c}\text { Apparatus } \\
12\end{array}$} & $45.81 \%$ & $100.00 \%$ & $45.81 \%$ \\
\hline & & US6727885 & & $54.19 \%$ & $83.33 \%$ & $44.62 \%$ \\
\hline \multirow{2}{*}{$\begin{array}{l}\text { Case } 6 \\
\text { US7692625 } \\
\text { citing } \\
\text { US8228304 }\end{array}$} & \multirow[b]{2}{*}{ United States } & US7084859 & \multirow[b]{2}{*}{ Method 1} & $70.00 \%$ & $100.00 \%$ & $70.00 \%$ \\
\hline & & US4639720 & & $30.00 \%$ & $100.00 \%$ & $30.00 \%$ \\
\hline \multirow{4}{*}{$\begin{array}{l}\text { Case } 6 \\
\text { US7692625 } \\
\text { citing } \\
\text { US8330726 }\end{array}$} & \multirow{4}{*}{ United States } & US6803906 & \multirow{2}{*}{$\begin{array}{c}\text { Apparatus } \\
1\end{array}$} & $80.41 \%$ & $74.38 \%$ & $59.81 \%$ \\
\hline & & $\begin{array}{l}\text { US20010019 } \\
325\end{array}$ & & $19.59 \%$ & $96.67 \%$ & $18.74 \%$ \\
\hline & & US6803906 & \multirow{2}{*}{$\begin{array}{c}\text { Apparatus } \\
21\end{array}$} & $89.56 \%$ & $94.22 \%$ & $84.38 \%$ \\
\hline & & $\begin{array}{l}\text { US20010019 } \\
325\end{array}$ & & $10.44 \%$ & $67.86 \%$ & $7.08 \%$ \\
\hline \multirow{4}{*}{$\begin{array}{l}\text { Case } 6 \\
\text { US7692625 } \\
\text { citing } \\
\text { US8400415 }\end{array}$} & \multirow{4}{*}{ United States } & US7456824 & \multirow{4}{*}{$\begin{array}{c}\text { Apparatus } \\
1\end{array}$} & $66.67 \%$ & $100.00 \%$ & $66.67 \%$ \\
\hline & & US6492633 & & $8.33 \%$ & $100.00 \%$ & $8.33 \%$ \\
\hline & & US6411287 & & $9.52 \%$ & $100.00 \%$ & $9.52 \%$ \\
\hline & & US5317140 & & $15.48 \%$ & $100.00 \%$ & $15.48 \%$ \\
\hline \multirow{3}{*}{$\begin{array}{l}\text { Case } 6 \\
\text { US7692625 } \\
\text { citing } \\
\text { US8513546 }\end{array}$} & \multirow{3}{*}{ United States } & US5896403 & \multirow{3}{*}{ Method 1} & $84.45 \%$ & $81.10 \%$ & $68.49 \%$ \\
\hline & & $\begin{array}{l}\text { US20020047 } \\
822\end{array}$ & & $2.22 \%$ & $100.00 \%$ & $2.22 \%$ \\
\hline & & US4331955 & & $13.33 \%$ & $100.00 \%$ & $13.33 \%$ \\
\hline
\end{tabular}

Table 26: Pooled Interdependency Citation And Claim Similarity.

Table 27 provides a summary for Case 1 and Case 2, the same invention patented in Europe and the United States. This table reveals the relative amount of the citation in the independent allowed claims and the relative amount of new knowledge as percentage new. 


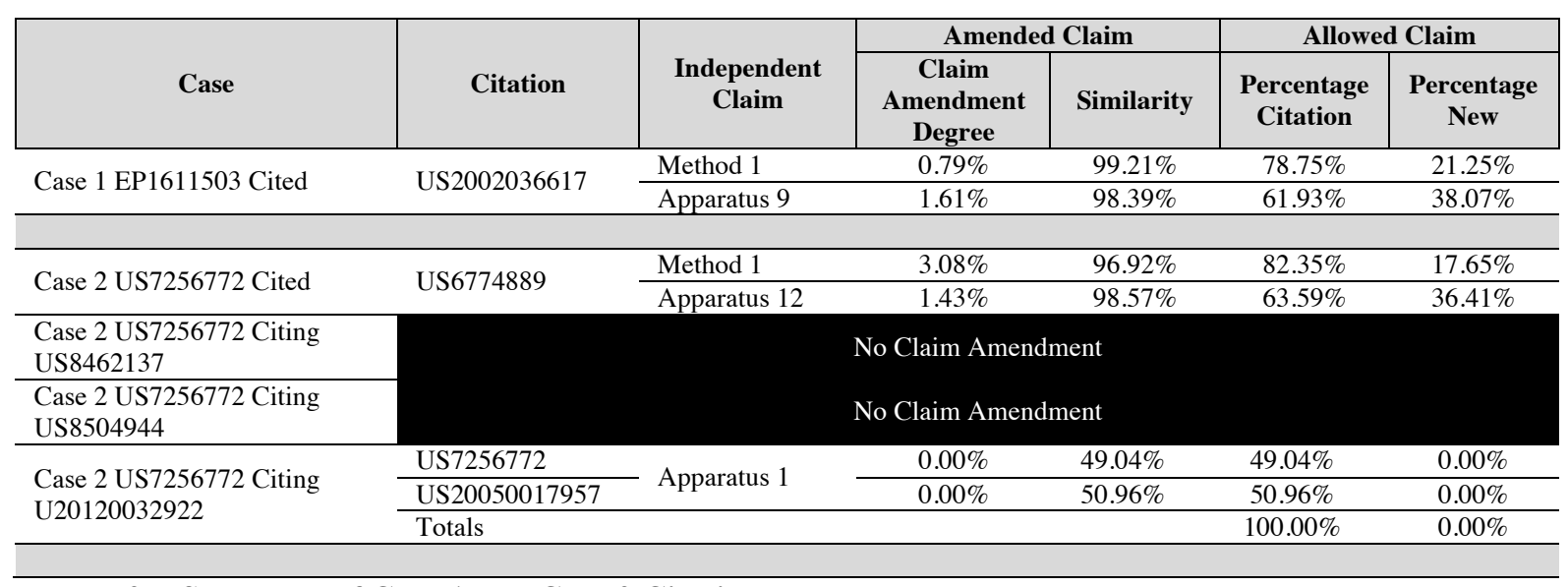

Table 27: Summary of Case 1 and Case 2 Citation Interdependency.

Table 28 provides a summary for Case 3 and Case 4, the same invention also patented in Europe and the United States. This table reveals the relative amount of the citation in the independent allowed claims and the relative amount of new knowledge as percentage new.

\begin{tabular}{|c|c|c|c|c|c|c|}
\hline \multirow[b]{2}{*}{ Case } & \multirow[b]{2}{*}{ Citation } & \multirow[b]{2}{*}{$\begin{array}{l}\text { Independent } \\
\text { Claim }\end{array}$} & \multicolumn{2}{|c|}{ Amended Claim } & \multicolumn{2}{|c|}{ Allowed Claim } \\
\hline & & & $\begin{array}{c}\text { Claim } \\
\text { Amendment } \\
\text { Degree }\end{array}$ & Similarity & $\begin{array}{l}\text { Percentage } \\
\text { Citation }\end{array}$ & $\begin{array}{l}\text { Percentage } \\
\text { New }\end{array}$ \\
\hline Case 3 EP1766501 Cited & WO200203316 & Apparatus 1 & $12.50 \%$ & $87.50 \%$ & $63.19 \%$ & $36.81 \%$ \\
\hline \multirow{3}{*}{ Case 4 US7492357 Cited } & \multirow{3}{*}{ US51317140 } & Apparatus 1 & $10.42 \%$ & $89.58 \%$ & $66.15 \%$ & $33.85 \%$ \\
\hline & & Apparatus 55 & $0.00 \%$ & $100.00 \%$ & $73.18 \%$ & $26.82 \%$ \\
\hline & & Apparatus 63 & $0.11 \%$ & $99.09 \%$ & $66.87 \%$ & $33.13 \%$ \\
\hline \multirow{4}{*}{$\begin{array}{l}\text { Case } 4 \text { US7492357 Citing } \\
\text { US7630002 }\end{array}$} & US20050162381 & Apparatus 1 & $36.48 \%$ & $63.52 \%$ & $29.97 \%$ & $70.03 \%$ \\
\hline & US20050162381 & \multirow{3}{*}{ Apparatus 14} & $1.82 \%$ & $98.18 \%$ & $61.36 \%$ & $13.64 \%$ \\
\hline & US6975369 & & $12.19 \%$ & $87.81 \%$ & $20.46 \%$ & $4.54 \%$ \\
\hline & Totals & & & & $81.82 \%$ & $18.18 \%$ \\
\hline $\begin{array}{l}\text { Case } 4 \text { US7492357 Citing } \\
\text { US7751671 }\end{array}$ & \multicolumn{6}{|c|}{ No Claim Amendment } \\
\hline $\begin{array}{l}\text { Case } 4 \text { US7492357 Citing } \\
\text { US8462137 }\end{array}$ & \multicolumn{6}{|c|}{ No Claim Amendment } \\
\hline $\begin{array}{l}\text { Case } 4 \text { US7492357 Citing } \\
\text { US8504944 }\end{array}$ & \multicolumn{6}{|c|}{ No Claim Amendment } \\
\hline
\end{tabular}

Table 28: Summary of Case 3 and Case 4 Citation Interdependency. 
Table 29 provides a summary for Case 5 and Case 6 , the same invention also patented in Europe and the United States. This table reveals the relative amount of the citation in the independent claims and the relative amount of new knowledge as percentage new.

\begin{tabular}{|c|c|c|c|c|c|c|}
\hline \multirow[b]{2}{*}{ Case } & \multirow[b]{2}{*}{ Citation } & \multirow[b]{2}{*}{$\begin{array}{l}\text { Independent } \\
\text { Claim }\end{array}$} & \multicolumn{2}{|c|}{ Amended Claim } & \multicolumn{2}{|c|}{ Allowed Claim } \\
\hline & & & $\begin{array}{c}\text { Claim } \\
\text { Amendment } \\
\text { Degree }\end{array}$ & Similarity & $\begin{array}{l}\text { Percentage } \\
\text { Citation }\end{array}$ & $\begin{array}{l}\text { Percentage } \\
\quad \text { New }\end{array}$ \\
\hline \multirow{2}{*}{ Case 5 EP1297488 Cited } & \multirow{2}{*}{ US4746770 } & Apparatus 1 & $6.67 \%$ & $93.33 \%$ & $97.96 \%$ & $2.04 \%$ \\
\hline & & Method 19 & $2.94 \%$ & $97.06 \%$ & $98.51 \%$ & $1.49 \%$ \\
\hline Case 5 EP1739528 Cited & WO199940562 & Method 1 & $1.30 \%$ & $98.70 \%$ & $66.67 \%$ & $33.33 \%$ \\
\hline Case 5 EP1739529 Cited & & & No Claim Amen & ment & & \\
\hline \multirow{7}{*}{$\begin{array}{l}\text { Case } 5 \text { EP1297488 Citing } \\
\text { EP2089791 }\end{array}$} & US2004201575 & Apparatus 1 & $0.00 \%$ & $100.00 \%$ & $100.00 \%$ & $0.00 \%$ \\
\hline & US2004201575 & \multirow{2}{*}{ Apparatus 8} & $0.00 \%$ & $100.00 \%$ & $58.25 \%$ & $20.39 \%$ \\
\hline & US7057647 & & $0.00 \%$ & $100.00 \%$ & $18.45 \%$ & $2.91 \%$ \\
\hline & Totals & \multirow{4}{*}{ Apparatus 12} & & & $76.70 \%$ & $23.30 \%$ \\
\hline & US2004201575 & & $0.00 \%$ & $100.00 \%$ & $45.65 \%$ & $31.52 \%$ \\
\hline & US7057647 & & $0.00 \%$ & $100.00 \%$ & $19.57 \%$ & $3.26 \%$ \\
\hline & Totals & & & & $65.22 \%$ & $34.78 \%$ \\
\hline \multirow{3}{*}{ Case 6 US7692625 Cited } & \multirow{3}{*}{ US4746770 } & Apparatus 1 & $29.41 \%$ & $70.59 \%$ & $46.15 \%$ & $53.85 \%$ \\
\hline & & Apparatus 25 & $9.32 \%$ & $90.68 \%$ & $72.30 \%$ & $27.70 \%$ \\
\hline & & Method 46 & $49.25 \%$ & $50.75 \%$ & $32.08 \%$ & $67.92 \%$ \\
\hline \multirow{3}{*}{$\begin{array}{l}\text { Case } 6 \text { US7692625 Citing } \\
\text { US7932899 }\end{array}$} & US7515141 & \multirow{3}{*}{ Apparatus 12} & $0.00 \%$ & $100.00 \%$ & $36.60 \%$ & $1.55 \%$ \\
\hline & US6727885 & & $16.67 \%$ & $83.33 \%$ & $43.30 \%$ & $18.55 \%$ \\
\hline & Totals & & & & $79.90 \%$ & $21.10 \%$ \\
\hline $\begin{array}{l}\text { Case } 6 \text { US7692625 Citing } \\
\text { US8131502 }\end{array}$ & \multirow{2}{*}{\multicolumn{6}{|c|}{ No Claim Amendment }} \\
\hline $\begin{array}{l}\text { Case } 6 \text { US7692625 Citing } \\
\text { US8135561 }\end{array}$ & & & & & & \\
\hline \multirow{3}{*}{$\begin{array}{l}\text { Case } 6 \text { US7692625 Citing } \\
\text { US8228304 }\end{array}$} & US084859 & \multirow{3}{*}{ Method 1} & $0.00 \%$ & $100.00 \%$ & $70.00 \%$ & $0.00 \%$ \\
\hline & US4639720 & & $0.00 \%$ & $100.00 \%$ & $30.00 \%$ & $0.00 \%$ \\
\hline & Totals & & & & $100.00 \%$ & $0.00 \%$ \\
\hline $\begin{array}{l}\text { Case } 6 \text { US7692625 Citing } \\
\text { US8232511 }\end{array}$ & US20050243070 & Apparatus 2 & $0.00 \%$ & $100.00 \%$ & $90.53 \%$ & $9.47 \%$ \\
\hline $\begin{array}{l}\text { Case } 6 \text { US7692625 Citing } \\
\text { US8305363 }\end{array}$ & & & No Claim Amer & ment & & \\
\hline \multirow{6}{*}{$\begin{array}{l}\text { Case } 6 \text { US7692625 Citing } \\
\text { US8330726 }\end{array}$} & US6803906 & \multirow{2}{*}{ Apparatus 1} & $25.62 \%$ & $74.38 \%$ & $37.54 \%$ & $47.32 \%$ \\
\hline & US20010019325 & & $3.33 \%$ & $96.67 \%$ & $9.15 \%$ & $5.99 \%$ \\
\hline & Totals & \multirow{3}{*}{ Apparatus 21} & & & $46.69 \%$ & $53.31 \%$ \\
\hline & US6803906 & & $5.78 \%$ & $94.22 \%$ & $41.69 \%$ & $45.01 \%$ \\
\hline & US20010019325 & & $32.14 \%$ & $67.86 \%$ & $4.86 \%$ & $8.44 \%$ \\
\hline & Totals & \multirow{5}{*}{ Apparatus 1} & & & $46.55 \%$ & $53.45 \%$ \\
\hline \multirow{5}{*}{$\begin{array}{l}\text { Case } 6 \text { US7692625 Citing } \\
\text { US8400415 }\end{array}$} & US6803906 & & $0.00 \%$ & $100.00 \%$ & $62.22 \%$ & $6.67 \%$ \\
\hline & US6492633 & & $0.00 \%$ & $100.00 \%$ & $7.78 \%$ & $0.00 \%$ \\
\hline & US6411287 & & $0.00 \%$ & $100.00 \%$ & $8.89 \%$ & $0.00 \%$ \\
\hline & US5317140 & & $0.00 \%$ & $100.00 \%$ & $14.44 \%$ & $0.00 \%$ \\
\hline & Totals & & & & $93.33 \%$ & $6.67 \%$ \\
\hline \multirow{3}{*}{$\begin{array}{l}\text { Case } 6 \text { US7692625 Citing } \\
\text { US8513546 }\end{array}$} & US5896403 & & $18.90 \%$ & $81.10 \%$ & $57.22 \%$ & $27.22 \%$ \\
\hline & US20020047822 & Method 1 & $0.00 \%$ & $100.00 \%$ & $1.67 \%$ & $0.56 \%$ \\
\hline & US4331955 & & $0.00 \%$ & $100.00 \%$ & $13.33 \%$ & $0.00 \%$ \\
\hline & Totals & & & & $72.22 \%$ & $27.78 \%$ \\
\hline $\begin{array}{l}\text { Case } 6 \text { US7692625 Citing } \\
\text { US8515128 }\end{array}$ & US7650015 & Apparatu & $0.00 \%$ & $100.00 \%$ & 74.7 & $\begin{array}{l}25 . \\
30 \\
\%\end{array}$ \\
\hline & US6624833 & Apparatus 1 & $0.00 \%$ & $100.00 \%$ & $49.30 \%$ & $50.70 \%$ \\
\hline $\begin{array}{l}\text { Case } 6 \text { US7692625 Citıng } \\
\text { US8547327 }\end{array}$ & US6624833 & Apparatus 25 & $29.44 \%$ & $70.56 \%$ & $81.29 \%$ & $18.71 \%$ \\
\hline & US6624833 & Apparatus 26 & $0.00 \%$ & $100.00 \%$ & $33.33 \%$ & $66.67 \%$ \\
\hline
\end{tabular}

Table 29: Summary of Case 5 and Case 6 Citation Interdependency. 
In summary, the attributes of the constructs are coded at the completion of this phase of document examination and data analysis. This includes the Technology Patent Citation attribute, the Legal Rejection Type attribute, the Claim Amendment attribute, the Degree of Claim Amendment attribute and the Sequential Claim Amendment attribute. The descriptive statistics are also determined to view the complex qualitative data from the words used in the claims with the amended words in the claims. This permits a logical comparison of interdependency between the technology patent citations and independent claims of the technology patents.

\subsubsection{Comparing Noise And Pertinence}

A comparison between noise and pertinent citations is determined for all technology patent citations in each of the six cases. The noise and pertinence of this research is the difference between the amount of noise and the amount of pertinence of the technology patent citations from the complete list of technology patent citations identified with a technology patent. This is used two ways. Firstly, to indicate an amount of noise in the technology patent citations listed with the technology patent. Secondly, to indicate an amount of pertinence between the technology patent citations and technology patent.

The relative amount of pertinence is determined by the following equation:

$$
\text { Pertinence }=\left(\frac{\text { Number of Pertinent Technology Patent Citations }}{\text { Total Number Of Technology Patent Citations }}\right) * 100
$$

Equation 5: Relative Amount of Technology Patent Citation Pertinence. 
The relative amount of noise is determined by the following equation:

$$
\text { Noise }=100-\text { Pertience }
$$

Equation 6: Relative Amount of Technology Patent Citation Noise.

The result of the document examination and data analysis for the noise and pertinence is shown in Table 30 below.

\begin{tabular}{|c|c|c|c|c|}
\hline \multirow{2}{*}{ Identification } & \multirow{2}{*}{$\begin{array}{c}\text { Total } \\
\text { Citations } \\
\end{array}$} & \multirow{2}{*}{$\begin{array}{c}\text { Interdependency } \\
\text { Citations }\end{array}$} & \multicolumn{2}{|c|}{ Comparison } \\
\hline & & & Noise & Pertinence \\
\hline Case 1 EP1611503 Cited & 3 & 1 & $66.67 \%$ & $33.33 \%$ \\
\hline Case 2 US7256772 Cited & 65 & 1 & 98.46 & $1.54 \%$ \\
\hline Case 2 US7256772 Citing US8462137 & 13 & 0 & $100.00 \%$ & $0.00 \%$ \\
\hline Case 2 US7256772 Citing US8504944 & 20 & 0 & $100.00 \%$ & $0.00 \%$ \\
\hline Case 2 US7256772 Citing US20120032922 & 5 & 2 & $60.00 \%$ & $40.00 \%$ \\
\hline Case 3 EP1766501 Cited & 4 & 1 & $75.00 \%$ & $25.00 \%$ \\
\hline Case 4 US7492357 Cited & 101 & 1 & $99.01 \%$ & $0.99 \%$ \\
\hline Case 4 US7492357 Citing US7630002 & 27 & 1 & 96.93 & $3.07 \%$ \\
\hline Case 4 US7492357 Citing US7751671 & 17 & 0 & $100.00 \%$ & $0.00 \%$ \\
\hline Case 4 US7492357 Citing US8462137 & 13 & 0 & $100.00 \%$ & $0.00 \%$ \\
\hline Case 4 US7492357 Citing US8504944 & 20 & 0 & $100.00 \%$ & $0.00 \%$ \\
\hline Case 5 EP1297488 Cited & 3 & 1 & $66.67 \%$ & $33.33 \%$ \\
\hline Case 5 EP1739528 Cited & 5 & 1 & $80.00 \%$ & $20.00 \%$ \\
\hline Case 5 EP1739529 Cited & 7 & 0 & $100.00 \%$ & $0.00 \%$ \\
\hline Case 5 CEP1297488 Citing EP2089791 & 10 & 2 & $80.00 \%$ & $20.00 \%$ \\
\hline Case 6 US7692629 Cited & 103 & 1 & $99.03 \%$ & $0.97 \%$ \\
\hline Case 6 US7692629 Citing US7932899 & 57 & 2 & $96.49 \%$ & $3.51 \%$ \\
\hline Case 6 US7692629 Citing US8131502 & 14 & 0 & $100.00 \%$ & $0.00 \%$ \\
\hline Case 6 US7692629 Citing US8135561 & 14 & 0 & $100.00 \%$ & $0.00 \%$ \\
\hline Case 6 US7692629 Citing US8228304 & 115 & 2 & $98.26 \%$ & 1.74 \\
\hline Case 6 US7692629 Citing US8232511 & 15 & 1 & $93.33 \%$ & $6.67 \%$ \\
\hline Case 6 US7692629 Citing US8305363 & 28 & 0 & $100.00 \%$ & $0.00 \%$ \\
\hline Case 6 US7692629 Citing US8330726 & 80 & 2 & $97.50 \%$ & $2.50 \%$ \\
\hline Case 6 US7692629 Citing US8400415 & 16 & 4 & $75.00 \%$ & $25.00 \%$ \\
\hline Case 6 US7692629 Citing US8513546 & 17 & 3 & $82.35 \%$ & $17.65 \%$ \\
\hline Case 6 US7692629 Citing US8515128 & 29 & 1 & $96.55 \%$ & $3.45 \%$ \\
\hline Case 6 US7692629 Citing US8547327 & 29 & 1 & $96.55 \%$ & $3.45 \%$ \\
\hline
\end{tabular}

Table 30: Data Analysis To Compare Noise And Pertinence.

There are a number of patterns with respect to Table 30 that emerged from the data and the analysis of the data concerning noise and pertinence. There can be $100 \%$ noise with the list of citations or there can be a ratio of noise and pertinent citations. The amount of 
pertinent citations is always significantly less than the amount of noise when pertinent citations are present.

The citation list included with the published patent suggests that the amount of pertinent citations should be higher and the amount of noise should be lower. The rival explanation is that patent searchers and examiners consider a higher amount of citations to be pertinent based upon opinion and the procedures and requirements of patent prosecution. However, when compared with the results in Table 30 and the evidence as it specifically relates to interdependency, the amount of pertinent citations is much lower and tied directly to interdependency.

\subsubsection{Comparing Patent Citation Interdependency}

The citations are compared for all technology patent citations in each of the six cases. The comparison reveals the amount of interdependency with the claims of the technology patent for each citation. A ratio is determined between the relative amount and portion of the old knowledge and the relative amount and portion of new knowledge in the claim of the technology patent. The degree of citation similarity is determined; portion of old knowledge and the portion of new knowledge in the granted claim. The results for this example are shown in Table 31 below. 


\begin{tabular}{|c|c|c|c|c|c|}
\hline \multirow[b]{2}{*}{ Identification } & \multirow[b]{2}{*}{ Citation } & \multirow{2}{*}{$\begin{array}{l}\text { Independent } \\
\text { Claim }\end{array}$} & \multirow{2}{*}{$\begin{array}{l}\text { Citation } \\
\text { Similarity }\end{array}$} & \multicolumn{2}{|c|}{ Allowed Claim } \\
\hline & & & & $\begin{array}{l}\text { Portion Old } \\
\text { Citation }\end{array}$ & $\begin{array}{l}\text { Portion } \\
\text { New }\end{array}$ \\
\hline \multirow{2}{*}{ Case 1 EP1611503 Cited } & \multirow{2}{*}{ US2002036617 } & Method 1 & $99.21 \%$ & $78.75 \%$ & $21.25 \%$ \\
\hline & & Apparatus 9 & $98.39 \%$ & $61.93 \%$ & $38.07 \%$ \\
\hline \multirow{2}{*}{ Case 2 US7256772 Cited } & \multirow{2}{*}{ US6774889 } & Method 1 & $96.92 \%$ & $82.35 \%$ & $17.65 \%$ \\
\hline & & Apparatus 12 & $98.57 \%$ & $63.59 \%$ & $36.41 \%$ \\
\hline Case 2 US7256772 Citing US8462137 & & & None & & \\
\hline Case 2 US7256772 Citing US8504944 & & & None & & \\
\hline $\begin{array}{l}\text { Case } 2 \text { US7256772 Citing } \\
\text { US20120032922 }\end{array}$ & US20050017957 & Apparatus 1 & $50.96 \%$ & $50.96 \%$ & $0.00 \%$ \\
\hline Case 3 EP1766501 Cited & WO200203316 & Apparatus 1 & $87.50 \%$ & $63.19 \%$ & $36.81 \%$ \\
\hline \multirow{3}{*}{ Case 4 US7492357 Cited } & \multirow{3}{*}{ US51317140 } & Apparatus 1 & $89.58 \%$ & $66.15 \%$ & $33.85 \%$ \\
\hline & & Apparatus 55 & $100.00 \%$ & $73.18 \%$ & $26.82 \%$ \\
\hline & & Apparatus 63 & $99.09 \%$ & $66.87 \%$ & $33.13 \%$ \\
\hline \multirow{2}{*}{ Case 4 US7492357 Citing US7630002 } & \multirow{2}{*}{ US20050162381 } & Apparatus 1 & $63.52 \%$ & $29.97 \%$ & $70.03 \%$ \\
\hline & & Apparatus 14 & $98.18 \%$ & $61.36 \%$ & $13.64 \%$ \\
\hline Case 4 US7492357 Citing US7751671 & & & None & & \\
\hline Case 4 US7492357 Citing US8462137 & & & None & & \\
\hline Case 4 US7492357 Citing US8504944 & & & None & & \\
\hline \multirow{2}{*}{ Case 5 EP1297488 Cited } & \multirow{2}{*}{ US4746770 } & Apparatus 1 & $93.33 \%$ & $97.96 \%$ & $2.04 \%$ \\
\hline & & Method 19 & $97.06 \%$ & $98.51 \%$ & $1.49 \%$ \\
\hline Case 5 EP1739528 Cited & WO199940562 & Method 1 & $98.70 \%$ & $66.67 \%$ & $33.33 \%$ \\
\hline Case 5 EP1739529 Cited & & & None & & \\
\hline \multirow{3}{*}{ Case 5 CEP1297488 Citing EP2089791 } & \multirow{3}{*}{ US2004201575 } & Apparatus 1 & $100.00 \%$ & $100.00 \%$ & $0.00 \%$ \\
\hline & & Apparatus 8 & $100.00 \%$ & $58.25 \%$ & $20.39 \%$ \\
\hline & & Apparatus 12 & $100.00 \%$ & $45.65 \%$ & $31.52 \%$ \\
\hline \multirow{3}{*}{ Case 6 US7692625 Cited } & \multirow{3}{*}{ US4746770 } & Apparatus 1 & $70.59 \%$ & $46.15 \%$ & $53.85 \%$ \\
\hline & & Apparatus 25 & $90.68 \%$ & $72.30 \%$ & $27.70 \%$ \\
\hline & & Method 26 & $50.75 \%$ & $32.08 \%$ & $67.92 \%$ \\
\hline Case 6 US7692625 Citing US7932899 & US6727885 & Apparatus 12 & $83.33 \%$ & $43.30 \%$ & $18.55 \%$ \\
\hline Case 6 US7692625 Citing US8131502 & & & None & & \\
\hline Case 6 US7692625 Citing US8135561 & & & None & & \\
\hline Case 6 US7692625 Citing US8228304 & US7084859 & Method 1 & $100.00 \%$ & $70.00 \%$ & $0.00 \%$ \\
\hline Case 6 US7692625 Citing US8232511 & US20050243070 & Apparatus 1 & $100.00 \%$ & $90.53 \%$ & $9.47 \%$ \\
\hline Case 6 US7692625Citing US8305363 & & & None & & \\
\hline \multirow{2}{*}{ Case 6 US7692625 Citing US8330726 } & \multirow{2}{*}{ US6803906 } & Apparatus 1 & $74.38 \%$ & $37.54 \%$ & $47.32 \%$ \\
\hline & & Apparatus 21 & $94.22 \%$ & $41.69 \%$ & $45.01 \%$ \\
\hline Case 6 US7692625 Citing US8400415 & US6803906 & Apparatus 1 & $100.00 \%$ & $62.22 \%$ & $6.67 \%$ \\
\hline Case 6 US7692625 Citing US8513546 & US5896403 & Method 1 & $81.10 \%$ & $57.22 \%$ & $27.22 \%$ \\
\hline Case 6 US7692625 Citing US8515128 & US7650015 & Apparatus 1 & $100.00 \%$ & $74.70 \%$ & $25.30 \%$ \\
\hline \multirow{3}{*}{ Case 6 US7692625 Citing US8547327 } & \multirow{3}{*}{ US6624833 } & Apparatus 1 & $100.00 \%$ & $49.30 \%$ & $50.70 \%$ \\
\hline & & Apparatus 25 & $70.56 \%$ & $81.29 \%$ & $18.71 \%$ \\
\hline & & Apparatus 26 & $100.00 \%$ & $33.33 \%$ & $66.67 \%$ \\
\hline
\end{tabular}

Table 31: Data Analysis To Compare Citation Interdependency.

There are a number of patterns with respect to the summary provided in Table 31 that also emerged from the data and the analysis of the data concerning citation interdependency. For the case of sole interdependency, there is one dominant citation having a substantial similarity with the broad claim of the patent. For the case of pooled 
interdependency, there is also one dominant citation having the highest amount of similarity with the broad claim of the patent. A possible rival explanation is that Examiners have a different view and opinion of the citation contribution during the examination process. However, when the amount of similarity is compared between the citation and the broad claim of the patent, the amount of similarity is dependent upon the specific interdependency between the citation and the broad claim of the patent in question.

\subsubsection{Case Analysis}

The data is first analyzed with respect to the individual cases and then compared across all of the cases. The tables constructed in the data analysis phase were supplemented with graphs of the data to assist with detailed comparisons of the cases seeking to identify similarities and differences to develop constructs and theoretical logic that emerged from the data (Brown \& Eisenhardt, 2001).

Case analysis is conducted for each of the three inventions and corresponding six cases. The following data and tables are applied to the case analysis from the perspective of the noise and pertinence:

- Table 24 - Case summaries of the claim amendment attribute, sequence attribute, legal rejection type attribute and presence or lack of technology patent citation noise or pertinence, and

- Table 30 - Case summaries for the technology patent citation noise and pertinence ratios. 
The following data and tables are applied to the case analysis from the perspective of the citation interdependency:

- Table 27 - Case 1 and case 2 summary of technology patent citation interdependency,

- Table 28 - Case 3 and case 4 summary of technology patent citation interdependency,

- Table 29 - Case 5 and case 6 summary of technology patent citation interdependency, and

- Table 31 - Case summaries for the technology patent dominant citation ratios.

\subsubsection{Phase 4: Within Case Analysis}

The within case analysis is based upon Tables 23 and 26 through 30 inclusive to analyze the research data and develop overall patterns and themes within the cases. In particular, the analysis focuses upon citation noise, the sequence required in the patent prosecution process, the technology patent, citation and noise pertinence and the citation interdependency.

\subsubsection{Phase 5: Across Case Analysis}

The across case analysis is also based upon Tables 24 and 27 through 31 inclusive to analyze the research data and develop overall patterns and themes within the cases. This analysis looks across all cases, the European Cases and the United States cases. The analysis focuses upon the citation noise, the sequence required in the patent prosecution 
process, the technology patent citation noise and pertinence and the citation interdependency.

\subsection{Summary Of The Research Method}

Chapter 3 presented and described in detail the research method for this thesis. The Firm Smart Technologies Inc. was selected for this research based upon a specific set of criteria. Each of the six cases was selected based upon criteria that required both a European patent and United States patent for each of the three inventions.

A unique method was developed for this research in anticipation of the large data associated with the six cases to turn something completely unmanageable into something manageable. This unique method includes a set of initial preprocessing procedures and criteria to identify relevant documents. This is followed by a final set of preprocessing procedures and criteria to identify relevant pages from these documents.

Another set of procedures and criteria were developed including specialized instruments to assist and guide the analysis of the data. Relevant pages from documents are examined to identify independent claims, objections to independent claims and the corresponding technology patent citation and amendments to independent claims. This data is recorded in attributes as a technology patent citation identification number, the presence or absence of a claim amendment, a legal rejection type, word counts for the original and amended independent claims and the number of sequential claim amendments. 
A final set of procedures and criteria were developed for the analysis of data to calculate the percentage of noise, a percentage of pertinence, a percentage of similarity, and a percentage of new and old knowledge reflected in the independent patent claims. All of this data is used in the case analysis of this research. 


\section{Results}

The results presented in this chapter were obtained by following the detailed research method and data analysis described in Chapter 3 of this thesis. This chapter describes the results of the research and begins with a discussion of the research methods ability to deal with large data found in the black box of historical patent data. This is followed by a discussion of the results and findings pertaining to a first interdependency introduced as the noise pertinence interdependency ratio. A second interdependency introduced as a dominant technology patent citation interdependency ratio is then discussed. This chapter concludes with a summary of the results.

\subsection{Research Method \& Large Data}

The black box of historical patent documents contains large data associated with each patent. This relates to the number of technology patent citations that must be examined and the amount of documents that must be examined to reveal interdependency. The unique method designed for this research, including the procedures, criteria and instruments, made it possible to deal very affectively with raw large data. The results of following this research method and procedures are shown in Table 32 and Table 33. 


\begin{tabular}{|c|c|c|c|c|c|c|c|c|}
\cline { 3 - 9 } \multicolumn{2}{c|}{} & \multicolumn{2}{c|}{ Case 1 \& 2 } & \multicolumn{2}{c|}{ Case 3 \& 4 } & \multicolumn{2}{c|}{ Case 5 \& 6 } & \multirow{2}{*}{ Sub-Totals } \\
\cline { 3 - 9 } \multicolumn{2}{c|}{} & \multirow{2}{*}{ Cited } & Citing & \multirow{2}{*}{ Cited } & \multirow{2}{*}{ Citing } & \multirow{2}{*}{ Cited } & \multirow{2}{*}{ Citing } & \\
\hline \multirow{4}{*}{ Europe } & Total Documents & 88 & 0 & 69 & 0 & 181 & 38 & 376 \\
\cline { 2 - 9 } & Relevant Documents & 8 & 0 & 5 & 0 & 11 & 3 & 27 \\
\cline { 2 - 9 } & Total Document Pages & 292 & 0 & 299 & 0 & 1938 & 149 & 2678 \\
\cline { 2 - 9 } & Relevant Pages & 11 & 0 & 17 & 0 & 7 & 10 & 45 \\
\hline \multirow{3}{*}{$\begin{array}{c}\text { United } \\
\text { States }\end{array}$} & Total Documents & 80 & 126 & 109 & 290 & 174 & 972 & 1751 \\
\cline { 2 - 9 } & Relevant Documents & 5 & 8 & 6 & 18 & 13 & 59 & 109 \\
\cline { 2 - 9 } & Total Document Pages & 535 & 804 & 1020 & 3520 & 1411 & 12527 & 19817 \\
\cline { 2 - 9 } & Relevant Pages & 16 & 20 & 16 & 23 & 24 & 150 & 249 \\
\hline
\end{tabular}

Table 32: Raw And Preprocessed Research Data Volume.

\begin{tabular}{|c|c|c|}
\hline $\begin{array}{c}\text { Cited Technology Patent } \\
\text { Citations }\end{array}$ & $\begin{array}{c}\text { Citing Technology Patent } \\
\text { Citations }\end{array}$ & $\begin{array}{c}\text { Total Technology Patent } \\
\text { Citations To Examine }\end{array}$ \\
\hline 301 & 418 & 719 \\
\hline
\end{tabular}

Table 33: Number Of Identified Technology Patent Citations.

The total number of raw documents for all six cases is 2,127 . This includes 22,495 pages of historical archival document information. Following the research methods initial preprocessing procedures reduced the raw document count to 136 relevant documents with 1,123 pages. Finishing up with the final preprocessing procedure further reduced the number of pages to a manageable 294 relevant pages for all six cases.

A finding of the preprocessing approach of this unique research method is the ability to preprocess raw large historical patent data into a manageable collection of pages in a few days of manual effort without error. This enables researchers to apply historical patent documents and interdependency as a practical option for improving citation based patent evaluation methodologies.

\subsection{Noise Pertinence Interdependency Ratio}

A first interdependency pattern emerged from the data in the form of a noise pertinence interdependency ratio. The results and findings of a noise pertinence interdependency 
ratio are presented in this section. Table 34 is a summary of the results for the six cases from Table 30 formatted into cited technology patent citations and citing technology patent citations. Case 1 and case 2 did not have any citing technology patent citations.

\begin{tabular}{|c|c|c|c|c|c|}
\hline \multirow[t]{2}{*}{ Identification } & \multirow[t]{2}{*}{ Jurisdiction } & \multicolumn{2}{|c|}{$\begin{array}{c}\text { Cited Technology Patent } \\
\text { Citations }\end{array}$} & \multicolumn{2}{|c|}{$\begin{array}{c}\text { Citing Technology Patent } \\
\text { Citations }\end{array}$} \\
\hline & & Noise & Pertinence & Noise & Pertinence \\
\hline Case 1 & Europe & $66.67 \%$ & $33.33 \%$ & \multicolumn{2}{|c|}{ Not Available } \\
\hline Case 2 & United States & $98.55 \%$ & $1.45 \%$ & $98.15 \%$ & $1.85 \%$ \\
\hline Case 3 & Europe & $75.00 \%$ & $25.00 \%$ & \multicolumn{2}{|c|}{ Not Available } \\
\hline Case 4 & United States & $99.00 \%$ & $1.00 \%$ & $98.15 \%$ & $1.85 \%$ \\
\hline Case 5 & Europe & $80.56 \%$ & $19.44 \%$ & $77.78 \%$ & $22.22 \%$ \\
\hline Case 6 & United States & $99.03 \%$ & $0.97 \%$ & $94.37 \%$ & $5.63 \%$ \\
\hline \multirow{3}{*}{ All Cases } & Europe & $74.08 \%$ & $25.92 \%$ & $77.78 \%$ & $22.22 \%$ \\
\hline & United States & $98.86 \%$ & $1.14 \%$ & $96.89 \%$ & $3.11 \%$ \\
\hline & Europe \& United States & $86.47 \%$ & $13.53 \%$ & $87.34 \%$ & $12.66 \%$ \\
\hline
\end{tabular}

Table 34: Summary of Noise Pertinence Ratio Case Results.

The results in Table 34 reveal for each case and across the cases that technology patent citations may or may not form interdependencies with the technology patent. When technology patent citations form interdependency, they are pertinent to the technology patent. The amount of noise, pertinence and interdependency are unique for each case. From Tables 24 and 30, when the noise is $100 \%$ and the pertinence is $0 \%$ and there is no claim amendment, there is no interdependency with the technology patent. From Tables 24 and 30, when the noise is $0 \%$ and the pertinence is $100 \%$ and there is a claim amendment, there is either partial or complete interdependency with the technology patent. Complete interdependency results in a refusal of the patent and partial results in an allowance of an amended independent claim. 
Table 35 summarizes the patterns of the noise and pertinence for each case and across the cases. The patterns in each case may be a mix of noise and pertinence leading to interdependency between the pertinent citation and technology patent. There may be $100 \%$ noise leading to an absence of interdependency between the citations and the technology patent. There may be $100 \%$ pertinence leading to complete interdependency between the pertinent citation and the technology patent.

\begin{tabular}{|c|c|c|}
\hline Identification & Jurisdiction & Technology Patent Citations \\
\hline Case 1 & Europe & Citations are a mix of noise and pertinence. \\
\hline Case 2 & United States & $\begin{array}{l}\text { Citations may be a mix of noise and pertinence. } \\
\text { All citations in US } 8462137 \text { and US } 850494 \text { may be } 100 \% \text { noise. } \\
\text { One citation in US20120032922 is } 100 \% \text { pertinent. }\end{array}$ \\
\hline Case 3 & Europe & One citation is $100 \%$ pertinent. \\
\hline Case 4 & United States & $\begin{array}{l}\text { Citations are a mix of noise and pertinence. } \\
\text { Citations in US7751671, US8462137 and US8504944 are } 100 \% \text { noise. }\end{array}$ \\
\hline Case 6 & United States & $\begin{array}{l}\text { Citations are a mix of noise and pertinence. } \\
\text { Citations in US8131502, US8135561 and US8305363 are } 100 \% \text { noise. }\end{array}$ \\
\hline \multirow[t]{2}{*}{ All Cases } & Europe & $\begin{array}{l}\text { Citations may be a mix of noise and pertinence, } 100 \% \text { pertinent and } 100 \% \\
\text { noise. }\end{array}$ \\
\hline & $\begin{array}{l}\text { Europe \& United } \\
\text { States }\end{array}$ & $\begin{array}{l}\text { Citations may be a mix of noise and pertinence, } 100 \% \text { pertinent and } 100 \% \\
\text { noise. }\end{array}$ \\
\hline
\end{tabular}

Table 35: Summary of Noise Pertinence Types.

The data for each of the six cases from the cited technology patent citations group from Table 34 is presented in the form of a graph as shown in Figure 6 and provides a comparison between European cases and United States Cases for cited technology patent citations. 


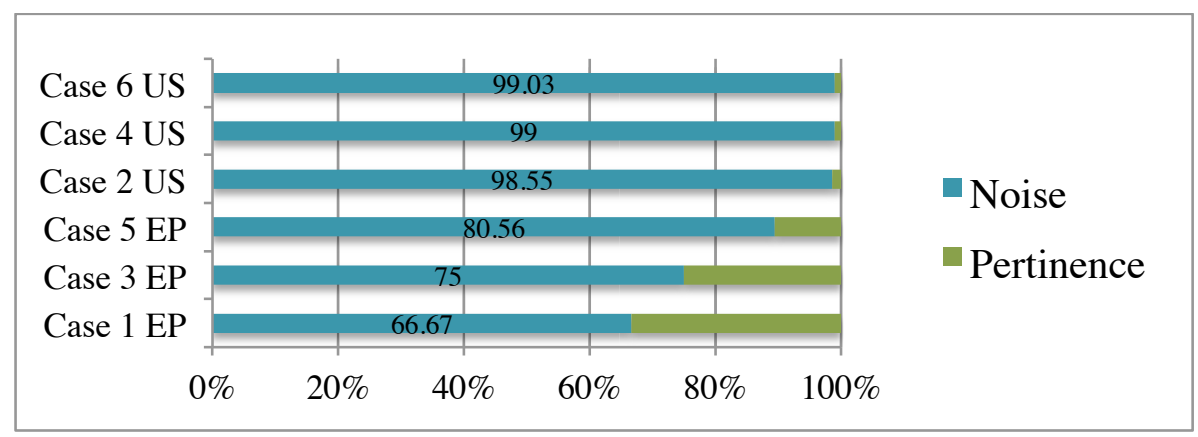

Figure 6: Cited Technology Patent Citation Noise \& Pertinence.

As shown in Figure 6 there is a significant amount of noise associated with the cited technology patent citation data for both the European and the United States cases. The range across the European cases is between $66.67 \%$ and $80.56 \%$. The range across the United States cases is between $98.55 \%$ and $99.03 \%$. This suggests overall that a larger portion of the cited technology patent citations do not form interdependency with the technology patent and the technology patent citation data contains a substantial amount of noise.

Another finding is that the amount of noise varies more between the cases in Europe more than the cases in the United States. The noise in the cited technology patent citation data is more consistent in the United States. The findings also suggest from an across case perspective the amount of noise in the cited technology patent citation data is higher in the United States cases when compared with the cases from Europe.

The graph presented in Figure 7 provides a comparison between the European cases and United States cases for citing technology patent citations. 


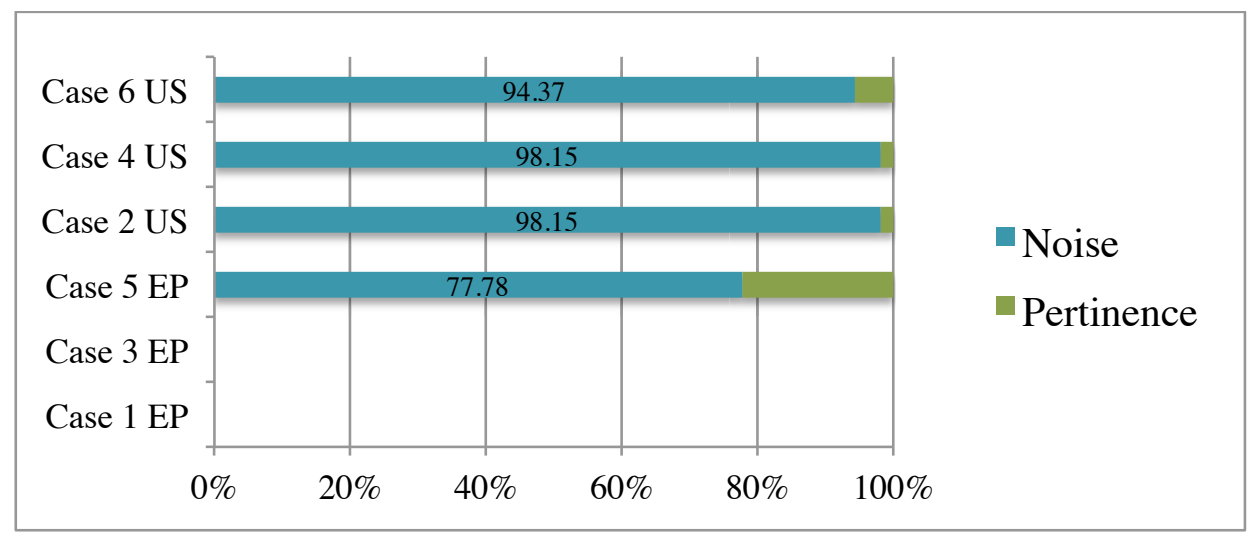

Figure 7: Citing Technology Patent Citation Noise \& Pertinence.

As shown in Figure 7, there is also a significant amount of noise associated with the citing technology patent citation data. For the one European case, there is $77.78 \%$ noise in the data. The range for the United States is between $94.37 \%$ and $98.15 \%$. This suggests overall that a larger portion of the citing technology patent citations do not form interdependency with the technology patent representing a substantial amount of noise.

The noise in the citing technology patent citation data is again consistent in the United States. The findings also suggest the amount of noise in the citing technology patent citation data is higher in the United States cases when compared to the one European case.

The graph presented in Figure 8 illustrates the results for all the European cases and provides a comparison for both the cited and citing technology patent citations in Europe. 


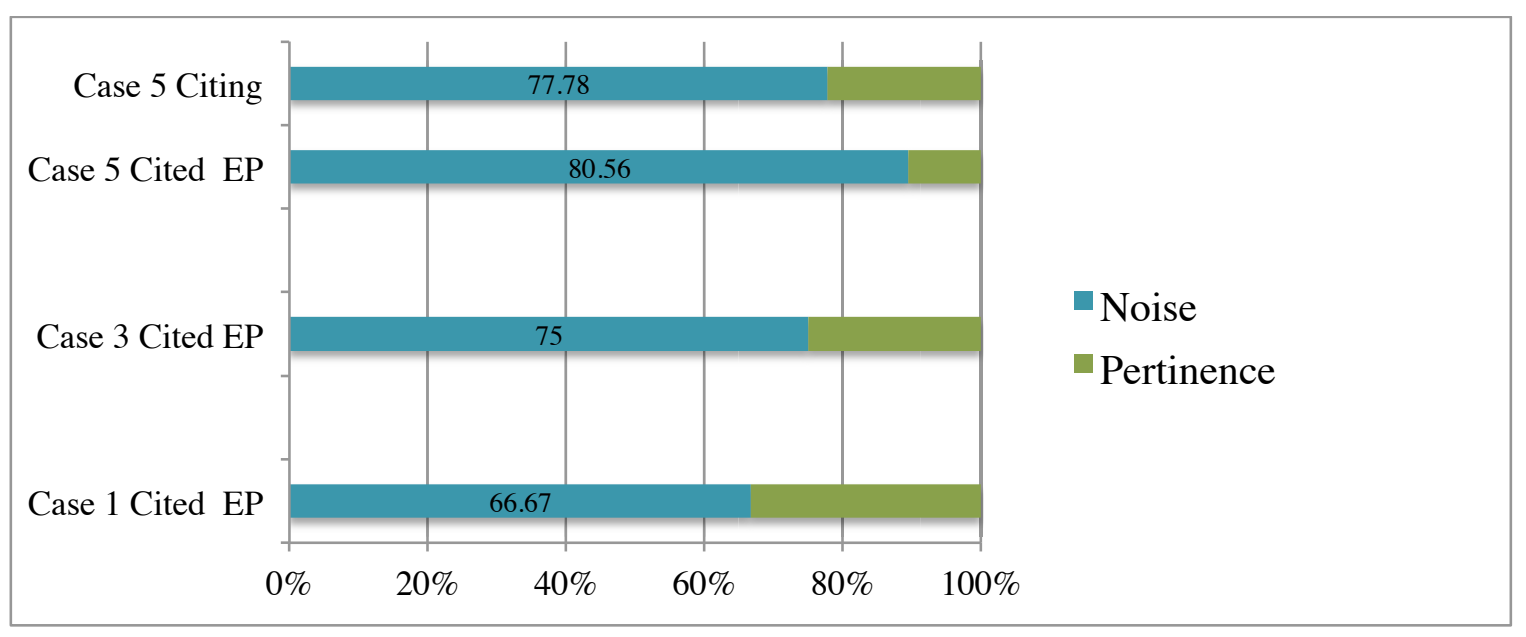

Figure 8: European Case Noise And Pertinence.

The results suggest that both the cited and citing technology patent citations for the European cases contain a substantial amount of noise and a less amount of pertinence or interdependency with the technology patent. Here we see the amount of noise in the European cases varies to some degree within a range.

The graph presented in Figure 9 show the results for all the United States cases and provides a comparison for the cited and citing technology patent citations in the United States.

The results suggest that both the cited and citing technology patent citations for the United States cases contain a substantial amount of noise greater than $94.37 \%$ and a less amount of pertinence or interdependency with the technology patent. The amount of noise here is less for the citing cases in the United States compared with the cited cases in the United States suggesting the cited technology patent citation data contains more noise that the citing technology patent citation data. 


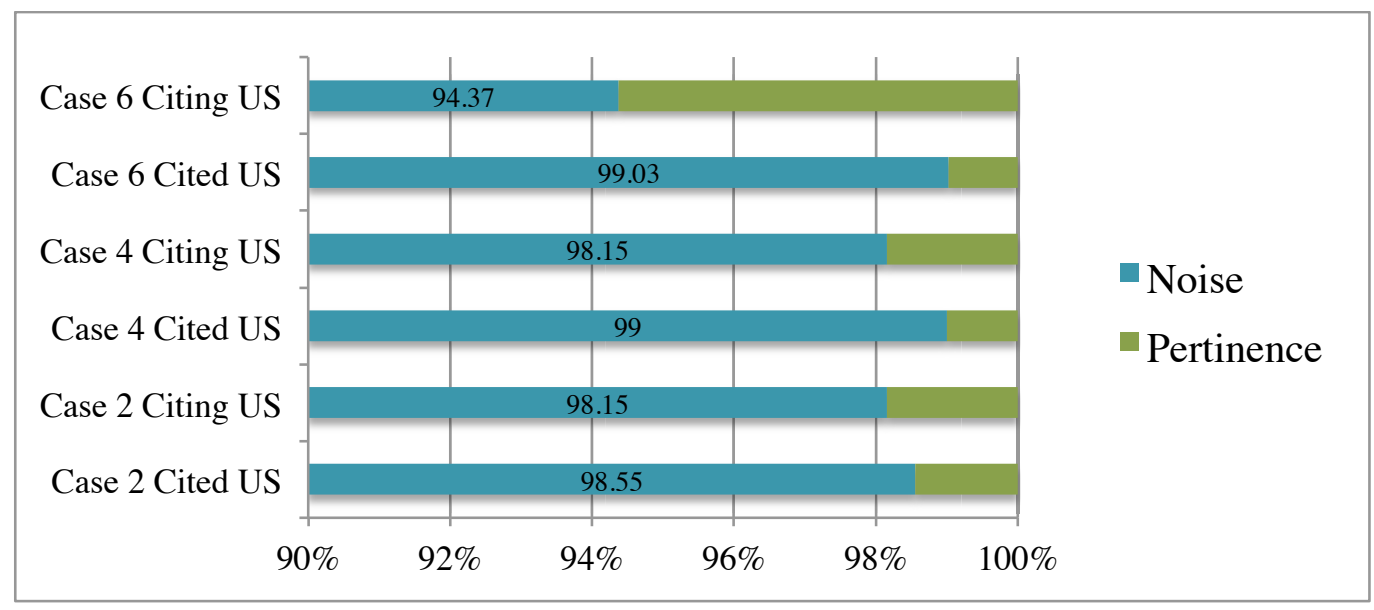

Figure 9: United States Cases Noise And Pertinence.

The graph presented in Figure 10 provides a combined comparison for the European cases the United States cases for both cited and citing technology patent citations.

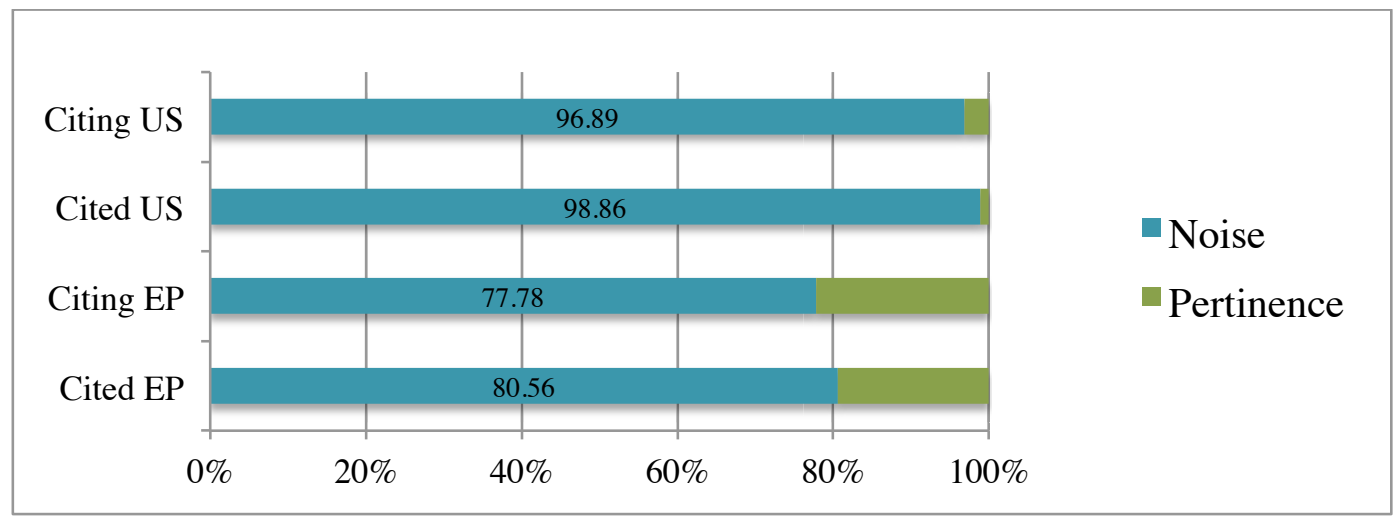

Figure 10: European And United States Noise And Pertinence.

Again, the results suggest the United States technology patent citations contain more nose and less pertinence than the European technology patent citations. Another finding is the amount of noise in the citing cases for both Europe and the United States is less then the amount of noise in the cited European and United States cases. 


\subsubsection{Summary Of Noise Pertinence Interdependency Ratio}

Technology patent citations may or may not form interdependency with the technology patent. When they form interdependency with the technology patent, the technology patent citation is pertinent. This results in two situations. Complete interdependency results in a refusal of the patent. Partial interdependency occurs when an amended claim is allowed. The technology patent citation is noise and there is no interdependency when the technology patent citation does not form interdependency with the technology patent.

There is more noise than pertinence in every one of the cases suggesting there are a small amount of interdependency between technology patent citations and a technology patent. The cited technology patent citations generally have more noise than the citing technology patent citations suggesting citing technology patent citations have more interdependency than cited technology patent citations.

\subsubsection{Noise Pertinence Ratio Interdependency Construct}

The noise pertinence ratio construct and attributes that emerged from the research are shown in Figure 11. The noise pertinence ratio has two attributes, the total number of technology patent citations and the number of technology patent citations causing a claim amendment. The total number of technology patent citations attribute is a count of the technology patent citations from the prior art citations construct. The number of technology patent citations causing a claim amendment attribute is a count from the claim amendment attribute of the technology patent interdependencies construct based upon the technology patent citation that caused a claim amendment. 


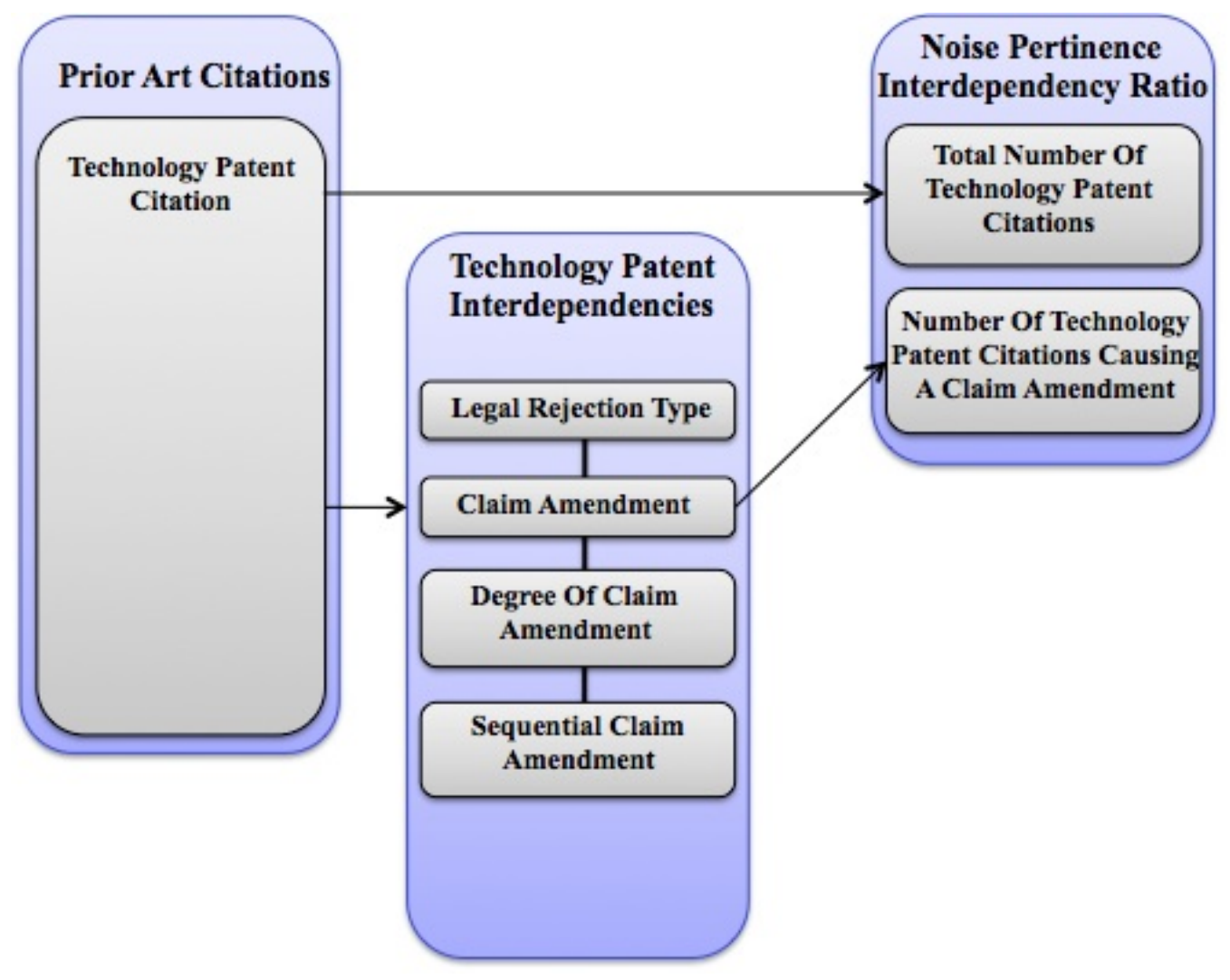

Figure 11: Emergence Of Noise Pertinence Ratio Construct.

\subsection{Dominant Technology Patent Citation Interdependency Ratio}

A second interdependency pattern emerged from the data in the form of a dominant technology patent citation interdependency ratio. The results and findings of a dominant technology patent citation interdependency ratio are presented in this section.

The results and findings for the "sole" dominant technology patent citation interdependency with the technology patent are next described. Then, the results and findings for the "pooled" dominant technology patent citation interdependency with the 
technology patent. This subsection concludes with a description of the dominant technology patent citation interdependency ratio construct.

\subsubsection{Sole Dominant Technology Patent Citation Interdependency}

The sole dominant technology patent citation interdependency is interdependency between one technology patent citation and one technology patent citation. Table 36 is a summary for the sole dominant cited technology patent citations data. Table 37 is for the sole dominant citing technology patent citations data. These tables are summaries from Tables 24 and 27 through 29 inclusive. The interdependency is dominant because there is only one pertinent citation that found interdependency with the technology patent.

The results further suggest that a dominant technology patent citation is readily identifiable from the larger sample of technology patent citations and noise for each technology patent. The results also suggest the degree of interdependency varies with different independent claims. The degree of similarity and corresponding interdependency between a technology patent citation and technology patent is higher in Europe when compared to the United States for cited citations. 


\begin{tabular}{lllll}
\hline Identification & Jurisdiction & $\begin{array}{c}\text { Dominant } \\
\text { Technology } \\
\text { Patent Citation }\end{array}$ & $\begin{array}{c}\text { Citation } \\
\text { Similarity }\end{array}$ & Sequence \\
\hline $\begin{array}{l}\text { Case 1 } \\
\text { EP1611503 }\end{array}$ & Europe & US2002036617 & $98.80 \%$ & 3 \\
\hline $\begin{array}{l}\text { Case 2 } \\
\text { US7256772 }\end{array}$ & United States & US6774889 & $97.75 \%$ & 3 \\
\hline $\begin{array}{l}\text { Case 3 } \\
\text { EP1766501 }\end{array}$ & Europe & WO200203316 & $87.50 \%$ & 2 \\
\hline $\begin{array}{l}\text { Case 4 } \\
\text { US7492357 }\end{array}$ & United States & US5315140 & 96.22 & 3 \\
\hline $\begin{array}{l}\text { Case 5 } \\
\text { EP1297488 }\end{array}$ & Europe & US4746770 & $69.72 \%$ & 4 \\
\hline $\begin{array}{l}\text { Case 5 } \\
\text { EP1739528 }\end{array}$ & Europe & WO199940562 & $98.70 \%$ & 7 \\
\hline $\begin{array}{l}\text { Case 6 } \\
\text { US7692625 }\end{array}$ & United States & US4746770 & 69.72 & \\
\hline
\end{tabular}

Table 36: Sole Dominant Technology Patent Cited Citation.

The degree of similarity and corresponding interdependency between a technology patent citation and technology patent is higher in Europe when compared to the United States for citing citations.

\begin{tabular}{|c|c|c|c|c|}
\hline Identification & Jurisdiction & $\begin{array}{c}\text { Dominant } \\
\text { Technology } \\
\text { Patent Citation }\end{array}$ & $\begin{array}{c}\text { Citation } \\
\text { Similarity }\end{array}$ & Sequence \\
\hline $\begin{array}{l}\text { Case } 4 \\
\text { US7492357 } \\
\text { citing } \\
\text { US7630002 }\end{array}$ & United States & US20050162381 & $63.52 \%$ & 2 \\
\hline $\begin{array}{l}\text { Case 5 } \\
\text { EP1297488 } \\
\text { citing } \\
\text { EP2089791 }\end{array}$ & Europe & US2004201575 & $100.00 \%$ & 1 \\
\hline $\begin{array}{l}\text { Case } 6 \text { US } \\
7692625 \text { citing } \\
\text { US8232511 }\end{array}$ & United States & US20050243070 & $100.00 \%$ & 2 \\
\hline $\begin{array}{l}\text { Case 6 } \\
\text { US7692625 } \\
\text { Citing } \\
\text { US8547327 }\end{array}$ & United States & US6624833 & $80.19 \%$ & 3 \\
\hline
\end{tabular}

Table 37: Sole Dominant Technology Patent Citing Citation.

The graph presented in Figure 12 illustrates the results for the European and United States cases for cited technology patent citations having a sole degree of 
interdependency. As shown in Figure 12, the interdependency is represented by the degree of similarity between the technology patent citation and the technology patent.

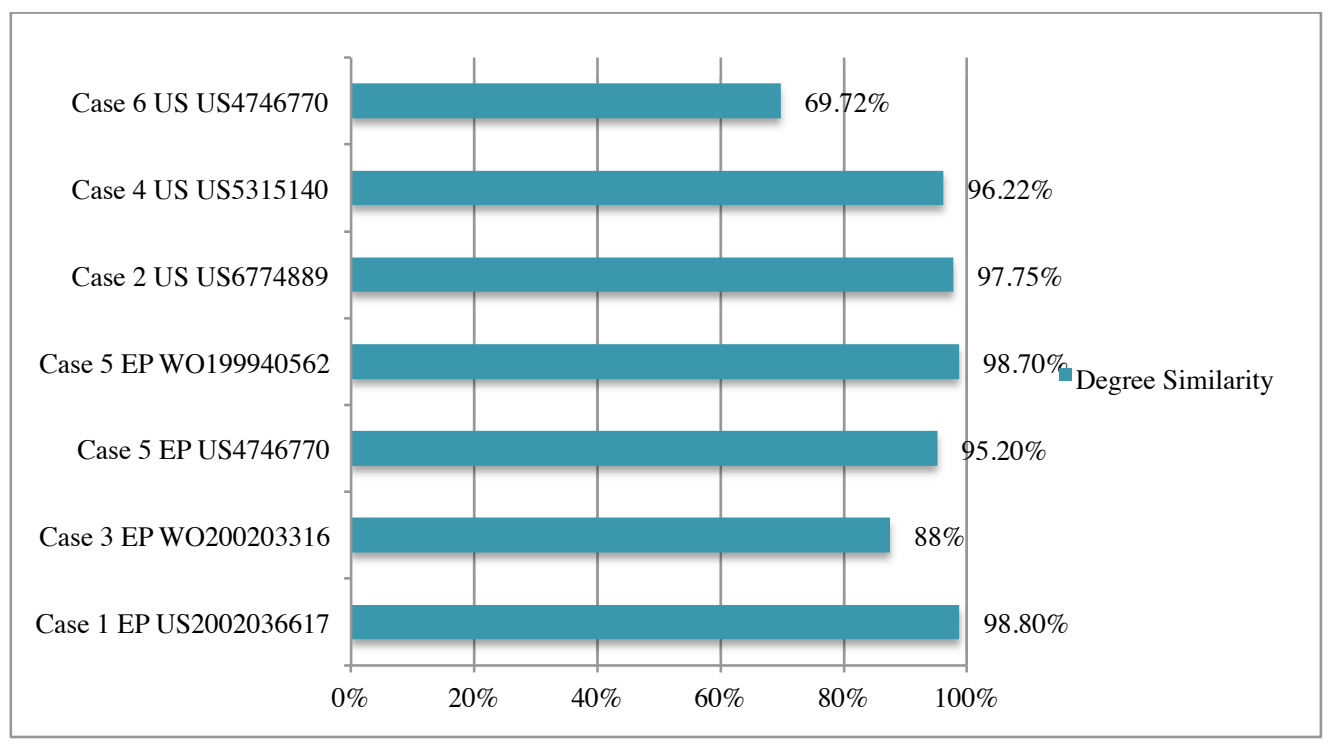

Figure 12: Sole Interdependency Cited Technology Patent Citations.

The range in the United States is between $69.72 \%$ and $97.75 \%$ similarity where the range in Europe is between $88.00 \%$ and $98.80 \%$. Another finding is the sole dominant cited technology patent citation has a similarity greater than $69.72 \%$ in the United States and greater than $88.00 \%$ in Europe. This suggests a higher degree of similarity and interdependency in Europe.

The graph presented in Figure 13 illustrates the results and provides a comparison between the European cases and the United States cases for citing technology patent citations having a sole degree of interdependency represented by the degree of similarity. This reveals the degree of interdependency between the citing technology patent citation 
and the technology patent across the citing cases. There is only once case in Europe that tends to limit the results and findings for the European case. The range in the United States is between $64.00 \%$ and $80.19 \%$. Another finding is the dominant citing technology patent citation has a degree of similarity greater than $64.00 \%$ in the United States suggesting a higher interdependency for the sole dominant citing technology patent citations in Europe.

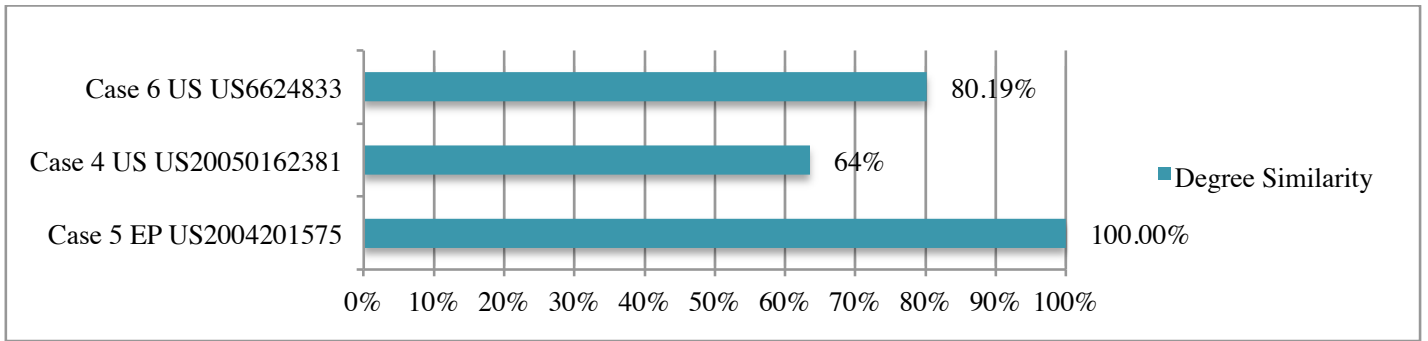

Figure 13: Sole Interdependency Citing Technology Patent Citations.

The graph in Figure 14 provides a comparison of the results for cited and citing technology patent citations for all European cases having a sole dominant technology patent citation. The degree of interdependency in Europe is higher for citing and less for cited based upon the degree of similarity between the dominant technology patent citations and the technology patent.

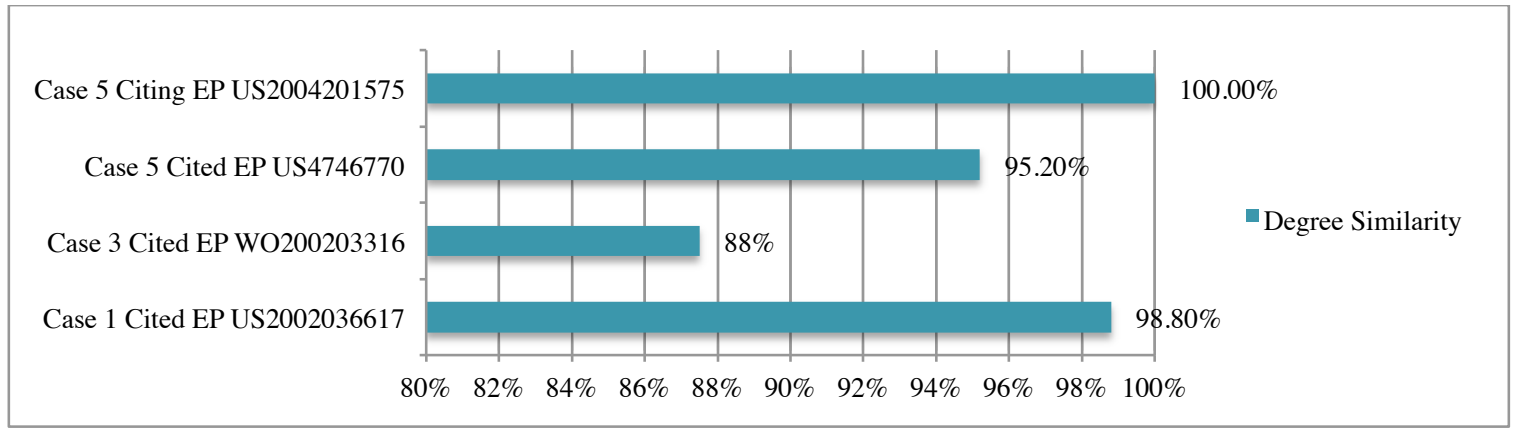

Figure 14: Comparison For Sole Interdependency In Europe. 
The graph in Figure15 provides a comparison of the results for cited and citing technology patent citations for all the United States cases. The degree of interdependency in the United States is generally higher for a cited technology patent citation and less for a citing technology patent citation.

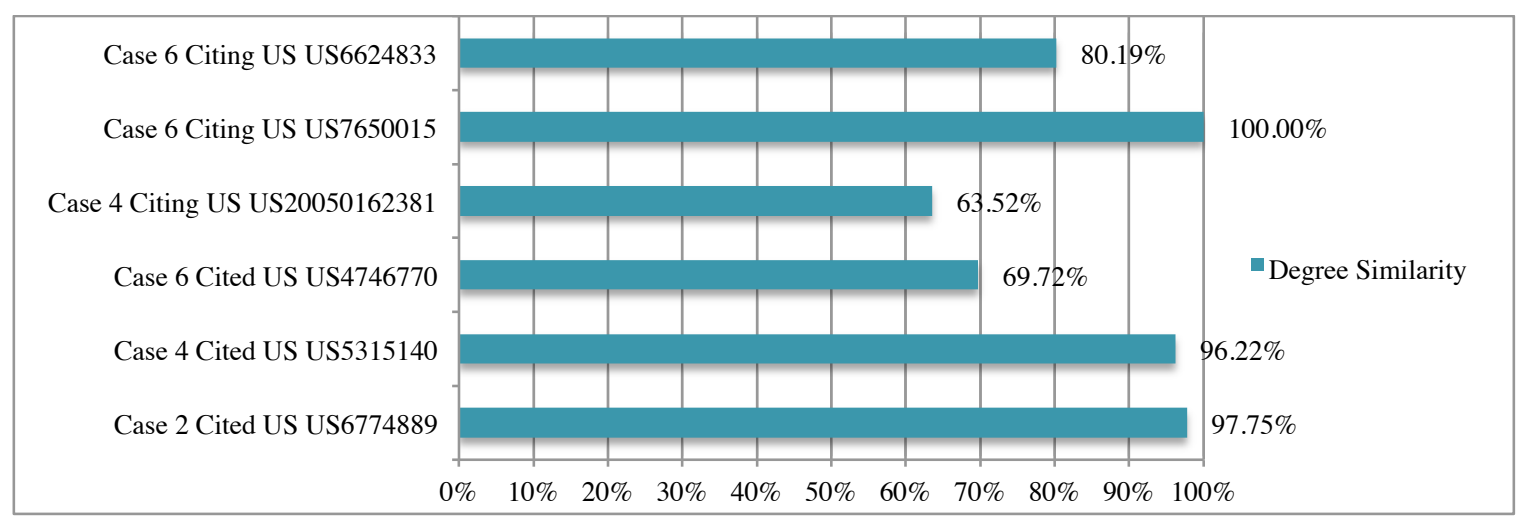

Figure 15: Comparison For Sole Interdependency In The United States.

The graph in Figure 16 provides a comparison of the results for the cited and citing technology patent citations for the European cases and the United States cases having a sole degree of interdependency. The degree of interdependency between the dominant technology patent citations in Europe is higher than the United States. The degree of similarity and interdependency is also less for a cited dominant technology patent citation and higher for a citing dominant technology patent citation in the United States, but is more for the citing dominant technology patent citation and less for the cited technology patent citation in Europe. 


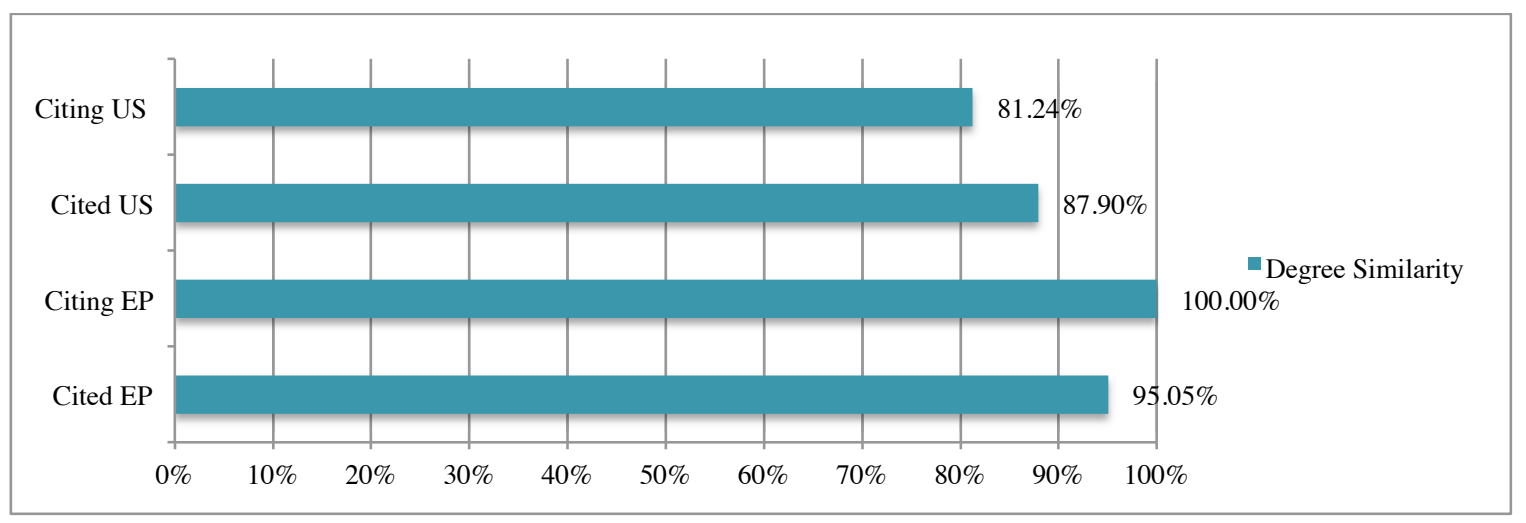

Figure 16: Comparison Of Sole Interdependency In Europe And The United States.

\subsubsection{Pooled Dominant Technology Patent Citation Interdependency}

The pooled dominant technology patent citation relates to the outcome where the interdependency is based upon a pooled legal rejection type. This is a relationship of more than one technology patent citation to one technology patent citation. Surprising, the technology patent cited citations did not result in any pooled dominant technology patent citations. Table 38 provides a summary for the pooled dominant citing technology patent citation interdependency with a technology patent. This table is based upon Table 24 and 27 through 29 inclusive. 


\begin{tabular}{|c|c|c|c|c|}
\hline Identification & Jurisdiction & $\begin{array}{c}\text { Dominant } \\
\text { Technology Patent } \\
\text { Citation } \\
\end{array}$ & $\begin{array}{c}\text { Citation } \\
\text { Similarity }\end{array}$ & Sequence \\
\hline Case 2 US7256772 citing US20120032922 & United States & US20050017957 & $50.96 \%$ & 2 \\
\hline Case 4 US7492357 citing US7630002 & United States & US20050162381 & $98.18 \%$ & 2 \\
\hline Case 5 EP1297488 citing EP2089791 & Europe & US2004201575 & $100.00 \%$ & 1 \\
\hline Case 6 US7692625 citing US7932899 & Unites States & US6727885 & $83.33 \%$ & 2 \\
\hline Case 6 US7692625 citing US8228304 & United States & US7084859 & $100.00 \%$ & 2 \\
\hline Case 6 US7692625 citing US8330726 & United States & US6803906 & $84.30 \%$ & 3 \\
\hline Case 6 US7692625 citing US8400415 & United States & US7456824 & $100.00 \%$ & 4 \\
\hline Case 6 US7692625 citing US8513546 & United States & US5896403 & $70.56 \%$ & 3 \\
\hline Case 6 US7692625 citing US8547327 & United States & US6624833 & $70.56 \%$ & 3 \\
\hline
\end{tabular}

Table 38: Pooled Dominant Technology Patent Citing Citation.

The graph presented in Figure 17 illustrates and provides a comparison of the results for the pooled dominant technology patent citation interdependencies. The degree of interdependency is represented by the degree of similarity for the dominant technology patent citations with respect to the independent claims for the technology patent. Again, the findings here are that the degree of interdependently in the United States cases tends to be less than the European cases.

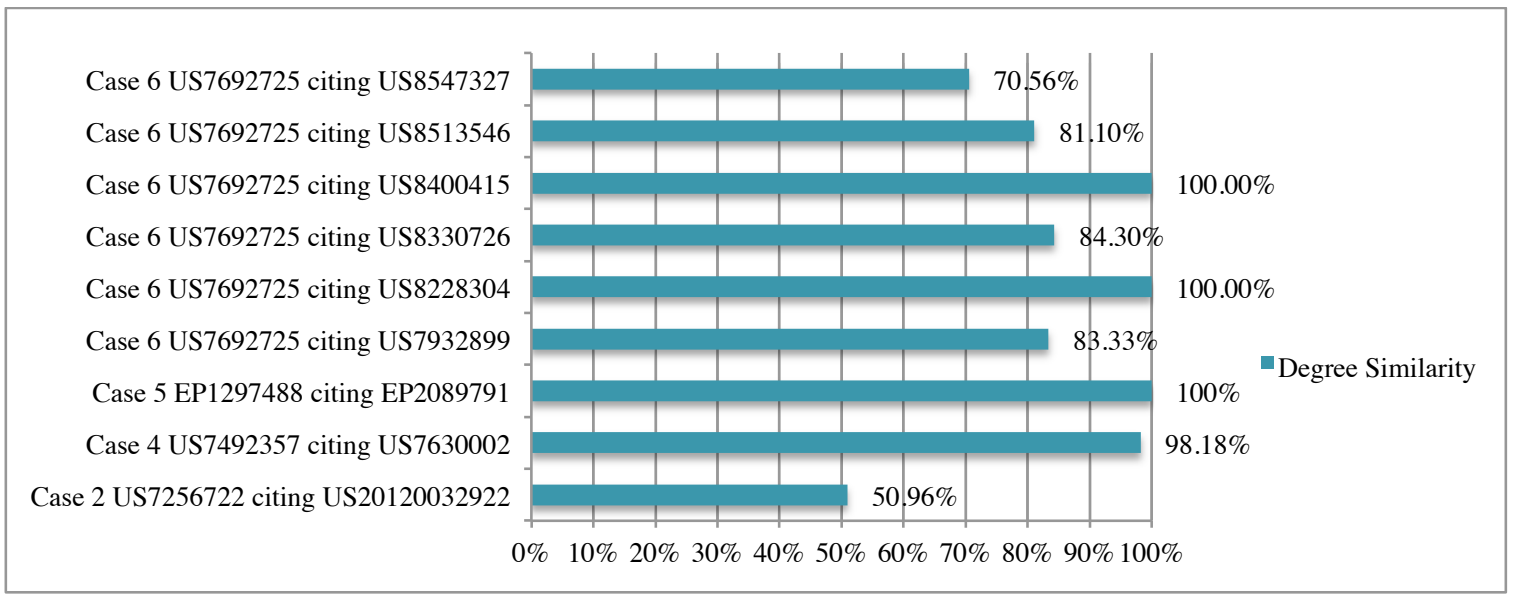

Figure 17: Pooled Dominant Technology Patent Citation Interdependencies.

The graph presented in Figure 18 provides a comparison of the results for the European cases with the United States cases for citing technology patent citations. The results 
suggest the European cases for citing pooled dominant technology patent citations have a higher interdependency with the technology patent than the United States cases.

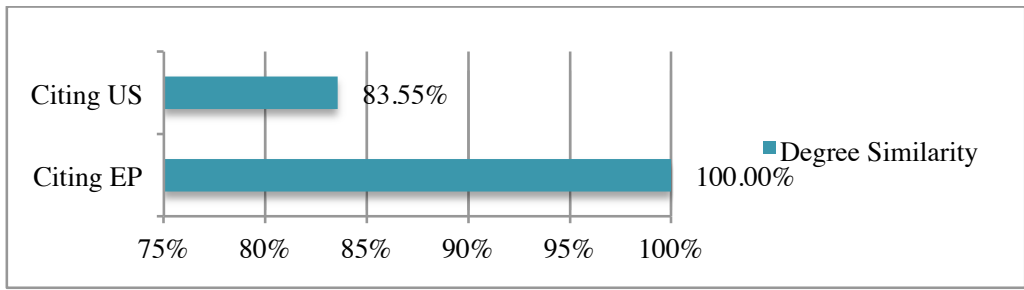

Figure 18: Pooled Comparison Between Europe and United States Cases.

\subsubsection{Summary Of Dominant Technology Patent Citation Interdependency Ratio}

Technology patent citations may form interdependency with the technology patent in one of two ways. The interdependency may a sole interdependency and the interdependency may be a pooled interdependency.

In each of the cases, there is one dominant technology patent citation having the greatest amount of similarity and interdependency with the technology patent. The dominant technology patent citation is identifiable for both the cases of sole interdependency and pooled interdependency. The degree of the claim amendment and the sequential claim amendment form the final amount of interdependency with the technology patent citation. The higher the sequential claim amendment, the lower the amount of interdependency between the technology patent citation and the technology patent.

Across the cases there is a higher similarity and interdependency of the technology patent cited and citing citations in the Europe when compared with the United States. The 
amount of similarity in Europe is less for cited citations when compared with citing citations. The amount of similarity in the United States is less for citing citations when compared with cited citations.

\subsubsection{Dominant Technology Patent Citation Interdependency Ratio Construct}

The dominant technology patent citation interdependency ratio construct and attributes that emerged from the research are shown in Figure 19. The construct has two attributes, the technology patent citations causing a claim amendment attribute and the technology patent citations similarity to the granted claim attribute. The technology patent citations causing a claim amendment are an identification of each technology patent citation that caused a claim amendment. The technology patent citation similarity to the granted claim attribute is the amount of similarity between the citation and claim of the patent.

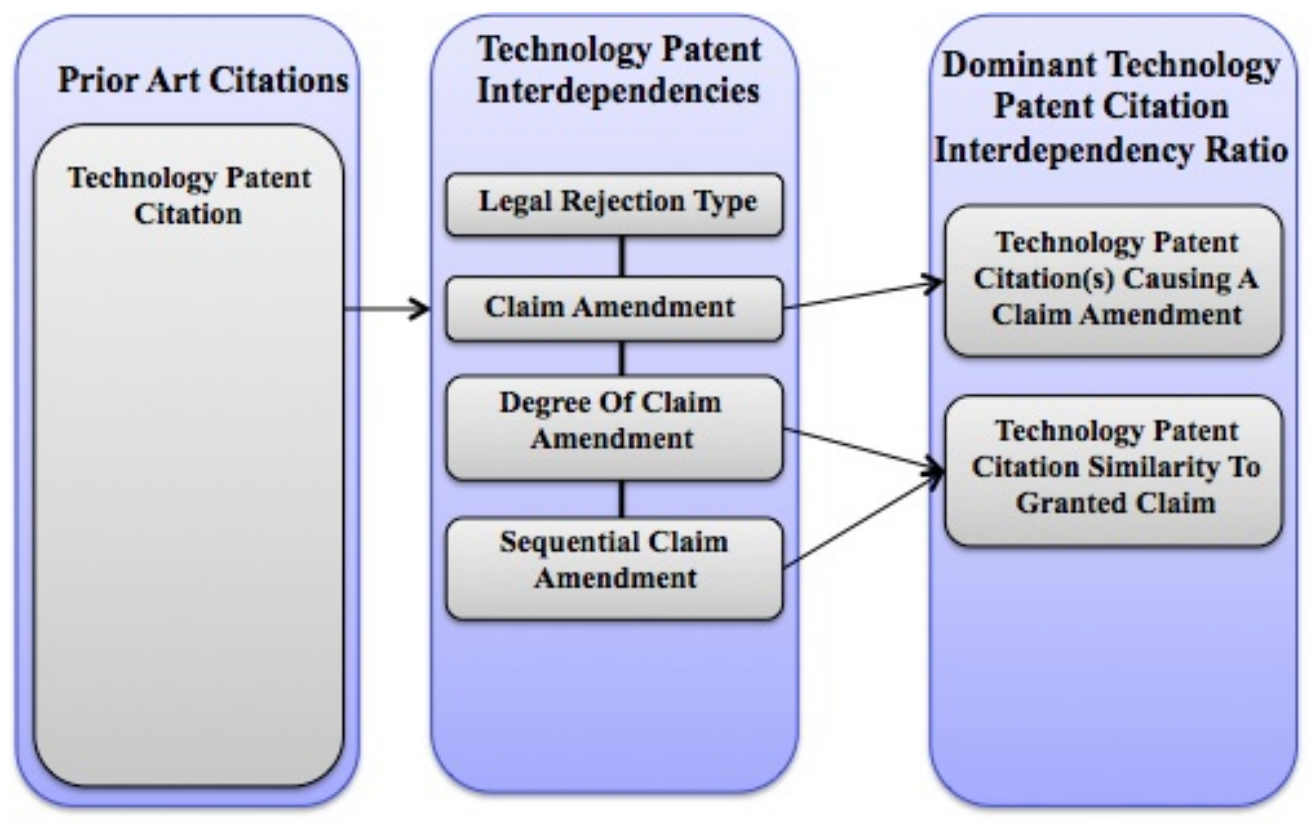

Figure 19: Dominant Technology Patent Citation Ratio Construct. 


\subsection{Summary Of The Results and Findings}

Chapter 4 presented the results and findings on this research. The results suggest technology patent citations may or may not form interdependencies with the associated technology patent. When technology patent citations form interdependencies, the interdependencies vary in the type of interdependency and in the degree of similarity with the technology patent.

The results further suggest that the interdependencies formed between a technology patent citation and a technology patent can refine technology patent citation data and identify the amount of noise and the amount of pertinence in the technology patent citation data. This further suggests that the ratios may be applied to remove noise by identifying the number of pertinent technology patent citations from the total number of technology patent citations and the dominant technology patent citation.

The key findings for technology patent citation noise and pertinence are summarized in Table 39.

\begin{tabular}{|c|c|c|}
\hline & Noise & Pertinence \\
\hline $\begin{array}{l}\text { Cited } \\
\text { Technology } \\
\text { Patent } \\
\text { Citations }\end{array}$ & $\begin{array}{l}\text { - The amount of noise varies more in the } \\
\text { European cases than the United States } \\
\text { cases. } \\
\text { The amount of noise is more consistent } \\
\text { in the United States cases. } \\
\text { The amount of noise is higher in the } \\
\text { United States cases when compared } \\
\text { with the European cases. }\end{array}$ & $\begin{array}{l}\text { - The amount of pertinence and associated } \\
\text { interdependency varies more in the } \\
\text { European cases than the United States } \\
\text { cases. } \\
\text { The amount of pertinence and associated } \\
\text { interdependency is more consistent in the } \\
\text { United States cases then the European } \\
\text { cases. } \\
\text { The amount of pertinence and associated } \\
\text { interdependency is lower in the United } \\
\text { States cases when compared with the } \\
\text { European cases. }\end{array}$ \\
\hline $\begin{array}{l}\text { Citing } \\
\text { Technology } \\
\text { Patent } \\
\text { Citations }\end{array}$ & $\begin{array}{l}\text { - The amount of noise is higher in the } \\
\text { United States cases when compared } \\
\text { with the European cases. }\end{array}$ & $\begin{array}{l}\text { - The amount of pertinence and associated } \\
\text { interdependency is lower in the United } \\
\text { States cases when compared with the } \\
\text { European cases. }\end{array}$ \\
\hline
\end{tabular}

Table 39: Summary Of Key Findings For Noise And Pertinence. 
The key findings for the dominant technology patent citation are summarized in Table 40 .

\begin{tabular}{|c|c|c|c|}
\cline { 2 - 4 } \multicolumn{1}{c|}{} & \multicolumn{1}{c|}{ Dominant Technology Patent Citation } \\
\cline { 2 - 4 } \multicolumn{1}{c|}{} & \multicolumn{1}{c|}{ Sole } & \multicolumn{1}{c|}{ Pooled } \\
\hline $\begin{array}{c}\text { Technology } \\
\text { Patent } \\
\text { Citations }\end{array}$ & $\bullet \begin{array}{l}\text { The degree of interdependency is lower in } \\
\text { the United States cases. } \\
\text { The degree of interdependency is higher in } \\
\text { the European cases. }\end{array}$ & $\begin{array}{l}\text { The cited technology patent citations did not } \\
\text { reveal any pooled dominant technology patent } \\
\text { citations. }\end{array}$ \\
\hline $\begin{array}{c}\text { Cechnology } \\
\text { Patent } \\
\text { Citations }\end{array}$ & $\bullet \begin{array}{l}\text { The degree of interdependency is high in } \\
\text { the United States cases. } \\
\text { The degree of interdependency is lower in } \\
\text { the European cases. }\end{array}$ & $\begin{array}{l}\text { The Degree of interdependency is lower in the } \\
\text { United Sates cases. } \\
\text { Degree of interdependency is higher for the } \\
\text { European cases. }\end{array}$ \\
\hline
\end{tabular}

Table 40: Summary Of Key Findings For Dominant Technology Patent Citations.

Other findings from the research include:

1. The technology patent citation noise is generally higher in the United States when compared to Europe. In addition, the sequence of claim amendments is generally higher in the United States cases when compared to European cases.

2. There is a high amount of noise and a small amount of pertinence in technology patent citation data suggesting most technology patent citations do not form interdependency with technology patents.

3. Significantly, when interdependency forms, there is one key dominant technology patent citation in the technology patent citations associated with a technology patent.

4. The United States cases experience a higher amount of noise in cited technology patent citations and a less amount of noise is citing technology patent citations.

5. The European cases experience a higher amount of noise in cited technology patent citations and a less amount of noise in citing technology patent citations. 
6. The amount of noise is generally higher in the United States cases when compared with the European cases and the amount of sequential claim amendments in the United States cases is higher than the European cases by a factor of 1.87. This suggests that the higher amount of overall noise in the United States cases is impacting the process and efficiencies at the United States Patent \& Trademark Office.

7. One dominant technology patent citation is identifiable from the noise associated with the technology patent citations when interdependency forms between a technology patent citation and the technology patent. 


\section{Discussion Of The Results}

Chapter 5 presents a discussion of the results, the important findings and connections to the extant literature on citation based patent evaluation methodologies. This chapter begins with a summary of the research and findings. This is followed by a discussion of research findings with respect to the extant literature. Then the theoretical connections are discussed through two examples comparing and contrasting citation dependent patent evaluation methodology extant theory with the results of this research. Next, the research contribution is described. Chapter 5 concludes with a summary of the results.

\subsection{Summary Of The Research And Findings}

Citation dependent patent evaluation methodologies require citation data in the form of a proxy to reveal the hidden attributes captured in and around a technology patent. This enables stakeholder business decision capabilities concerning a patent asset or assets.

However, citation data brings a problem with noise (Deng, 2008; Hall et al., 2005; Jaffe et al., 1993; Bacchiocchi \& Montobbio, 2010; Criscuolo \& Verspagen, 2008; Gay \& Le Bas, 2005; Gay et al., 2005; Hu \& Jaffe, 2003; Hu et al., 2012; Jaffee \& Trajtenberg, 2002; van Zeebroeck, 2011). The perspective of noise is the inability to detect relevant from irrelevant citations. This noise impedes a citation dependent patent evaluation methodology's ability to accurately reveal the hidden attributes. This limits the methodology's effectiveness and subsequent stakeholder business decision capability. 
This research went through a deep dive into the black box of patent data (Reitzig, 2004). Technology patent citations and the interdependency between technology patent citations and the corresponding technology patent were examined. The research answers the question and explains "How can the interdependencies formed between a technology patent citation and a technology patent improve citation dependent patent evaluation methodologies?"

The method followed by this research to address the citation noise problem and answer the research question is an empirical multi-case research approach. The research perspective is qualitative to explore, describe and explain the phenomenon. Guidance from Brown \& Eisenhardt (2011) was followed for the case analysis phase of the research method where tables and graphs were applied to visually assist with the analysis of complex qualitative data. Guidance from Bernard \& Ryan (2010) was followed for the data analysis approach pertaining to the qualitative historical documents concerning claim language and amendments. This assisted viewing this complex data and enabled logical comparisons of the qualitative data.

The most relevant findings are synthesized and illustrated in Figure 20. The research found technology patent citations contain a significant amount of noise. When a technology patent citation forms interdependency with the corresponding technology patent, it becomes pertinent. When the technology patent citation is independent from the technology patent, it is noise. This forms the basis for the noise pertinence interdependency ratio construct. 
Pertinent technology patent citations will include one sole dominant technology patent citation identifiable from the degree of interdependency. Pertinent technology patent citations may also optionally include secondary citations also identifiable from the degree of interdependency. This forms the basis for the dominant technology patent citation interdependency ratio construct.

The significant findings as illustrated in Figure 20 are synthesized and integrated with the research framework of Figure 2 to form the technology citation ratio interdependency framework that emerged from the data. This new framework is illustrated in Figure 21.

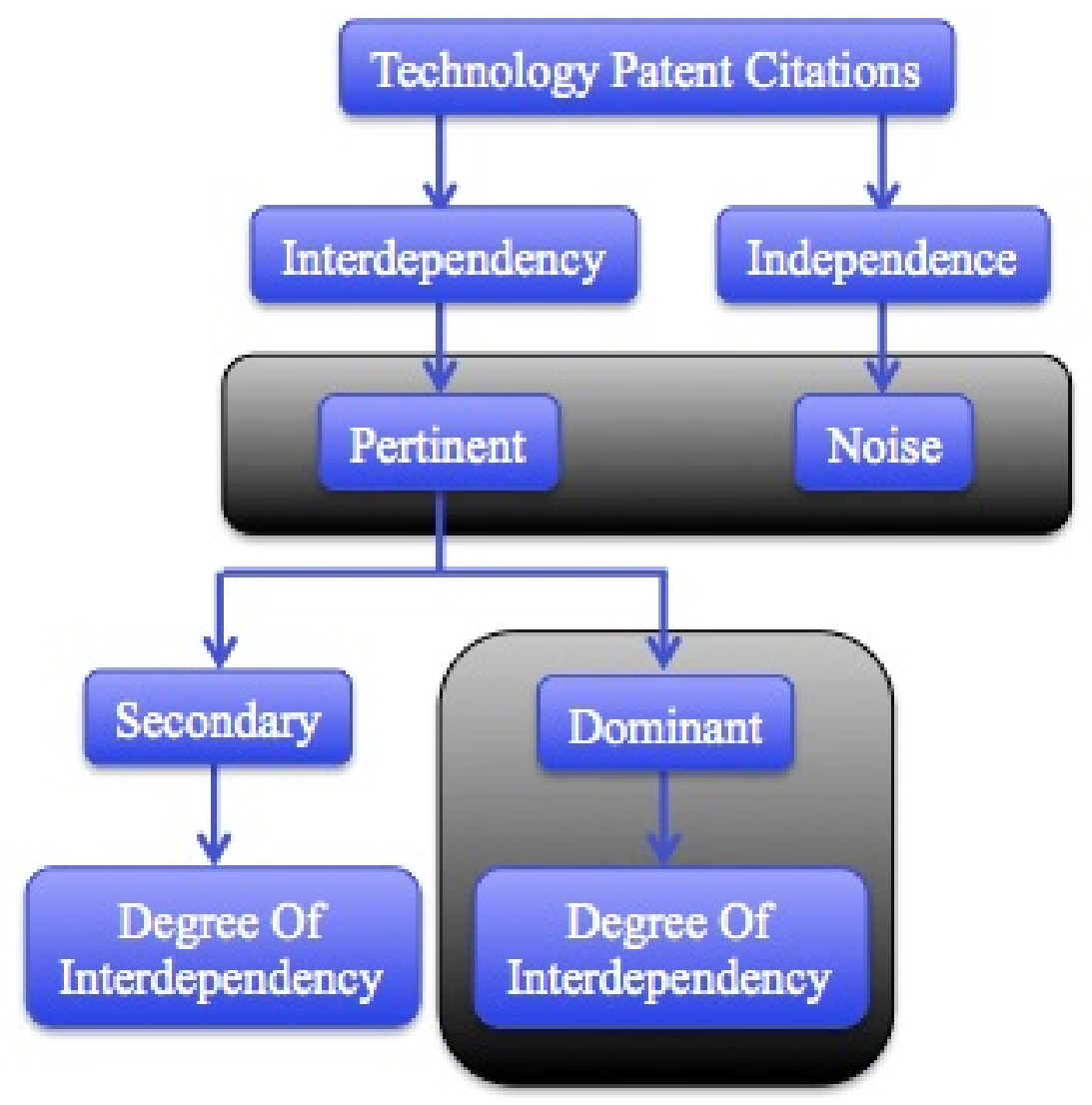

Figure 20: Summary Of Significant Findings. 
The noise pertinence interdependency ratio construct provides for the identification of noise and pertinence for technology patent citations. The dominant technology patent citation interdependency ratio construct provides for the identification of a dominant technology patent citation and the amount of interdependency between the dominant technology patent citation and the technology patent.

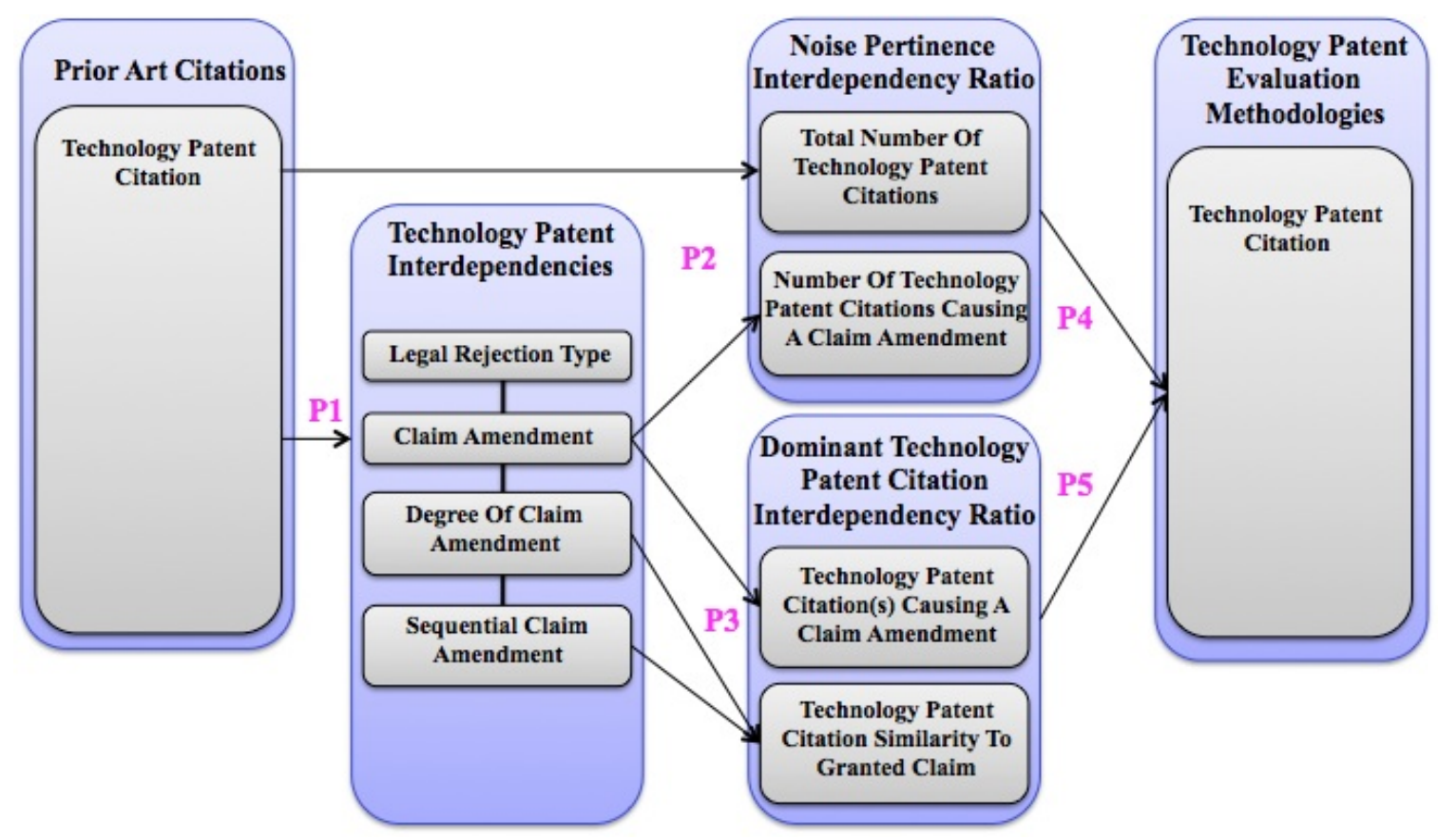

Figure 21: Technology Patent Citation Ratio Interdependency Framework. 
The following propositions are based upon the findings and formulated to include:

P1 - Technology patent citations may or may not form interdependency with the associated technology patent,

P2 - When technology patent citations form interdependency, the noise may be separated from the pertinent citations in the form of a noise pertinence interdependency ratio,

P3 - When technology patent citations form interdependency, the interdependencies vary in the type of interdependency and in the degree of interdependency. A dominant technology citation may be identified in the form of a dominant technology patent citation interdependency ratio,

P4 - The noise pertinence interdependency ratio improves a technology patent evaluation methodology that requires a frequency or count of technology patent citations, and

P5 - The Dominant technology patent citation interdependency ratio improves a technology patent evaluation methodology that requires a map or link of technology patent citations.

The most relevant findings from this research are as follows:

1) Technology Patent Citation Ratio Interdependency Framework:

a) A novel technology patent citation ratio interdependency framework that explains how to determine and apply the interdependencies between technology patent citations and technology patents and improve citation dependent patent evaluation methodologies through two novel constructs. The first novel construct is the 
noise pertinence interdependency ratio construct. The second novel construct is the dominant technology patent citation interdependency construct.

2) Noise Pertinence Interdependency Ratio Construct:

a) The novel noise pertinence interdependency ratio construct provides a first approach to identifying and separating noise from pertinence in technology patent citation data.

i) Noise in technology patent citation data is remarkably higher than suggested by the extant literature. The research further confirms the noise higher in the United States than in Europe (Gay \& Le Bas, 2005; van Zeebroeck, 2011; Criscudo \& Verspagen, 2008).

ii) There can be $100 \%$ noise in the technology patent citation data devoid of any interdependency between any technology patent citation and the corresponding technology patent.

iii) There is typically one pertinent technology patent citation in the data that forms interdependency with the corresponding technology patent.

iv) There is a high amount of noise and low amount of pertinence in technology patent citation data suggesting most technology patent citations do not form interdependency with technology patents.

v) Pertinent technology patent citations are identifiable in technology patent citation data. 
3) Dominant Technology Patent Citation Interdependency Ratio Construct:

a) The novel dominant technology patent citation interdependency construct provides a second approach to identifying and separating noise from pertinence and identifying the dominant technology patent citation in the technology patent citation data.

i) When interdependency forms, there is one dominant technology patent citation associated with a technology patent.

ii) Dominant technology patent citations are identifiable in technology patent citation data.

iii) Dominant technology patent citation interdependency is in a range greater than $0 \%$ up to and including $100 \%$.

4) Technology Patent Interdependency And Noise:

a) The interdependency between technology patent citations and the corresponding technology patent is lower in the United States when compared with Europe.

b) The sequence of patent examination in the United States is approximately twice that of Europe.

c) The amount of interdependency is higher in Europe when compared with the United States.

\subsection{Extant Literature \& The Research Findings}

Tracking knowledge flow through technology patent citations is one-way technology patent citations are applied in a citation dependent patent evaluation methodology 
(Bacchiocchi \& Montobbio, 2010; Hu \& Jaffe, 2003; Gay \& Le Bas, 2005; Jaffee \& Trajtenberg, 2002). In this application the citations and technology patents are tracked with their frequency in a patent map or network nodal analysis approach. These citation links may also reveal and identify regions, countries, technologies (Bacchiocchi \& Montabbio, 2010), actors (Gay \& Le Bas, 2005) and knowledge exchange between actors (Hu \& Jaffe, 2003). These citation links may also reveal the internal (Firm self cited) and external (other cited) flow of knowledge (Bapuji et al., 2011). Tracking also reveals the distribution of knowledge between inventors and firms (Hall et al., 2005) associated in the technology patent citation network.

Assessing technological, or invention value through technology patent citations is another way citations are applied in a citation dependent patent evaluation methodology (Nikulainen et al., 2008; Jaffee \& Trajtenberg, 2002). A lower frequency of citations suggests a low basicness and high technological significance. A high frequency of citations suggests a high basicness and invention of low technological significance. Higher citation rates in other areas of technological files or classifications also suggest a higher significance of the invention (Hu et al., 2012; Jaffee \& Trajtenberg, 2002). A higher number of citing technology patent citations suggests a high potential or breakthrough innovation (Kelley et al., 2013). Cited technology patents suggest the degree of novelty and inventiveness (Reitzig, 2003).

Assessing the potential patent value through technology patent citations is yet another way citations are applied in a citation dependent patent evaluation methodology. A 
higher frequency of citing technology patent citations suggests a higher value to appropriate and broader application of the invention (van Zeebroeck, 2011). A higher importance of a patent portfolio is suggested by a higher frequency of citing technology patent citations (Deng, 2008; Jaffe et al., 1993).

The extant literature assumes that relevance exists between the technology patent citations and the technology patent. This is merely based upon the citation being listed with the technology patent. However, the results of this research suggest that there may or may not be any relevance in the form of pertinence between the technology patent citations and the corresponding technology patent. This lack of pertinence may be absolute across all technology patent citations, or the lack of pertinence may be selective across the technology patent citations. Many scholars have also identified the problem with noise in technology patent citation data. In particular, the relevance or lack of relevance of each citation with a patent. This suggests the extant theories based upon technology patent citation data for tracking knowledge flow, technological value or patent value in citation dependent patent evaluation methodologies are problematic at least and concerning at best due to the citation noise.

\subsubsection{Technology Patent Citation Interdependency Framework}

Extant literature concerning citation dependent patent evaluation methodologies suggests the technology patent citation data including the noise from the prior art citations construct feeds directly into the technology patent evaluation methodologies construct. 
The technology patent citation interdependency framework includes three intermediate constructs between the prior art citation construct and the technology patent evaluation methodologies construct. The technology patent interdependency construct contains attributes that reveal interdependency between technology patent citations and the corresponding technology patent. The noise pertinence interdependency ratio construct identifies the noise and the pertinence in the technology patent citations. This may be applied as technology patent citation data for technology patent evaluation methodologies that require a count or frequency of technology patent citations. The dominant technology patent citation interdependency ratio construct identifies the noise. The dominant technology patent citation may be determined from technology patent citation data. Technology patent evaluation methodologies that track technology patent citations in a patent map or network nodal analysis approach benefit from the dominant citation.

\subsubsection{Noise Pertinence Interdependency Ratio Construct}

The results of this research suggest technology patent citations may or may not form interdependency with the corresponding technology patent. Key to detecting the presence or absence of interdependency is a claim amendment accepted and entered into the prosecution history data. When interdependency is present, the technology patent citation(s) causing the amendment is identified as a count of the citation(s) forming interdependency. A count of the total number of technology patent citations referenced with the technology patent is also provided to the noise pertinence interdependency ratio construct. The ratio is then determined by the total count of technology patent citations 
and the count of technology patent citations that have interdependency with the technology patent.

The noise pertinence interdependency will be $100 \%$ when all the technology patent citations are noise without any interdependency. The noise pertinence interdependency will be $0 \%$ if all the technology patent citations are pertinent having interdependency. The ratio will be in the range of $1 \%$ to $99 \%$ depending upon the mix and ratio of noise and interdependency. The noise varies from technology patent to technology patent, but when interdependency forms, there is always at least one pertinent technology patent citation. This ratio permits comparison of like technology patent citations to like technology patent citations.

The noise pertinence interdependency ratio is then applicable to a technology patent evaluation methodology where the methodology is improved by having a number of pertinent technology patent citations and indication to the amount of noise and pertinence in the technology patent citations.

\subsubsection{Technology Patent Citation Interdependency Ratio Construct}

The technology patent citation interdependency ratio requires a technology patent citation that formed interdependency with the technology patent. This is indicated by a claim amendment accepted and entered into the prosecution history data. 
When interdependency is present, the technology patent citation(s) and legal rejection type and claim amendment are identified. The degree of claim amendment, or amount of change in the claim language to move away from the technology patent citation and the number of sequences are provided to the technology patent citation interdependency ratio. Then, for each technology patent citation causing a claim amendment, the technology patent citation similarity to the granted claim is determined.

The dominant technology patent citation interdependency ratio is then applicable to a technology patent evaluation methodology where the methodology is again improved. The methodology is improved by having an indication to the dominant citation and the amount of interdependency between the technology patent citation and the technology patent without any associated noise.

\subsection{Theoretical Connections}

The theoretical connections are described through two brief examples. The first example is a citation dependent patent evaluation methodology to track knowledge flow through a citation network to reveal relevant technologies and actors indirectly associated with a technology patent. The second example is a citation dependent patent evaluation methodology to assess patent or technological and inventive value of a small sample of technology patents. 


\subsubsection{Tracking Knowledge Flow}

Case 4 US7492357 citing is selected for this first example and theoretical connection. A diagram of the cited and citing technology patents surrounding the key technology patent US7492357 is shown in Figure 22. The key technology patent US7492357 has 65 cited technology patent citations illustrated as rectangles. Case 4 is also citing 4 technology patents illustrated as ovals. The blue circles on the left are a count of the cited technology patent citations and on the right is a count of the citing technology patent citations within this portion of a citation network.

This type of citation based technology patent evaluation is generally applied to evaluate knowledge flow to identify and target other firms and actors indirectly associated with the key technology patent US7492357.

Extant theory suggests that there are 65 relevant technologies and actors indirectly associated with the key technology patent identified in the citied technology patent citations. Extant theory also suggests that the key technology patent US7492357 is indirectly associated with 4 other technologies and actors identified in the citing technology patent citations. 


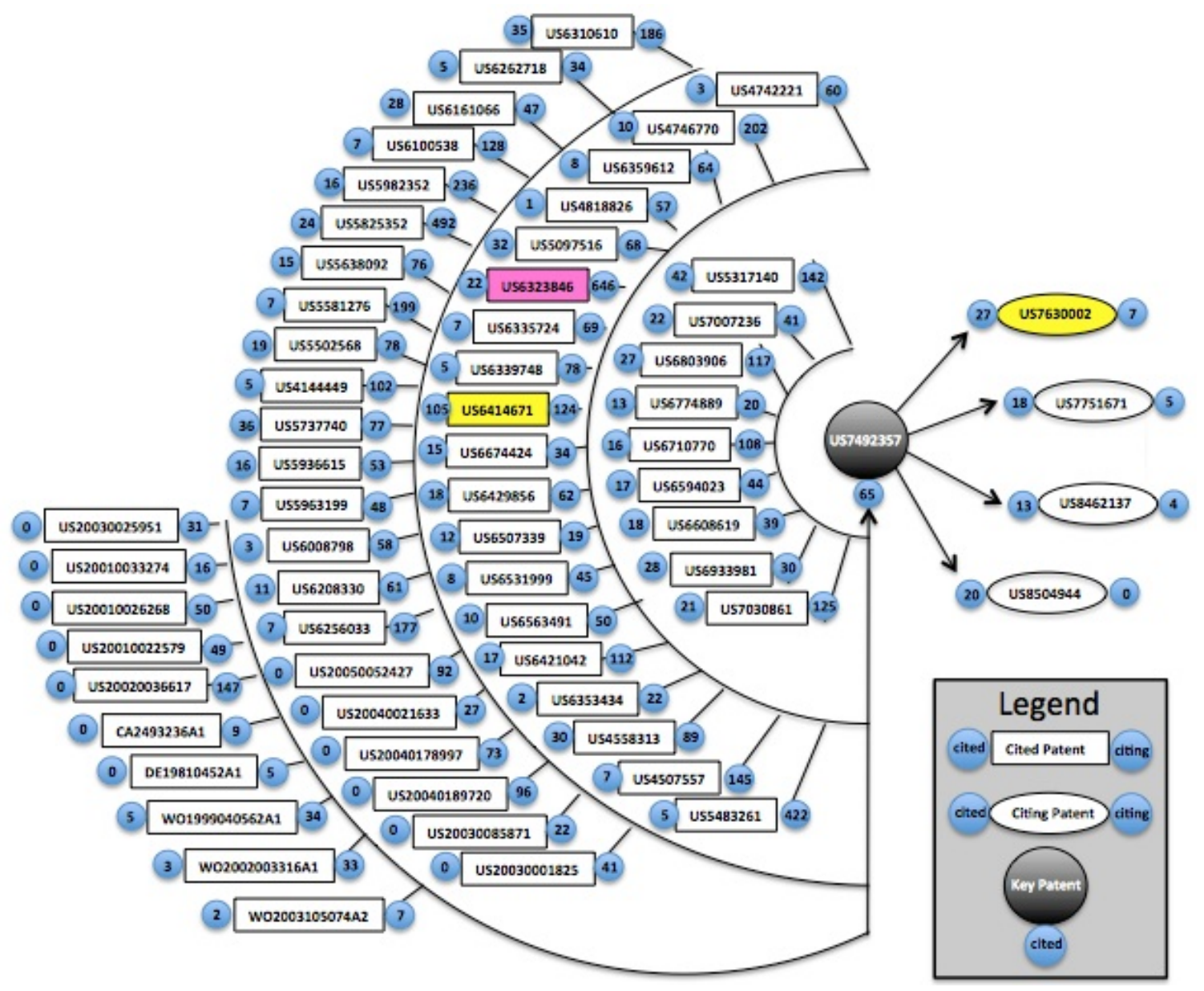

Figure 22: Previous Approach To Evaluate Technology Patents.

Applying extant theory to this example suggests there are three technology patent citations of higher value or importance associated with the key technology patent that may be of significance. These citations are identified as US6323846 because it has the highest number of citing citations at 646, US6414671 because it has the highest number of cited citations at 105, and US7630002 because it has the highest number of citing citations at 27. 
Applying the technology patent citation ratio interdependency framework and associated constructs of this research reveals a very different result to this example. Extant theory and this research agree that technology patent citations are noisy. This is clearly a problem with citation dependent patent evaluation methodologies. The technology patent citation ratio interdependency framework is applied to Case 4 in this example. The noise pertinence interdependency ratio for the key technology patent US7492357 and 65 cited technology patent citations are $98.5 \%$ noise and $1.5 \%$ pertinence.

In sharp contrast to extant theory, this suggests there is a very small amount of knowledge flow from the cited technology patent citations network into the key technology patent US7492357. It further suggests that identifying other relevant technology or the key actor(s) or firm(s) is highly obscured in the noise.

The noise pertinence interdependency ratio for the 4 citing technology patent citations relating to the key technology patent US7492357 is as follows. US7630002 is $96.93 \%$ noise and $3.07 \%$ pertinence, US7751671 is $100 \%$ noise, US8462137 is $100 \%$ noise and US8504944 is $100 \%$ noise. That suggests that three of the citing technology patents are simply noise and unrelated to the key technology patent US7492357. It further suggests that there may be a relationship to the US7630002 citing technology patent.

However, the pertinence with US7630002 is with US20050162381 and not the US7630002 patent. The dominant technology patent citation interdependency ratio for the cited technology patent citation and key technology patent US7492357 is $96.22 \%$ 
interdependency and $3.78 \%$ independence. The dominant technology patent citation is also identified as US5317140. There is no interdependency between the key technology patent US7492357 and the citing technology patent citations. The US7630002 patent is noise with respect to the citing technology patent.

The results of applying the technology patent citation ratio interdependency framework and associated constructs are shown in Figure 23. The noise has been removed from the citation data. The dominant technology patent citation has been identified with the associated link in the citation network to the key technology patent US7492357. The interdependency between the technology patent citation US5317140 and the key technology patent US7492357 is $96.22 \%$. This suggests the key technology patent is an incremental improvement of the technology patent citation and a strong tie with knowledge flow between the corresponding inventions. Secondary hidden information reveals the actor associated with the technology patent citation. 


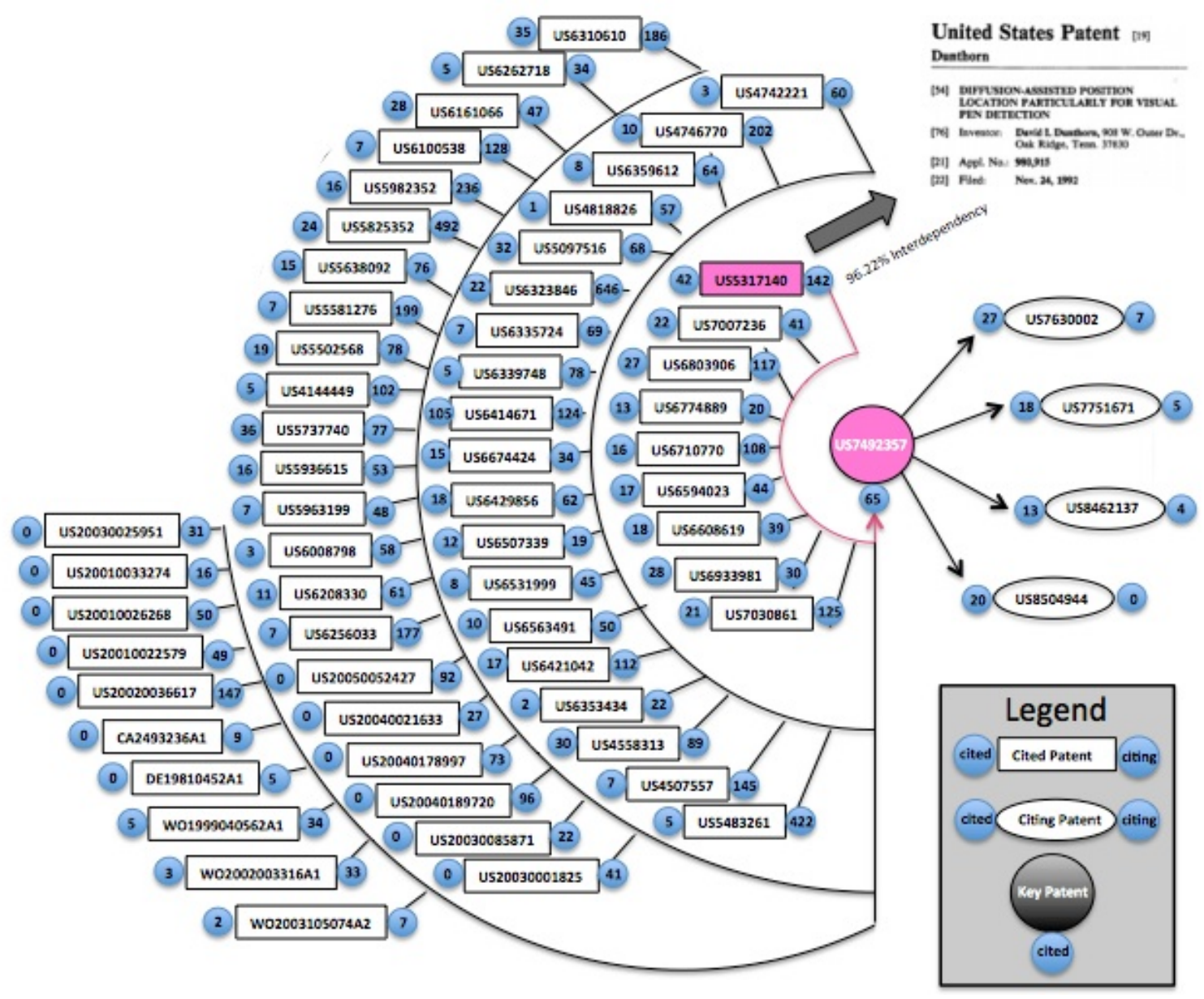

Figure 23: Refined Citation Data Example Patent Evaluation Methodology.

In summary, extant theory appears limited in the ability to track knowledge flow in a citation network of a citation based patent evaluation methodology. This is due to the significant amount of noise inherent in technology patent citation data. This further appears to limit identifying the relevant actors and firms from within the noise. A citation count or frequency is also seriously limited in the ability to identify a degree of basicness or level of innovation due to the amount of citation noise. Extant theory would suggest the key technology patent is a relatively basic invention due to the amount of 
cited technology patent citations (65) but there is only one relevant technology patent citation (pertinent).

The results go against the teachings of the extant theory. Application of this research framework further suggests the key technology patent is a basic incremental invention. However, that suggestion is based upon the dominant technology patent citation interdependency ratio and in particular, the $96.22 \%$ interdependency between the dominant technology patent citation and technology patent. This interdependency also leads to the identification of a highly relevant actor and associated technology.

\subsubsection{Patents And Technological Or Inventive Value}

The next example is based upon Case 5 of this research and includes Cited EP1739528, Cited EP1738529, Cited EP1297488 and Citing EP208971. This is shown in Figure 24.

This type of citation based technology patent evaluation is generally applied to assess relative technological or invention value of a patent when applying cited technology patent citations in the citation based patent evaluation methodology. The other aspect of this type of citation based technology patent evaluation is generally applied to assess the relative ability to appropriate a patent when applying citing technology patent citations in the citation based patent evaluation methodology. 


\section{Extant Theory - Technological Inventive Value}

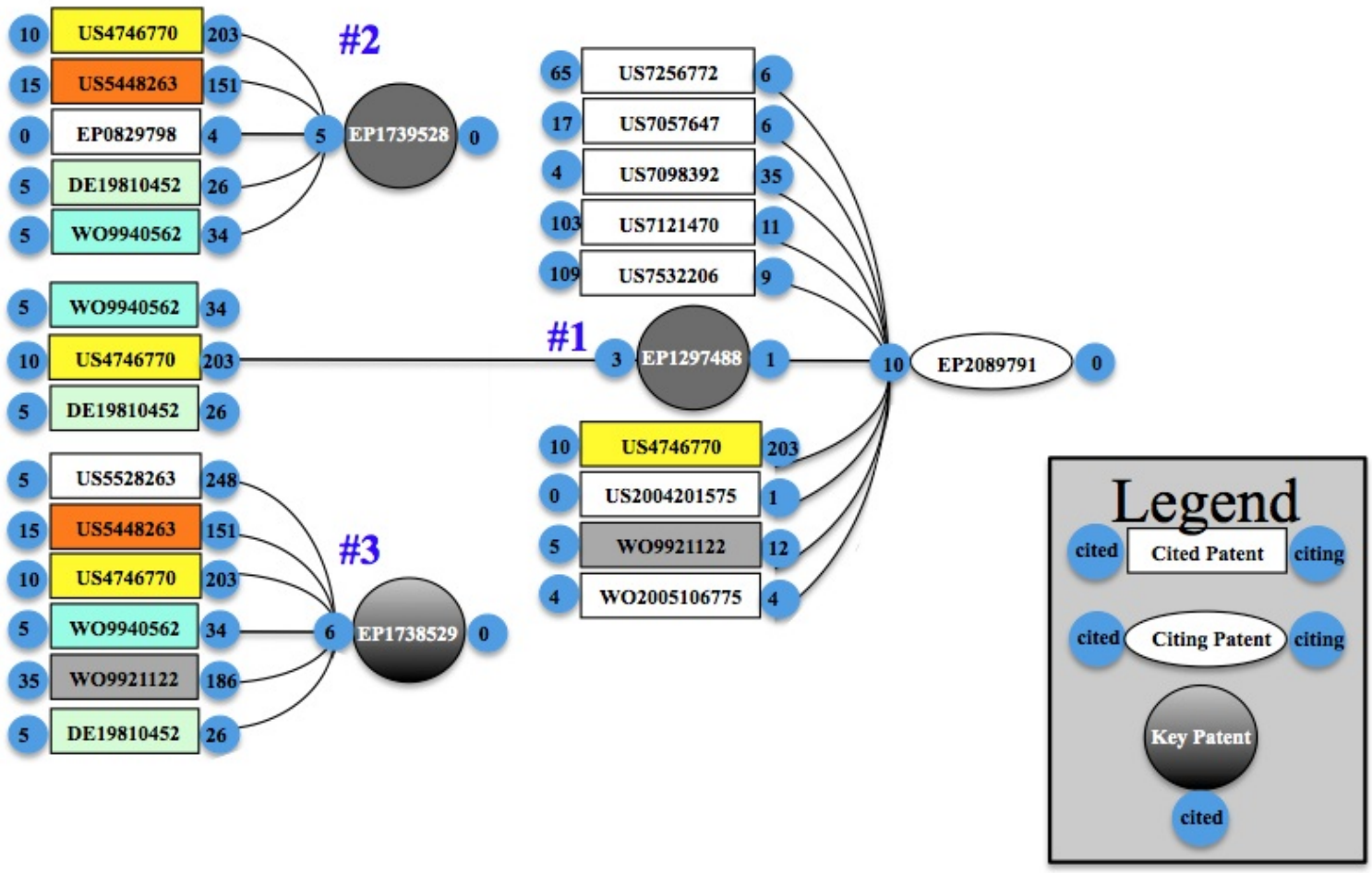

Figure 24: Patent Portfolio Evaluation Example.

Technology patent EP1739528 has five cited technology patent citations without any citing citations. Technology patent EP1738529 has six cited technology patent citations without any citing citations. Technology patent EP1297488 has three cited technology patent citations and one citing citation to EP208971 in combination with nine other technology patent citations.

This example first assesses the three patents (EP1739528, EP1738529 and EP1297488) in accordance with extant theory. This is to determine the relative technological or inventive value for each of the three patents and the relative future value. 
The relative technological or inventive value is based upon a count of the cited technology patents associated with each of the three patents. EP1297488 has the highest relative technological or inventive value as it has the lowest number (three) of technology patent citations. EP1739528 has the next highest relative technological or inventive value with the number of technology patent citations being five and EP1738529 has the lowest relative technological or inventive value with the highest number of cited technology patent citations (six).

Applying extant theory to the question or relative appropriability, EP1297488 has the highest potential future value, as this patent is the only one of the three with a citing citation to EP2089791.

Applying the technology patent citation ratio interdependency framework and associated constructs of this research reveals a very different outcome as well. The results from Case 5 of this research are applied to this second example. This is shown in Figure 25.

The noise pertinence interdependency ratio for EP1739528 is $80 \%$ noise and $20 \%$ pertinence. The noise pertinence interdependency ratio for EP1297488 is $66.67 \%$ noise and $33.33 \%$ pertinence. The noise pertinence interdependency ratio for EP1738529 is $100 \%$ noise. 
Therefore, we know EP1738529 does not have a dominant technology patent citation and relatively speaking against the other two European patents, EP1738529 has the highest relative technological or inventive value when compared against the other two European patents as none of the six cited technology patent citations formed interdependency with EP1738529.

The dominant citation technology patent citation interdependency ratio for EP1739528 is identified as WO199940562 with an interdependency of $98.70 \%$. The dominant citation technology patent citation interdependency ratio for EP1297488 is identified as US474670 with an interdependency of $95.20 \%$.

Therefore, as a result of applying the technology patent citation ratio interdependency framework and associated constructs of this research, EP1738529 has the highest relative technological or invention value, EP1297488 has the next relative technological or invention value and EP1739528 has the lowest relative technological or invention value. This is completely different from the results of applying extant theory to the Case 5 example. 


\section{Extant Theory - Technological Inventive Value}

\section{Research - Technological Inventive Value}

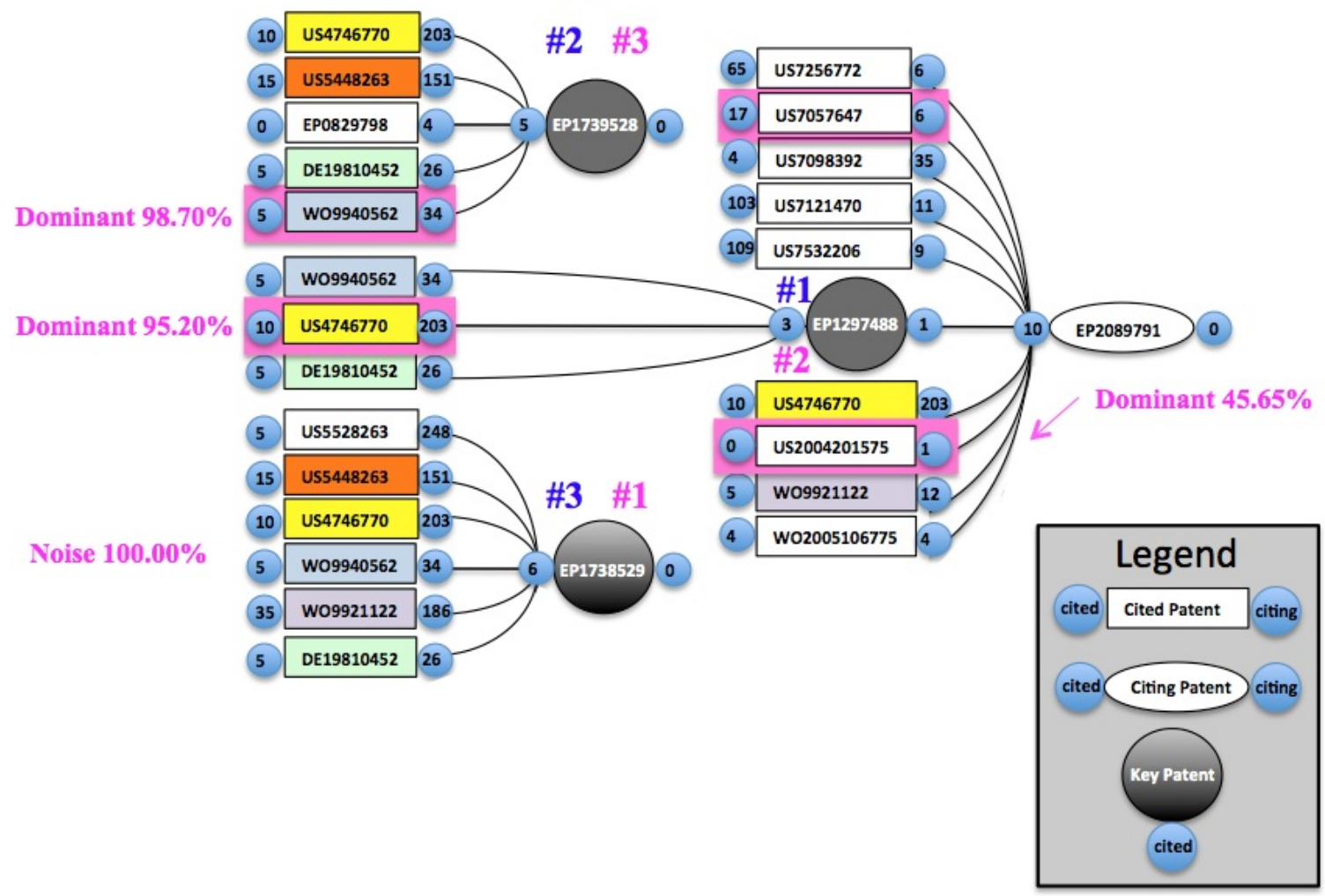

Figure 25: Noise And Interdependency Revealed.

The noise pertinence interdependency ratio for EP2089791 is $80 \%$ noise and $20 \%$ pertinence. There will be a dominant technology patent citation. There are two pertinent technology patent citations, US2004201575 and US7057647. US2004201575 is the dominant technology patent citation with $45.65 \%$ interdependency. This suggests that EP2089791 is an improvement of the US2004201575 invention.

EP1297488 did not form interdependency with EP2089791 and is simply part of the citation noise. This suggests that from the perspective of future value and appropriability 
that there is no difference in the future value of the three European patents of Case 5. This result is also completely different from applying extant theory to this example.

In summary, citation dependent technology patent evaluations that seek to assess the relative technological or invention value of a patent are seriously limited by the noise in the technology patent citation data as well. Extant theory would suggest the technology or inventive value to be in the order of:

1. High - EP1297488

2. Medium - EP 1739528

3. Low - EP1738529

Applying the framework and constructs of the present research to remove the noise from the citation data and identify the dominant technology patent citations suggest a completely different order of technological or inventive value:

1. High - EP1738529

2. Medium - EP1297488

3. Low - EP11729528

In addition, extant theory would suggest EP1297488 has a better ability to appropriate than the other two European patents. However, there is absolutely no interdependency and therefore, all three European patents are on the same level for appropriability. 


\subsection{Research Contribution}

A first contribution of this research relates to researchers broadly interested in the use of prior art citation data and more narrowly interested in citation dependent patent evaluation methodologies. The black box of patent data and information is now partially open as it relates to interdependency between prior art citations and a technology patent. The new case study based research method designed for the research provides an approach for researchers to examine patent citation data and information.

The research method provides a way to identify documents relating to the formation of interdependency between prior art citations and the technology patent. This is important in dealing with large amounts of historical patent prosecution data and the need to preprocess this large data into a manageable amount of data. The approach leverages database hierarchies at the European Patent Office and the United States Patent Office and the approach is broadly applicable to other patent offices in other jurisdictions based upon other patent office database hierarchies.

The research method also provides a way to view and compare complex historical qualitative patent claim language. The approach to overlay the amended text from the longitudinal history of prosecution to identify deleted text and added text and use word counts is broadly applicable to other qualitative research requiring a comparison between an original piece of text and an amended piece of text. This leads to a clear comparison. 
The research method also presents a new opportunity to researchers to revisit previous research into citation dependent patent evaluation methodologies and opens up new opportunities for research into citation dependent patent evaluation methodologies.

A second contribution of this research relates to practitioners interested in conducting a patent evaluation based upon a strategic business consideration. There are four strategic business considerations and associated information for a citation dependent patent evaluation identified and grouped from the literature review. This is illustrated in Figure 26. Citation information, business information and patent information are required dependent upon the type of business consideration. Citation information is a key requirement to all four-business considerations and corresponding patent evaluation methodologies. One form of general value to practitioners is the ability to remove citation noise from the citation information. This leads to cogent patent evaluations.

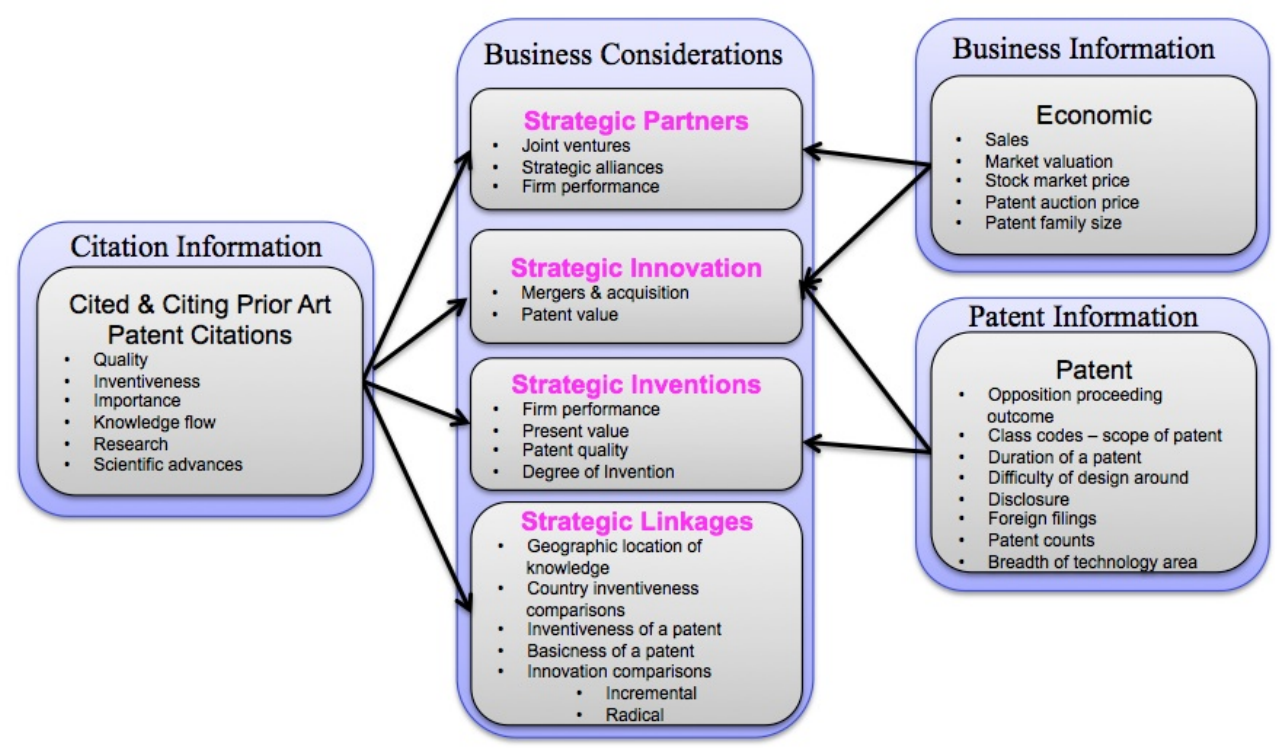

Figure 26: Practice Considerations. 
The strategic partners evaluation requires citation information and business information. This provides stakeholders with the opportunity to identify firms for joint ventures, strategic alliances and assess firm performance by evaluating a patent or patents. The perspective is mixed including the importance or value of the patent or patents and economic relating to the financial health of the firm.

The strategic innovation evaluation requires citation information, business information and corresponding patent information. This provides stakeholders with the opportunity to identify a firm's patent value for potential mergers and acquisitions. This perspective is also mixed including the importance or value of select patents, the economic financial health of the firm and the overall relationship of the select patents to a broader portfolio of patents.

The strategic inventions evaluation requires citation information and patent information. This provides stakeholders with the opportunity to identify and assess attributes of a patent and the performance of a firm. A mixed perspective includes the importance or value of select patents and the overall relationship to the broader portfolio of patents.

The strategic linkages evaluation is based upon citation information. This provides stakeholders with an opportunity to identify and assess many different attributes of a patent based upon the linkages between the citations and the corresponding patent. The perspective is that of information links between the prior art citations and the corresponding patent. 
Practitioners involved in patent portfolio management have a better ability to identify strategic innovation and inventions when considering the select patents in the portfolio. Venture capitalists and investors have a better ability to identify strategic partners by assessing the patent value and performance of the firm when considering a potential investment. Business ecosystem platform owners, mangers and participants have an ability to assess a firm or actor's patents with linkages to a similar technological scope. This is valuable for developing or enhancing the ecosystem and platform. This is also value to actors considering an entry into the business ecosystem or seeking to identify potential partners in the ecosystem.

\subsection{Summary Of The Results}

The results of this multi-case study research revealed that the noise associated with technology patent citations is much higher than suggested by the extant research. A total of 719 technology patent citations were examined against 27 patents. The results found that $87 \%$ of the technology patent citations were noise and lacking in relevance to the corresponding technology patents.

The noise is higher in the United States when compared with Europe. The sequence of prosecution is also higher in the United States with a lower degree of interdependency between the technology patent citations and corresponding technology patents when compared with the results in Europe. This suggests that the noise generated at the source 
in the United States is impeding the efficiency of patent examination at the United States Patent \& Trademark Office.

Analysis of the case study qualitative data revealed the technology patent citation interdependency ratio framework, a noise pertinence interdependency ratio construct and a dominant technology patent citation interdependency ratio construct. Five propositions that help explain how to identify and remove noise from technology patent citations for improving citation dependent patent evaluation methodologies were also found. 


\section{Conclusions}

Chapter 6 presents the conclusions, implications, limitations and opportunities for future research concerning citation dependent patent evaluation methodologies.

\subsection{Conclusions}

This research set a bold goal and departed upon a brief journey to partially open up the black box of historical patent data. The research found out how the interdependences between technology patent citations and technology patents could be applied to improve citation dependent patent evaluation methodologies. The technology patent citation ratio interdependency framework that emerged from the empirical data illustrates and explains how to improve citation dependent patent evaluation methodologies. The results of this research are an original novel contribution to the theoretical knowledge.

The research found the noise to be significantly higher than that suggested by extant literature. This creates a controversy to the effectiveness of citation dependent patent evaluation methodologies that include citation noise. The high amount of noise suggests efficiency of patent examination is impeded and requires longer sequences of examination in higher noise jurisdictions. The high amount of noise also suggests citation based patent evaluation methodologies are obscured by the noise. These methodologies cannot provide meaningful evaluations to stakeholders when obscured by noise. 
The research found a missing piece in the prior knowledge and understanding concealed within the black box of historical patent data. Empirical evidence from this case study suggests that pertinent technology patent citations may be identified from the citation noise. The evidence further suggests that one dominant technology patent citation having interdependency with the technology patent may be further identified from the pertinent technology patent citations. Pertinent and dominant citations are visible, relevant and separate from the citation noise. They are valuable.

There are two ways to remove noise and improve citation dependent patent evaluation methodologies. The noise pertinence ratio is one way to remove noise from technology patent citation data by providing an indication to the ratio of noise in technology patent citation data. The dominant technology patent citation ratio is a second way to remove noise from technology patent citation data and reveal the dominant or key citation in the data. Dominant technology patent citations will either form a sole interdependency with the technology patent or they will form a pooled interdependency with a small number of other technology patent citations. Pertinent and dominant citations are free of noise and are capable to improve a suite of citation dependent patent evaluation methodologies.

The results of this research suggest we can fundamentally change the way we evaluate patents with citation based technology patent evaluation methodologies and enable a broad range of better stakeholder decisions. Pertinent citations guide stakeholders to higher inventive value patents. Dominant citations guide stakeholders to people, firms and technology highly relevant to a Firms business. 


\subsection{Research Contributions And Implications}

Our understanding and body of theoretical knowledge with citation noise and citation dependent technology patent evaluation methodologies have been advanced by this research. There is a new understanding concerning citation noise and the significant amount of noise in citation data.

The theoretical connections of this research to extant theory suggest the significant amount of citation noise obscures critical citation data required to provide a useful and meaningful evaluation. This suggests prior research concerning citation dependent patent evaluation methodologies should be revisited from the perspective of citation noise.

The findings also provide a novel theoretical understanding of citation noise and how to identify pertinent citations and dominant citations from the noise. Removing noise suggests a more useful and meaningful patent evaluation. This suggests prior research concerning citation dependent patent evaluation methodologies should be revisited from the perspective of noise, pertinence and dominant citations.

The findings further provided for a revision to the research framework that was inductively abstracted from a review of the extant literature. This revision resulted in the novel technology interdependency ratio framework, the noise pertinence interdependency ratio construct and the dominant citation interdependency ratio construct. The framework and constructs are empirically validated by this research. 
The findings with respect to the much higher levels of noise, greater sequences in the patent prosecution examination suggest a policy implication. Jurisdictions with higher citation noise require higher sequences in prosecution and are less efficient than other jurisdictions with lower citation noise. Policy makers should revisit current policy to adjust, amend or align procedures with lower noise jurisdictions. This could lead to improved efficiencies, a reduction of noise at the source and a reduction of patent office backlog.

As a practice implication, stakeholders must remove citation noise from their technology patent citation data. The findings suggest that removing the noise leads to better evaluations and reveals business information. This better information leads to better stakeholder decisions based upon improved citation dependent patent evaluation methodologies. Platform owners and managers can identify other technology, people and firms to enhance or further develop the business ecosystem. Patent portfolio managers can identify dominant patents with relatively higher invention value. Venture capitalists and investors can conduct better patent evaluations and identify firms for acquisition, strategic alliances and mergers.

\subsection{Limitations}

There are a number of limitations associated with this case study research. The research focused on two key jurisdictions, Europe and the United States. Historical patent data was obtained from two patent organizations, the European Patent Office and the United States Patent and Trademark Office. The sample pertained to six cases and was drawn 
from a small global patent portfolio of a Canadian company. Only one of the three European cases had citing citations where all six of the United States cases had citing citations. The prior art citations and patents for this research relates to smart white board technology. Prior art citations are restricted to technology patents and exclude other forms of prior art citations such as academic literature. Patents are restricted to utility patents and design patents are excluded from the sample. Patent claims are restricted to broad independent claims and narrow dependent claims are excluded from the sample.

The review of the literature failed to identify a robust and proven research methodology that could be applied to this research. This necessitated the design of a new research methodology based upon the case study approach. Therefore, there are limitations associated with a new unproven methodology.

There are limitations with the search of the literature. Only one database, Business Source Complete was considered. Certain prior art citation terms in the literature have synonyms and colloquial terminology resulting in a difficult topic to search extensively.

The research is further limited by the choice of attributes (legal rejection type, claim amendment, degree of claim amendment and sequential claim amendment) from the literature that resulted in the technology patent interdependencies construct of the research framework. 


\subsection{Future Research}

There are research opportunities to validate the results of this research statistically. The technology patent citation ratio independency framework should be validated. The noise pertinence interdependency ratio construct provides another opportunity. The dominant technology patent citation interdependency ratio construct provides another opportunity. The extent of the correlations between these constructs and the technology patent citation interdependency ratio framework provides another opportunity.

There are compelling reasons to revisit extant research on citation dependent patent evaluation methodologies. Scholars have not understood the magnitude and amount of noise in citation data. This citation noise obscures citation based patent evaluation methodologies. A broader understanding of citation noise and the impact on citation dependent patent evaluation methodologies is necessary.

There are also research opportunities to extend and expand this research. Prior art citations could be examined from other jurisdictions and patent organizations. There are other technologies beyond smart white boards to examine. Research could be across a suite of other technologies. Research could focus on scientific or academic prior art citations alone or in combination with technology patent prior art citations. 


\section{Appendices}

\section{Appendix A}

This is a summary of the literature review organized by streams. This includes the prior art citation based patent evaluation methodologies stream, the prior art citations stream and the interdependency between prior art citations and patent stream.

\section{A.1 Stream 1 Prior Art Citation Based Patent Evaluation Methodologies}

\begin{tabular}{|c|c|c|}
\hline $\begin{array}{c}\text { Author } \\
\text { (Year) }\end{array}$ & Source & Citation Based Technology Patent Evaluation Methodologies \\
\hline $\begin{array}{l}\text { Bapuji et al. } \\
(2011)\end{array}$ & $\begin{array}{l}\text { Journal of } \\
\text { Engineering } \\
\text { and } \\
\text { Technology } \\
\text { Management }\end{array}$ & $\begin{array}{l}\text { - Empirical research with patent citation and business data in the integrated circuit manufacturing } \\
\text { industry. Examined the relationship between internal and external knowledge and firm } \\
\text { performance. } \\
\text { - Suggests that patents cite prior knowledge on which the patent is built. Citations are a proxy for } \\
\text { internal and external knowledge flow. Firm's citations are internal knowledge and other firm } \\
\text { citations are external knowledge. } \\
\text { - Sales are used as a proxy for firm performance } \\
\text { - Findings relate to patent and product portfolio management and joint ventures and strategic } \\
\text { alliances. The use of external knowledge has a negative effect on firm performance especially } \\
\text { when entering new product markets. Also found that firms with a higher capacity to absorb } \\
\text { knowledge can mitigate risks and costs associated with high external knowledge usage. }\end{array}$ \\
\hline $\begin{array}{l}\text { Breitzman \& } \\
\text { Thomas } \\
(2002)\end{array}$ & $\begin{array}{l}\text { Research } \\
\text { Technology } \\
\text { Management }\end{array}$ & $\begin{array}{l}\text { - Empirical research to examine how patent portfolios analysis aids M\&A targeting and due } \\
\text { diligence. } \\
\text { - Suggests that patent citation analysis is a measure for patent quality. Inventors and examiners add } \\
\text { citations to demonstrate novelty and inventiveness as citations limit the scope of an invention. } \\
\text { - Combined metrics and data such as a patent count, recent patents, high impact patents (based on } \\
\text { citation quintiles), links to science and emerging technology to identify M\&A targets. } \\
\text { - Patent portfolio analysis assists with identifying key inventors and technology during the M\&A } \\
\text { due diligence process. } \\
\text { - Targeting companies with different high impact areas may identify higher impact patents to } \\
\text { - Pompare and assess technological compatibility. } \\
\text { cycle time, R\&D intensity) with market to book values reveal the quality of a patent portfolio with } \\
\text { stock market value. } \\
\text { Found that patent citation data in combination with other metrics and data are useful in the M\&A } \\
\text { process. }\end{array}$ \\
\hline $\begin{array}{l}\text { Chen \& } \\
\text { Chang (2010) }\end{array}$ & $\begin{array}{l}\text { Technology } \\
\text { Analysis \& } \\
\text { Strategic } \\
\text { Management }\end{array}$ & $\begin{array}{l}\text { - Empirical research with US pharmaceutical firms to examine the relationship of patent indicators } \\
\text { with firm performance. The patent indicators include patent share, relative patent position and } \\
\text { patent citations. } \\
\text { - Suggests that a patent is more valuable when the citations are higher to other firms. } \\
\text { - Firm market value relates to patent share, relative patent position and patent citations. } \\
\text { - Found that patent share had a negative effect on firm market value, relative patent share had a } \\
\text { positive effect on firm market value. Patent citations had an inverse U-shaped effect on firm } \\
\text { market value suggesting an optimal value for patent citations. Enhancing patent citations can } \\
\text { increase market value if the citations stay below an optimal value. }\end{array}$ \\
\hline Deng (2008) & $\begin{array}{l}\text { International } \\
\text { Journal of } \\
\text { Industrial } \\
\text { Organization }\end{array}$ & $\begin{array}{l}\text { - Empirical research with US semiconductor firms to examine the economic value of knowledge } \\
\text { spillovers contained in patent citations. } \\
\text { - Suggests that citations represent existing knowledge that a citing patent builds upon for which a } \\
\text { citing patent cannot have a claim. Citations are a potential measure of knowledge spillovers from } \\
\text { past technology to the current technology. Citations contain a substantial amount of noise } \\
\text { - Combined market valuation (stock market value and book value) with knowledge assets based } \\
\text { upon patent R\&D ratio, weighted average number of citations. Backward citations are a proxy for } \\
\text { knowledge spillover and forward citations are a proxy for patent portfolio importance. } \\
\text { - Found an average dollar amount of economic value per patent citation. This value declines as the }\end{array}$ \\
\hline
\end{tabular}




\begin{tabular}{|c|c|c|}
\hline & & $\begin{array}{l}\text { firms patent portfolio increases. Self citations (internal knowledge) are more valuable than } \\
\text { external citations. }\end{array}$ \\
\hline $\begin{array}{l}\text { Fischer \& } \\
\text { Leidinger } \\
(2014)\end{array}$ & $\begin{array}{l}\text { Research } \\
\text { Policy }\end{array}$ & $\begin{array}{l}\text { - Empirical research to examine patent value indicators and patent value associated with the Ocean } \\
\text { Tomo patent auction data. } \\
\text { - The patent value indicators include quality (forward citations), economic relevance (family size) } \\
\text { and patent scope (IPC classes). } \\
\text { - The patent value indicators are associated with economic value from the patent auction data. } \\
\text { - Found that forward citations and family size are significant indicators for patent value. There was } \\
\text { no support between value and the number of IPCs. }\end{array}$ \\
\hline $\begin{array}{l}\text { Hall et al. } \\
(2005)\end{array}$ & $\begin{array}{l}\text { RAND } \\
\text { Journal of } \\
\text { Economics }\end{array}$ & $\begin{array}{l}\text { - Empirical research to explore patent citations as a measure of important patents as indicated by } \\
\text { stock market valuation of intangible knowledge. } \\
\text { - Suggests that citations are a legal function that delimits the scope of the claims in the patent and } \\
\text { that citations represent existing knowledge that a patent builds upon. Citations also provide } \\
\text { linkages between inventions, inventors and firms based upon secondary information contained } \\
\text { with a patent. Citations are also indicators of importance and a way of gauging the value of a } \\
\text { patent. Also suggests that citations are noisy. } \\
\text { - Found that patent citations include information relating to the market value of firms and the } \\
\text { knowledge stock of a firm. }\end{array}$ \\
\hline $\begin{array}{l}\text { Harhoff et al. } \\
(2002)\end{array}$ & $\begin{array}{l}\text { Research } \\
\text { Policy }\end{array}$ & $\begin{array}{l}\text { - Empirical research to examine the value of patent rights with estimates of the value from survey } \\
\text { data and a set of patent indicators. } \\
\text { - The patent indicators include the number of citations in the German system, analogous citations in } \\
\text { the EPO system, number of references to prior patents, number of references made to non-patent } \\
\text { literature, outcome of opposition proceedings, family size and the IPC classifications as a proxy for } \\
\text { scope of the patent. } \\
\text { - Found and confirmed a correlation between patent value and forward citations. Backward } \\
\text { citations, family size and opposition outcomes also correlate to patent value. The PIC } \\
\text { classifications did not have any correlation to patent value. }\end{array}$ \\
\hline $\begin{array}{l}\text { Hirschey \& } \\
\text { Richardson } \\
(2004)\end{array}$ & $\begin{array}{l}\text { Journal of } \\
\text { Empirical } \\
\text { Finance }\end{array}$ & $\begin{array}{l}\text { - Empirical research to examine stock market prices and patent quality for different firm sizes and } \\
\text { growth opportunity. } \\
\text { - Patent quality indicators include forward citations a proxy for important scientific advances, } \\
\text { reference to non-patent citations a proxy to research, and a technology cycle indicator. } \\
\text { - Found that various measures of patent quality have a positive statistically significant effect on the } \\
\text { price of a firms stock. The number of patents, value of R\&D expenditures, patent quality provides } \\
\text { a basis to gage firms inventive and innovation activities. }\end{array}$ \\
\hline $\begin{array}{l}\text { Jaffe, et al. } \\
(1993)\end{array}$ & $\begin{array}{l}\text { Quarterly } \\
\text { Journal of } \\
\text { Economics }\end{array}$ & $\begin{array}{l}\text { - Empirical research to examine patent citations and geographic location of knowledge spillovers for } \\
\text { university and firm patents. } \\
\text { - Citations are a proxy for knowledge flow and knowledge spillovers. Secondary information } \\
\text { associated with the patent is a proxy for geographic location. Citations introduce noise. } \\
\text { - Suggests citations represent old knowledge that is built upon by the subsequent patent. } \\
\text { - Found patterns of geographic localization with patent citations. Citations are highly localized in } \\
\text { the early life of a patent and fade over time. }\end{array}$ \\
\hline $\begin{array}{l}\text { Nair, et al. } \\
(2011)\end{array}$ & Technovation & $\begin{array}{l}\text { - Empirical research to examine the relationship between patent latent variables and the price of a } \\
\text { patent based upon the Ocean Tomo patent auction price. } \\
\text { - The literature review suggests citations are noisy. } \\
\text { - The latent variables are proxies for patent value and include age, generality, originality, foreign } \\
\text { filings, technology field, and citations (forward and backward). } \\
\text { - Found a positive correlation between patent price and forward citations and foreign filings. }\end{array}$ \\
\hline $\begin{array}{l}\text { Reitzig } \\
(2003)\end{array}$ & $\begin{array}{l}\text { Research } \\
\text { Policy }\end{array}$ & $\begin{array}{l}\text { - Empirical research to explore indicators of patent value in the semiconductor industry. } \\
\text { - Potential patent value indicators include the life of the patent, novelty and inventiveness as } \\
\text { reflected by backward citations, breadth of the claims, degree of difficulty to design around, the } \\
\text { disclosure, position of a patent in a portfolio of patents, exclusive rights and the use of patents to } \\
\text { negotiate licenses. } \\
\text { - Findings suggest they may be specific to patents that are used to negotiate licenses to determine } \\
\text { present day value. Knowledge of technical importance, position in the portfolio, competitive } \\
\text { learning value (disclosure), difficulty in design around is a good approximation for present value. } \\
\text { Suggested forward citations as a proxy for inventiveness should be indicators for patent value. }\end{array}$ \\
\hline Tseng (2009) & $\begin{array}{l}\text { Industrial } \\
\text { Research } \\
\text { Institute }\end{array}$ & $\begin{array}{l}\text { - Empirical research to examine U.S. patent and citation data for inventors from Brazil, Russia, India } \\
\text { and China to compare technological innovation in four countries. } \\
\text { - Citation data is a proxy for quality, the higher the number of citations the more significant the } \\
\text { technology. Suggests that a high amount of scientific citations reflect fundamental innovation and } \\
\text { a low amount of scientific citations reflect applied innovation. Self-citing ratios may distinguish } \\
\text { between incremental and radical innovation where a high ratio indicates incremental invention. } \\
\text { - Based in part upon the IPC codes, the innovation strength for each of the four countries is in a } \\
\text { different grouping of technologies. Russia is mostly fundamental innovation. India is slightly } \\
\text { fundamental innovation. Brazil and China pursue applied innovation. Russia and India exhibit } \\
\text { incremental innovation where China and Brazil exhibit radical innovation. }\end{array}$ \\
\hline
\end{tabular}

Table 41: Literature Review Summary Of Stream 1. 


\section{A.2 Stream 2 Prior Art Citations}

\begin{tabular}{|c|c|c|}
\hline $\begin{array}{c}\text { Author } \\
\text { (Year) }\end{array}$ & Source & Applicability and Limitations of Technology Patent Citations \\
\hline Bacchiocchi & The & $-\quad$ Empirical research to examine knowledge diffusion and patent citation home bias effect from
\end{tabular}

\& Montobbio Scandinavian

(2010) Journal of

Economics patent data at the United States Patent \& Trademark Office and the European Patent Office.

- Patent citations can be a proxy to track knowledge flows between patents and measure the intensity of knowledge flows. Secondary patent data provides an indication to regions, countries and specific technologies.

- $\quad$ Patent citation noise may include the home bias effect (inventors in one country cite inventors in same country) and citation lag.

- $\quad$ Found that the home bias effect depends upon different patent examination legal and procedures that generation patent citations, patent citations are localized at the European Patent Office with a less number of citations per patent than the United States Patent \& Trademark Office, patent citation lag is different across technologies and patent offices.

\begin{tabular}{llll}
\hline Criscuolo \& & Research & - & Empirical research to examine citations added by inventors in contrast to citations added by \\
Verspagen & Policy
\end{tabular}
Verspagen Policy patent examiners in Europe to study noise in patent citations.

(2008) - Patent citations are a proxy for knowledge flow and create a paper trail of the flow of knowledge.

- Citations are a noisy measure of knowledge flow as the final decision rests with a patent examiner. The European patents have fewer citations than United States patents that suggest European patent citations have less noise.

- Found that examiner citations will anticipate claims and inventor citations describe state of the art or are involved in inventive step rejections.

Gay \& Le Economic of - A review of literature concerning the use and noise in patent citations as a proxy for measuring

Bas (2005) Innovation value and knowledge.

and New - Patent citations may be a proxy to assess the technical value of inventions, indicate the origins

Technology and flow of codified knowledge and lead to a measure of technical significance. Patent citations can reveal the network of technological communities. Cited citations contain codified knowledge and are a proxy for cumulative knowledge. Cited and citing citations are a proxy for knowledge flow. Secondary information reveals business intelligence concerning the actors associated with the patent citation, geographic proximity and knowledge exchange between actors.

- Patent citations are noisy suggesting they are a poor indicator of economic value. The citation rate in the United States is three times greater than that of Europe.

Gay, Le Bas, Economics of - Empirical research to examine patents in the United States to British and French assignees.

Patel \& Innovation The examination focused on characteristics of highly cited patents to include; citation lag,

Touach and New

(2005) Technology

- Patent citations can be a proxy to the technological value of inventions based upon the citation rate, or frequency of citation in other technological fields.

- Patent citation noise may include citation lag and citation variability (diversity of technology value).

- Found that the frequency of citations is an indicator of technology importance if the citation is quickly cited with a high frequency in other technological fields suggesting a broader patent citation.

\begin{tabular}{|c|c|c|}
\hline $\begin{array}{l}\text { Hu \& Jaffe } \\
(2003)\end{array}$ & $\begin{array}{l}\text { International } \\
\text { Journal of } \\
\text { Industrial } \\
\text { Organization }\end{array}$ & $\begin{array}{l}\text { - Empirical research to examine knowledge flow and diffusion from the United Sates and Japan } \\
\text { to Korea and Taiwan based upon patent citations as an indicator of knowledge flow. } \\
\text { - Citations are a proxy for knowledge flows between patents. With secondary patent data such } \\
\text { as the inventor name and country, a proxy for knowledge flows between countries. } \\
\text { - Citations are noisy indicator of knowledge flow as many citations occur absence of any } \\
\text { knowledge flow. } \\
\text { - Found that knowledge diffusion through citations from advanced economies is import to } \\
\text { countries of lessor economies. }\end{array}$ \\
\hline $\begin{array}{l}\text { Hu et al. } \\
(2012)\end{array}$ & $\begin{array}{l}\text { Journal Of } \\
\text { The } \\
\text { American } \\
\text { Society For } \\
\text { Information } \\
\text { Science And } \\
\text { Technology. }\end{array}$ & $\begin{array}{l}\text { - } \\
\text { Empirical research to build and examine a patent citation network with a focus on a target } \\
\text { - } \\
\text { Patent citations can be a proxy to technological value when citing and a proxy to knowledge } \\
\text { flow when cited against the target patent. Cited patents represent knowledge flows of old or } \\
\text { known knowledge. Citing patents represent knowledge flows of new ideas and knowledge } \\
\text { (Gay \& Le Bas, 2005). } \\
\text { - Simple citation counts are noisy and may not be suitable across technology fields, there is no } \\
\text { direction relation to technology of a patent, do not relate to technical complexity of patents } \\
\text { and cannot indicate factors related to the value of a patent. } \\
\text { Found that citation counting provides partial information towards patent value and that the } \\
\text { patent citation network reflects patent performance based upon cited and citing citations. }\end{array}$ \\
\hline
\end{tabular}




Jaffee \& $\quad$ The MIT $\quad$ - A book and collection of research papers on the subject of patent, citations and innovations
Trajtenberg Press - Patent citations make it possible to trace the links between patents and citations and the flow (2002) of technological knowledge between the citations and patent. Citations may be an indicator of invention importance for the degree of generality or originality. Citations illustrate how technological knowledge combines to produce new knowledge over time. A highly cited patent suggests importance. Citations may also be used as a proxy for technological impact and when used to weight a count of patents, this leads to more meaningful information.

- Citations are noisy measure between patents, cited and citing citations in part due to a truncation problem.

Kelley et al. Journal Of - Empirical examination of high potential, or breakthrough patents in the United States from the (2013) Product drug and semiconductor industries by comparing breakthrough patents with non-breakthrough Innovation patents. The research examined knowledge structures associated with patents.

Management. - The highest number of citing citations can be a proxy for high potential or breakthrough inventions. Cited citations can be a proxy for intermediate value of a technology.

- Found that breakthrough inventions are built upon past knowledge reflected in the number of cited citations, more recent citations (date based), and geographic proximity. Breakthrough innovations have a greater technological breadth capturing knowledge from a larger number of technology citations.

\begin{tabular}{ll}
\hline Nikulainen et & International \\
al. (2008) & Journal of \\
& Innovation \\
& and \\
& Technology \\
& Management
\end{tabular}

Empirical research to provide insight into the technological and economic significance of European patents in the Finish biotechnology industry.

- Cited citations are a proxy for the present economic value of a company and they position the patent with respect to the basicness and originality of the patent. A relatively low count suggests low basicness and technological significance. Citing citations are a proxy for technological significance indicating a potential for higher economic return. The higher the citing citations the higher the value for appropriating and applying the invention.

- Found that cited citations are below average in Finland and that citing citations are higher when compared to other technologies. Further found that the cited citations tend to be indicators for present and future earnings of economic value.

\begin{tabular}{ll}
\hline Van & Economics of \\
Zeebroeck & Innovation \\
$(2011)$ & and New \\
& Technology
\end{tabular}

- Empirical research in Europe to examine five different patent indicators that are correlated with value can be extracted from patent databases and could provide information on the potential market for invention. These indicators are citing citations; grant decisions, families, renewals and oppositions.

- $\quad$ Patent citations provide the linkages between upstream and downstream technology knowledge. Downstream they reveal previous research activity and upstream citations suggest value of inventions.

- Citations are noisy and may arrive at any point in time. A major challenge is the significant number of citations associated with a single patent. European patents tend to have fewer citations than the United States suggesting less noise in Europe. Raw counts of citations may underestimate the actual number of citations.

- Found that the five different patent indicators are correlated with the monetary value of patents perceived by inventors.

\begin{tabular}{|c|c|c|}
\hline $\begin{array}{l}\text { Trajtenberg } \\
\text { (1990) }\end{array}$ & $\begin{array}{l}\text { RAND } \\
\text { Journal of } \\
\text { Economics }\end{array}$ & $\begin{array}{l}\text { - Empirical research to examine patent citations as indicators or importance or value in the } \\
\text { computed tomography scanner technology area. } \\
\text { - Citations can be an indicator to the importance of value of a patent. A frequency or count of } \\
\text { citations is applied to calculate a weighted count of patents. Citations that cross technology } \\
\text { areas are indicative of knowledge spillover. } \\
\text { - Findings suggest a causal relationship between cited and citing patents. A patent could be } \\
\text { important if the patent opened up other advances and this importance could be identified } \\
\text { through citations. The subsequent patents in the citation chain would be either refining or } \\
\text { improving the original patented technology. }\end{array}$ \\
\hline $\begin{array}{l}\text { Trajtenberg } \\
\text { et al. (1997) }\end{array}$ & $\begin{array}{l}\text { Economics of } \\
\text { Innovation } \\
\text { and New } \\
\text { Technology }\end{array}$ & $\begin{array}{l}\text { - } \\
\text { - } \\
\text { Aspects of basicness and appropriability exist in the relationships between cited and citing } \\
\text { patent citations. Basic relates to each innovation building upon a body of existing knowledge } \\
\text { before it and appropriability relates to benefiting from the earlier patented innovation. } \\
\text { Citations can therefore identify and trace the citation relationships. A patent is important if it } \\
\text { is highly citing and a patent is basic if it is highly cited. } \\
\text { - Suggests that cited citations are old knowledge a subsequent patent builds upon and cannot be } \\
\text { claimed in the subsequent patent. } \\
\text { Found that university patents are more basic than firm patents. }\end{array}$ \\
\hline
\end{tabular}

Table 42: Literature Review Summary Of Stream 2. 


\section{A.3 Stream 3 Interdependency Between Prior Art Citations and Patent}

\begin{tabular}{|c|c|c|}
\hline Author (Year) & Source & Technology Patent \& Citation Interdependencies \\
\hline $\begin{array}{l}\text { Abbott } \\
\text { Laboratories } \\
\text { Inc. v. Baxter } \\
\text { Pharmaceutical } \\
\text { Products Inc. } \\
(2003)\end{array}$ & $\begin{array}{l}\text { Intellectual } \\
\text { Property \& } \\
\text { Technology } \\
\text { Law } \\
\text { Journal }\end{array}$ & $\begin{array}{l}\text { - Report and discussion concerning a decision in the United States Courts on a patent invalidity } \\
\text { challenge between Abbott Laboratories and Baxter Pharmaceutical Products. } \\
\text { - The presence of prior art citations on an information disclosure statement does not provide any } \\
\text { indication to the relevance or lack of relevance of the prior art citations and the claims in the } \\
\text { patent that define the invention. }\end{array}$ \\
\hline $\begin{array}{l}\text { Berger et al. } \\
(2011)\end{array}$ & $\begin{array}{l}\text { Research } \\
\text { Policy }\end{array}$ & $\begin{array}{l}\text { - Empirical research into the filing behavior of actors that set industry standards and the attributes } \\
\text { associated with an industry essential patent. } \\
\text { - The examination process (prosecution) provides for voluntary amendments or amendments in } \\
\text { response to an Examiners action, based on formality issues. Then, the process continues with a } \\
\text { formal rejection (if there is one) based upon the prior art, and amendment to the claims (or not) } \\
\text { where the Examiner must accept the amendment. The examination process continues with a } \\
\text { sequence of rejections and amendments until final disposition of the patent application by the } \\
\text { Examiner that results in either allowance of the application or rejection of the applications. } \\
\text { Found that for essential patents the applicants will delay the final decision of the prosecution } \\
\text { process as long as possible and the application will undergo } 25 \% \text { more amendments than a non- } \\
\text { essential patent. }\end{array}$ \\
\hline $\begin{array}{l}\text { Cotropia et al. } \\
(2013)\end{array}$ & $\begin{array}{l}\text { Research } \\
\text { Policy }\end{array}$ & $\begin{array}{l}\text { - Empirical research that examined the choice of prior art references (citations) by Examiners in } \\
\text { the prosecution process to determine patentability in the United States. } \\
\text { - Examiner rejections include a test for novelty and a test for inventiveness or non-obvious subject } \\
\text { matter. Section } 102 \text { concerns novelty and an Examiner will reject the proposed invention if it is } \\
\text { not described in a printed publication or publically used or sold in the United States more than } 1 \\
\text { year before the filing date of the patent application. Section } 103 \text { concerns obviousness and the } \\
\text { Examiner will reject the proposed invention if the difference over the prior art is not inventive. } \\
\text { - Office actions cite specific reasons formulated by an Examiner in the form of rejections. } \\
\text { - Found that most prior art citations provided by applicants are not applied by Examiners in } \\
\text { evaluating or limiting the scope of the patent claims and that the citations are noisy. Further } \\
\text { found that some of the noise in citations could be identified and reduced based upon an } \\
\text { identification of a citation in an office action, or list of office actions from the file history. }\end{array}$ \\
\hline Donner (2007) & $\begin{array}{l}\text { Patent } \\
\text { Prosecution } \\
\text { Law, } \\
\text { Practice, } \\
\text { and } \\
\text { Procedure }\end{array}$ & $\begin{array}{l}\text { - } 35 \text { U.S.C section } 102 \text { provides for novelty and an invention is novel if the invention was not } \\
\text { described in a printed publication (including citations) or in public use, on sale or otherwise } \\
\text { publically available before the effective filing date. Considering novelty requires a single prior } \\
\text { art reference or citation. } \\
\text { - } 35 \text { U.S.C section } 102 \text { provides for invention (non-obvious) and an invention is not obvious if the } \\
\text { differences between the claims and the prior art would not be obvious at the effective filing date. } \\
\text { Considering obviousness may require multiple prior art references or citations. } \\
\text { - Claims are drafted with a specific form and function that includes a preamble, a transition and a } \\
\text { body. The preamble sets out the technical field of the invention. The transitional phrase sets the } \\
\text { context of the specific elements of the invention. The body describes the elements or process } \\
\text { steps of the invention and the logical relationship between the elements. } \\
\text { - Examiners at the United States Patent \& Trademark Office examine a patent application. If the } \\
\text { parent application fails to meet the requirements, such as } 35 \text { U.S.C. } 102 \text { and } 35 \text { U.S.C } 103 \text {, then } \\
\text { the Examiner provides the first action and arguments for rejecting the application. The } \\
\text { Applicant responds with arguments and any amendments to the claims. Amendments to the } \\
\text { claims are to distinguish over the prior art. The Examiner considers the Applicant's response } \\
\text { and this process continues in sequence until the Examiner either grants or refuses the patent } \\
\text { application. }\end{array}$ \\
\hline $\begin{array}{l}\text { European } \\
\text { Patent Office } \\
(2007)\end{array}$ & $\begin{array}{l}\text { European } \\
\text { Patent } \\
\text { Convention }\end{array}$ & $\begin{array}{l}\text { - Article } 52 \text { provides for patentable inventions and states that patents shall be granted when the } \\
\text { invention is novel with an inventive step (non-obvious difference) and industrial application. } \\
\text { - Article } 54 \text { provides for novelty and an invention is novel over the state of the art, including prior } \\
\text { art citations, if the invention does not form part with any of the state of the art. Considering } \\
\text { novelty requires a single prior art reference or citation. } \\
\text { - Article } 56 \text { provides for inventive step if the invention is not obvious to a person skilled in the art. } \\
\text { Considering inventive step may require multiple prior art references or citations and an } \\
\text { Examiner normally applies a problem solution approach. } \\
\text { - The claims define the invention and are drafted in terms of the technical features of the invention } \\
\text { in a specific form and function. The claims may be further provided in two-part form to indicate } \\
\text { the general technical class followed by a definition of the claimed subject matter. } \\
\text { - A patent application shall be examined upon request to the European Patent Office. If the patent } \\
\text { application fails to meet the requirements of the Convention, such as articles } 52,54 \text { and } 56 \text {, then } \\
\text { the applicant may file observations and amendments to the application and the pending patent } \\
\text { claims to overcome prior art citations and Examiner rejections. Amendments to the claims are to } \\
\text { distinguish over the prior art. The procedure continues in a sequence until the Examining } \\
\text { Division either permits grant of the patent or refusal of the patent. }\end{array}$ \\
\hline
\end{tabular}




\begin{tabular}{|c|c|c|}
\hline $\begin{array}{l}\text { Kica \& } \\
\text { Groenendijk } \\
(2011)\end{array}$ & $\begin{array}{l}\text { Innovation } \\
\text { - The } \\
\text { European } \\
\text { Journal of } \\
\text { Social } \\
\text { Science } \\
\text { Research }\end{array}$ & $\begin{array}{l}\text { - Empirical research concerning the European patent system and patentability of emerging } \\
\text { technologies. } \\
\text { - Technical experts at the European Patent Office examine patent applications. Article 52(1) EPC } \\
\text { (European Patent Convention) requires a patent to be new and novel over the prior art and } \\
\text { inventive (non-obvious) with industrial applicability. } \\
\text { - Patent applications are examined using the prior art citations from a search report. Amendments } \\
\text { may or may not occur and the European Patent Office grants or rejects the patent application } \\
\text { based upon the legal arguments and/or amendments to the pending claims. } \\
\text { - The authors provide policy recommendations to the pre-grant patent application process in the } \\
\text { form of a pre-grant advisory board to oversee assessment decisions and evaluations concerning } \\
\text { emerging technology with an ex-ante impact assessment to avoid negative implications of } \\
\text { emerging technologies and socio-economic value. }\end{array}$ \\
\hline $\begin{array}{l}\text { Kukrus \& } \\
\text { Kartus (2007) }\end{array}$ & $\begin{array}{l}\text { Working } \\
\text { Papers In } \\
\text { Economics }\end{array}$ & $\begin{array}{l}\text { - Empirical research concerning new developments towards a global patent prosecution system } \\
\text { through a new route and contrasting the issues between developed and developing countries. } \\
\text { - The patent prosecution highway is a new route for applicants to seek grant of a patent } \\
\text { application in more than one country. The patent application is filed with a first patent office in } \\
\text { a first country. A subsequent patent application pending in another country may request } \\
\text { accelerated examination from a member patent office in a second country by submitting the } \\
\text { results of examination for novelty and invention (non-obvious) from the first patent office. } \\
\text { Examination in the second country move to consideration of the results from a different patent } \\
\text { system and determination of the results is based upon the requirements of the patent prosecution } \\
\text { highway. If the requirements are not met, then the second national or regional patent office will } \\
\text { formulate a decision to grant or refuse the patent application. } \\
\text { - Countries using the pilot system do not have to change national patent laws in order to } \\
\text { accommodate granting a patent application. } \\
\text { Found there are deepening patent contradictions between developed and developing countries on } \\
\text { a global scale. The World Intellectual Property Organization (WIPO) agenda does not consider } \\
\text { the economy of developing countries and favors larger companies to extend patent law } \\
\text { backwards into developing countries. }\end{array}$ \\
\hline Laub, C. (2006) & $\begin{array}{l}\text { Journal of } \\
\text { World } \\
\text { Intellectual } \\
\text { Property }\end{array}$ & $\begin{array}{l}\text { - Empirical research to examine the standards at the European Patent Office and the United States } \\
\text { Patent \& Trademark office concerning software embodied inventions. } \\
\text { - Patentability in Europe requires the invention to be new, have inventiveness and industrial } \\
\text { applicability. The claimed subject matter must be new according to EPC (54) and have } \\
\text { inventiveness EPC (56). Patentability in the United States requires an invention must be new } \\
\text { (100 definitions) and have inventiveness (non-obvious) under section 103. The European and } \\
\text { United States patent examination practices are based upon different legal principles and } \\
\text { procedures. } \\
\text { Found the differences in dealing with software subject matter is more restrictive than the United } \\
\text { States and led to higher rejection and withdrawal rates for software patent application in Europe. }\end{array}$ \\
\hline
\end{tabular}




\section{Appendix B}

Appendix B contains the results of a detailed examination of the relevant historical archival patent documents that make up the sample of this research. Each of Table 44 through Table 70 inclusive corresponds to a case in this research. The tables document the evidence from the relevant historical document in quotes, the sequence of prosecution, the legal rejection type(s), the total number of citations for each case, the total number of relevant citations, and an indication of a claim amendment and the final outcome reached by the patent Examiner.

\section{B.1 Case 1 Document Examination And Attribute Coding.}

\begin{tabular}{|c|c|c|c|c|c|c|}
\hline $\begin{array}{l}\text { Longitudinal } \\
\text { Sequence }\end{array}$ & $\begin{array}{c}\text { Evidence From Relevant Historical } \\
\text { Document }\end{array}$ & $\begin{array}{c}\text { Legal } \\
\text { Rejection } \\
\text { Type }\end{array}$ & $\begin{array}{c}\text { Total } \\
\text { citations }\end{array}$ & $\begin{array}{l}\text { Relevant } \\
\text { Citations }\end{array}$ & $\begin{array}{c}\text { Claim } \\
\text { Amendment }\end{array}$ & $\begin{array}{l}\text { Examiner } \\
\text { Outcome }\end{array}$ \\
\hline 1 & $\begin{array}{l}\text { Independent Claim " } 1 . \text { In a touch system } \\
\text { having a touch screen with a touch } \\
\text { surface on which an image is displayed, } \\
\text { a method of automatically mapping a } \\
\text { touch screen co-ordinate system to the } \\
\text { display co-ordinate system comprising } \\
\text { the steps of:" } \\
\text { Independent Claim "9. A touch system } \\
\text { comprising:" } \\
\text { "D1: US2002/036617" } \\
\text { "The present application does not meet } \\
\text { the requirements of Article 52(1) EPC, } \\
\text { because the subject-matter of claims } 1,9 \\
\text { and } 20 \text { is not new in the sense of Article } \\
54(1) \text { and (2) EPC. }\end{array}$ & Sole & 3 & 1 & Yes & Rejection \\
\hline 2 & $\begin{array}{l}\text { "The present application does not meet } \\
\text { the requirements of Article 52(1) EPC } \\
\text { because the subject-matter of claims } 1 \\
\text { and } 10 \text { does not involve an inventive } \\
\text { step within the meaning of Article } 56 \\
\text { EPC. }\end{array}$ & Sole & 3 & 1 & Yes & Rejection \\
\hline 3 & $\begin{array}{l}\text { "You are informed that the Examining } \\
\text { Division intends to grant a European } \\
\text { patent on the basis of the above } \\
\text { application with the text and drawings } \\
\text { as indicated below". }\end{array}$ & Sole & 3 & 1 & No & $\begin{array}{l}\text { Decision } \\
\text { To Grant }\end{array}$ \\
\hline
\end{tabular}

Table 44: Evidence Case 1: EP1611503 Cited Citations. 


\section{B.2 Case 2 Document Examination And Attribute Coding.}

\begin{tabular}{|c|c|c|c|c|c|c|}
\hline $\begin{array}{l}\text { Longitudinal } \\
\text { Sequence }\end{array}$ & $\begin{array}{c}\text { Evidence From Relevant Historical } \\
\text { Document }\end{array}$ & $\begin{array}{c}\text { Legal } \\
\text { Rejection } \\
\text { Type }\end{array}$ & $\begin{array}{l}\text { Total } \\
\text { citations }\end{array}$ & $\begin{array}{l}\text { Relevant } \\
\text { Citations }\end{array}$ & $\begin{array}{c}\text { Claim } \\
\text { Amendment }\end{array}$ & $\begin{array}{l}\text { Examiner } \\
\text { Outcome }\end{array}$ \\
\hline 1 & $\begin{array}{l}\text { Independent Claim " } 1 \text {. In a touch system } \\
\text { having a touch screen with a touch } \\
\text { surface on which an image is displayed, } \\
\text { a method of automatically mapping a } \\
\text { touch screen co-ordinate system to the } \\
\text { display co-ordinate system comprising } \\
\text { the steps of:" } \\
\text { Independent Claim " } 12 \text {. A touch system } \\
\text { comprising:" } \\
\text { "Claims } 1,2,4,5,6,12,13,14,31 \text { and } \\
32 \text { are rejected under } 35 \text { U.S.C. } 103(\text { a) } \\
\text { as being unpatentable over Zhang et al. } \\
\text { (US } 6,774,889 \text { B } 1 \text { ) in view of Pryor (US } \\
\text { 2002/0036617 A1)." } \\
\text { (Claims } 1 \text { and } 12 \text { are independent } \\
\text { apparatus claims). }\end{array}$ & Pooled & 65 & 2 & Yes & Rejection \\
\hline 2 & $\begin{array}{l}\text { "Claims } 1,2,4-6,12-14,31,32,33,35 \\
\text { and } 41-43 \text { are rejected under } 35 \text { U.S.C. } \\
\text { 102(b) as being anticipated by Pryor } \\
\text { (US 2002/0036617 A1)". }\end{array}$ & Sole & 65 & 1 & Yes & Rejection \\
\hline 3 & $\begin{array}{l}\text { "Claims } 1-7,9,1-15,18-26,27-31,35- \\
41 \text { and } 45-48 \text { are allowed". }\end{array}$ & Sole & 65 & 1 & No & $\begin{array}{l}\text { Notice of } \\
\text { Allowance }\end{array}$ \\
\hline
\end{tabular}

Table 45: Evidence Case 2: US7256772 Cited Citations.

\begin{tabular}{|c|c|c|c|c|c|c|}
\hline $\begin{array}{l}\text { Longitudinal } \\
\text { Sequence }\end{array}$ & $\begin{array}{c}\text { Evidence From Relevant Historical } \\
\text { Document }\end{array}$ & $\begin{array}{c}\text { Legal } \\
\text { Rejection } \\
\text { Type }\end{array}$ & $\begin{array}{c}\text { Total } \\
\text { citations }\end{array}$ & $\begin{array}{l}\text { Relevant } \\
\text { Citations }\end{array}$ & $\begin{array}{c}\text { Claim } \\
\text { Amendment }\end{array}$ & $\begin{array}{l}\text { Examiner } \\
\text { Outcome }\end{array}$ \\
\hline 1 & $\begin{array}{l}\text { Independent Claim " } 1 \text {. An object } \\
\text { detection calibration system } \\
\text { comprising:" } \\
\text { Independent Claim "7. A method of } \\
\text { performing object detection calibration } \\
\text { for a touch screen, the method } \\
\text { comprising:" } \\
\text { "The allowed claims(s) is/are 1-11." } \\
\text { (Claim } 1 \text { is an independent apparatus } \\
\text { claim and claim } 7 \text { is an independent } \\
\text { method claim). }\end{array}$ & N.A. & 13 & 0 & No & Allowance \\
\hline
\end{tabular}

Table 46: Evidence Case 2: US7256772 Citing US8462137 Citations.

\begin{tabular}{|c|c|c|c|c|c|c|}
\hline $\begin{array}{l}\text { Longitudinal } \\
\text { Sequence }\end{array}$ & $\begin{array}{c}\text { Evidence From Relevant Historical } \\
\text { Document }\end{array}$ & $\begin{array}{c}\text { Legal } \\
\text { Rejection } \\
\text { Type }\end{array}$ & $\begin{array}{c}\text { Total } \\
\text { citations }\end{array}$ & $\begin{array}{l}\text { Relevant } \\
\text { Citations }\end{array}$ & $\begin{array}{c}\text { Claim } \\
\text { Amendment }\end{array}$ & $\begin{array}{l}\text { Examiner } \\
\text { Outcome }\end{array}$ \\
\hline 1 & $\begin{array}{l}\text { Independent Claim "1. An image } \\
\text { processing apparatus comprising:" } \\
\text { Independent Claim "7. A method of } \\
\text { displaying an image, the method } \\
\text { comprising the steps of:" } \\
\text { Independent Claim " } 8 \text {. An image } \\
\text { display program that allows a computer } \\
\text { to function as:" } \\
\text { "The allowed claims(s) is/are 1-9." } \\
\text { (Claims } 1,8 \text { and } 9 \text { are independent } \\
\text { apparatus claims and claim } 7 \text { is an } \\
\text { independent method claim). }\end{array}$ & N.A. & 20 & 0 & No & Allowance \\
\hline
\end{tabular}

Table 47: Evidence Case 2 US7256772 Citing US8504944 Citations. 


\begin{tabular}{|c|c|c|c|c|c|c|}
\hline $\begin{array}{l}\text { Longitudinal } \\
\text { Sequence }\end{array}$ & $\begin{array}{c}\text { Evidence From Relevant Historical } \\
\text { Document }\end{array}$ & $\begin{array}{c}\text { Legal } \\
\text { Rejection } \\
\text { Type }\end{array}$ & $\begin{array}{l}\text { Total } \\
\text { citations }\end{array}$ & $\begin{array}{l}\text { Relevant } \\
\text { Citations }\end{array}$ & $\begin{array}{c}\text { Claim } \\
\text { Amendment }\end{array}$ & $\begin{array}{l}\text { Examiner } \\
\text { Outcome }\end{array}$ \\
\hline & $\begin{array}{l}\text { Independent Claim "1. An optical touch } \\
\text { system, comprising:" }\end{array}$ & & & & & \\
\hline 1 & $\begin{array}{l}\text { "Claim } 1,4, \& 5 \text { are rejected under } 35 \\
\text { U.S.C. } 103(\text { a) as being unpatentable } \\
\text { over Morrison (U.S. 7,256,772 B2) in } \\
\text { view of Yi (U.S. 2005/0017957 A1). } \\
\text { (Claim } 1 \text { is an independent apparatus } \\
\text { claim). }\end{array}$ & Pooled & 5 & 2 & Yes & Rejection \\
\hline 2 & $\begin{array}{l}\text { "Claim } 1,4, \& 5 \text { are rejected under } \\
\text { U.S.C. } 103(\text { a) as being unpatentable } \\
\text { over Morrison (U.S. 7,256,772 B2) in } \\
\text { view of Yi (U.S. 2005/0017957 A1). }\end{array}$ & Pooled & 5 & 2 & No & $\begin{array}{c}\text { Final } \\
\text { Rejection }\end{array}$ \\
\hline
\end{tabular}

Table 48: Evidence Case 2 US7256772 Citing US20120032922 Citations.

\section{B.3 Case 3 Document Examination And Attribute Coding.}

\begin{tabular}{|c|c|c|c|c|c|c|}
\hline $\begin{array}{l}\text { Longitudinal } \\
\text { Sequence }\end{array}$ & $\begin{array}{c}\text { Evidence From Relevant Historical } \\
\text { Document }\end{array}$ & $\begin{array}{c}\text { Legal } \\
\text { Rejection } \\
\text { Type }\end{array}$ & $\begin{array}{l}\text { Total } \\
\text { citations }\end{array}$ & $\begin{array}{l}\text { Relevant } \\
\text { Citations }\end{array}$ & $\begin{array}{c}\text { Claim } \\
\text { Amendment }\end{array}$ & $\begin{array}{l}\text { Examiner } \\
\text { Outcome }\end{array}$ \\
\hline 1 & $\begin{array}{l}\text { Independent Claim " } 1 \text {. An apparatus } \\
\text { (50) for detecting a pointer relative to a } \\
\text { touch surface }(54,254,354) \\
\text { comprising:" } \\
\text { "A. 54, } 56 \text { EPC } 3 \text {. Reference is made to } \\
\text { the following document: D1 WO } \\
\text { 02/03316 A (SMART } \\
\text { TECHNOLOGIES INC [CA]; } \\
\text { MORRISON GERALD [CA]; } \\
\text { HOLMGREN DAVID [CA] } 10 \text { January } \\
\text { 2002 (2002-01-10)." } \\
\text { "as the possibilities of amending the } \\
\text { application are limited and most subject- } \\
\text { matter is known from or not inventive in } \\
\text { the view of D1, the application is likely } \\
\text { to be refused." (Claim } 1 \text { is an } \\
\text { independent apparatus claim). }\end{array}$ & Sole & 4 & 1 & Yes & Rejection \\
\hline 2 & $\begin{array}{l}\text { "Main request A. 54, 56 EPC } 4 . \\
\text { Reference is made to the following } \\
\text { document: D1 WO 02/03316 A } \\
\text { (SMART TECHNOLOGIES INC [CA]; } \\
\text { MORRISON GERALD [CA]; } \\
\text { HOLMGREN DAVID [CA] } 10 \text { January } \\
2002 \text { (2002-01-10)." } \\
\text { "Hence none of claims 2-10 was } \\
\text { apparently meeting the requirements of } \\
\text { Art. 56 EPC." } \\
\text { "The division refused the application } \\
\text { Article 97(2) EPC for reasons given } \\
\text { above, as none of the requests fulfill the } \\
\text { requirements of the EPC." }\end{array}$ & Sole & 4 & 1 & No & $\begin{array}{l}\text { Refusal to } \\
\text { Grant }\end{array}$ \\
\hline
\end{tabular}

Table 49: Evidence Case 3 EP1766501 Cited Citations. 


\section{B.4 Case 4 Document Examination And Attribute Coding.}

\begin{tabular}{|c|c|c|c|c|c|c|}
\hline $\begin{array}{l}\text { Longitudinal } \\
\text { Sequence }\end{array}$ & $\begin{array}{c}\text { Evidence From Relevant Historical } \\
\text { Document }\end{array}$ & $\begin{array}{c}\text { Legal } \\
\text { Rejection } \\
\text { Type }\end{array}$ & $\begin{array}{l}\text { Total } \\
\text { citations }\end{array}$ & $\begin{array}{l}\text { Relevant } \\
\text { Citations }\end{array}$ & $\begin{array}{c}\text { Claim } \\
\text { Amendment }\end{array}$ & $\begin{array}{l}\text { Examiner } \\
\text { Outcome }\end{array}$ \\
\hline 1 & $\begin{array}{l}\text { Independent Claim " } 1 . \text { An apparatus for } \\
\text { detecting a pointer relative to a touch } \\
\text { surface comprising:" } \\
\text { Independent Claim " } 55 \text {. A camera-based } \\
\text { touch system comprising:" } \\
\text { Independent Claim " } 63 \text {. An apparatus } \\
\text { for detecting a pointer relative to a } \\
\text { generally rectangular touch surface } \\
\text { comprising:" } \\
\text { "Claims } 1-7,9-10,53-59,63-65 \text { are } \\
\text { rejected under } 35 \text { U.S.C. } 102(\text { b) as being } \\
\text { anticipated by Dunthorn ( } 5,317,140) . " \\
\text { "Claim } 8 \text { is rejected under } 35 \text { U.S.C. } \\
\text { 103(a) as being unpatentable over } \\
\text { Dunthorn." (Claims } 1,55, \text { and } 63 \text { are } \\
\text { independent apparatus claims) }\end{array}$ & Sole & 101 & 1 & Yes & Rejection \\
\hline 2 & $\begin{array}{l}\text { "Claims } 1-7,9-10,53-59,63-65 \text { are } \\
\text { rejected under } 35 \text { U.S.C. 102(b) as being } \\
\text { anticipated by Dunthorn }(5,316,140) . " \\
\text { "Claim } 8 \text { is rejected under } 35 \text { U.S.C. } \\
103 \text { (a) as being unpatentable over } \\
\text { Dunthorn." }\end{array}$ & Sole & 101 & 1 & Yes & Rejection \\
\hline 3 & $\begin{array}{l}\text { "The allowed claim(s) is/are } 1-39,52- \\
56,59-79, \text { renumbered as } 1-75 " .\end{array}$ & Sole & 101 & 1 & No & $\begin{array}{l}\text { Notice of } \\
\text { Allowance }\end{array}$ \\
\hline
\end{tabular}

Table 50: Evidence Case 4 US7492357 Cited Citations.

\begin{tabular}{|c|c|c|c|c|c|c|}
\hline $\begin{array}{l}\text { Longitudinal } \\
\text { Sequence }\end{array}$ & $\begin{array}{c}\text { Evidence From Relevant Historical } \\
\text { Document }\end{array}$ & $\begin{array}{c}\text { Legal } \\
\text { Rejection } \\
\text { Type }\end{array}$ & $\begin{array}{l}\text { Total } \\
\text { citations }\end{array}$ & $\begin{array}{l}\text { Relevant } \\
\text { Citations }\end{array}$ & $\begin{array}{c}\text { Claim } \\
\text { Amendment }\end{array}$ & $\begin{array}{l}\text { Examiner } \\
\text { Outcome }\end{array}$ \\
\hline 1 & $\begin{array}{l}\text { Independent Claim "1. An interactive } \\
\text { display system comprising:" } \\
\text { Independent Claim " } 14 \text {. An image } \\
\text { merging mechanism for use with an } \\
\text { interactive display system" } \\
\text { "Claims } 1-5,7,12,13 \text { and } 18-20 \text { are } \\
\text { rejected under } 35 \text { U.S.C. 102(b) as being } \\
\text { anticipated by US Pub. No. } \\
\text { 2005/0162381 A1 filed by Bell et al., } \\
\text { hereinafter 'Bell'." } \\
\text { "Claims } 8-11 \text { and } 14-16 \text { are rejected } \\
\text { under } 35 \text { U.S.C. } 103 \text { (a) as being } \\
\text { unpatentable over Bell in view of US } \\
\text { Patent No. 6,975,360 B2 issued to } \\
\text { Slatter. }\end{array}$ & $\begin{array}{l}\text { Claim } 1 \\
\text { Sole } \\
\text { Claim } 14 \\
\text { pooled }\end{array}$ & 27 & 2 & Yes & Rejection \\
\hline 2 & "The allowed claim(s) is/are 1-31." & $\begin{array}{l}\text { Sole and } \\
\text { Pooled }\end{array}$ & 27 & 2 & No & $\begin{array}{l}\text { Notice of } \\
\text { Allowance }\end{array}$ \\
\hline
\end{tabular}

Table 51: Evidence Case 4 US7492357 Citing US763002 Citations. 


\begin{tabular}{|c|l|c|c|c|c|}
\hline $\begin{array}{c}\text { Longitudinal } \\
\text { Sequence }\end{array}$ & $\begin{array}{c}\text { Evidence From Relevant Historical } \\
\text { Document }\end{array}$ & $\begin{array}{c}\text { Legal } \\
\text { Rejection } \\
\text { Type }\end{array}$ & $\begin{array}{c}\text { Total } \\
\text { citations }\end{array}$ & $\begin{array}{c}\text { Relevant } \\
\text { Citations }\end{array}$ & $\begin{array}{c}\text { Claim } \\
\text { Amendment } \\
\text { Outcome }\end{array}$ \\
\hline & $\begin{array}{l}\text { Independent Claim “1. A mounting } \\
\text { assembly for mounting an optical } \\
\text { member to a panel, comprising:" } \\
\text { Independent Claim "9. An optical } \\
\text { member mounting assembly } \\
\text { comprising:" } \\
\text { "The Allowed claim(s) is/are 1-14." }\end{array}$ & N.A. & 17 & 0 & Notice of \\
Allowance
\end{tabular}

Table 52: Evidence Case 4 US7492357 Citing US 7751671 Citations.

\begin{tabular}{|c|c|c|c|c|c|c|}
\hline $\begin{array}{l}\text { Longitudinal } \\
\text { Sequence }\end{array}$ & $\begin{array}{c}\text { Evidence From Relevant Historical } \\
\text { Document }\end{array}$ & $\begin{array}{c}\text { Legal } \\
\text { Rejection } \\
\text { Type }\end{array}$ & $\begin{array}{c}\text { Total } \\
\text { citations }\end{array}$ & $\begin{array}{l}\text { Relevant } \\
\text { Citations }\end{array}$ & $\begin{array}{c}\text { Claim } \\
\text { Amendment }\end{array}$ & $\begin{array}{l}\text { Examiner } \\
\text { Outcome }\end{array}$ \\
\hline 1 & $\begin{array}{l}\text { Independent Claim "1. An object } \\
\text { detection calibration system } \\
\text { comprising:" } \\
\text { Independent Claim "7. A method of } \\
\text { performing object detection calibration } \\
\text { for a touch screen, the method } \\
\text { comprising:" } \\
\text { "The allowed claim(s) is/are 1-11) }\end{array}$ & N.A. & 13 & 0 & No & $\begin{array}{l}\text { Notice of } \\
\text { Allowance }\end{array}$ \\
\hline
\end{tabular}

Table 53: Evidence Case 4 US7492357 Citing US8462137 Citations.

\begin{tabular}{|c|c|c|c|c|c|c|}
\hline $\begin{array}{l}\text { Longitudinal } \\
\text { Sequence }\end{array}$ & $\begin{array}{c}\text { Evidence From Relevant Historical } \\
\text { Document }\end{array}$ & $\begin{array}{c}\text { Legal } \\
\text { Rejection } \\
\text { Type }\end{array}$ & $\begin{array}{c}\text { Total } \\
\text { citations }\end{array}$ & $\begin{array}{l}\text { Relevant } \\
\text { Citations }\end{array}$ & $\begin{array}{c}\text { Claim } \\
\text { Amendment }\end{array}$ & $\begin{array}{l}\text { Examiner } \\
\text { Outcome }\end{array}$ \\
\hline 1 & $\begin{array}{l}\text { Independent Claim "1. An image } \\
\text { processing apparatus comprising:" } \\
\text { Independent Claim "7. A method of } \\
\text { displaying an image, the method } \\
\text { comprising the steps of:" } \\
\text { Independent Claim "8. An image } \\
\text { display program that allows a computer } \\
\text { to function as:" } \\
\text { "The allowed claim(s) is/are 1-9." }\end{array}$ & N.A. & 20 & 0 & No & $\begin{array}{l}\text { Notice of } \\
\text { Allowance }\end{array}$ \\
\hline
\end{tabular}

Table 54: Evidence Case 4 US7492357 Citing US8504944 Citations. 


\section{B.5 Case 5 Document Examination And Attribute Coding.}

\begin{tabular}{|c|c|c|c|c|c|c|}
\hline $\begin{array}{l}\text { Longitudinal } \\
\text { Sequence }\end{array}$ & $\begin{array}{c}\text { Evidence From Relevant Historical } \\
\text { Document }\end{array}$ & $\begin{array}{c}\text { Legal } \\
\text { Rejection } \\
\text { Type } \\
\end{array}$ & $\begin{array}{l}\text { Total } \\
\text { citations }\end{array}$ & $\begin{array}{l}\text { Relevant } \\
\text { Citations }\end{array}$ & $\begin{array}{c}\text { Claim } \\
\text { Amendment }\end{array}$ & $\begin{array}{l}\text { Examiner } \\
\text { Outcome }\end{array}$ \\
\hline 1 & $\begin{array}{l}\text { Independent Claim "1. A camera-based } \\
\text { touch system (50) comprising:" } \\
\text { Independent Claim "13. A camera-based } \\
\text { touch system comprising:" } \\
\text { Independent Claim "17. A method of } \\
\text { detecting the position of a pointer } \\
\text { relative to a touch surface comprising } \\
\text { the steps of:" } \\
\text { "The following documents (D) are } \\
\text { referred to in this communication; the } \\
\text { numbering will be adhered to in the rest } \\
\text { of the procedure: D1: WO 99 } 40562 \text { A } \\
\text { (AZARIA HAIM; LEV JOSEPH (IL) } \\
12 \text { August } 1999 \text { (1999-08-12) D2: US- } \\
\text { A-4 746 770 (MCAVINNEY PAUL) } 24 \\
\text { May } 1988 \text { (1988-05-24) D3: DE } 19810 \\
452 \text { A (WACOM CO LTD) } 17 \\
\text { December 1998 (1998-12-17)." } \\
\text { "Notwithstanding the objections raised } \\
\text { in point } 2 \text { above, concerning clarity of } \\
\text { the claims, the subject-matter of } \\
\text { independent claims 1, 13 and } 17 \text { do not } \\
\text { appear to be new." }\end{array}$ & Sole & 3 & 1 & Yes & Rejection \\
\hline 2 & $\begin{array}{l}\text { "Therefore claim } 1 \text { has not been } \\
\text { amended so as to contain subject-matter } \\
\text { which is new over the prior art } \\
\text { according to D } 1 \ldots \text { The statements made } \\
\text { to the system claim } 1 \text { apply to the } \\
\text { method claim } 19 \text { respectively" }\end{array}$ & $\begin{array}{c}\text { Sole Claim } \\
1 \text { and sole } \\
\text { claim } 19\end{array}$ & 3 & 1 & Yes & Rejection \\
\hline 3 & $\begin{array}{l}\text { "Reference is made that the criterion for } \\
\text { lack of novelty is not literal identify } \\
\text { with a prior art document as it has been } \\
\text { repeatedly held by the Boards of Appeal } \\
\text { of the EPO; the deceive question rather } \\
\text { is what teachings have been made } \\
\text { available to a skilled person by said } \\
\text { document. Thus, system of claim } 1 \text { and } \\
\text { the method according to claim } 19 \text { is not } \\
\text { new." } \\
\text { "Thus, the system of claim } 1 \text { and the } \\
\text { method according to claim } 19 \text { does not } \\
\text { involve an inventive step". }\end{array}$ & $\begin{array}{c}\text { Sole Claim } \\
1 \text { and sole } \\
\text { claim } 19\end{array}$ & 3 & 1 & Yes & Rejection \\
\hline 4 & $\begin{array}{l}\text { "Decision to grant a European patent } \\
\text { pursuant to article } 97(2) \text { EPC. }\end{array}$ & $\begin{array}{c}\text { Sole Claim } \\
1 \text { and sole } \\
\text { claim } 19\end{array}$ & 3 & 1 & No & $\begin{array}{l}\text { Decision } \\
\text { to Grant }\end{array}$ \\
\hline
\end{tabular}

Table 55: Evidence Case 5 EP1297488 cited Citations. 


\begin{tabular}{|c|c|c|c|c|c|c|}
\hline $\begin{array}{l}\text { Longitudinal } \\
\text { Sequence }\end{array}$ & $\begin{array}{c}\text { Evidence From Relevant Historical } \\
\text { Document }\end{array}$ & $\begin{array}{c}\text { Legal } \\
\text { Rejection } \\
\text { Type }\end{array}$ & $\begin{array}{c}\text { Total } \\
\text { citations }\end{array}$ & $\begin{array}{l}\text { Relevant } \\
\text { Citations }\end{array}$ & $\begin{array}{c}\text { Claim } \\
\text { Amendment }\end{array}$ & $\begin{array}{l}\text { Examiner } \\
\text { Outcome }\end{array}$ \\
\hline 1 & $\begin{array}{l}\text { Independent Claim "1. A method of } \\
\text { aligning digital cameras (63) in a touch } \\
\text { system (50) having a touch surface (60) } \\
\text { on which pointer contacts are to be } \\
\text { made, each digital camera (63) having a } \\
\text { selectable pixel array, said method } \\
\text { comprising the steps of:" } \\
\text { "The following document (D) is cited by } \\
\text { the Examiner (see Guidelines C-VI, } 8.2 \\
\text { and } 8.3 \text { ). A copy of the document is } \\
\text { annexed to the communication and the } \\
\text { numbering will be adhered to in the rest } \\
\text { of the procedure: D4: WO 99/40562". } \\
\text { "As acknowledged in D4 (page } 6, \text { figs. } \\
5,8 \text { and corresponding description), it is } \\
\text { well known to capture images from } \\
\text { different angle and by utilizing the Z } \\
\text { axis (vertical coordinates) displacement } \\
\text { of touches relative to the surface can be } \\
\text { easily tracked. Hence, newly filed } \\
\text { method claim } 1 \text { is not allowable." }\end{array}$ & $\begin{array}{l}\text { Sole Claim } \\
\quad 1\end{array}$ & 5 & 1 & Yes & Rejection \\
\hline 2 & $\begin{array}{l}\text { "You are informed that the Examining } \\
\text { Division intends to grant a European } \\
\text { patent on the basis of the above } \\
\text { application with the text and drawings } \\
\text { as indicated below:" }\end{array}$ & $\begin{array}{l}\text { Sole Claim } \\
\quad 1\end{array}$ & 5 & 1 & No & $\begin{array}{l}\text { Decision } \\
\text { to Grant }\end{array}$ \\
\hline
\end{tabular}

Table 56: Evidence Case 5 EP1739528 Cited Citations.

\begin{tabular}{|c|c|c|c|c|c|c|}
\hline $\begin{array}{l}\text { Longitudinal } \\
\text { Sequence }\end{array}$ & $\begin{array}{c}\text { Evidence From Relevant Historical } \\
\text { Document }\end{array}$ & $\begin{array}{c}\text { Legal } \\
\text { Rejection } \\
\text { Type }\end{array}$ & $\begin{array}{c}\text { Total } \\
\text { citations }\end{array}$ & $\begin{array}{l}\text { Relevant } \\
\text { Citations }\end{array}$ & $\begin{array}{c}\text { Claim } \\
\text { Amendment }\end{array}$ & $\begin{array}{l}\text { Examiner } \\
\text { Outcome }\end{array}$ \\
\hline 1 & $\begin{array}{l}\text { Independent Claim "1. A camera-based } \\
\text { touch system comprising:" } \\
\text { Independent Claim "17. A method of } \\
\text { detecting the position of a pointer within } \\
\text { a region of interest, comprising:" } \\
\text { "You are informed that the Examining } \\
\text { Division intends to grant a European } \\
\text { patent on the basis of the above } \\
\text { application with the text and drawings } \\
\text { as indicated below:" }\end{array}$ & N.A. & 7 & 0 & No & $\begin{array}{l}\text { Decision } \\
\text { To Grant }\end{array}$ \\
\hline
\end{tabular}

Table 57: Evidence Case 5 EP1739529 Cited Citations.

\begin{tabular}{|c|c|c|c|c|c|c|}
\hline $\begin{array}{l}\text { Longitudinal } \\
\text { Sequence }\end{array}$ & $\begin{array}{c}\text { Evidence From Relevant Historical } \\
\text { Document }\end{array}$ & $\begin{array}{c}\text { Legal } \\
\text { Rejection } \\
\text { Type }\end{array}$ & $\begin{array}{c}\text { Total } \\
\text { citations }\end{array}$ & $\begin{array}{l}\text { Relevant } \\
\text { Citations }\end{array}$ & $\begin{array}{c}\text { Claim } \\
\text { Amendment }\end{array}$ & $\begin{array}{l}\text { Examiner } \\
\text { Outcome }\end{array}$ \\
\hline 1 & $\begin{array}{l}\text { Independent Claim "1. An interactive } \\
\text { input system comprising:" } \\
\text { Independent Claim "8. A touch system } \\
\text { comprising:" } \\
\text { Independent Claim "12. An interactive } \\
\text { input system comprising:" } \\
\text { "You are informed that the Examining } \\
\text { Division intends to grant a European } \\
\text { patent on the basis of the above } \\
\text { application with the text and drawings } \\
\text { as indicated below:" }\end{array}$ & $\begin{array}{l}\text { Sole claim } \\
1, \text { pooled } \\
\text { claim } 8 \text { and } \\
\text { pooled } \\
\text { claim } 12\end{array}$ & 10 & 0 & No & $\begin{array}{l}\text { Decision } \\
\text { To Grant }\end{array}$ \\
\hline
\end{tabular}

Table 58: Evidence Case 5 EP1297488 Citing EP2089791 Citations. 


\section{B.6 Case 6 Document Examination And Attribute Coding.}

\begin{tabular}{|c|c|c|c|c|c|c|}
\hline $\begin{array}{l}\text { Longitudinal } \\
\text { Sequence }\end{array}$ & $\begin{array}{c}\text { Evidence From Relevant Historical } \\
\text { Document }\end{array}$ & $\begin{array}{l}\text { Legal } \\
\text { Rejection } \\
\text { Type }\end{array}$ & $\begin{array}{l}\text { Total } \\
\text { citations }\end{array}$ & $\begin{array}{l}\text { Relevant } \\
\text { Citations }\end{array}$ & $\begin{array}{c}\text { Claim } \\
\text { Amendment }\end{array}$ & $\begin{array}{l}\text { Examiner } \\
\text { Outcome }\end{array}$ \\
\hline 1 & $\begin{array}{l}\text { Independent Claim "1. A camera-based } \\
\text { touch system comprising:" } \\
\text { Independent Claim " } 25 \text {. A camera-based } \\
\text { touch system comprising:" } \\
\text { Independent Claim " } 46 \text {. A method of } \\
\text { detecting the position of a pointer } \\
\text { relative to a touch surface comprising } \\
\text { the steps of:" } \\
\text { "Claims } 1-5,25-27,43-49 \text { are rejected } \\
\text { under } 35 \text { U.S.C. } 102(\text { b) as being } \\
\text { anticipated by McAvinney (US Patent } \\
\text { No. } 4,746,770) . "\end{array}$ & $\begin{array}{l}\text { Sole Claim } \\
1, \text { sole } \\
\text { claim } 25 \\
\text { and sole } \\
\text { claim } 46\end{array}$ & 103 & 1 & Yes & Rejection \\
\hline 2 & $\begin{array}{l}\text { "Claims 1-4, 25-26, 43-46, 48-49 are } \\
\text { rejected under } 35 \text { U.S.C. 102(b) as being } \\
\text { anticipated by McAvinney (US Patent } \\
\text { No. } 4,746,770) . "\end{array}$ & $\begin{array}{l}\text { Sole Claim } \\
1, \text { sole } \\
\text { claim } 25 \\
\text { and sole } \\
\text { claim } 46\end{array}$ & 103 & 1 & Yes & Rejection \\
\hline 3 & $\begin{array}{l}\text { "Claims 1-4, 25-26, 43-46, 48-49 are } \\
\text { rejected under } 35 \text { U.S.C. 102(b) as being } \\
\text { anticipated by McAvinney (US Patent } \\
\text { No. 4,746,770)." }\end{array}$ & $\begin{array}{l}\text { Sole Claim } \\
1, \text { sole } \\
\text { claim } 25 \\
\text { and sole } \\
\text { claim } 46\end{array}$ & 103 & 1 & Yes & Rejection \\
\hline 4 & $\begin{array}{l}\text { "Claims 1-4, 25-26, 43-46, 48-49, } 51 \text { are } \\
\text { rejected under } 35 \text { U.S.C. 103(a) as being } \\
\text { unpatentable over McAvinney (US } \\
\text { Patent No. 4,746,770)." }\end{array}$ & $\begin{array}{l}\text { Sole Claim } \\
1, \text { sole } \\
\text { claim } 25 \\
\text { and sole } \\
\text { claim } 46\end{array}$ & 103 & 1 & Yes & Rejection \\
\hline 5 & $\begin{array}{l}\text { "Claims 1-4, 25-26, 43-46, 48-49, } 51 \text { are } \\
\text { rejected under } 35 \text { U.S.C. 103(a) as being } \\
\text { unpatentable over McAvinney (US } \\
\text { Patent No. 4,746,770)." }\end{array}$ & $\begin{array}{l}\text { Sole Claim } \\
1, \text { sole } \\
\text { claim } 25 \\
\text { and sole } \\
\text { claim } 46\end{array}$ & 103 & 1 & Yes & Rejection \\
\hline 6 & $\begin{array}{l}\text { "Claims } 1-4,25-26,43-46,48-49,51 \text { are } \\
\text { rejected under } 35 \text { U.S.C. 103(a) as being } \\
\text { unpatentable over McAvinney } \\
(4,746,770) \text { in view of Dunthom } \\
(5,317,140) \text {. }\end{array}$ & Pooled & 103 & 2 & Yes & Rejection \\
\hline 7 & $\begin{array}{l}\text { "The allowed claim(s) is/are } 1-2,4,7- \\
14,20-23,25,28-35,39-73 \text {, renumbered } \\
\text { as } 1-56 . "\end{array}$ & Pooled & 103 & 2 & No & $\begin{array}{l}\text { Notice of } \\
\text { Allowance }\end{array}$ \\
\hline
\end{tabular}

Table 59: Evidence Case 6: US7692625 Cited Citations.

\begin{tabular}{|c|c|c|c|c|c|c|}
\hline $\begin{array}{l}\text { Longitudinal } \\
\text { Sequence }\end{array}$ & $\begin{array}{c}\text { Evidence From Relevant Historical } \\
\text { Document }\end{array}$ & $\begin{array}{c}\text { Legal } \\
\text { Rejection } \\
\text { Type } \\
\end{array}$ & $\begin{array}{l}\text { Total } \\
\text { citations }\end{array}$ & $\begin{array}{l}\text { Relevant } \\
\text { Citations }\end{array}$ & $\begin{array}{c}\text { Claim } \\
\text { Amendment }\end{array}$ & $\begin{array}{l}\text { Examiner } \\
\text { Outcome }\end{array}$ \\
\hline 1 & $\begin{array}{l}\text { Independent Claim " } 1 . \text { A position } \\
\text { detection system comprising:" } \\
\text { "Claims } 1,2 \text { and } 5 \text { are rejected under } 5 \\
\text { U.S.C. } 103 \text { (a) as being unpatentable } \\
\text { over Kobayashi (US } 7,515,141 \text { ) in view } \\
\text { of Ishino et al. (US } 6,727,885 \text { ) }\end{array}$ & $\begin{array}{l}\text { Pooled } \\
\text { claim } 1\end{array}$ & 49 & 2 & Yes & Rejection \\
\hline 2 & "The allowed claim(s) is/are 1-13. & $\begin{array}{l}\text { Pooled } \\
\text { claim } 1\end{array}$ & 49 & 2 & No & $\begin{array}{l}\text { Notice of } \\
\text { Allowance }\end{array}$ \\
\hline
\end{tabular}

Table 60: Evidence Case 6 US7692625 Citing US7932899 Citations. 


\begin{tabular}{|c|c|c|c|c|c|c|}
\hline $\begin{array}{l}\text { Longitudinal } \\
\text { Sequence }\end{array}$ & $\begin{array}{c}\text { Evidence From Relevant Historical } \\
\text { Document }\end{array}$ & $\begin{array}{c}\text { Legal } \\
\text { Rejection } \\
\text { Type }\end{array}$ & $\begin{array}{l}\text { Total } \\
\text { citations }\end{array}$ & $\begin{array}{l}\text { Relevant } \\
\text { Citations }\end{array}$ & $\begin{array}{c}\text { Claim } \\
\text { Amendment }\end{array}$ & $\begin{array}{l}\text { Examiner } \\
\text { Outcome }\end{array}$ \\
\hline 1 & $\begin{array}{l}\text { Independent Claim "1. A sensing } \\
\text { system, comprising:" } \\
\text { Independent Claim "12. A sensing } \\
\text { system, comprising:" } \\
\text { Independent Claim "26. A method for } \\
\text { obtaining a location of a pointer" } \\
\text { Independent Claim "28. A method for } \\
\text { obtain allocation of a pointer" } \\
\text { "The allowed claim(s) is/are } 1-57 . "\end{array}$ & N.A. & 14 & 0 & No & $\begin{array}{l}\text { Notice of } \\
\text { Allowance }\end{array}$ \\
\hline
\end{tabular}

Table 61: Evidence Case 6 US7692625 Citing US8131502 Citations.

\begin{tabular}{|c|c|c|c|c|c|c|}
\hline $\begin{array}{l}\text { Longitudinal } \\
\text { Sequence }\end{array}$ & $\begin{array}{c}\text { Evidence From Relevant Historical } \\
\text { Document }\end{array}$ & $\begin{array}{c}\text { Legal } \\
\text { Rejection } \\
\text { Type }\end{array}$ & $\begin{array}{c}\text { Total } \\
\text { citations }\end{array}$ & $\begin{array}{l}\text { Relevant } \\
\text { Citations }\end{array}$ & $\begin{array}{c}\text { Claim } \\
\text { Amendment }\end{array}$ & $\begin{array}{l}\text { Examiner } \\
\text { Outcome }\end{array}$ \\
\hline 1 & $\begin{array}{l}\text { Independent Claim " } 1 \text {. A sensing system } \\
\text { adapted to sense a pointer and calculate } \\
\text { a location of the pointer, comprising:" } \\
\text { Independent Claim " } 10 \text {. A the sensing } \\
\text { system adapted to sense a pointer and } \\
\text { calculate a location of the pointer, } \\
\text { comprising:" } \\
\text { "The allowed claim(s) is/are 1-11". }\end{array}$ & N.A. & 14 & 0 & No & $\begin{array}{l}\text { Notice of } \\
\text { Allowance }\end{array}$ \\
\hline
\end{tabular}

Table 62: Evidence Case 6 US7692625 Citing US8135561 Citations.

\begin{tabular}{|c|c|c|c|c|c|c|}
\hline $\begin{array}{l}\text { Longitudinal } \\
\text { Sequence }\end{array}$ & $\begin{array}{c}\text { Evidence From Relevant Historical } \\
\text { Document }\end{array}$ & $\begin{array}{c}\text { Legal } \\
\text { Rejection } \\
\text { Type }\end{array}$ & $\begin{array}{c}\text { Total } \\
\text { citations }\end{array}$ & $\begin{array}{l}\text { Relevant } \\
\text { Citations }\end{array}$ & $\begin{array}{l}\text { Claim } \\
\text { Amendment }\end{array}$ & $\begin{array}{l}\text { Examiner } \\
\text { Outcome }\end{array}$ \\
\hline 1 & $\begin{array}{l}\text { Independent Claim "1. A method } \\
\text { comprising:" } \\
\text { Independent Claim "13. A method } \\
\text { comprising:" } \\
\text { Independent Claim " } 23 \text {. A method } \\
\text { comprising:" } \\
\text { Independent Claim "33. A method } \\
\text { comprising:" } \\
\text { Claims 1-12 rejected under } 35 \text { U.S.C. } \\
\text { 103(a) as being unpatentable over Pryor } \\
\text { Timothy R (US7084859 B1) in view of } \\
\text { Pryor Timothy R et al. (US 5854491 A) } \\
\text { and William R. Rympalski et al. (US } \\
\text { 4,639,720 A)." }\end{array}$ & $\begin{array}{l}\text { Pooled } \\
\text { claim } 1\end{array}$ & 115 & 3 & Yes & Rejection \\
\hline 2 & "The allowed claim(s) is/are 13-36 & None & 115 & 0 & No & $\begin{array}{c}\text { Claims 1- } \\
12 \\
\text { cancelled } \\
\text { and Notice } \\
\text { of } \\
\text { Allowance }\end{array}$ \\
\hline
\end{tabular}

Table 63: Evidence Case 6 US7692625 Citing US8228304 Citations. 


\begin{tabular}{|c|c|c|c|c|c|c|}
\hline $\begin{array}{l}\text { Longitudinal } \\
\text { Sequence }\end{array}$ & $\begin{array}{c}\text { Evidence From Relevant Historical } \\
\text { Document }\end{array}$ & $\begin{array}{c}\text { Legal } \\
\text { Rejection } \\
\text { Type }\end{array}$ & $\begin{array}{l}\text { Total } \\
\text { citations }\end{array}$ & $\begin{array}{l}\text { Relevant } \\
\text { Citations }\end{array}$ & $\begin{array}{c}\text { Claim } \\
\text { Amendment }\end{array}$ & $\begin{array}{l}\text { Examiner } \\
\text { Outcome }\end{array}$ \\
\hline 1 & $\begin{array}{l}\text { Independent Claim " } 1 \text {. A sensing system } \\
\text { adapted to sense a pointer and calculate } \\
\text { a location of the pointer, comprising:" } \\
\text { Claims } 1-3,5,9,11,15-16 \text { and } 18-19 \\
\text { are rejected under } 35 \text { U.S.C. } 102 \text { (b) as } \\
\text { being anticipated by Ung (patent App. } \\
\text { Pub. No. US } 2005 / 0243070) \text {. }\end{array}$ & $\begin{array}{c}\text { Sole claim } \\
1\end{array}$ & 15 & 1 & Yes & Rejection \\
\hline 2 & $\begin{array}{l}\text { "The allowed claim(s) is/are 1-5, 7-11 } \\
\text { and } 15-21 . "\end{array}$ & $\begin{array}{c}\text { Sole claim } \\
1\end{array}$ & 15 & 1 & No & $\begin{array}{l}\text { Notice of } \\
\text { Allowance }\end{array}$ \\
\hline
\end{tabular}

Table 64: Evidence Case 6 US7692625 Citing US8232511 Citations.

\begin{tabular}{|c|c|c|c|c|c|c|}
\hline $\begin{array}{l}\text { Longitudinal } \\
\text { Sequence }\end{array}$ & $\begin{array}{c}\text { Evidence From Relevant Historical } \\
\text { Document }\end{array}$ & $\begin{array}{c}\text { Legal } \\
\text { Rejection } \\
\text { Type }\end{array}$ & $\begin{array}{l}\text { Total } \\
\text { citations }\end{array}$ & $\begin{array}{l}\text { Relevant } \\
\text { Citations }\end{array}$ & $\begin{array}{c}\text { Claim } \\
\text { Amendment }\end{array}$ & $\begin{array}{l}\text { Examiner } \\
\text { Outcome }\end{array}$ \\
\hline 1 & $\begin{array}{l}\text { Independent Claim "1. A sensing } \\
\text { system, comprising:" }\end{array}$ & N.A. & 28 & & & \\
\hline
\end{tabular}

Table 65: Evidence Case 6 US7692625 Citing US8305363 Citations.

\begin{tabular}{|c|c|c|c|c|c|c|}
\hline $\begin{array}{l}\text { Longitudinal } \\
\text { Sequence }\end{array}$ & $\begin{array}{c}\text { Evidence From Relevant Historical } \\
\text { Document }\end{array}$ & $\begin{array}{c}\text { Legal } \\
\text { Rejection } \\
\text { Type }\end{array}$ & $\begin{array}{c}\text { Total } \\
\text { citations }\end{array}$ & $\begin{array}{l}\text { Relevant } \\
\text { Citations }\end{array}$ & $\begin{array}{c}\text { Claim } \\
\text { Amendment }\end{array}$ & $\begin{array}{c}\text { Examiner } \\
\text { Outcome }\end{array}$ \\
\hline 1 & $\begin{array}{l}\text { Independent Claim "1. A position } \\
\text { detection apparatus for detecting a } \\
\text { pointing device being situation on a } \\
\text { detection plane, said position detection } \\
\text { apparatus comprising:" } \\
\text { Independent Claim " } 21 \text {. A position } \\
\text { detection apparatus for detecting a } \\
\text { pointing device being situated on a } \\
\text { detection lane, the position detection } \\
\text { apparatus comprising:" } \\
\text { "The allowed claim(s) is/are 1-9." }\end{array}$ & $\begin{array}{l}\text { Pooled } \\
\text { Claim } 1\end{array}$ & 80 & 0 & No & $\begin{array}{l}\text { Notice of } \\
\text { Allowance }\end{array}$ \\
\hline
\end{tabular}

Table 66: Evidence Case 6 US7692625 Citing US8330726 Citations. 


\begin{tabular}{|c|c|c|c|c|c|c|}
\hline $\begin{array}{l}\text { Longitudinal } \\
\text { Sequence }\end{array}$ & $\begin{array}{c}\text { Evidence From Relevant Historical } \\
\text { Document }\end{array}$ & $\begin{array}{c}\text { Legal } \\
\text { Rejection } \\
\text { Type }\end{array}$ & $\begin{array}{l}\text { Total } \\
\text { citations }\end{array}$ & $\begin{array}{l}\text { Relevant } \\
\text { Citations }\end{array}$ & $\begin{array}{c}\text { Claim } \\
\text { Amendment }\end{array}$ & $\begin{array}{l}\text { Examiner } \\
\text { Outcome }\end{array}$ \\
\hline 1 & $\begin{array}{l}\text { Independent Claim "1. An interactive } \\
\text { input system comprising:" } \\
\text { Independent Claim " } 23 \text {. An interactive } \\
\text { input system comprising:" } \\
\text { "Claims } 1,3,12-18,21-23 \text { and } 30 \text { are } \\
\text { rejected under } 35 \text { U.S.C. } 103 \text { (a) as being } \\
\text { unpatentable over Yoshimura (US } \\
7,456,824 \text { B2) in view of Nakazawa et } \\
\text { al. (US 6,492633 b2; hereinafter referred } \\
\text { to as Nakazawa)." }\end{array}$ & $\begin{array}{c}\text { Pooled } \\
\text { claim } 1 \text { and } \\
\text { pooled } \\
\text { claim } 23\end{array}$ & 16 & 2 & Yes & Rejection \\
\hline 2 & $\begin{array}{l}\text { "Claims } 1,12-18,21-23,33,34,40-41 \\
\text { and } 38-39 \text { are rejected under U.S.C. } \\
\text { 103(a) as being unpatentable over } \\
\text { Yoshimura (US 7,456,824 B2) in view } \\
\text { of Nakazawa et al. (US 6,492,633 B2; } \\
\text { hereinafter referred to as Nakazawa) and } \\
\text { further in view of Scharff et al. *US } \\
6,411,287 \text { B1; hereinafter referred to as } \\
\text { Schafrr)." }\end{array}$ & $\begin{array}{c}\text { Pooled } \\
\text { Claim } 1 \\
\text { and pooled } \\
\text { claim } 23\end{array}$ & 16 & 3 & Yes & Rejection \\
\hline 3 & $\begin{array}{l}\text { "Claims } 1,12-23,38-39 \text { and } 40-41 \text { are } \\
\text { rejected under } 35 \text { U.S.C. } 103 \text { (a) as being } \\
\text { unpatentable over Yoshimura (US } \\
7,456,824 \text { B2) in view of Nakazawa et } \\
\text { al. (US 6,492,633 B2; hereinafter } \\
\text { referred to as Nakazawa) and in view of } \\
\text { Scharff et al. (US 6,411,287 B2; } \\
\text { hereinafter referred to as Scharff), and } \\
\text { further in view of Dunthorn (US } \\
5,317,140) . "\end{array}$ & $\begin{array}{c}\text { Pooled } \\
\text { Claim } 1 \\
\text { and Pooled } \\
\text { claim } 23\end{array}$ & 16 & 4 & Yes & Rejection \\
\hline 4 & $\begin{array}{l}\text { "The allowed claim(s) is/are 1, 6-22, 28- } \\
29,32-35 \text { and 38-61." }\end{array}$ & $\begin{array}{c}\text { Pooled } \\
\text { Claim } 1 \\
\text { and Pooled } \\
\text { claim } 23\end{array}$ & 16 & 4 & No & $\begin{array}{l}\text { Notice of } \\
\text { Allowance }\end{array}$ \\
\hline
\end{tabular}

Table 67: Evidence Case 6 US7692625 Citing US8400415 Citations.

\begin{tabular}{|c|c|c|c|c|c|c|}
\hline $\begin{array}{l}\text { Longitudinal } \\
\text { Sequence }\end{array}$ & $\begin{array}{c}\text { Evidence From Relevant Historical } \\
\text { Document }\end{array}$ & $\begin{array}{c}\text { Legal } \\
\text { Rejection } \\
\text { Type }\end{array}$ & $\begin{array}{c}\text { Total } \\
\text { citations }\end{array}$ & $\begin{array}{l}\text { Relevant } \\
\text { Citations }\end{array}$ & $\begin{array}{l}\text { Claim } \\
\text { Amendment }\end{array}$ & $\begin{array}{l}\text { Examiner } \\
\text { Outcome }\end{array}$ \\
\hline 1 & $\begin{array}{l}\text { Independent Claim "1. A method of } \\
\text { determining a coordinate on a micro } \\
\text { dotmap according to a moving vector, } \\
\text { comprising:" } \\
\text { "Claims 1-21 are rejected under } 35 \\
\text { U.S.C. 103(a) as being unpatentable } \\
\text { over Nagasaki; Tatsuo et al. (US } \\
\text { 5896403 A) in view of Kouji Senda et } \\
\text { al. (US 20020047822 A1)." }\end{array}$ & $\begin{array}{l}\text { Pooled } \\
\text { claim } 1\end{array}$ & 17 & 2 & Yes & Rejection \\
\hline 2 & $\begin{array}{l}\text { "Claims } 1-21 \text { and } 23 \text { are rejected under } \\
35 \text { U.S.C. } 103 \text { (a) as being unpatentable } \\
\text { over Nagasaki; Tatsuo et al. (US } \\
5896403 \text { A) in view of Kouji Senda et } \\
\text { al. (US 20020047822 A1) and Hansen } \\
\text { Walter (US 4,331,955 A)" }\end{array}$ & $\begin{array}{l}\text { Pooled } \\
\text { claim } 1\end{array}$ & 17 & 3 & Yes & Rejection \\
\hline 3 & "Claims 1-12 and 15-20 are allowed." & $\begin{array}{l}\text { Pooled } \\
\text { Claim } 1\end{array}$ & 17 & 3 & No & $\begin{array}{l}\text { Notice of } \\
\text { Allowance }\end{array}$ \\
\hline
\end{tabular}

Table 68: Evidence Case 6 US7692625 Citing US8513546 Citations. 


\begin{tabular}{|c|c|c|c|c|c|c|}
\hline $\begin{array}{l}\text { Longitudinal } \\
\text { Sequence }\end{array}$ & $\begin{array}{c}\text { Evidence From Relevant Historical } \\
\text { Document }\end{array}$ & $\begin{array}{c}\text { Legal } \\
\text { Rejection } \\
\text { Type }\end{array}$ & $\begin{array}{c}\text { Total } \\
\text { citations }\end{array}$ & $\begin{array}{l}\text { Relevant } \\
\text { Citations }\end{array}$ & $\begin{array}{c}\text { Claim } \\
\text { Amendment }\end{array}$ & $\begin{array}{l}\text { Examiner } \\
\text { Outcome }\end{array}$ \\
\hline 1 & $\begin{array}{l}\text { Independent Claim "1. An electronic } \\
\text { system comprising:" } \\
\text { "Claims } 1 \text { and } 3-5 \text { are rejected under } 35 \\
\text { U.S.C. } 102(\text { e) as being anticipated by } \\
\text { Pirim (U.S. 7,650,015 B2)." }\end{array}$ & $\begin{array}{l}\text { Sole } \\
\text { claim } 1\end{array}$ & 29 & 1 & Yes & Rejection \\
\hline 2 & $\begin{array}{l}\text { "The allowed claim(s) is/are 1-5 and 7- } \\
23 \text { (now renumbered 1-22)." }\end{array}$ & $\begin{array}{c}\text { Sole claim } \\
1\end{array}$ & 29 & 1 & No & $\begin{array}{l}\text { Notice of } \\
\text { Allowance }\end{array}$ \\
\hline
\end{tabular}

Table 69: Evidence Case 6 US7692625 Citing US8515128 Citations.

\begin{tabular}{|c|c|c|c|c|c|c|}
\hline $\begin{array}{l}\text { Longitudinal } \\
\text { Sequence }\end{array}$ & $\begin{array}{c}\text { Evidence From Relevant Historical } \\
\text { Document }\end{array}$ & $\begin{array}{l}\text { Legal } \\
\text { Rejection } \\
\text { Type }\end{array}$ & $\begin{array}{c}\text { Total } \\
\text { citations }\end{array}$ & $\begin{array}{l}\text { Relevant } \\
\text { Citations }\end{array}$ & $\begin{array}{c}\text { Claim } \\
\text { Amendment }\end{array}$ & $\begin{array}{c}\text { Examiner } \\
\text { Outcome }\end{array}$ \\
\hline 1 & $\begin{array}{l}\text { Independent Claim " } 1 . \text { An electronic } \\
\text { system comprising:" } \\
\text { Independent Claim " } 25 \text {. At least one } \\
\text { computer-readable storage medium } \\
\text { encoded with executable instructions } \\
\text { that, when executed by at least one } \\
\text { processor, cause the at least one } \\
\text { processor to perform operations } \\
\text { comprising:" } \\
\text { "Claims } 1,11-16,20,21 \& 23-26 \text { are } \\
\text { rejected under } 35 \text { U.S.C. } 102 \text { (b) as being } \\
\text { anticipated by Kumar et al. (US } \\
6,624,833 \text { )." }\end{array}$ & $\begin{array}{l}\text { Sole claim } \\
1 \text { sole claim } \\
25 \text { and sole } \\
\text { claim } 26\end{array}$ & 29 & 1 & Yes & Rejection \\
\hline 2 & $\begin{array}{l}\text { "Claim } 25 \text { is rejected under } 25 \text { U.S.C. } \\
102(\text { b) as being anticipated by Kumar et } \\
\text { al. (US } 6,624,833 \text { )." }\end{array}$ & $\begin{array}{l}\text { Sole Claim } \\
25\end{array}$ & 29 & 1 & Yes & Rejection \\
\hline 3 & "The allowed claim(s) is/are 1-27." & $\begin{array}{l}\text { Sole claim } \\
1 \text { sole claim } \\
25 \text { and sole } \\
\text { claim } 26\end{array}$ & 29 & 1 & No & $\begin{array}{l}\text { Notice of } \\
\text { Allowance }\end{array}$ \\
\hline
\end{tabular}

Table 70: Evidence Case 6 US7692625 Citing US8547327 Citations. 


\section{Appendix C}

Appendix $\mathrm{C}$ contains the results of a detailed examination pertaining to independent patent claims from the relevant historical patent documents and specific pages. Each illustration contains the original independent claim(s) ready for examination and all subsequent amendments to the claims that make up the sample of this research. Each illustration and table contains the textual evidence as an overlay of all amendments and the qualitative word count analysis. This simplifies the highly complex qualitative text data to reveal the degree of claim amendment, similarity of the claim to the relevant citation(s) and for the allowed claim, the portion relating to the citation(s) as a percentage of the words and the portion of new matter that does not relate to the citation(s) as a percentage. This reveals and contrasts the old pre-existing knowledge and the new knowledge represented in the words of the allowed claim. 


\section{C.1 Case 1 Cited Results Of Independent Claim Examination And Data Analysis.}

\section{Case 1: EP1611503 Cited}

Final US2002036617 Interdependencies With Method Claim 1

In a touch system having a touch screen with a touch surface on which an image is displayed, a method of automatically mapping a touch screen co-ordinate system to the display co-ordinate system comprising the steps of:

including in said displayed image at least one reference mark, the location of the at least one reference mark in said display coordinate system being known;

acquiring an at lease one image of said touch surface including said displayed image;

recognizing the at least one reference mark in the acquired images by comparing the at least one acquired images with reference marks stored in a reference mark library;

determining the location of said at least one reference mark in said at lease one acquired image relative to said touch screen co-ordinate system; and

automatically mapping said touch screen coordinate system to said display coordinate system using said determined location and the location of the at least one reference mark in said display coordinate system.

\begin{tabular}{|c|c|c|c|c|c|c|c|c|}
\hline \multirow{2}{*}{ Citation } & \multicolumn{9}{|c|}{ Amended Claim } & \multicolumn{2}{c|}{ Granted Claim } \\
\cline { 2 - 8 } & $\begin{array}{c}\text { Original } \\
\text { Words }\end{array}$ & $\begin{array}{c}\text { Deleted } \\
\text { Words }\end{array}$ & $\begin{array}{c}\text { Added } \\
\text { Words }\end{array}$ & $\begin{array}{c}\text { Final } \\
\text { Words }\end{array}$ & $\begin{array}{c}\text { Claim } \\
\text { Amendment } \\
\text { Degree }\end{array}$ & Similarity & $\begin{array}{c}\text { Percentage } \\
\text { Citation }\end{array}$ & $\begin{array}{c}\text { Percentage } \\
\text { New }\end{array}$ \\
\hline US2002036617 & 127 & 1 & 34 & 160 & $0.79 \%$ & $99.21 \%$ & $78.75 \%$ & $21.25 \%$ \\
\hline
\end{tabular}

Claim 1 granted with amendment. 


\section{Case 1: EP1611503 Cited}

Final US2002036617 Interdependencies With Apparatus Claim 9

A touch system comprising:

a touch screen having a touch surface on which an image is displayed;

at least one camera acquiring images of said touch surface including said displayed image;

a pointer contact data generator generating pointer position data in response to pointer contact with said touch surface, said pointer position data representation the location of said pointer on said touch surface where pointer contact is made; and

a processor communicating with said at least one camera and said pointer contact data generator, said processor using reference marks known points in said displayed images to calibrate automatically coordinate systems of said touch system, and using calibrated pointer position data to update image data that is used to present the displayed image on said touch surface.

wherein said processor calculates the locations of said reference marks using triangulation to determine locations of the reference marks in the touch screen coordinate system and uses the calculated locations to map the touch screen coordinate system to display coordinate system, said mapping being used to calibrate the pointer position data prior to updating said image data

wherein at lease one of said reference marks in an inherent computer operating system display element.

\begin{tabular}{|c|c|c|c|c|c|c|c|c|}
\hline \multirow{2}{*}{ Citation } & \multicolumn{4}{|c|}{ Amended Claim } & \multicolumn{2}{c|}{ Granted Claim } \\
\cline { 2 - 9 } & $\begin{array}{c}\text { Original } \\
\text { Words }\end{array}$ & $\begin{array}{c}\text { Deleted } \\
\text { Words }\end{array}$ & $\begin{array}{c}\text { Added } \\
\text { Words }\end{array}$ & $\begin{array}{c}\text { Final } \\
\text { Words }\end{array}$ & $\begin{array}{c}\text { Claim } \\
\text { Amendment } \\
\text { Degree }\end{array}$ & Similarity & $\begin{array}{c}\text { Percentage } \\
\text { Citation }\end{array}$ & $\begin{array}{c}\text { Percentage } \\
\text { New }\end{array}$ \\
\hline US2002036617 & 124 & 2 & 75 & 197 & $1.61 \%$ & $98.39 \%$ & $61.93 \%$ & $38.07 \%$ \\
\hline
\end{tabular}

Claim 9 granted with amendment. 


\section{C.2 Case 2 Cited Results Of Independent Claim Examination And Data Analysis.}

\section{Case 2 US7256772 Cited}

Final US6774889 Interdependencies With Method Claim 1

in a touch system having a touch screen with a touch surface on which an image is displayed, a method of automatically mapping an existing a touch screen coordinate system to the display coordinate system comprising the steps of

including in said displayed image at least one reference mark, the location of the at least one reference mark in said display coordinate system being known;

acquiring an image of said touch surface including said displayed image;

recognizing the at least one reference mark in said acquired image by comparing the acquired image with reference marks stored in a reference mark library;

determining the location of said recognized at lease one reference mark in said acquired image relative to said existing touch screen coordinate system; and

automatically mapping said existing touch screen coordinate system to said display coordinate system using said determined location and the location of that at least one reference mark in said display coordinate system.

\begin{tabular}{|c|c|c|c|c|c|c|c|c|}
\hline \multirow{3}{*}{ Citation } & \multicolumn{9}{|c|}{ Amended Claim } & \multicolumn{2}{c|}{ Granted Claim } \\
\cline { 2 - 8 } & $\begin{array}{c}\text { Original } \\
\text { Words }\end{array}$ & $\begin{array}{c}\text { Deleted } \\
\text { Words }\end{array}$ & $\begin{array}{c}\text { Added } \\
\text { Words }\end{array}$ & $\begin{array}{c}\text { Final } \\
\text { Words }\end{array}$ & $\begin{array}{c}\text { Claim } \\
\text { Amendment } \\
\text { Degree }\end{array}$ & Similarity & $\begin{array}{c}\text { Percentage } \\
\text { Citation }\end{array}$ & $\begin{array}{c}\text { Percentage } \\
\text { New }\end{array}$ \\
\hline US6774889 & 130 & 4 & 27 & 153 & $3.08 \%$ & 96.92 & $82.35 \%$ & $17.65 \%$ \\
\hline
\end{tabular}

Claim 1 granted with amendment. 


\section{Case 2 US7256772 Cited}

Final US6774889 Interdependencies With Apparatus Claim 12

A touch system comprising

a touch screen having a touch surface on which an image is displayed;

at least one camera acquiring images of said touch surface including said displayed image;

a pointer contact data generator generating pointer position data in response to pointer contact with said touch surface, said pointer position data representing the location of said pointer on said touch surface where pointer contact is made; and

a processor communicating with said at lease one camera and said pointer contact data generator, said processor using known points-reference marks in said displayed image to calibrate automatically coordinate systems of said touch system by mapping an existing coordinate system of said touch screen to the displayed image coordinate system, and

using calibrated pointer position data to update image data that is used to present the displayed image on said touch surface,

wherein said processor compared the acquired images of said touch surface with a library of reference mark data to identify the reference marks in said acquired images, calculates the locations of said identified reference marks in the touch screen coordinate system using triangulation and uses the calculated locations to map the touch screen coordinate system to the displayed image coordinate system, said mapping being used to calibrate the pointer position data prior to updating said image data.

\begin{tabular}{|c|c|c|c|c|c|c|c|c|}
\hline \multirow{2}{*}{ Citation } & \multicolumn{9}{|c|}{ Amended Claim } & \multicolumn{2}{c|}{ Granted Claim } \\
\cline { 2 - 8 } & $\begin{array}{c}\text { Original } \\
\text { Words }\end{array}$ & $\begin{array}{c}\text { Deleted } \\
\text { Words }\end{array}$ & $\begin{array}{c}\text { Added } \\
\text { Words }\end{array}$ & $\begin{array}{c}\text { Final } \\
\text { Words }\end{array}$ & $\begin{array}{c}\text { Claim } \\
\text { Amendment } \\
\text { Degree }\end{array}$ & Similarity & $\begin{array}{c}\text { Percentage } \\
\text { Citation }\end{array}$ & $\begin{array}{c}\text { Percentage } \\
\text { New }\end{array}$ \\
\hline US6774889 & 140 & 2 & 79 & 217 & $1.43 \%$ & $98.57 \%$ & $63.59 \%$ & $36.41 \%$ \\
\hline
\end{tabular}

Claim 12 granted with amendment. 


\section{C.3 Case 3 Cited Results Of Independent Claim Examination And Data Analysis.}

\section{Case 3 EP1766501 Cited}

Final WO200203316 Interdependencies With Apparatus Claim 1

An apparatus for detecting a pointer relative to a touch surface comprising;

at least two spaced imaging devices having overlapping fields of view, each of said imaging devices having a field of view that looks back at looking across the entire touch surface and being aimed such that said imaging devices device see sees Said touch surface including its four corners in three dimensions as a perspective view including the boundaries of said touch surface, said imaging devices acquiring overlapping images from different perspective view, each imaging device comparing acquired images with a model describing the boundaries of said touch surface thereby to determine a subset of pixels in each acquired image and processing each pixel subset to generate image data; and

a processor processing image data generated by at least one of said imaging devices to determine the location of the pointer relative to said touch surface wherein each imaging device is calibrated to establish the relationship between points in it perspective view and points in acquired images, each imaging device generating pointer coordinate data when appoint is captured in an acquired image.

\begin{tabular}{|c|c|c|c|c|c|c|c|c|}
\hline \multirow{2}{*}{ Citation } & \multicolumn{9}{|c|}{ Amended Claim } & \multicolumn{2}{c|}{ Granted Claim } \\
\cline { 2 - 8 } & $\begin{array}{c}\text { Original } \\
\text { Words }\end{array}$ & $\begin{array}{c}\text { Deleted } \\
\text { Words }\end{array}$ & $\begin{array}{c}\text { Added } \\
\text { Words }\end{array}$ & $\begin{array}{c}\text { Final } \\
\text { Words }\end{array}$ & $\begin{array}{c}\text { Claim } \\
\text { Amendment } \\
\text { Degree }\end{array}$ & Similarity & $\begin{array}{c}\text { Percentage } \\
\text { Citation }\end{array}$ & $\begin{array}{c}\text { Percentage } \\
\text { New }\end{array}$ \\
\hline WO200203316 & 104 & 13 & 53 & 144 & $12.50 \%$ & $87.50 \%$ & $63.19 \%$ & $36.81 \%$ \\
\hline
\end{tabular}

Patent grant refused. 


\section{C.4 Case 4 Cited Results Of Independent Claim Examination And Data Analysis.}

\section{Case 4 US7492357 Cited}

Final US51317140 Interdependencies With Apparatus Claim 1

An apparatus for detecting a pointer relative to a touch surface comprising:

at least two spaced imaging devices having overlapping fields of view, each of said imaging devices being in front of the touch surface and looking having a field of view that looks back at the touch surface such that said imaging devices see said touch surface in three dimensions as a perspective view, including the boundaries of said touch surface said imaging devices acquiring overlapping images from different locations viewpoints, each imaging device processing comparing acquired images with a model describing the boundaries of said touch surface thereby to determine a subset of pixels in each acquired image and processing each pixel subset to generate image data, wherein said pixel subset encompasses the boundary of said touch surface within the perspective view of said imaging device; and

processing structure processing image data generated by at least one of said imaging devices to determine the location of the pointer.

\begin{tabular}{|c|c|c|c|c|c|c|c|c|}
\hline \multirow{2}{*}{ Citation } & \multicolumn{4}{|c|}{ Amended Claim } & \multicolumn{2}{c|}{ Granted Claim } \\
\cline { 2 - 9 } & $\begin{array}{c}\text { Original } \\
\text { Words }\end{array}$ & $\begin{array}{c}\text { Deleted } \\
\text { Words }\end{array}$ & $\begin{array}{c}\text { Added } \\
\text { Words }\end{array}$ & $\begin{array}{c}\text { Final } \\
\text { Words }\end{array}$ & $\begin{array}{c}\text { Claim } \\
\text { Amendment } \\
\text { Degree }\end{array}$ & Similarity & $\begin{array}{c}\text { Percentage } \\
\text { Citation }\end{array}$ & $\begin{array}{c}\text { Percentage } \\
\text { New }\end{array}$ \\
\hline US51317140 & 96 & 10 & 44 & 130 & $10.42 \%$ & $89.58 \%$ & $66.15 \%$ & $33.85 \%$ \\
\hline
\end{tabular}

Claim 1 granted with amendment. 


\section{Case 4 US7492357 Cited}

Final US51317140 Interdependencies With Apparatus Claim 55

A camera based touch system comprising:

a generally rectangular passive touch surface on which contacts are made using a pointer;

camera devices removably mounted adjacent at least two corners of said touch surface, each of said camera devices being disposed in front of the plane of the touch surface and having a field of view looking across and back towards said touch surface, the fields of view of said camera devices overlapping over said touch surface such that said camera devices see said touch surface an the boundaries thereof in perspective views, said camera devices acquiring images of said touch surface from different viewpoints, each camera device comparing each acquired image with a mathematical model describing the boundaries of said touch surface as seen by said camera device to determine a subset of relevant pixels of the acquired image corresponding generally to said touch surface and processing a the subset of relevant pixels of each acquired image to generate image data, wherein said pixel subset encompasses the boundary of said touch surface within the perspective view of said camera device; and

A processor receiving and processing said image data to determine the location of said pointer relative to said touch surface via triangulation.

\begin{tabular}{|c|c|c|c|c|c|c|c|c|}
\hline \multirow{3}{*}{ Citation } & \multicolumn{9}{|c|}{ Amended Claim } & \multicolumn{2}{c|}{ Granted Claim } \\
\cline { 2 - 9 } & $\begin{array}{c}\text { Original } \\
\text { Words }\end{array}$ & $\begin{array}{c}\text { Deleted } \\
\text { Words }\end{array}$ & $\begin{array}{c}\text { Added } \\
\text { Words }\end{array}$ & $\begin{array}{c}\text { Final } \\
\text { Words }\end{array}$ & $\begin{array}{c}\text { Claim } \\
\text { Amendment } \\
\text { Degree }\end{array}$ & Similarity & $\begin{array}{c}\text { Percentage } \\
\text { Citation }\end{array}$ & $\begin{array}{c}\text { Percentage } \\
\text { New }\end{array}$ \\
\hline US51317140 & 161 & 0 & 59 & 220 & $0.00 \%$ & $100.00 \%$ & $73.18 \%$ & $26.82 \%$ \\
\hline
\end{tabular}

Claim 55 granted with amendment. 


\section{Case 4 US7492357 Cited}

Final US51317140 Interdependencies With Apparatus Claim 63

An apparatus for detecting a pointer relative to a generally rectangular touch surface comprising:

at least two spaced imaging devices having overlapping fields of view encompassing said touch surface, said imaging devices being spaced in front of said touch surface and looking back to see said touch surface in three dimensions as a perspective view with the perspective view including at least the four corners and sides of said touch surface, said imaging devices acquiring overlapping images from different locations-viewpoints, each imaging device comparing each captured image with a mathematical model describing the boundaries of the touch surface to determine a subset of relevant pixels within the capture image and processing a the subset of relevant pixels in each acquired captured image to generate image data, said relevant pixel subset encompassing the boundary of said touch surface; and

a processor receiving and processing image data generated by at least one of said imaging devices to determine the location of the pointer relative to said touch surface using triangulation.

\begin{tabular}{|c|c|c|c|c|c|c|c|c|}
\hline \multirow{3}{*}{ Citation } & \multicolumn{9}{|c|}{ Amended Claim } & \multicolumn{2}{c|}{ Granted Claim } \\
\cline { 2 - 8 } & $\begin{array}{c}\text { Original } \\
\text { Words }\end{array}$ & $\begin{array}{c}\text { Deleted } \\
\text { Words }\end{array}$ & $\begin{array}{c}\text { Added } \\
\text { Words }\end{array}$ & $\begin{array}{c}\text { Final } \\
\text { Words }\end{array}$ & $\begin{array}{c}\text { Claim } \\
\text { Amendment } \\
\text { Degree }\end{array}$ & Similarity & $\begin{array}{c}\text { Percentage } \\
\text { Citation }\end{array}$ & $\begin{array}{c}\text { Percentage } \\
\text { New }\end{array}$ \\
\hline US51317140 & 110 & 1 & 54 & 163 & $0.11 \%$ & $99.09 \%$ & $66.87 \%$ & $33.13 \%$ \\
\hline
\end{tabular}

Claim 63 granted with amendment. 


\section{C.5 Case 5 Cited Results Of Independent Claim Examination And Data Analysis.}

\section{Case 5 EP1297488 Cited}

Final US4746770 Interdependencies With Apparatus Claim 1

A camera based touch system comprising:

at least two cameras associated with a touch surface and having overlapping fields of view encompassing said touch surface, said at least two cameras acquiring images of said touch surface from different locations and generating image data; and

processing means receiving pixel subsets of image data generated by said at least two cameras, and selecting pixel subsets of said acquired images pixel data of the selected pixel subsets being processed to generate pointer data when a pointer exists in said acquired images, said processing means triangulating the pointer data to determine the location of said pointer relative to said touch surface.

\begin{tabular}{|c|c|c|c|c|c|c|c|c|}
\hline \multirow{3}{*}{ Citation } & \multicolumn{9}{|c|}{ Amended Claim } & \multicolumn{2}{c|}{ Granted Claim } \\
\cline { 2 - 9 } & $\begin{array}{c}\text { Original } \\
\text { Words }\end{array}$ & $\begin{array}{c}\text { Deleted } \\
\text { Words }\end{array}$ & $\begin{array}{c}\text { Added } \\
\text { Words }\end{array}$ & $\begin{array}{c}\text { Final } \\
\text { Words }\end{array}$ & $\begin{array}{c}\text { Claim } \\
\text { Amendment } \\
\text { Degree }\end{array}$ & Similarity & $\begin{array}{c}\text { Percentage } \\
\text { Citation }\end{array}$ & $\begin{array}{c}\text { Percentage } \\
\text { New }\end{array}$ \\
\hline US4746770 & 105 & 9 & 2 & 98 & $6.67 \%$ & $93.33 \%$ & $97.96 \%$ & $2.04 \%$ \\
\hline
\end{tabular}

Claim 1 granted with amendment. 


\section{Case 5 EP1297488 Cited}

Final US4746770 Interdependencies With Methods Claim 19

A method of detecting the position of a pointer relative to a touch surface comprising the steps of:

acquiring multiple overlapping images of a pointer relative to said touch surface; and

selecting receiving pixel subsets of said acquired images; and

processing pixel data of said pixel subsets to detect the existence of said pointer therein and to determine the location of said pointer relative o said touch surface using triangulation.

\begin{tabular}{|c|c|c|c|c|c|c|c|c|}
\hline \multirow{3}{*}{ Citation } & \multicolumn{9}{|c|}{ Amended Claim } & \multicolumn{2}{c|}{ Granted Claim } \\
\cline { 2 - 9 } & $\begin{array}{c}\text { Original } \\
\text { Words }\end{array}$ & $\begin{array}{c}\text { Deleted } \\
\text { Words }\end{array}$ & $\begin{array}{c}\text { Added } \\
\text { Words }\end{array}$ & $\begin{array}{c}\text { Final } \\
\text { Words }\end{array}$ & $\begin{array}{c}\text { Claim } \\
\text { Amendment } \\
\text { Degree }\end{array}$ & Similarity & $\begin{array}{c}\text { Percentage } \\
\text { Citation }\end{array}$ & $\begin{array}{c}\text { Percentage } \\
\text { New }\end{array}$ \\
\hline US4746770 & 68 & 2 & 1 & 67 & $2.94 \%$ & $97.06 \%$ & $98.51 \%$ & $1.49 \%$ \\
\hline
\end{tabular}

Claim 19 granted with amendment. 


\section{Case 5 EP1739528 Cited}

Final WO199940562 Interdependencies With Method Claim 1

A method of calibrating digital cameras in a touch system having a touch surface on which pointer contacts are to be made, each digital camera having a selectable pixel array, said method comprising the steps of:

for each digital camera, acquiring an image looking at and across said touch surface;

measuring vertical coordinates from the acquired images; and

using the measured vertical coordinates to determine the location of the touch surface in each of he acquired images, and selecting a pixel subset of the selectable pixel array of each digital camera based on the determined touch surface location so that only pixels of the pixel subsets are processed during normal operation of said touch system.

\begin{tabular}{|c|c|c|c|c|c|c|c|c|}
\hline \multirow{2}{*}{ Citation } & \multicolumn{9}{|c|}{ Amended Claim } & \multicolumn{2}{c|}{ Granted Claim } \\
\cline { 2 - 8 } & $\begin{array}{c}\text { Original } \\
\text { Words }\end{array}$ & $\begin{array}{c}\text { Deleted } \\
\text { Words }\end{array}$ & $\begin{array}{c}\text { Added } \\
\text { Words }\end{array}$ & $\begin{array}{c}\text { Final } \\
\text { Words }\end{array}$ & $\begin{array}{c}\text { Claim } \\
\text { Amendment } \\
\text { Degree }\end{array}$ & Similarity & $\begin{array}{c}\text { Percentage } \\
\text { Citation }\end{array}$ & $\begin{array}{c}\text { Percentage } \\
\text { New }\end{array}$ \\
\hline W0199940562 & 77 & 1 & 38 & 114 & $1.30 \%$ & $98.70 \%$ & $66.67 \%$ & $33.33 \%$ \\
\hline
\end{tabular}

Claim 1 granted with amendment. 


\section{C.6 Case 6 Cited Results Of Independent Claim Examination And Data Analysis.}

\section{Case 6 US7692625 Cited}

Final US4746770 Interdependencies With Apparatus Claim 1

A camera based touch system comprising:

at least two digital cameras associated with a passive-touch surface and having overlapping fields of view encompassing said touch surface, said at least two digital cameras acquiring images of said touch surface from different locations vantages and generating image data for each acquired image, outputting a pixel subset of the acquired image, said pixel subset comprising pixel data from selected a subset of pixel rows of the acquired image; and

a processor processing structure receiving and processing said pixel subsets of image data the acquired images generated by said at least two digital cameras, the pixel data of the pixel subsets being processed to generate pointer data when a pointer exists in said acquired images, said processing structure triangulating the pointer data to determine the location of a pointer relative to said touchy surface when said pointer is captured in images acquired by said at least two cameras.

\begin{tabular}{|c|c|c|c|c|c|c|c|c|}
\hline \multirow{2}{*}{ Citation } & \multicolumn{4}{|c|}{ Amended Claim } & \multicolumn{2}{c|}{ Granted Claim } \\
\cline { 2 - 9 } & $\begin{array}{c}\text { Original } \\
\text { Words }\end{array}$ & $\begin{array}{c}\text { Deleted } \\
\text { Words }\end{array}$ & $\begin{array}{c}\text { Added } \\
\text { Words }\end{array}$ & $\begin{array}{c}\text { Final } \\
\text { Words }\end{array}$ & $\begin{array}{c}\text { Claim } \\
\text { Amendment } \\
\text { Degree }\end{array}$ & Similarity & $\begin{array}{c}\text { Percentage } \\
\text { Citation }\end{array}$ & $\begin{array}{c}\text { Percentage } \\
\text { New }\end{array}$ \\
\hline US4746770 & 85 & 25 & 70 & 130 & $29.41 \%$ & $70.59 \%$ & $46.15 \%$ & $53.85 \%$ \\
\hline
\end{tabular}

Claim 1 granted with amendment. 


\section{Case 6 US7692625 Cited}

Final US4746770 Interdependencies With Apparatus Claim 25

A camera based touch system comprising:

a generally rectangular passive touch surface on which contacts are made using a pointer;

a digital camera mounted adjacent each corner at least two corners of said touch surface, said digital cameras having overlapping fields of view encompassing said touch surface, said digital cameras acquiring images of said touch surface and generating image data for each acquired image, outputting image data comprising a pixel subset, said pixel subset comprising pixel data from selected a subset of pixel rows that includes the median line $\mathrm{x}$ and pointer tip location $\mathrm{z}$ of a pointer when said pointer is captured in images acquired by said digital cameras; and

a processor receiving and processing only a the pixel subsetsubsets of the image data generated by said digital cameras and processing the pixel data of the pixel subsets to determine the location of said pointer relative to said touch surface and whether said pointer is in contact with said touch surface.

\begin{tabular}{|c|c|c|c|c|c|c|c|c|}
\hline \multirow{3}{*}{ Citation } & \multicolumn{9}{|c|}{ Amended Claim } & \multicolumn{2}{c|}{ Granted Claim } \\
\cline { 2 - 8 } & $\begin{array}{c}\text { Original } \\
\text { Words }\end{array}$ & $\begin{array}{c}\text { Deleted } \\
\text { Words }\end{array}$ & $\begin{array}{c}\text { Added } \\
\text { Words }\end{array}$ & $\begin{array}{c}\text { Final } \\
\text { Words }\end{array}$ & $\begin{array}{c}\text { Claim } \\
\text { Amendment } \\
\text { Degree }\end{array}$ & Similarity & $\begin{array}{c}\text { Percentage } \\
\text { Citation }\end{array}$ & $\begin{array}{c}\text { Percentage } \\
\text { New }\end{array}$ \\
\hline US4746770 & 118 & 11 & 41 & 148 & $9.32 \%$ & $90.68 \%$ & $72.30 \%$ & $27.70 \%$ \\
\hline
\end{tabular}

Claim 25 granted with amendment. 


\section{Case 6 US7692625 Cited}

Final US4746770 Interdependencies With Method Claim 46

A method of detecting the position of a pointer relative to a touch surface comprising the steps of:

acquiring multiple overlapping images of said touch surface from different locations using cameras having overlapping fields of view and generating image data pointer proximate to said touch surface using cameras having fields of view at least looking at said touch surface and outputting from each camera a pixel subset of each image, each said pixel subset comprising pixel data from selected a subset of pixel rows of the acquired image; and

processing said image data receiving at processing structure the outputted pixel subsets of said acquired images and processing the pixel data of said pixel subsets to detect the existence of a pointer within said acquired images and to determine the location of said pointer relative to said touch surface using triangulation.

\begin{tabular}{|c|c|c|c|c|c|c|c|c|}
\hline \multirow{2}{*}{ Citation } & \multicolumn{4}{|c|}{ Amended Claim } & \multicolumn{2}{c|}{ Granted Claim } \\
\cline { 2 - 9 } & $\begin{array}{c}\text { Original } \\
\text { Words }\end{array}$ & $\begin{array}{c}\text { Deleted } \\
\text { Words }\end{array}$ & $\begin{array}{c}\text { Added } \\
\text { Words }\end{array}$ & $\begin{array}{c}\text { Final } \\
\text { Words }\end{array}$ & $\begin{array}{c}\text { Claim } \\
\text { Amendment } \\
\text { Degree }\end{array}$ & Similarity & $\begin{array}{c}\text { Percentage } \\
\text { Citation }\end{array}$ & $\begin{array}{c}\text { Percentage } \\
\text { New }\end{array}$ \\
\hline US4746770 & 67 & 33 & 72 & 106 & $49.25 \%$ & $50.75 \%$ & $32.08 \%$ & $67.92 \%$ \\
\hline
\end{tabular}

Claim 46 granted with amendment. 


\section{C.7 Case 2 Citing Results Of Independent Claim Examination And Data Analysis.}

\section{Case 2: US7256772 Citing US2012032922}

Final US7256772 and US20050017957 Interdependencies With Apparatus Claim 1

An optical touch system comprising;

a substrate having a touch region;

at least a sensor used for capturing a full size image of the touch region, wherein the full size image comprised a central region image near a light axis of the at least one sensor, and a side region image;

a processing unit used for sampling the central region image to obtain a central compressed image and transmitting the central compressed image and the side region image under a normal mode; and

an analysis unit used for analyzing the central compressed image and the side region image to obtain a touch point coordinate.

\begin{tabular}{|l|c|c|c|c|c|c|c|c|}
\hline \multirow{2}{*}{ Citation } & \multicolumn{9}{|c|}{ Amended Claim } & \multicolumn{2}{c|}{ Granted Claim } \\
\cline { 2 - 8 } & $\begin{array}{c}\text { Original } \\
\text { Words }\end{array}$ & $\begin{array}{c}\text { Deleted } \\
\text { Words }\end{array}$ & $\begin{array}{c}\text { Added } \\
\text { Words }\end{array}$ & $\begin{array}{c}\text { Final } \\
\text { Words }\end{array}$ & $\begin{array}{c}\text { Claim } \\
\text { Amendment } \\
\text { Degree }\end{array}$ & Similarity & $\begin{array}{c}\text { Percentage } \\
\text { Citation }\end{array}$ & $\begin{array}{c}\text { Percentage } \\
\text { New }\end{array}$ \\
\hline US7256772 & 51 & 0 & 0 & 51 & $0.00 \%$ & $49.04 \%$ & $49.04 \%$ & $0.00 \%$ \\
\hline US20050017957 & 53 & 0 & 0 & 53 & $0.00 \%$ & $50.96 \%$ & $50.96 \%$ & $0.00 \%$ \\
\hline Totals & 104 & 0 & 0 & 104 & $0.00 \%$ & $100.00 \%$ & $100 / 00 \%$ & $0.00 \%$ \\
\hline
\end{tabular}

Patent grant refused. 


\section{C.8 Case 4 Citing Results Of Independent Claim Examination And Data Analysis.}

\section{Case 4 US7492357 Citing US763002}

Final US20050162381 Interdependencies With Apparatus Claim 1

An interactive display system comprising:

a display screen comprising one or more display layers;

an illuminator positioned at a single location so as to illuminate one of the inner surface or outer surface of the display screen from the single location, the illuminator causing at least a first specular reflection that is detected by a first camera and a second specular reflection that is detected by a second camera;

a the first camera being positioned so as to view and capture a first image of at least a first area and a second area of the illuminated surface of the display screen using light emitted from the illuminator, at a position such that when the illuminator is illuminated, wherein the first image captured by the first camera includes: a first image portion that corresponds to the first area of the illuminated surface and that includes the first specular reflection that is caused by light from the illuminator and a second image portion that corresponds to the second area of the illuminated surface and that is free from the first and second specular reflection caused by light from the illuminator; eccurs at an area of an image as captured by the first camera;

a the second camera being positioned so as to view and capture a second image of at least the first area and the second area of the illuminated surface of the display screen using light emitted from the illuminator, wherein the second image captured by the second camera includes: a third image portion that corresponds to the second area of the illuminated surface and that include the second specular reflection that is caused by light from the illuminator and a forth image portion that corresponds to the first area of the illuminated surface and that is free from the first and second specular reflection caused by light from the illuminator; and at a position such that when the illuminator is illumined, the second camera is able to view at least a portion of the specular reflection area of the first camera; and

an image merging mechanism configured to combine the first and second images from the first camera and from the second camera respectively, in such a way that at least the first specular reflections are reflection is at least reduced in a merged image in comparison with the first specular reflection captured in the first image captured by the first camera.

\begin{tabular}{|c|c|c|c|c|c|c|c|c|}
\hline \multirow{2}{*}{ Citation } & \multicolumn{5}{|c|}{ Amended Claim } & \multicolumn{2}{c|}{ Granted Claim } \\
\cline { 2 - 8 } & $\begin{array}{c}\text { Original } \\
\text { Words }\end{array}$ & $\begin{array}{c}\text { Deleted } \\
\text { Words }\end{array}$ & $\begin{array}{c}\text { Added } \\
\text { Words }\end{array}$ & $\begin{array}{c}\text { Final } \\
\text { Words }\end{array}$ & $\begin{array}{c}\text { Claim } \\
\text { Amendment } \\
\text { Degree }\end{array}$ & Similarity & $\begin{array}{c}\text { Percentage } \\
\text { Citation }\end{array}$ & $\begin{array}{c}\text { Percentage } \\
\text { New }\end{array}$ \\
\hline US20050162381 & 159 & 58 & 236 & 337 & $36.48 \%$ & $63.52 \%$ & $29.97 \%$ & $70.03 \%$ \\
\hline
\end{tabular}

Claim 1 granted with amendment. 


\section{Case 4 US7492357 Citing US763002}

Final US20050162381 and US6975360 Interdependencies With Apparatus Claim 14

An image merging mechanism for use with an interactive display system that includes one or more display layers, a first camera positioned so as to view an illumined surface of the one or more display layers at a first position such that when the an illuminator that is positioned at a particular location is illuminated a specular reflection occurs at an a specular reflection area of an image as captured by the first camera, a second camera positioned so as to view an illuminated surface of the one or more display layers at a second position such that when the illuminator is illuminated from the particular location the second camera is able to view and capture at least a portion of the specular reflection area of the first camera without capturing the specular reflection,

the image merging mechanism configured to perform the following act: an act of combining images from the first and second camera such that the specular reflection reflections are is at least reduced as compared to a level of the specular reflection levels present in captured by the first camera.

\begin{tabular}{|l|c|c|c|c|c|c|c|c|}
\hline \multirow{2}{*}{ Citation } & \multicolumn{9}{|c|}{ Amended Claim } & \multicolumn{2}{c|}{ Granted Claim } \\
\cline { 2 - 8 } & $\begin{array}{c}\text { Original } \\
\text { Words }\end{array}$ & $\begin{array}{c}\text { Deleted } \\
\text { Words }\end{array}$ & $\begin{array}{c}\text { Added } \\
\text { Words }\end{array}$ & $\begin{array}{c}\text { Final } \\
\text { Words }\end{array}$ & $\begin{array}{c}\text { Claim } \\
\text { Amendment } \\
\text { Degree }\end{array}$ & Similarity & $\begin{array}{c}\text { Percentage } \\
\text { Citation }\end{array}$ & $\begin{array}{c}\text { Percentage } \\
\text { New }\end{array}$ \\
\hline US20050162381 & 110 & 2 & 24 & 132 & $1.82 \%$ & $98.18 \%$ & $61.36 \%$ & $13.64 \%$ \\
\hline US6975360 & 41 & 5 & 8 & 44 & $12.19 \%$ & $87.81 \%$ & $20.46 \%$ & $4.54 \%$ \\
\hline Totals & 151 & 7 & 32 & 176 & & & $81.82 \%$ & $18.18 \%$ \\
\hline
\end{tabular}

Claim 14 granted with amendment. 


\section{C.9 Case 5 Citing Results Of Independent Claim Examination And Data Analysis.}

\section{Case 5 EP1297488 Citing EP2089791}

Final US2004201575 Interdependencies With Apparatus Claim 1

An interactive input system comprising:

Imaging devices with different viewpoints and having at least partially overlapping fields of view encompassing a region of interest, at least two of the imaging devices having different focal lengths; and

Processing structure processing image data acquired by the imaging devices to detect the existence of a pointer and determine the location of the pointer within the region of interest.

\begin{tabular}{|c|c|c|c|c|c|c|c|c|}
\hline \multirow{2}{*}{ Citation } & \multicolumn{9}{|c|}{ Amended Claim } & \multicolumn{2}{c|}{ Granted Claim } \\
\cline { 2 - 9 } & $\begin{array}{c}\text { Original } \\
\text { Words }\end{array}$ & $\begin{array}{c}\text { Deleted } \\
\text { Words }\end{array}$ & $\begin{array}{c}\text { Added } \\
\text { Words }\end{array}$ & $\begin{array}{c}\text { Final } \\
\text { Words }\end{array}$ & $\begin{array}{c}\text { Claim } \\
\text { Amendment } \\
\text { Degree }\end{array}$ & Similarity & $\begin{array}{c}\text { Percentage } \\
\text { Citation }\end{array}$ & $\begin{array}{c}\text { Percentage } \\
\text { New }\end{array}$ \\
\hline US2004201575 & 65 & 0 & 0 & 65 & $0.00 \%$ & $100.00 \%$ & $100.00 \%$ & $0.00 \%$ \\
\hline
\end{tabular}

Claim 1 deleted and did not grant with the patent. 


\section{Case 5 EP1297488 Citing EP2089791}

Final US2004201575 and US7057647 Interdependencies With Apparatus Claim 8

An touch system comprising:

a touch surface on which an image is visible;

imaging assemblies about the periphery of said touch surface, said imaging assemblies having at least partially overlapping fields of view encompassing said touch surface,

\section{each imaging assembly comprising at least two imaging devices acquiring image data} with each imaging device having a different focal length; and

processing structure processing pointer data generated by the imaging assemblies to determine the location of at least one pointer relative to the touch surface, wherein each imaging assembly generates said pointer data using image data acquired by only one of the imaging devices thereof.

\begin{tabular}{|l|c|c|c|c|c|c|c|c|}
\hline \multirow{2}{*}{ Citation } & \multicolumn{9}{|c|}{ Amended Claim } & \multicolumn{2}{c|}{ Granted Claim } \\
\cline { 2 - 8 } & $\begin{array}{c}\text { Original } \\
\text { Words }\end{array}$ & $\begin{array}{c}\text { Deleted } \\
\text { Words }\end{array}$ & $\begin{array}{c}\text { Added } \\
\text { Words }\end{array}$ & $\begin{array}{c}\text { Final } \\
\text { Words }\end{array}$ & $\begin{array}{c}\text { Claim } \\
\text { Amendment } \\
\text { Degree }\end{array}$ & Similarity & $\begin{array}{c}\text { Percentage } \\
\text { Citation }\end{array}$ & $\begin{array}{c}\text { Percentage } \\
\text { New }\end{array}$ \\
\hline US2004201575 & 60 & 0 & 21 & 81 & $0.00 \%$ & $100.00 \%$ & $58.25 \%$ & $20.39 \%$ \\
\hline US7057647 & 19 & 0 & 3 & 22 & $0.00 \%$ & $100.00 \%$ & $18.45 \%$ & $2.91 \%$ \\
\hline Totals & 79 & 0 & 24 & 103 & & & $76.70 \%$ & $23.30 \%$ \\
\hline
\end{tabular}

Claim 8 granted as claim 1 with amendment. 


\section{Case 5 EP1297488 Citing EP2089791}

Final US2004201575 and US7057647 Interdependencies With Apparatus Claim 12

An interactive input system comprising:

a camera assemblies with different viewpoints and having fields of view encompassing a region of interest,

each camera assembly comprising at least two image sensors acquiring image data with the image sensors having different focal lengths; and

processing structure processing image data acquired by said camera assemblies to detect one or more pointers in said region of interest, the image data acquired by only one of the image sensors of each camera assembly being used to determine the location of each pointer in said region of interest.

\begin{tabular}{|l|c|c|c|c|c|c|c|c|}
\hline \multirow{2}{*}{ Citation } & \multicolumn{9}{|c|}{ Amended Claim } & \multicolumn{2}{c|}{ Granted Claim } \\
\cline { 2 - 8 } & $\begin{array}{c}\text { Original } \\
\text { Words }\end{array}$ & $\begin{array}{c}\text { Deleted } \\
\text { Words }\end{array}$ & $\begin{array}{c}\text { Added } \\
\text { Words }\end{array}$ & $\begin{array}{c}\text { Final } \\
\text { Words }\end{array}$ & $\begin{array}{c}\text { Claim } \\
\text { Amendment } \\
\text { Degree }\end{array}$ & Similarity & $\begin{array}{c}\text { Percentage } \\
\text { Citation }\end{array}$ & $\begin{array}{c}\text { Percentage } \\
\text { New }\end{array}$ \\
\hline US2004201575 & 42 & 0 & 29 & 71 & $0.00 \%$ & $100.00 \%$ & $45.65 \%$ & $31.52 \%$ \\
\hline US7057647 & 18 & 0 & 3 & 21 & $0.00 \%$ & $100.00 \%$ & $19.57 \%$ & $3.26 \%$ \\
\hline Totals & 60 & 0 & 32 & 92 & & & $65.22 \%$ & $34.78 \%$ \\
\hline
\end{tabular}

Claim 12 granted as claim 6 with amendment. 


\section{C.10 Case 6 Citing Results Of Independent Claim Examination And Data Analysis.}

\section{Case 6 US 7692625 Citing US7932899}

Final US7515141 and US6727885 Interdependencies With Apparatus Claim 12

A position detection system comprising:

a first optical unit configured to image a space;

a second optical unit configured to image the space;

a memory; and

a processing device interface to the memory and the optical units, the processing device configured to:

access image data from the first and second optical units;

iteratively determine at least one of a current first touch position and a current second touch position using the accessed image data;

in one iteration when both the current first touch position and the current second touch position are determined using the accessed image data; define, in memory, a polygon based on the current first and current second touch positions if both the current first and eurrent second positions are determined using the accessed image data, the polygon having at least four sides; and

if in a subsequent iteration when only one of the current first touch position or the current second touch position are is determined using the accessed image data;

access the polygon as previously defined in the memory, and use the current first touch position or the current second touch position determined using the accessed image data, and the previously defined polygon, to estimate the other touch position that was not determined using the accessed image data.

\begin{tabular}{|l|c|c|c|c|c|c|c|c|}
\hline \multirow{3}{*}{ Citation } & \multicolumn{9}{|c|}{ Amended Claim } & \multicolumn{2}{c|}{ Granted Claim } \\
\cline { 2 - 8 } & $\begin{array}{c}\text { Original } \\
\text { Words }\end{array}$ & $\begin{array}{c}\text { Deleted } \\
\text { Words }\end{array}$ & $\begin{array}{c}\text { Added } \\
\text { Words }\end{array}$ & $\begin{array}{c}\text { Final } \\
\text { Words }\end{array}$ & $\begin{array}{c}\text { Claim } \\
\text { Amendment } \\
\text { Degree }\end{array}$ & Similarity & $\begin{array}{c}\text { Percentage } \\
\text { Citation }\end{array}$ & $\begin{array}{c}\text { Percentage } \\
\text { New }\end{array}$ \\
\hline US7515141 & 71 & 0 & 3 & 74 & $0.00 \%$ & $100.00 \%$ & $36.60 \%$ & $1.55 \%$ \\
\hline US6727885 & 102 & 18 & 36 & 120 & $16.67 \%$ & $83.33 \%$ & $43.30 \%$ & $18.55 \%$ \\
\hline Totals & 173 & 18 & 39 & 194 & & & $79.90 \%$ & $20.10 \%$ \\
\hline
\end{tabular}

Claim 12 granted as claim 6 with amendment. 


\section{Case 6 US 7692625 Citing US8228304}

Final US7084859 and US4639720 Interdependencies With Method Claim 1

A method comprising:

acquiring images of a pointer proximate an input surface from different vantages;

processing pixel data of each image to determine edges of said pointer; and

triangulating an input area of said pointer based on said determined edges.

\begin{tabular}{|l|c|c|c|c|c|c|c|c|}
\hline \multirow{2}{*}{ Citation } & \multicolumn{4}{|c|}{ Amended Claim } & \multicolumn{2}{c|}{ Granted Claim } \\
\cline { 2 - 8 } & $\begin{array}{c}\text { Original } \\
\text { Words }\end{array}$ & $\begin{array}{c}\text { Deleted } \\
\text { Words }\end{array}$ & $\begin{array}{c}\text { Added } \\
\text { Words }\end{array}$ & $\begin{array}{c}\text { Final } \\
\text { Words }\end{array}$ & $\begin{array}{c}\text { Claim } \\
\text { Amendment } \\
\text { Degree }\end{array}$ & Similarity & $\begin{array}{c}\text { Percentage } \\
\text { Citation }\end{array}$ & $\begin{array}{c}\text { Percentage } \\
\text { New }\end{array}$ \\
\hline US7084859 & 28 & 0 & 0 & 28 & $0.00 \%$ & $100.00 \%$ & $70.00 \%$ & $0.00 \%$ \\
\hline US4639720 & 12 & 0 & 0 & 12 & $0.00 \%$ & $100.00 \%$ & $30.00 \%$ & $0.00 \%$ \\
\hline Totals & 40 & 0 & 0 & 40 & & & $100.00 \%$ & $0.00 \%$ \\
\hline
\end{tabular}

Claim 1 was deleted and did not grant with the patent. 


\section{Case 6 US 7692625 Citing US8232511}

Final US20050243070 Interdependencies With Apparatus Claim 1

A sensing system adapted to sense a pointer and calculate a location of the pointer,
comprising:

a panel having a first plane and a fist area located at the first plane, the first area being quadrangular and having a first boundary, a second boundary, a third boundary and a fourth boundary which are connected in order;

a reflective element disposed at the first boundary and located on the first plane, the reflective element having a second plane substantially perpendicular to the first plane, the second plane being a reflective mirror plane and mirroring the first area to form a second area;

an image sensor disposed at a corner at which the third boundary and the fourth boundary intersects and located on the first plane, a sensing range of the image sensor covering the first area and the second area; and a processor electrically connected to the image sensor; a fist light source disposed beside the image sensor;

a first reflector disposed at the second boundary and located on the first plane, the first reflector being mirrored by the reflective element to form a second mirror image, the first reflector having a first retro-reflective surface, the first retro-reflective surface being adapted to reflect the light emitted by the first light source; and a second reflector disposed at the third boundary and located on the first plane, the second reflector being mirrored by the reflective element to form a third mirror image, the second reflector having a second retro-reflective surface, the second retro-reflective surface being adapted to reflect the light emitted by the first light source, the fourth boundary being mirrored by the reflective element to form a fourth mirror image; the reflective element, the first reflector, the second reflector and the fourth boundary surrounding the first area; the reflective element, the second mirror image, the third mirror image and the fourth mirror image surrounding the second area; and the first reflector, the second mirror image and the third mirror image being in the sensing range of the image sensor, wherein when the pointer approaches the first area and the pointer is mirrored by the reflective element to form a first mirror image such that the pointer and the first mirror image is in the sensing range of the image sensor and when a portion of the pointer adjacent to the first area, a portion of the first mirror image adjacent to the second area and the image sensor are not collinear, the image sensor senses the pointer and the first mirror image and the processor calculates the location of the pointer.

\begin{tabular}{|c|c|c|c|c|c|c|c|c|}
\hline \multirow{2}{*}{ Citation } & \multicolumn{9}{|c|}{ Amended Claim } & \multicolumn{2}{c|}{ Granted Claim } \\
\cline { 2 - 8 } & $\begin{array}{c}\text { Original } \\
\text { Words }\end{array}$ & $\begin{array}{c}\text { Deleted } \\
\text { Words }\end{array}$ & $\begin{array}{c}\text { Added } \\
\text { Words }\end{array}$ & $\begin{array}{c}\text { Final } \\
\text { Words }\end{array}$ & $\begin{array}{c}\text { Claim } \\
\text { Amendment } \\
\text { Degree }\end{array}$ & Similarity & $\begin{array}{c}\text { Percentage } \\
\text { Citation }\end{array}$ & $\begin{array}{c}\text { Percentage } \\
\text { New }\end{array}$ \\
\hline US20050243070 & 430 & 0 & 45 & 475 & $0.00 \%$ & $100.00 \%$ & $90.53 \%$ & $9.47 \%$ \\
\hline
\end{tabular}

Claim 1 granted with the amendment. 


\section{Case 6 US 7692625 Citing US8330726}

Final US6803906 and US20010019325 Interdependencies With Apparatus Claim 1

A position detection apparatus for detecting a pointing device being situated on a detection plane, said position detection apparatus comprising;

a pair of imaging sections, each ef these which includes imaging section comprising an area image sensor, in which light-sensitive elements are arrayed in a two-dimensional pattern, to produce a two-dimensional image of pixels, and an image formation lens, and the pair of the imaging sections image-images an area over the detection plane in a given field of view from the two lateral two points sides of the detection plane to output an image signal corresponding to all pixels of the given field of view, wherein the twodimensional image includes a two-dimensional space that is both parallel to the detection plane and perpendicular to the detection plane,

marker means disposed to at least four peripheral corners of the detection plane and each functioning as a reference for defining a particular field of view along the a distortion of the detection plane within the range of the given field of view to be imaged by the imaging sections,

a selection means utilizing the image signal as an input to select particular pixels as a portion of all of the pixels in a the two dimensional space including an inflected portion, based on a line forming formed by connecting images of the marker means which are disposed to the at least four peripheral corners along the distortion of the detection plane, corresponding to the particular field of view within the range of the given field of view from the light-sensitive elements, only the particular pixels of the particular field of view configured for processing, the particular pixels comprising:

a first row of a plurality of pixels parallel to the detection plane; and a second row of a plurality of pixels parallel to the detection plane, the second row being different from the first row wherein the second row of the plurality of pixels comprises a number of pixels different from a number of pixels for the first row of the plurality of pixels; and

an image processing means which utilizes a particular image signal corresponding to the particular pixels having been selected by the selection means as an input to execute the image processing, thereby outputting a coordinate of an indicating position on the detection plane indicated by the pointing device.

\begin{tabular}{|l|c|c|c|c|c|c|c|c|}
\hline \multirow{2}{*}{ Citation } & \multicolumn{4}{|c|}{ Amended Claim } & \multicolumn{2}{c|}{ Granted Claim } \\
\cline { 2 - 8 } & $\begin{array}{c}\text { Original } \\
\text { Words }\end{array}$ & $\begin{array}{c}\text { Deleted } \\
\text { Words }\end{array}$ & $\begin{array}{c}\text { Added } \\
\text { Words }\end{array}$ & $\begin{array}{c}\text { Final } \\
\text { Words }\end{array}$ & $\begin{array}{c}\text { Claim } \\
\text { Amendment } \\
\text { Degree }\end{array}$ & Similarity & $\begin{array}{c}\text { Percentage } \\
\text { Citation }\end{array}$ & $\begin{array}{c}\text { Percentage } \\
\text { New }\end{array}$ \\
\hline US6803906 & 160 & 41 & 150 & 269 & $25.62 \%$ & $74.38 \%$ & $37.54 \%$ & $47.32 \%$ \\
\hline US20010019325 & 30 & 1 & 19 & 48 & $3.33 \%$ & $96.67 \%$ & $9.15 \%$ & $5.99 \%$ \\
\hline Totals & 190 & 42 & 169 & 317 & & & $46.69 \%$ & $53.31 \%$ \\
\hline
\end{tabular}

Claim 1 granted with the amendment. 


\section{Case 6 US 7692625 Citing US8330726}

Final US6803906 and US20010019325 Interdependencies With Apparatus Claim 21

A position detection apparatus for detecting a pointing device being situated on a detection plane, the position detection apparatus comprising:

a pair of imaging sections, each of those which includes an area image sensor, in which light-sensitive elements are arrayed in a two-dimensional pattern to produce a twodimensional image, and an image formation lens, and images an area over the detection plane in a given field of view from two the lateral two points sides of the detection plane to output an image signal corresponding to all light-sensitive elements of the given field of view, wherein the two-dimensional image includes a two-dimensional space that is both parallel to the detection plane and perpendicular to the detection plane;

marker means each functioning as a reference for defining a given part particular field of view which is not influenced by the along a distortion of the detection plane within the a range of the given field of view to be imaged by the imaging sections, the marker means comprising at least one of the following two structures: a light reflection member and a light-emitting source;

An image processing means that utilizes an the image signal being outputted from the imaging sections as an input, defines a given part of the image signal on the basis of a line forming images of the marker means wherein the line comprises an angle, and uses the image signal of the given part having been defined to work out a coordinate of an indicating position on the detection plane being indicated by a pointing device, and the given part of the image signal comprising a configuration of a portion of the plurality of the light-sensitive elements in the two-dimensional space along the line, only the configuration of the light-sensitive elements are utilized for detecting a pointing device, the configuration comprising a first row of a plurality of light-sensitive elements parallel to the detection plane; and a second row of a plurality of light-sensitive elements parallel to the detection plane, the second row being different from the first row, wherein the second row of the plurality of light-sensitive elements comprises a number of lightsensitive elements different from a number of light-sensitive elements for the first row of the plurality of light-sensitive elements; and

a follow-up means for detecting the changes in the positions of the marker means either automatically at a given interval or manually at operator's option to renewedly define the given part.

\begin{tabular}{|l|c|c|c|c|c|c|c|c|}
\hline \multirow{2}{*}{ Citation } & \multicolumn{9}{|c|}{ Amended Claim } & \multicolumn{2}{c|}{ Granted Claim } \\
\cline { 2 - 9 } & $\begin{array}{c}\text { Original } \\
\text { Words }\end{array}$ & $\begin{array}{c}\text { Deleted } \\
\text { Words }\end{array}$ & $\begin{array}{c}\text { Added } \\
\text { Words }\end{array}$ & $\begin{array}{c}\text { Final } \\
\text { Words }\end{array}$ & $\begin{array}{c}\text { Claim } \\
\text { Amendment } \\
\text { Degree }\end{array}$ & Similarity & $\begin{array}{c}\text { Percentage } \\
\text { Citation }\end{array}$ & $\begin{array}{c}\text { Percentage } \\
\text { New }\end{array}$ \\
\hline US6803906 & 173 & 10 & 176 & 339 & $5.78 \%$ & $94.22 \%$ & $41.69 \%$ & $45.01 \%$ \\
\hline US20010019325 & 28 & 9 & 33 & 52 & $32.14 \%$ & $67.86 \%$ & $4.86 \%$ & $8.44 \%$ \\
\hline Totals & 201 & 19 & 209 & 391 & & & $46.55 \%$ & $53.45 \%$ \\
\hline
\end{tabular}

Claim 21 granted with the amendment. 


\section{Case 6 US 7692625 Citing US8400415}

Final US6803906 and US6492633 and US6411287 and US5317140 Interdependencies With Apparatus Claim 1

An interactive input system comprising:

at least one imaging device having a field of view looking into a region of interest;

at least one radiation source emitting radiation into said region of interest;

a pliable bezel at least partially surrounding said region of interest and comprising at least one strap, said bezel having a reflective surface in the field of view of said at least one imaging device wherein said pliable bezel borders multiple sides of said region of

\section{interest; and}

a plurality of bezel guides at spaced locations about the periphery of said region of interest around which said at lest one strap is partially wrapped,

wherein each bezel guide in the field of view of said at least one imaging device is coated with a reflective material and wherein one or more of said bezel guides comprises retaining structure.

\begin{tabular}{|l|c|c|c|c|c|c|c|c|}
\hline \multirow{2}{*}{ Citation } & \multicolumn{9}{|c|}{ Amended Claim } & \multicolumn{2}{c|}{ Granted Claim } \\
\cline { 2 - 9 } & $\begin{array}{c}\text { Original } \\
\text { Words }\end{array}$ & $\begin{array}{c}\text { Deleted } \\
\text { Words }\end{array}$ & $\begin{array}{c}\text { Added } \\
\text { Words }\end{array}$ & $\begin{array}{c}\text { Final } \\
\text { Words }\end{array}$ & $\begin{array}{c}\text { Claim } \\
\text { Amendment } \\
\text { Degree }\end{array}$ & Similarity & $\begin{array}{c}\text { Percentage } \\
\text { Citation }\end{array}$ & $\begin{array}{c}\text { Percentage } \\
\text { New }\end{array}$ \\
\hline US6803906 & 56 & 0 & 6 & 62 & $0.00 \%$ & $100.00 \%$ & $62.22 \%$ & $6.67 \%$ \\
\hline US6492633 & 7 & 0 & 0 & 7 & $0.00 \%$ & $100.00 \%$ & $7.78 \%$ & $0.00 \%$ \\
\hline 6411287 & 8 & 0 & 0 & 8 & $0.00 \%$ & $100.00 \%$ & $8.89 \%$ & $0.00 \%$ \\
\hline 5317140 & 13 & 0 & 0 & 13 & $0.00 \%$ & $100.00 \%$ & $14.44 \%$ & $0.00 \%$ \\
\hline Totals & 84 & 0 & 6 & 90 & & & $93.33 \%$ & $6.67 \%$ \\
\hline
\end{tabular}

Claim 1 granted with the amendment. 


\section{Case 6 US 7692625 Citing US8513546}

Final US5896403 and US20020047822 and US4331955 Interdependencies With Method Claim 1

A method of determining a coordinate on a micro dotmap according to a moving vector, comprising;

decoding a first coordinate of a first frame corresponding to a first displaying medium according to the first frame retrieved by scanning the first displaying medium at a first moment, the first displaying medium including a micro dotmap displayed thereon, and the first coordinate indicates a coordinate of a first encoding block on the displayed micro dotmap;

scanning the first displaying medium at a second moment to retrieve a second frame, wherein the second moment is later than the first moment;

calculating a first moving vector according to at least one difference between the first frame and the second frame both the first frame and a second frame, wherein the second frame is retrieved by scanning the first displaying medium at a second moment; and

determining a second coordinate of the second frame corresponding to the first displaying medium according to both the first coordinate and the first moving vector;

wherein the first displaying medium is an electronic displaying device, the micro dotmap is printed on a transparent plate with whit paints, and the transparent plate is disposed above a displaying panel comprised by the electronic display device..

\begin{tabular}{|l|c|c|c|c|c|c|c|c|}
\hline \multirow{2}{*}{ Citation } & \multicolumn{9}{|c|}{ Amended Claim } & \multicolumn{2}{c|}{ Granted Claim } \\
\cline { 2 - 9 } & $\begin{array}{c}\text { Original } \\
\text { Words }\end{array}$ & $\begin{array}{c}\text { Deleted } \\
\text { Words }\end{array}$ & $\begin{array}{c}\text { Added } \\
\text { Words }\end{array}$ & $\begin{array}{c}\text { Final } \\
\text { Words }\end{array}$ & $\begin{array}{c}\text { Claim } \\
\text { Amendment } \\
\text { Degree }\end{array}$ & Similarity & $\begin{array}{c}\text { Percentage } \\
\text { Citation }\end{array}$ & $\begin{array}{c}\text { Percentage } \\
\text { New }\end{array}$ \\
\hline US5896403 & 127 & 24 & 49 & 152 & $18.90 \%$ & $81.10 \%$ & $57.22 \%$ & $27.22 \%$ \\
\hline US20020047822 & 3 & 0 & 1 & 4 & $0.00 \%$ & $100.00 \%$ & $1.67 \%$ & $0.56 \%$ \\
\hline US4331955 & 0 & 0 & 24 & 24 & $0.00 \%$ & $100.00 \% \%$ & $13.33 \%$ & $0.00 \%$ \\
\hline Totals & 130 & 24 & 74 & 180 & & & $72.22 \%$ & $27.78 \%$ \\
\hline
\end{tabular}

Claim 1 granted with the amendment. 


\section{Case 6 US 7692625 Citing US8515128}

Final US7650015 Interdependencies With Apparatus Claim 1

\section{An electronic system comprising:}

a display device configured to display images at a display surface where users are able to perceive images displayed by the display device;

a camera having a field of view of a first area in front of the display surface, the first area in front of the display surface being an area in which users are able to perceive the display surface;

an illumination source that is configured to illuminate a second area in front of the display surface, the second area interesting the first area to define an anticipated input region within the field of view of the camera, the anticipated input region being less than all of the field of view of the camera and corresponding to a location in front of the display surface where physical objects are expected to be positioned when user input is being provided to the electronic system and where physical objects are expected to be absent when user input is not being provided to the electronic system; and

a processing unit configured to perform operations comprising;

capturing an image from the camera while the illumination source is illuminating the second area in front of the display surface;

analyzing the image captured by the camera to detect an object within the anticipated input region based on illumination of the illumination source wherein analyzing the image comprises comparing portions of the image captured by the camera to a brightness threshold that defines a brightness level at which an illuminated object should surpass, but an unilluminated object should not surpass; identifying portions of the image captured by the camera that are above the brightness threshold based on the comparison; and detecting the object within the anticipated input region based on the identified portions of the image captured by the camera that are above the brightness threshold;

determining user input based on the object detected within the anticipated input region; and controlling an application based on the determined user input.

\begin{tabular}{|c|c|c|c|c|c|c|c|c|}
\hline \multirow{3}{*}{ Citation } & \multicolumn{5}{|c|}{ Amended Claim } & \multicolumn{2}{c|}{ Granted Claim } \\
\cline { 2 - 8 } & $\begin{array}{c}\text { Original } \\
\text { Words }\end{array}$ & $\begin{array}{c}\text { Deleted } \\
\text { Words }\end{array}$ & $\begin{array}{c}\text { Added } \\
\text { Words }\end{array}$ & $\begin{array}{c}\text { Final } \\
\text { Words }\end{array}$ & $\begin{array}{c}\text { Claim } \\
\text { Amendment } \\
\text { Degree }\end{array}$ & Similarity & $\begin{array}{c}\text { Percentage } \\
\text { Citation }\end{array}$ & $\begin{array}{c}\text { Percentage } \\
\text { New }\end{array}$ \\
\hline US7650015 & 245 & 0 & 83 & 328 & $0.00 \%$ & $100.00 \%$ & $74.70 \%$ & $25.30 \%$ \\
\hline
\end{tabular}

Claim 1 granted with the amendment. 


\section{Case 6 US 7692625 Citing US8547327}

Final US6624833 Interdependencies With Apparatus Claim 1

An electronic system comprising;

a camera having a field of view of a first area;

a display screen configured to display a graphical user interface, wherein the camera is positioned at a first side of the display screen, is angled with respect to the display screen and the field of view of the camera is of the first area in front of the display screen;

an illumination source that is angled with respect to the camera and that is configured to illuminate a second area, the second area intersecting the first area to define an intersection region within the field of view of the camera; wherein the illumination source is positioned at a second side of the display screen, is angled with respect to the display screen and is configured to illuminate the second area in front of the display screen, the second area in front of the display screen interesting the first area in front of the display screen to define the intersection region; and

a processing unit configured to perform operations comprising:

capturing an image from the camera;

analyzing the image captured by the camera to detect an object within the intersection region;

determining user input based on the object detected within the intersection region; and controlling an application based on the determined user input.

\begin{tabular}{|c|c|c|c|c|c|c|c|c|}
\hline \multirow{3}{*}{ Citation } & \multicolumn{9}{|c|}{ Amended Claim } & \multicolumn{2}{c|}{ Granted Claim } \\
\cline { 2 - 8 } & $\begin{array}{c}\text { Original } \\
\text { Words }\end{array}$ & $\begin{array}{c}\text { Deleted } \\
\text { Words }\end{array}$ & $\begin{array}{c}\text { Added } \\
\text { Words }\end{array}$ & $\begin{array}{c}\text { Final } \\
\text { Words }\end{array}$ & $\begin{array}{c}\text { Claim } \\
\text { Amendment } \\
\text { Degree }\end{array}$ & Similarity & $\begin{array}{c}\text { Percentage } \\
\text { Citation }\end{array}$ & $\begin{array}{c}\text { Percentage } \\
\text { New }\end{array}$ \\
\hline US6624833 & 107 & 0 & 110 & 217 & $0.00 \%$ & $100.00 \%$ & $49.30 \%$ & $50.70 \%$ \\
\hline
\end{tabular}

Claim 1 granted with the amendment. 


\section{Case 6 US 7692625 Citing US8547327}

Final US6624833 Interdependencies With Apparatus Claim 25

At least one computer readable storage medium encoded with executable instructions that, when executed by at least one processor, cause the at least one processor o perform operations comprising;

capturing an image of an intersection region from a camera wherein the camera is positioned at a first side of a display screen, the camera is-and angled with respect to the display screen, and the intersection region being defined within a field of view of the camera is of a first area in front of the display screen;

analyzing the image captured by the camera to detect an object within an intersection region defined within the camera's field of view by an illuminations source wherein the illuminations source is positioned at a second side of the display screen, the illuminations source is and angled with respect to the display screen, and the illuminations source is configured so as to illuminate the -a second area in front of the display screen, the second area in front of the display sereen intersecting the first area in front of the display screen to define the intersection region in front of the display screen.;

analyzing the image from the camera to detect an object within the intersection region;

determining user input based on the object detected within the intersection region; and controlling an application based on the determined user input.

\begin{tabular}{|c|c|c|c|c|c|c|c|c|}
\hline \multirow{3}{*}{ Citation } & \multicolumn{9}{|c|}{ Amended Claim } & \multicolumn{2}{|c|}{ Granted Claim } \\
\cline { 2 - 8 } & $\begin{array}{c}\text { Original } \\
\text { Words }\end{array}$ & $\begin{array}{c}\text { Deleted } \\
\text { Words }\end{array}$ & $\begin{array}{c}\text { Added } \\
\text { Words }\end{array}$ & $\begin{array}{c}\text { Final } \\
\text { Words }\end{array}$ & $\begin{array}{c}\text { Claim } \\
\text { Amendment } \\
\text { Degree }\end{array}$ & Similarity & $\begin{array}{c}\text { Percentage } \\
\text { Citation }\end{array}$ & $\begin{array}{c}\text { Percentage } \\
\text { New }\end{array}$ \\
\hline US6624833 & 197 & 58 & 32 & 171 & $29.44 \%$ & $70.56 \%$ & $81.29 \%$ & $18.71 \%$ \\
\hline
\end{tabular}

Claim 25 granted with the amendment. 


\section{Case 6 US 7692625 Citing US8547327}

Final US6624833 Interdependencies With Apparatus Claim 26

A method comprising:

capturing an image from a camera wherein the camera is positioned at a first side of a display screen, the camera is angled with respect to the display screen, and the field of view of the camera is of a first area in front of the display screen;;

analyzing the image captured by the camera to detect an object within an intersection region defined within the camera's field of view by an illumination source wherein the illumination source is positioned at a second side of the display screen, the illuminations source is angled with respect to the display screen, and the illuminations source is configured to illuminate the second area in front of the display screen, the second area in front of the display screen intersecting the first area in front of the display screen to define the intersection region in front of the display screen;

determining user input based on the object detected within the intersection region; and controlling an application based on the determined user input.

\begin{tabular}{|c|c|c|c|c|c|c|c|c|}
\hline \multirow{3}{*}{ Citation } & \multicolumn{9}{|c|}{ Amended Claim } & \multicolumn{2}{|c|}{ Granted Claim } \\
\cline { 2 - 8 } & $\begin{array}{c}\text { Original } \\
\text { Words }\end{array}$ & $\begin{array}{c}\text { Deleted } \\
\text { Words }\end{array}$ & $\begin{array}{c}\text { Added } \\
\text { Words }\end{array}$ & $\begin{array}{c}\text { Final } \\
\text { Words }\end{array}$ & $\begin{array}{c}\text { Claim } \\
\text { Amendment } \\
\text { Degree }\end{array}$ & Similarity & $\begin{array}{c}\text { Percentage } \\
\text { Citation }\end{array}$ & $\begin{array}{c}\text { Percentage } \\
\text { New }\end{array}$ \\
\hline US6624833 & 57 & 0 & 114 & 171 & $0.00 \%$ & $100.00 \%$ & $33.33 \%$ & $66.67 \%$ \\
\hline
\end{tabular}

Claim 25 granted with the amendment. 


\section{References}

Abbott Laboratories Inc. v. Baxter Pharmaceutical Products Inc. (2003). Mere Disclosure of Prior Art During Prosecution Does Not Limit Scope of Claimed Invention, Intellectual Property \& Technology Law Journal, 15(9): 13.

Bacchiocchi, E., \& Montobbio, R. 2010. International Knowledge Diffusion and Homebias Effect: Do USPTO and EPO Patent Citations Tell the Same Story?, The Scandinavian Journal of Economics, 112(3): 441 - 470.

Bapuki, H., Loree, D., \& Crossan. M. 2011. Connecting external knowledge usage and firm performance: An empirical analysis, Journal of Engineering and Technology Management. 28(2011): 215 - 231.

Berger, F., \& Blind, K. \& Thumm, N. 2011. Filing behavior regarding essential patent in industry standards, Research Policy, 41(1): 216 - 225.

Bernard, H. R., \& Ryan, G. W. 2010 Analyzing Qualitative Data Systematic Approaches. Thousand Oaks, California; SAGE Publications.

Breitzman, A., \& Thomas, P. 2001. Using patent Citation Analysis To Target/Value M\&A Candidates, Research Technology Management. September - October 2002: $28-36$.

Brown, S. L., \& Eisenhardt, K. M. 2001. Chapter 10: The art of continuous Change, Organizational Improvisation, 2001: 225 - 256.

Caballero, R. J., \& Jaffe, A. B. 1993. How High Are The Giants' Shoulders: An Empirical Assessment of Knowledge Spillovers and creative Destruction In A 
Model Of Economic Growth, National Bureau of Economic Research Macroeconomics Annual, 8. MIT Press.

Chen Y., \& Chang, K. 2010. Exploring the nonlinear effects of patent citations, patent share and relative patent position on market value in the US pharmaceutical industry, Technology Analysis \& Strategic Management, 22(2): 153 - 169.

Criscuolo, P., \& Verspagen, B. 2008. Does It Matter Where Patent Citations Come From ? Inventor vs. Examiner citations in European Patents, Research Policy, 37(3008): $1892-1908$.

Cotopia, C. A., \& Lemley, M. A., \& Sampat, B. 2013. Do Applicant Patent Citations Matter? Research Policy, 42(2013): 844 - 854.

Deng, Y. 2008. The value of knowledge spillovers in the U.S. semiconductor industry, International Journal of Industrial Organization, 26(2008): 1044 - 1058.

Donner, I. H. 2007. Patent Prosecution Law, Practice, and Procedure. Washington D.C.: BNA Books.

Eisenhardt, K. M.1989. Building Theories From Case Study Research. Academy of Management Review, 14(4): 532 - 550.

Eisenhardt, K. M., \& Graebner, M. W. 2007. Theory Building From Cases: Opportunities And Challenges. Academy of Management Journal, 50(1): 25 32.

European Patent Office. 2007. European Patent Convention. Germany: European Patent Office. 
Fischer, T., \& Leidinger, J. 2014. Testing patent value indicators on directly observed patent value - An empirical analysis of Ocean Tomo patent auctions, Research Policy, 43(2014): $519-529$.

Gay, C., \& Le Bas, C. 2005. Uses Without Too Many Abuses Of Patent citations Or The Simple Economics Of Patent Citations As a Measure Of Value And Flows Of Knowledge, Economics of Innovation and New Technology, 14(5): 333 - 338.

Gay, C., \& Le Bas, C., \& Patel, P., \& Touach, K. 2005. The Determinants Of Patent Citations: An Empirical Analysis Of French And British Patents In The US, Economics Of Innovation and New Technology, 14(5): 339 - 350.

Hall, B. H., Jaffe, A., \& Trajtenberg, M. 2005. Market value and patent citations, RAND Journal of Economics, 36(1): 16 - 38.

Haroff, D., \& Scherer, F. M., \& Vopel, K. 2003. Citations, Family Size, Opposition And The Value Of Patent Rights. Research Policy, 32(2003): 1343 - 1363.

Henderson, R., Jaffe, A. B., \& Trajtenberg, M. 1998. Universities As A Source Of Commercial Technology: A Detailed Analysis Of University Patenting, 1965 1988, Review of Economics and Statistics, 80(1998): 119 - 127.

Hirschey, M., \& Richardson, V. 2003. Are Scientific Indicators Of Patent Quality Useful To Investors? Journal of Empirical Finance, 11(1): 91 - 107.

Hu, X., \& Rousseau, R., \& Chen, J. 2012. A New Approach for Measuring the Value of Patents Based on Structural Indicators for Ego Patent Citation Networks, Journal Of The American Society For Information Science And Technology, 63(9): $1834-1842$. 
Hu, A. G. Z., \& Jaffe, A. B. 2003. Patent Citations And International Knowledge Flow:

The Cases of Korea And Taiwan, International Journal of Industrial Organization, 21(2003): $849-880$.

Jaffe, A. B., Fogarty, M. S., \& Banks, B. A. 1998. Evidence From Patents And Patent Citations On The Impact Of NASA And Other Federal Labs On Commercial Innovation, Journal of Industrial Economics, 46(1998): 183 - 204.

Jaffe, A. B., \& Trajtenberg, M. 1996. Flows Of Knowledge From Universities and Federal Laboratories: Modeling The Flow Of Patent Citations Over Time And Across Institutional And Geographic Boundaries, Proceedings of the National Academy of Science, 93(1996): 12671 - 12677.

Jaffe, A. B., \& Trajtenberg, M. 1999. International Knowledge Flows: Evidence From Patent Citations, Economics of Innovation and New Technology, 8(1999): 105 $-136$.

Jaffe, A. B., \& Trajtenberg, M. 2002. Patents, Citations \& Innovations a Window on the Knowledge Economy. Cambridge, Massachusetts: The MIT Press. Jaffe, A. B., Trajtenberg, M., \& Henderson R. 1993. Geographic Localization Of Knowledge Spillovers As Evidenced By Patent Citations, Quarterly Journal of Economics, 108(1993): 577 - 598.

Kelley, D. J., \& Ali, A., \& Zahra, S. A. 2013. Where Do Breakthroughs Come From? Characteristics Of High-Potential Inventions, Journal of Product Innovation Management, 30(6): 1212 -1226. 
Kica, E., \& Groenendijk, N. 2011. The European Paten System: Dealing With Emerging Technologies, Innovation - The European Journal of Social Science Research, 24(1-2): $85-105$.

Kukrus, A., \& Kartus, R. 2007. Internationalization of Patent Systems and New Developments in Globalizing World, Working Papers in Economics, 22(155158): $59-79$.

Laub, C. 2006. Software Patenting: Legal Standards in Europe and the US in view of Strategic Limitations of the IP Systems, Journal of World Intellectual Property, 9(3): $344-372$.

Lee, C., \& Park, H., \& Park, Y. 2013. Keeping Abreast Of Technology-Driven Business Model Evolution: A dynamic Patent Analysis Approach. Technology Analysis \& Strategic Management, 25(5): 487 - 505.

Nair, S. S., Mathew, M., \& Nag, D. 2011. Dynamics between patent latent variables and patent price, Technovation, 31(2011): $648-654$.

Nikulainen, T., \& Hermans, R., \& Kulvik, M. 2008. Patent Citations Indicating Present Value Of The Biotechnology Business, International Journal of Innovation and Technology Management, 5(3): 2279 - 301.

Reitzig, M. 2003. What Determines Patent Value? Insights From The Semiconductor Industry. Research Policy, 32(2003): $13-26$.

Reitzig, M. 2004. Improving patent valuations for management purposes-validating new indicators by analyzing application rationales. Research Policy, 33(2004): 939957. 
Shin, J., \& Kim, C. M. 2013. Risk-adjusted Performance Forecasting Of Future Key Technology, Technology Analysis \& Strategic Management, 25(2): 147 - 161.

SMART. 2013. Company Overview. http://smarttech.com, first accessed January 2013.

Trajtenberg, M. 1990. A Penny For Your Quotes: Patent Citations And The Value of Innovations, RAND Journal of Economics, 20(1990): 172 - 187.

Trajtenberg, M., Henderson, R., \& Jaffe, A. B. 1997. University Versus Corporate Patents: A Window On The Basicness Of Invention, Economics of Innovation and New Technology, 5(1997): 19 - 50.

Tseng, C. 2009. Technological Innovation In The Bric Economies. Research and Technology Management, March-April 2009: 29 - 35.

Van Zeebroeck, N. 2011. The Puzzle Of Patent Value Indicators, Economics of Innovation and New Technology, 20(1): $33-62$.

Yin, R. K. 2009. Case Study Research Design and Methods Forth Edition. Washington, DC: Sage. 